\title{
CCTV: A technology under the radar?
}

\author{
$\mathrm{PhD}$ Thesis \\ University College London \\ 2009
}

Inga Kroener 


\section{Declaration:}

I, Inga Kroener, declare that the work presented in this thesis is my own. Where information has been derived from other sources, I confirm that this has been indicated in the thesis. 


\section{Acknowledgements:}

First and foremost I want to thank my supervisors Jane Gregory, for her unfailing support, encouragement and invaluable ideas, and Jon Agar, for his realistic advice and enthusiasm, particularly towards the empirical part of this thesis.

Thanks also go to everyone in the Department of Science and Technology Studies at UCL for their help and encouragement along the way. Special thanks must go to Brian Balmer for his help with questionnaire development and statistics. I also want to thank Charles Thorpe for his advice and supervision during the first two years of this project. Thanks also go to Daniel Neyland for his help and advice during the later stages of my research.

To all the people who participated in the questionnaire and interviews for this thesis - thank you for giving up your time.

And to my friends and family - I am tremendously grateful for all your support and understanding throughout this process.

Finally, this thesis is dedicated to my parents. For everything. 


\section{Abstract:}

Closed-circuit television (CCTV) cameras have become a ubiquitous feature of everyday life in the UK over the last thirty years. In this thesis I undertake an examination of the historical, political, social, economic, and technological factors, influencing the development, usage, and widespread dissemination of CCTV in the UK. I focus on the issue of why the UK has become so camerasurveilled, and especially the specific role that the public has played in relation to the development and use of the technology.

I examine the historical factors through an analysis of the development of surveillance, policing, and political change, during the $20^{\text {th }}$ and early $21^{\text {st }}$ centuries, and early and contemporary uses of CCTV, situating this in the wider context of a history of the criminal justice system. I also look at the media and policy context in which CCTV has developed and become widespread, with this element of the thesis particularly informed by an analysis of the way in which the public are constructed. Next, I carry out an empirical study exploring public engagement and consultation in relation to, and feelings towards, the installation of CCTV onto two estates in East London as part of a project to expand access to digital services in London. Finally, I give an overview of international experiences of CCTV providing a broader context for the final analysis.

I argue that the lack of legislation and regulation at the time of the inception of CCTV allowed its subsequent and rapid proliferation. The initial growth of CCTV also occurred at a time when public debate and engagement in science and technology policy did not take place. Its use as a tool for crime prevention was cemented by a police force looking for a shoulder to share the burden of fighting crime. This coupled with an availability of public money for the installation of CCTV systems, the need for a political solution to rising levels of crime, and an apparently passive public, formed the ideal environment for the rise of CCTV. 


\section{Contents:}

Abstract.............................................................................................

\section{Chapter I:}

Introduction to the Thesis.........................................................11

1.1 CCTV in the UK.......................................................................11

1.2 Summary of research...............................................................12

1.3 Research questions.......................................................................................13

1.4 Outline of the thesis..........................................................................14

\section{Chapter II:}

Theories and Frameworks of Society, Technology,

Risk and the Media......................................................................17

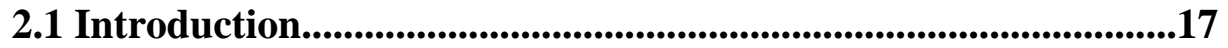

2.2 Risk Society........................................................................19

2.3 Technocratic ideology and the role of experts.............................22

2.4 Technological determinism and social shaping............................25

2.5 The network, information, surveillance society...........................32

2.6 The public sphere...........................................................................39

2.7 Media effects and moral panics.................................................44

2.8 Conclusion...................................................................................48 


\section{Chapter III:}

CCTV Literature Review.......................................................50

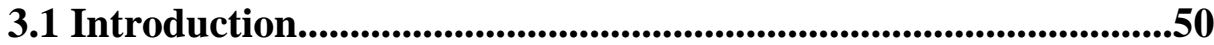

3.2 CCTV and effectiveness...............................................................50

3.3 CCTV and social control..............................................................57

3.4 CCTV and the public................................................................64

3.5 CCTV, privacy, and human rights.............................................67

3.6 International CCTV research...................................................69

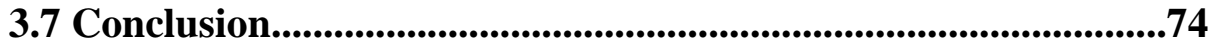

\section{Chapter IV:}

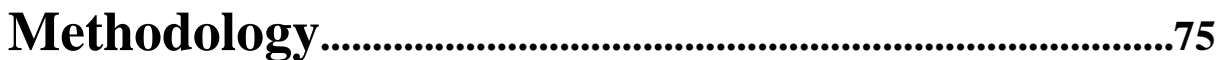

4.1 Introduction...........................................................................................75

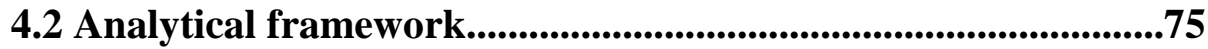

4.3 Selection of methodological approach and research instruments.........................................................................78

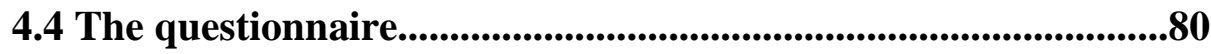

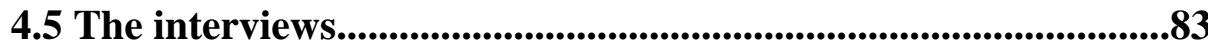

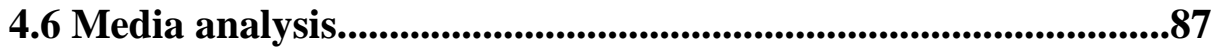

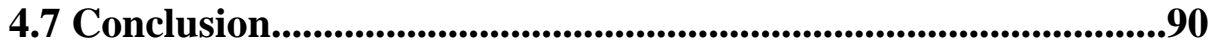

Chapter V:

A Social and Political History of Britain in the $20^{\text {th }}$ and Early $21^{\text {st }}$ Centuries.

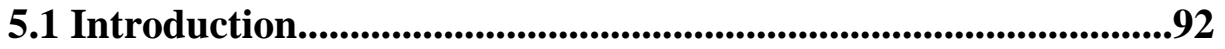

5.2 Britain in the $20^{\text {th }}$ and early $21^{\text {st }}$ centuries...................................92

5.3 Conclusion..............................................................................111 


\section{Chapter VI:}

6.1 Introduction

6.2 Criminal justice.

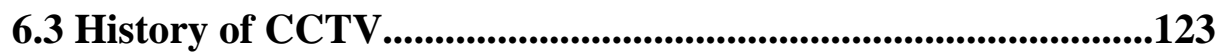

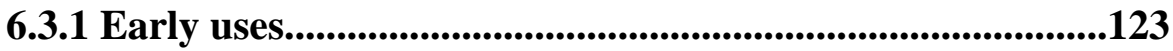

6.4 Surveillance of the miners' strike....................................................133

6.5 CCTV after the miners' strike....................................................141

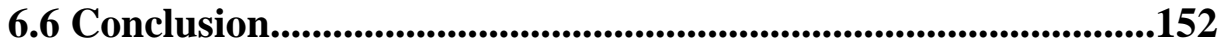

\section{Chapter VII:}

CCTV and the Public .154

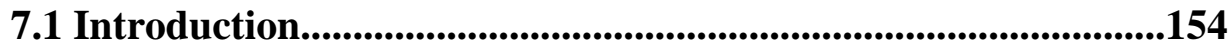

7.2 Local government promotion of CCTV .......................................155

7.3 Consultation and public engagement..........................................161

7.3.1 The Identity Cards Scheme.........................................................162

7.3.2 National promotion of CCTV.................................................168

7.4 Media analysis......................................................................................170

7.4.1 Press coverage of CCTV during the 1990s........................173

7.4.2 Press coverage of CCTV from 2000 - 2005.......................176

7.4.3 Press coverage of the 7 July London Underground bombings...........................................................................183

7.4.4 Press coverage of CCTV from 2006 - 2008..........................191

7.5 CCTV in the press...........................................................................202

7.6 Conclusion...................................................................................205 


\section{Chapter VIII:}

\section{The Digital Bridge}

.206

8.1 Introduction.........................................................................................206

8.2 The Digital Bridge Project.................................................................206

8.2.1 Press coverage of the Digital Bridge project..............................211

8.3 Questionnaire results.............................................212

8.4 Analysis of questionnaire responses...............................219

8.4.1 Closed questions........................................................................219

8.4.2 Open questions.....................................................................................221

8.4.3 Summary.......................................................................................223

8.5 Interview results.............................................................................224

8.5.1 CCTV in principle....................................................................224

8.5.2 CCTV on the estate..................................................................228

8.5.3 Analysis of interviews............................................................233

8.6 Conclusion...............................................................................................235

\section{Chapter IX:}

CCTV Internationally.............................................................236

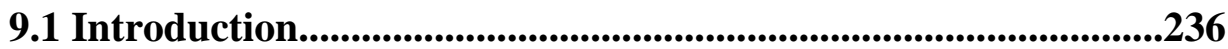

9.2 Right to privacy and data protection legislation...........................236

9.3 Surveillance technologies across the European Union...............239

9.3.1 Identity Cards...............................................................................239

9.3.2 Video surveillance........................................................................240

9.4 CCTV in Germany.............................................................................243

9.5 CCTV in France...................................................................................244

9.6 CCTV in Spain..................................................................................245

9.7 CCTV in the United States................................................................246 


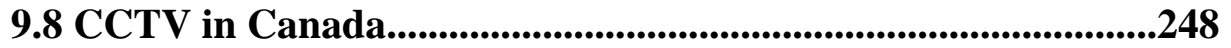

9.9 Analysis of CCTV in an international context..........................249

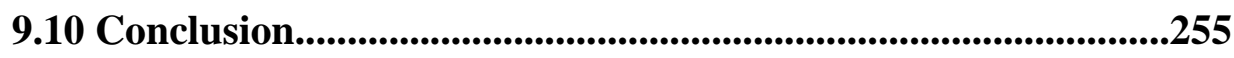

\section{Chapter X:}

Conclusions..................................................................................256

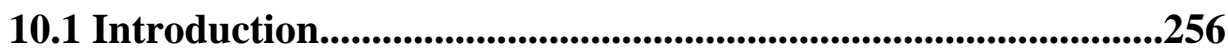

10.2 CCTV and theories of social change.............................................256

10.3 Why is the UK so camera-surveilled, and what has been the role of the public?...........................................................................258

10.4 Reflections on the issue of CCTV and the public......................262

Bibliography ...................................................264

Appendix I......................................................................295

Appendix II...............................................................................296 


\section{List of figures:}

Fig. 5.1 Known Militant Suffragettes (1914)

Fig. 5.2 Known Militant Suffragettes (1914)

Fig. 6.1 Miners at Orgreave

Fig. 7.1 Graph showing the results of a 'CCTV' keyword search in The Times and The Guardian

Fig. 7.2 Graph showing the results of a 'CCTV' keyword search in The Times, The Guardian, The Daily Telegraph, and The Independent

Fig. 8.1 Number of respondents

Fig. 8.2 Television use

Fig. 8.3 Awareness of CCTV cameras

Fig. 8.4 Information received regarding CCTV installation

Fig.8.5 Levels of satisfaction regarding information received about CCTV installation

Fig. 8.6 Consultation prior to CCTV installation

Fig. 8.7 CCTV and feelings of safety

Fig. 8.8 CCTV and crime prevention

Fig. 8.9 CCTV and privacy

Fig. 8.10 Advantages to the community safety channel

Fig. 8.11 Victim of crime 


\section{Chapter I:}

\section{Introduction to the Thesis}

\subsection{CCTV in the UK}

Closed-circuit television (CCTV) is the use of a video camera system to transmit a signal to a specific monitor or set of monitors (as opposed to a public broadcast source). Walter Bruch, a German engineer, is credited with designing the first CCTV system in 1942, for the purpose of monitoring the launch of V-2 rockets. Nowadays cameras are used for a variety of purposes. It can be installed by home owners on their gates in order to see visitors (or intruders) on a screen inside their houses. Businesses use them for the protection of commercial premises, and shopping centres have cameras installed with images watched by staff in a control room. I concentrate on CCTV in public space in my thesis.

The UK leads the world in the number of surveillance cameras in operation in public spaces. The academic study of CCTV sits within the field of surveillance studies, and in a more disciplinary specific context within: criminology, sociology, geography, architecture and urban planning, computing studies, and legal studies. Within the literature focusing more specifically on CCTV there is a range of theoretical accounts focusing on power, social control and discipline, and how we are watched. What is lacking is a detailed historical narrative, exploring and detailing why the UK has become so camera-surveilled. It is not enough simply to start from the position that the UK has become a surveillance society, arguing that the introduction and use of CCTV was inevitable and situating CCTV in the larger context of a surveillance era. 


\subsection{Summary of research}

In this thesis I will approach the topic from a Science and Technology Studies (STS) perspective, and undertaking a cross-disciplinary analysis to answer the main research question - why has the UK become so camera-surveilled? I explore this research question through an interpretive framework focusing on sociotechnical and politico-economic structures, dynamics and histories. I take an integrative approach to my analysis of CCTV, combining micro- and macro-level analysis. Underlying this main research question is a subsidiary question focusing on the public in relation to CCTV. The peculiar role of the public in apparently accepting and not contesting CCTV in a time of resistance to new technologies (such as biotechnology and nuclear power) is an issue that I feel is interesting and worth exploring (and one that is missing from the academic literature on CCTV). I look at policy specifically on CCTV in relation to the public, public opinion and acceptance. I analyse how CCTV is portrayed by the media, and how the public are constructed in relation to CCTV. I also include an empirical social research element in order to explore further, how and why, CCTV has been developed and widely implemented under the radar of the public.

I argue that the lack of legislation and regulation at the time of the inception of CCTV (and which still continues today) allowed its subsequent and rapid proliferation, in terms of there not being a legal framework or any boundaries within which the installation of the technology had to operate. The barrier to installation for local authorities was cost, however this was solved at various times by the availability of funds for CCTV installation from the Home Office. Its use as a tool for crime prevention has been cemented by a police force looking for a shoulder to share the burden of fighting crime. This coupled with the need for a political solution to rising levels of crime formed the ideal environment for the expansion of the use of CCTV systems in public places.

Further to these reasons, I trace developments in the context of wider social changes at the time of the rise of CCTV. The technology began to be used more widely during the 1980s, a time of little or no public engagement in the UK in relation to science and technology. The lack of public resistance to the technology 
can therefore be explained partly due to this, although there are also a number of other incidents that cemented CCTV's place as a seemingly useful, necessary, and publicly acceptable, technology. I explore these incidents in detail later in the thesis.

\subsection{Research questions}

The overarching research question of my thesis is: why has the UK become so surveilled in terms of cameras? As mentioned previously there is also a main subsidiary issue arising from this question: What is the role of the public in the story of CCTV in the UK, and why have they apparently accepted the deployment of this technology so readily?

From this, a number of other questions arose, which have led to each of the chapters in this thesis. The specific questions are grouped together under broader thematic research objectives for the thesis:

i) To detail and analyse the history of policing and surveillance in the UK (Chapter 5)

- How has policing and crime control evolved in Britain since the beginning of the $21^{\text {st }}$ Century?

- What can this tell us about surveillance and CCTV in Britain?

- What is the broader context in which surveillance in Britain has developed?

- What is the broader social, economic, and political context in which CCTV has developed?

ii) To detail and analyse the history of CCTV in the UK (Chapter 6)

- How and why did CCTV first develop and become applied?

- What were the main social, political, economic and technological drivers at work influencing its widespread dissemination? 
iii) To analyse the public in relation to CCTV in the UK (Chapters 7 and 8)

- How does the use of CCTV construct certain types of public and of society?

- Why have the public apparently accepted the deployment of surveillance technologies? What judgements have been made and by whom? What does this tell us about power structures in policy-making in society?

- What are the broadsheet and tabloid media saying about CCTV, and how is CCTV constructed in relation to crime?

iv) To detail and analyse the international situation regarding CCTV (Chapter 9)

- What is the situation internationally with regard to the installation and use of CCTV?

- What can developments in relation to surveillance and CCTV add to our understanding of why the UK has become so camera-surveilled?

\subsection{Outline of the Thesis}

There are eight substantive chapters, with the first three acting to introduce relevant literature and the issues surrounding research on CCTV, and to outline my research questions and research process. The next two chapters explore the historical aspects of the thesis, starting the analytical work of the thesis. The final three chapters continue this analytical work, completing the empirical aspect of my thesis and providing various perspectives on CCTV prior to concluding.

\section{Chapter 1 - Introduction}

In this chapter I introduce the main research question of my thesis, the topic of CCTV and related disciplines, and the outline of the remainder of the chapters. I also provide a section concentrating on the history of Britain since 1945. This is important in terms of providing a broad historical and social context for the rest of my research. 
Chapter 2 - Theories and Frameworks of Society, Technology, Risk, and the Media

This chapter provides an overview of the main research literature on surveillance, theories of society, technological and social change, risk and the public, and media effects. I introduce this literature in order to later draw on the concepts and theories throughout my thesis. I also use this chapter to argue that explanations of a new era for society in terms of information, surveillance, and networks, are not enough to account for the widespread nature of CCTV in the UK.

\section{Chapter 3 - CCTV Literature Review}

I use this literature review to present the main studies of CCTV in the UK and internationally. I group the research thematically and against my own aims and objectives. In providing an overview of the main literature in this area, I also explain in greater detail where my research fits in and the gaps which I seek to fill.

\section{Chapter 4 - Methodology}

This chapter presents my general methodological approach and analytical framework, the main research questions of the thesis, and the methods of data collection and analysis I have used.

Chapter 5 - A Social and Political History of Britain in the $20^{\text {th }}$ and Early $21^{\text {st }}$ Centuries

This chapter aims to provide a wider political and social context to the history of CCTV, which I develop in chapter 6, by giving an overview of changes in Britain in the $20^{\text {th }}$ and early $21^{\text {st }}$ centuries. I focus on changes in politics, surveillance, policing, and the public sphere, as these are issues that have implications for later analysis. 


\section{Chapter 6 - History of CCTV}

This chapter traces the history of CCTV in terms of the social, economic, technological and political factors that have shaped its development and implementation in the UK. I first review changes in the criminal justice system in order to provide a context in which CCTV has developed as a crime prevention tool. The remainder of the chapter develops a historical analysis of CCTV.

\section{Chapter 7 - CCTV and the Public}

In this chapter I look at the promotion of CCTV by Government. This analysis involves a discussion of the consultation process on CCTV and research into the portrayal of CCTV by local and national government. I then move on to a media analysis, concentrating on the depiction and inclusion of CCTV into newspaper articles over the last fifteen years and exploring issues of the public.

\section{Chapter 8 - The Digital Bridge}

In this chapter I present the findings of my empirical research, exploring in more detail the issue of CCTV and the public. I provide background information on the Digital Bridge project, a broadband expansion project which included the installation of CCTV cameras onto two estates in London, as well as exploring relevant literature concentrating on communities and regeneration. I then present and analyse the results of my questionnaire and interviews with residents.

\section{Chapter 9 - CCTV in an International Context}

In this chapter I explore the use of CCTV in an international context. Included in this chapter is an overview of data protection and privacy legislation, the use of identity cards throughout the European Union (EU), and the use of CCTV throughout the EU and the United States and Canada. This chapter provides a final perspective for the thesis, after which I detail my conclusions.

\section{Chapter 10 - Conclusions}




\section{Chapter II:}

\section{Theories and Frameworks of Society, Technology, Risk, and the Media}

\subsection{Introduction}

In this section, I will introduce a range of literature which I later draw on throughout the thesis. I have delved into a diverse range of literature from a number of research areas, including: philosophy of science, sociology of technology, history of technology, public understanding of science, media effects, and studies of science communication and science in the media, surveillance studies, and Science and Technology Studies (STS), in order to answer the main research question - why has the UK become so camera-surveilled? Some of the literature is to be understood in a broad context; in terms of the emergence of recent theories of change in the social order. For some commentators we are entering an era of post-modernity, for others a time of post-capitalism or postindustrialism. For other commentators we are not entering a new era, simply one which is an extension and evolution of what has come before. The emergence of an information society has been heralded by some, and in the same vein a network society. Others see the development of a surveillance society in recent years. I look at these theories in order to provide the rest of my thesis with a context in terms of theories of society and social structures, of change, and of the possible emergence of a new era. The contemporary issue of CCTV, its development, and history, also needs to be understood within this aforementioned larger context of social change. Other literature will be drawn on more specifically throughout the thesis, in order to provide a theoretical framework from which to develop my own research and approach to the analysis of CCTV in the UK. 
The first section of the literature review looks at the concept of risk. Risk is an important concept in relation to surveillance; a perception on the part of the public that there is increasing risk in terms of levels of crime has led to a growth in strategies to manage that risk. ${ }^{1}$ CCTV is implemented as a risk-management technology, in order to make the public feel safer (although it may have the opposite effect). The concept of risk is therefore overviewed here, and referred back to during the thesis, as a possible reason why CCTV cameras have become so widespread.

The second section of the review provides an outline of literature concerned with technocratic ideology and the role of experts in policy-making. The aforementioned heightened awareness of risk is managed, in the case of CCTV, through a belief in the technological 'fix' and trust in expert advice. This literature is particularly relevant for chapter 7, when I analyse the promotion of CCTV by local and national government. Next, I move on to a discussion of the academic literature surrounding ideas of technological determinism and the social shaping of technology. This literature is important for later analysis concerned with how CCTV developed and became applied in the UK. My thesis is based on the premise that technology is co-produced. It steps away from traditional explanations of technology as the driving force for social change.

I then move on to an overview of literature covering ideas of the network society, information society, and the surveillance society. This literature is important because the history of surveillance in this country, and explanations of this history, is tied together with these grand theories of social change. In order to develop an analysis of why the UK has become so camera-surveilled, first the general surveillance situation must be looked at, and therefore also the theories behind these changes.

In the next section, I discuss ideas of the public and the public sphere, as well as literature concerned with the role of the media in connection with the public. 'The public' and CCTV is currently an underdeveloped area of research, which this

\footnotetext{
${ }^{1}$ Eiser, R. J. (2004) Public Perception of Risk Foresight Office of Science and Technology
} 
thesis aims to provide some contribution towards (who the public are in relation to CCTV, how they are conceptually developed and by whom and so on).

The final section of this literature review covers ideas of media effects and moral panics. Looking at theories of media effects and moral panics is important for this thesis, in order to create a conceptual framework from which to start thinking about the media and the public in relation to CCTV (which is carried out in chapter 7). At the same time, however, it is interesting at a more general level as much of the ideological baggage is the same as in literature surrounding CCTV and its effectiveness, which will be looked at more closely in the CCTV literature section.

\subsection{Risk Society}

In this section I introduce the concept of risk and risk society. Increased awareness of risk has led to urban fortification and increased surveillance in residential and public areas. ${ }^{2}$ Surveillance technologies are used as a strategy to manage risk associated with perceived or actual levels of crime, leading to widespread use of technologies such as CCTV.

Risk is not a new concept. In fact, Luhmann details the term as first appearing in the transitional period between the late Middle Ages and the early modern era, although at the time it was designated to describe the perils of maritime voyage. ${ }^{3}$ In this sense, therefore, the concept was not linked to human responsibility; the risk was from natural events rather than those which are human-made. ${ }^{4}$ This concept changed with the onset of modernity, defined by Giddens as:

At its simplest, modernity is a shorthand term for modern society or industrial civilization. Portrayed in more detail, it is associated with (1) a certain set of attitudes towards the world, the idea of the world as open to transformation by human intervention; (2) a complex of

\footnotetext{
${ }^{2}$ Garland, D. 'The Rise of Risk' in Ericson, R. V. and Doyle, A. (eds.) (2003) Risk and Morality University of Toronto Press; Toronto p.78

${ }^{3}$ Luhmann, N. et al. (1993) Risk: A sociological theory Walter de Gruyter p.9

${ }^{4}$ Lupton, D. (1999) Risk Routledge; London p.5
} 
economic institutions, especially industrial production and a market economy; (3) a certain range of political institutions, including the nation-state and mass democracy. Largely as a result of these characteristics, modernity is vastly more dynamic than any previous type of social order. It is a society - more technically, a complex of institutions - which unlike any preceding culture lives in the future rather than the past. ${ }^{5}$

With modernity came the idea that 'the key to human progress and social order is objective knowledge of the world through scientific exploration and rational thinking. It assumes that the social and natural worlds follow laws that may be measured, calculated and therefore predicted'. 6 This notion of measurement eventually led to the idea that risk could be calculated, the definition of which was extended in the nineteenth century to include those risks which were humanmade. ${ }^{7}$ During this time and until the end of the twentieth century, the term 'risk' was applied in both a positive and negative manner. ${ }^{8}$ Presently, the term is used to denote negative rather than positive outcomes, as Douglas states; 'the word risk now means danger; high risk means a lot of danger' ${ }^{9}$

Lupton argues that 'the contemporary obsession with the concept of risk has its roots in the changes inherent in the transformation of societies from pre-modern to modern and then to late modern or post-modern, as some theorists prefer to describe the contemporary era'. ${ }^{10}$ Late or post-modernity is generally defined as the 'broader socioeconomic and political changes that have taken place in western societies since World War Two'. ${ }^{11}$ Alongside these socioeconomic and political changes, it is argued that there is an increasing sense of uncertainty and a growing awareness of risk. ${ }^{12}$ This growing sense of insecurity and awareness of risk has

\footnotetext{
${ }^{5}$ Giddens, A. (1998) Conversations with Anthony Giddens: Making Sense of Modernity Stanford University Press; California p.94

${ }^{6}$ Lupton, D. op.cit. p.6

${ }^{7}$ Ewald, F. (1993) 'Two Infinities of Risk' in Massumi, B. (ed.) The Politics of Everyday Fear University of Minnesota Press; Minnesota pp.221-8 p.226

${ }^{8}$ Douglas, M. (1992) Risk and blame: Essays in Cultural Theory Routledge; London p.23

${ }^{9}$ Ibid. p.24

${ }^{10}$ Lupton, D. Op.cit. p.10

${ }^{11}$ Ibid.

${ }^{12}$ Ibid.
} 
led some commentators to describe post-modern or late modern society as being 'risk society'. ${ }^{13}$ Giddens defines risk society as one which is 'increasingly preoccupied with the future (and also with safety), which generates the notion of risk. ${ }^{14}$ Having coined the term, Beck describes modern society as risk society 'in the sense that it is increasingly occupied with debating, preventing and managing risks that it itself has produced'. 15

In relation to surveillance, risk is an important issue. For Bauman, the move to a risk society is a move from trust and faith in human progress (along the lines of enlightenment thought), to one where risks need to be anticipated. ${ }^{16}$ In terms of surveillance, new technologies for managing risk have increased significantly in recent times. Examples of this can be seen in the introduction of the DNA Database in the UK in 1995 (which I look at in greater detail in chapter 5) and the widespread use of CCTV. This strategy of managing risk via the increased use of surveillance technologies such as CCTV cameras is coupled with a move towards what has been termed by Norris and Armstrong as a 'stranger society'; a decline of communities and communication. ${ }^{17}$ Young argues that this loss of communication leads to 'less direct knowledge of fellow citizens', which leads to 'much less predictability of behaviour'. ${ }^{18}$ This 'stranger society' is intensified by the development of gated communities, the privatisation of public space, and the widespread use of CCTV cameras. ${ }^{19}$ Although these developments have been implemented in order to manage risk, and in the case of CCTV cameras to reduce the publics' fear of crime, they may instead have had the opposite effect. Spitzer has suggested that 'the more we enter into relationships to obtain the security commodity, the more insecure we feel; the more we depend on the commodity

\footnotetext{
${ }^{13}$ Beck, U. (1992) Risk Society: towards a new modernity Sage; London

${ }^{14}$ Giddens, A. (1999) 'Risk and Responsibility’ Modern Law Review 62(1): 1-10.

${ }^{15}$ Beck, U. (2006) 'Living in the World Risk Society’ Hobhouse Memorial Public Lecture http://www.lse.ac.uk/collections/sociology/pdf/Beck-LivingintheWorldRiskSociety-Feb2006.pdf

${ }^{16}$ Bauman, Z. (1992) Intimations of Postmodernity Routledge; London p.25

${ }^{17}$ Norris, C. and Armstrong, G. (1999) The Maximum Surveillance Society: The rise of CCTV Berg; Oxford p.21

${ }^{18}$ Young, J (1999) The Exclusive Society: social exclusion, crime and difference in late modernity Sage; London p.70

${ }^{19}$ Norris, C. and Armstrong, G. Op.cit. p.23
} 
rather than each other to keep us safe and confident, the less safe and confident we feel' ${ }^{20}$

At a more general level, Luhmann argues that 'more than any other single factor, the immense expansion of technological possibilities has contributed to drawing public attention to the risks involved'. ${ }^{21}$ So, risk is inherent in technologies (so there is an increasing sense of risk), but they are also seen as something to decrease risk (as a specific example, in terms of surveillance technologies). Douglas and Wildavsky argue that technological development has brought with it an expectation that risks and problems can be solved via technology, stating 'low technology originally set the lower normal expectancies, but high technology has given us now the hope that any present level of bad things may be lowered' ${ }^{22}$ This technocratic ideology, a belief in the technological 'fix', will be shown in chapters 6 and 7 to be rife in UK policy on CCTV.

In this section I have provided a summary of literature related to risk and the risk society. Technology has both contributed to, and is seen as a solution for, an increased sense of risk. This idea of technology as a solution to manage risk is tied together with a technocratic ideology, which will be looked at in the next section.

\subsection{Technocratic ideology and the role of experts}

Although the dominant theory of technological change in the STS literature is held by social shaping and construction theories, technological determinism, a technocratic ideology, and belief in the technical 'fix', seems prevalent in government and politics. The academic literature may have 'moved on', but policy, with specific reference to CCTV in this thesis, seems to lag behind. In this section I cover literature concerned with technology and progress, technocratic ideology and the role of experts in policy-making.

\footnotetext{
${ }^{20}$ Spitzer, S. (1987) 'Security and Control in Capitalist Societies: The Fetishism of Security and the Secret Thereof' in Lowman, J. Menzies, R. and Plays, T. (eds.) Transcarceration: Essays in the Sociology of Social Control Gower; Aldershot p.50

${ }^{21}$ Luhmann, N. et al. op.cit. p.83

22 Douglas, M and Wildavsky, A. (1982) Risk and Culture: An essay on the selection of technological and environmental dangers University of California Press; Los Angeles p.32
} 
A technocratic ideology is bound up with the idea of technology as progress. This notion of technology as progress stems from the $18^{\text {th }}$ century Enlightenment, when ideas of technology as the solution to humanity's problems emerged. ${ }^{23} \mathrm{By}$ the end of the nineteenth century, however, this progressivism had turned to technological determinism, where 'under the influence of Marx and Darwin ... technical progress was believed to ground humanity's advance toward freedom and happiness'. ${ }^{24}$ Of this time period, Ellul poetically states that technology:

Awakened vast hopes in human hearts ... the machine and all that came with it, all it brought in the way of progress, would put into human hands riches perhaps different but as impressive as those of legend ... poverty was retreating and, with it, man's suffering. The machine was taking over. This extreme view of things developed so rapidly that by the end of the nineteenth century people saw in their grasp the moment in which everything would be at the disposal of everyone, in which man, replaced entirely by the machine, would have only pleasures and play. ${ }^{25}$

This notion of progress seems unchanged since this time. Stunkel and Sarsar argue that:

Most technological change, even with its well publicised difficulties, is identified more often than not with progress ... an uneasy but still strong belief in progress and technological rationality under-gird modern industrial systems. ${ }^{26}$

Winner agrees and states:

The prevailing ideology of technology in our time, one that has endured for centuries, bears the name 'progress'... the idea of

\footnotetext{
${ }^{23}$ Stunkel, K. R. and Sarsar, S. (1994) Ideology, Values and Technology in Political Life University Press of America; London p. 75

${ }^{24}$ Feenberg, A. (1999) Questioning Technology Routledge; London pp. 1-2

${ }^{25}$ Ellul, J. (1965) The Technological Society Cape p.190

${ }^{26}$ Stunkel, K. R. and Sarsar, S. (1994) Ideology, Values and Technology in Political Life University Press of America; London p.76
} 
progress is still firmly implanted in the collective consciousness of western industrial societies. $^{27}$

This technocratic ideology therefore sees technology as providing solutions to problems; a technical 'fix' that can solve even the problems generated from the use of technology. Its presence in government means that technical expertise, rather than public participation, is seen as the way forward. ${ }^{28}$ This brings with it questions of the role of experts in policy-making, and the issue of where the power lies in the modern state. Other more day-to-day issues also come to the fore, such as the possibility of misunderstanding technical advice from experts:

Only the exceptional policy maker has specialist training to follow the language and techniques involved in a full expert explanation and, even then, probably only in part ... there is often a vain hope of maintaining the myth that all problems and issues are safely under their hand, usually with the help of expert advisors. ${ }^{29}$

Alongside the possibility of misunderstanding, there are also issues of accountability. If too much control is given to technical experts, where does the accountability lie? How much control in the policy-making process on technologies should be given to policy-makers and how much to technical experts? And finally, is there another way - opening up the policy-making process to the public, allowing technical decisions to be based on non-expert opinions? I will look at these issues further in chapter 7 and in my conclusion to the thesis.

In this section I have discussed a move from progressivism to a belief in technology as a solution to social problems. This idea of technology as a solution to social problems is linked with the notion of technology as progress - a technologically deterministic argument that technology drives change in society. I

\footnotetext{
${ }^{27}$ Winner, L. 'Three Paradoxes of the Information Age' in Bender, G. and Druckrey, T. (1994) (eds.) Culture on the Brink: Ideologies of technology Bay Press, Seattle p.191

${ }^{28}$ Feenberg, A. Op.cit. p.2

${ }^{29}$ Barker, A and Peters, B.G. (1993) The Politics of Expert Advice: Creating, using and manipulating scientific knowledge for public policy Edinburgh University Press pp. 3-4
} 
will look at the literature of technological determinism and the counter argument of the social shaping of technology in the next section.

\subsection{Technological determinism and social shaping}

In this section, I extend the above discussion of a belief in technology as progress into one centring on ideas of technological determinism, and, as a counterargument, the social shaping of technology. The current literature on CCTV and the surveillance society can be too technologically determinist; due to its reliance on theories of the inevitability of change resulting from developments in information technologies and surveillance technologies (I show that this is the case in my review of CCTV literature). ${ }^{30}$ I will look at social shaping and social constructionist literature which can add to our understanding of surveillance technologies and move further away from technological determinism, but will also add to knowledge by taking another perspective - a newer angle in STS/social sciences thought - that technology and society are co-produced and that this is the case with CCTV. In terms of policy on CCTV, I will later argue that a technocratic ideology reigns in the UK: technologically deterministic, and based on the notion of technology as progress. The implication of this for my thesis is that political decisions to implement the technology were based on this idea that CCTV was inevitably 'something good'. It would be easy therefore to slip into a technologically deterministic argument that the amount of camera surveillance in the UK was simply inevitable. However, as I mentioned before, I will include the social, economic, political and technological reasons for its introduction and subsequent widespread usage in my analysis.

Technological determinism is the theory that technology and technological developments are the driving force behind changes in societal structures. Technological determinism is a reductionist approach, breaking down the whole into parts and describing the effect of technology on society as one part affecting change on another part. Furthermore, it is a mono-causal theory, concentrating

\footnotetext{
${ }^{30}$ This is also noted by McCahill and Norris who argue that there is a 'tendency to take as a given the way CCTV systems are applied in practice. It is assumed that either visual surveillance systems have been introduced to detect and prevent crime or to extend the disciplinary potential of panoptic systems'.
} 
on cause and effect, and stating that social factors do not have an effect on technological development. $^{31}$

At the heart of this technologically determinist perspective is the notion that technology is an independent force from the society which it alters, as well as pronouncing that social change is sparked by changes in technology, as Mackenzie and Wajcman identify:

The first part of technological determinism is that technical change is in some sense autonomous, 'outside' of society, literally or metaphorically...the second part is that technical change causes social change. $^{32}$

The technological determinist approach is often associated with Karl Marx. Although he did not refer to 'technology' per se, but to the forces and means of production, these can be taken in a contemporary context to mean technology. Although there are complex debates surrounding interpretation of Marx's writings, it can be said that he emphasised the primacy of technological development in bringing about social change. Changes in the mode of production (which can be taken to mean technology), he argues, have a central role in shaping the development and structure of societies:

The mode of production of material life conditions the social, political and intellectual life in general. ${ }^{33}$

It can be argued that this is a highly technologically deterministic argument, yet not everyone sees Marx as a technological determinist. Some describe him as an economic determinist, whilst others argue that his 'materialist conception of history' does not necessarily mean that he is a technological determinist. However, in his Poverty of Philosophy in 1847, the technologically deterministic

\footnotetext{
${ }^{31}$ Chant, C. and Goodman, D. C. (1999) Pre-industrial Cities and Technology Routledge; London p.18

${ }^{32}$ Mackenzie, D. and Wajcman, J. (1985) The Social Shaping of Technology : how the refrigerator got its hum Open University Press; Milton Keynes pp.4-5

${ }^{33}$ Marx and Engels (1973) Selected Works vol.1 Foreign Languages Publishing House; Moscow pp.503-504
} 
argument is apparent - 'the hand-mill gives you society with the feudal lord; the steam-mill the society with the industrialist capitalist' ${ }^{34}$

Some argue that under the umbrella of technological determinism, there exist hard and soft forms. For example, Smith and Marx write that hard technological determinism denotes technology as the driving force shaping society:

At the 'hard' end of the spectrum, agency (the power to effect change) is imputed to technology itself, or to some of its intrinsic attributes; thus the advance of technology leads to a situation of inescapable necessity. In the hard determinists' vision of the future, we will have technologized our ways to the point where, for better or worse, our technologies permit few alternatives to their inherent dictates. $^{35}$

The soft determinist viewpoint includes other factors as shaping forces:

Instead of treating 'technology' per se as the locus of historical agency, the soft determinists locate it in a far more complex social, economic, political and cultural matrix. ${ }^{36}$

Although technology is no longer seen as being autonomous under a soft determinism perspective, it is still viewed as a major stimulus to the creation, direction and definition of society.

Others disregard this notion of hard and soft determinism entirely. As an example, Bimber sees the distinction between hard and soft determinism as defunct and argues that there are three forms of determinism; the nomological, the normative and unintended consequences. The normative he describes as being the viewpoint most often advanced in this school of thought. Those who take this stance see efficiency and technique as the overriding factors leading to a

\footnotetext{
${ }^{34}$ Marx, K. (1936) The Poverty of Philosophy Martin Lawrence; London

${ }^{35}$ Smith, M. R. and Marx, L. (1994) Does Technology Drive History? MIT Press; Cambridge p.xii

${ }^{36}$ Ibid. p.xiii
} 
technological society. Efficiency and technique replace social, political and economic norms. ${ }^{37}$ The nomological stance centres on the positive consequences of technological change; seeing these consequences as inevitable. Those who take this nomological stance therefore see only one possible outcome and direction for social change from technological developments. ${ }^{38}$ In contrast to the normative, the nomological has its basis in laws of nature rather than social norms. A possibility might be that:

Various technological processes, once begun, require forms of organization or commitments of political resources, regardless of their social desirability or of previous social practices. ${ }^{39}$

Essentially therefore, society moulds itself to adapt to developments in technology regardless of society's wants or needs. As an example, Heilbroner discusses the effect of technology 'in determining the socioeconomic order' ${ }^{40} \mathrm{He}$ also argues that, in the context of capitalism, technology takes on an autonomous role, dominating and producing alterations in social structures. ${ }^{41}$ Within the framework of unintended consequences, those determinists believe that no one can anticipate the effects of technology; that there will always be unintended consequences. This viewpoint suggests, at least in part, that technology is autonomous. $^{42}$

For Ellul, this is certainly the case. He argues that 'technique ... is artificial, autonomous, self-determining, and independent of all human intervention', and later reiterates that 'technique has become autonomous ... no human activity escapes this technical imperative'. ${ }^{43}$ When Ellul uses the term 'technique', he is referring to more than technology; it is a 'mode or manner of thinking that is

\footnotetext{
${ }^{37}$ Bimber, B. 'Three Faces of Technological Determinism' in Smith, M. R. and Marx, L. (1994) Does Technology Drive History? MIT Press; Cambridge p.82

${ }^{38}$ Ibid. p.83

${ }^{39}$ Bimber, B. Op.cit. p.83

${ }^{40}$ Heilbroner, R. L. (1967) ‘Do Machines Make History?’ Technology and Culture 8(3) pp.335345 p.335

${ }^{41}$ Ibid. p.345

${ }^{42}$ Bimber, B. Op.cit. p.85

${ }^{43}$ Ellul, J. (1962) 'The Technological Order' in Technology and Culture 3 p.10 and Ellul, J. (1964) La Technique Vintage Press pp.6-21
} 
inherently mechanistic' ${ }^{44}$ Although taking a negative view of technology and arguing vehemently against technocracy, he is a true technological determinist, pushing the notion of autonomy and inevitability.

Winner echoes the thoughts of Ellul, also focusing on the autonomous nature of technology; 'following its own course, independent of human direction'. 45 Winner differs from Ellul's belief in the rational nature of technology, however, describing it instead as an 'erratic and volatile phenomenon'. ${ }^{46}$ Further, Winner does not take as hard a line in describing technological development, 'depict[ing] technologies as social products as well as social forces' thereby coming 'very close to the governing paradigm among historians of technology', ${ }^{47}$ i.e. the social shaping of technology.

The opposing viewpoint to that of technological determinism is that of the social shaping of technology. This term is sometimes seen as being synonymous with the social construction of technology or the sociology of technology. I will use the term in this broad sense, to also encompass these areas of research. Essentially, proponents of the social shaping of technology viewpoint argue that technology is socially shaped, involving a variety of social factors as opposed to being autonomous and/or having a predetermined outcome. To characterise the idea that technology is socially shaped in its broadest fashion, its adherents believe technology to be inherently social; constructed and altered in the context of the society in which it develops. Just as technological determinists argue that technology is self-determining and consequently shapes the society around it, those who argue that technology is socially shaped contend that a variety of social forces and interpretations lead, via different problems and solutions, to different technological outcomes and developments. ${ }^{48}$

\footnotetext{
${ }^{44}$ Smith, M. R. and Marx, L. Op.cit. p.30

${ }^{45}$ Winner, L. (1977) Autonomous Technology: Technics-out-of-Control as a Theme in Political Thought MIT Press p.13

${ }^{46}$ Smith, M. R. and Marx, L. Op.cit. p.30

${ }^{47}$ Ibid. p.34

${ }^{48}$ Bijker, W. E., Hughes, T. P. and Pinch, T. J. (1987) The Social Construction of Technological Systems: new directions in the history and sociology of technology MIT Press; Cambridge p.42
} 
The social therefore shapes the technological, and under this viewpoint, the development of technology is a social process. If this is taken to be the case, the next question that can be asked is 'why did they actually take the form that they did? ${ }^{49}$ Some argue that it is political forces at work that control, shape and change technology. In essence, they argue that science has become politicised. ${ }^{50}$ Winner argues that 'technical systems of various kinds are deeply interwoven in the conditions of modern politics'. ${ }^{51}$ Some have seen Winner as a technological determinist, due to this attribution of politics to artifacts, in that he argues that technologies themselves have political properties. Within the same text, he also argues that 'what matters is not the technology itself, but the social or economic system in which it is embedded, 52

Dickson also argues that technological development is linked with politics, suggesting that technology is portrayed as an autonomous neutral entity by those in power, to ensure their continuation of power:

One can only understand the nature of technology developed in any society by relating it to the patterns of production, consumption and general social activity that maintain the interests of the politically dominant section of that society. ${ }^{53}$

From this viewpoint, technology is shaped by the political, which is in turn determined by class structure, with power held by the dominant class in society. Technology is therefore shaped by the politics of the ruling class. Along the same lines, yet without the neo-Marxist element, Feenberg also argues that the development of technological artifacts is inherently political, that technology can never be neutral and that it must be understood in its political context. In terms of social shaping of technology, he says:

\footnotetext{
${ }^{49}$ Ibid. p.3

${ }^{50}$ Webster, A. (1991) Science, Technology and Society Macmillan Educational Ltd.; London p.2

${ }^{51}$ Winner, L. (1980) ‘Do Artifacts have Politics?’ Daedalus pp.121-136 (p.122)

${ }^{52}$ Winner, L. (1980) 'Do Artifacts have Politics?' Daedalus pp.121-136 (p.122)

${ }^{53}$ Dickson, D. (1974) Alternative Technology and the Politics of Technical Change Fontana

Collins; Glasgow pp.10-11
} 
[There are a] variety of social factors that determine the development of technologies. It is therefore an intricate social process with a multiplicity of different actors and processes involved. ${ }^{54}$

This view is also taken by Bijker and Law, who argue that there are a variety of social factors which influence and shape technologies:

Our technologies mirror our societies. They reproduce and embody the complex interplay of professional, technical, economic, and political factors ... all technologies are shaped by and mirror the complex trade-offs that make up our societies ... technologies we are saying are shaped. ${ }^{55}$

Feenberg does, however, criticise those who reside within the Social Construction of Technology school of thought, arguing that they focus too specifically on certain technologies (Feenberg comes from a philosophy of technology perspective).

In terms of the interplay of factors mentioned in Bijker and Law's quote, Latour (alongside others such as Law and Callon) contributes to understanding the effects and influence of society on technology, and of technology on society, through an Actor-Network perspective; analysing actors and processes. Under an Actor-Network Theory perspective, human and non-human participants come together under a network, to act as a whole. An Actor-Network analysis concentrates on how these networks are formed, rather than why. It is a descriptive, rather than an explanatory study, designating all actors in the network equality and therefore leaving no room for power or social structures.

Actor-Network Theory does not give precedence to the social or the technological and is useful to begin mapping the network involved in the development and dissemination of CCTV (although its limitations have been described above).

\footnotetext{
${ }^{54}$ Feenberg, A. Op.cit. York p.213

${ }^{55}$ Bijker, W. E. and Law, J. (1992) (eds.) Shaping Technology, Building Society: Studies in Sociotechnical Change MIT Press; Cambridge p.3
} 
Along the same lines, Hughes has proposed a middle ground theory, arguing for a theory of co-production; that society is shaped or constructed alongside technology, thus avoiding the social determinism that can be found in the social shaping and social construction of technology literature. ${ }^{56}$ Misa also proposes 'a methodological advance toward synthesizing the social-shaping-of-technology thesis with the technological-shaping-of-society antithesis', arguing that a technologically deterministic stance is taken in macro-level analyses, and not when a micro-level analysis is undertaken. He argues for a 'meso' level analysis; 'the region conceptually intermediate between the macro and the micro' ${ }^{57}$ In my thesis I undertake an exploratory study of the development and use of CCTV in the UK, situated in this middle ground theory that society and technology are coproduced. I do not start with an assumption of the inevitability of the use of CCTV, or an assumption that it is only the social that determines the technology. In proposing a 'meso' level, Misa is attempting a balanced analysis, taking into consideration a range of factors and influences (both micro and macro). This type of analysis is appropriate for the study of CCTV, as it is both micro and macro influences that have shaped the technology, and micro and macro impacts that the technology has had on society.

\subsection{The network, information, surveillance society}

The majority of current CCTV literature does not situate developments and spread of CCTV in the wider context of social change. To understand the history of surveillance, changes such as developments in computing and the emergence of the network society must also be understood. The lack of research on the history of CCTV in the UK, and with this the apparent acceptance of the technology and its widespread nature, needs to be looked at in the wider context of technological developments, changes in the social structure and then in its political, economic and social context, which will form the basis of chapter 6. It is a mistake to base thoughts on CCTV on the inevitability of its appearance and

\footnotetext{
${ }^{56}$ Hughes, T. ‘Technological Momentum’ in Smith, M. R. and Marx, L. (1994) Does Technology Drive History? MIT Press; Cambridge pp.101-114

${ }^{57}$ Misa, T. J. 'Retrieving Sociotechnical Change from Technological Determinism' in Smith, M. R. and Marx, L. (1994) Does Technology Drive History? MIT Press; Cambridge p.139
} 
subsequent widespread dissemination - this should not be taken as a given. Despite technological determinism falling out of favour in the STS literature, within analyses of CCTV there seems to exist a technological determinism of sorts, an almost inevitability regarding its ubiquitous presence, its consequences, impacts and effects. Its history therefore needs to be looked at in order to develop a better contextualised picture. In this section I will look at the closely related concepts of the network society, the information society, and the surveillance society, drawing also on notions of modernity and post-modernity.

It has been suggested that we have entered, in recent times, an information society. According to Webster, the vast field of studies of the information society can be split into five areas; technological, economic, spatial, cultural, and occupational, although these areas need not be mutually exclusive. I do not want to concentrate on these areas individually, but it is worth pointing out that:

The most common definition of the information society lays emphasis upon spectacular, technological innovation. The key idea is that breakthroughs in information processing, storage and transmission have led to the application of Information Technologies (IT) in virtually all corners of society. ${ }^{58}$

Under technological definitions, the benefits of information technologies are seen as becoming increasingly widespread, impacting substantially on society, thereby creating an information society. As well as this technologically determinist slant, all notions of the information society, based on these five areas, are quantitative in nature; 'there is more information nowadays, therefore we have an information society, ${ }^{59}$ As Webster points out, this is flawed reasoning; at what point does the amount of information technology mean that we have entered an information society? ${ }^{60}$ Webster argues that a more qualitative line of thought, focusing on the character of the information, is required before the suggestion can be made that

\footnotetext{
${ }^{58}$ Webster, F. (1995) Theories of the Information Society Routledge: London and New York p.7

${ }^{59}$ Ibid. p.9

${ }^{60}$ Ibid p.11
} 
we have entered an information society. ${ }^{61}$ However, the majority of information society commentators unproblematically base their theories on this quantitative reasoning.

Kumar states that 'the birth of information, not merely as a concept but also an ideology, is inextricably linked to the development of the computer' ${ }^{62}$ The first digital computer - ENIAC - was developed during World War Two for the American Army. As developments in microelectronics increased at a rapid pace, they were hailed as the start of the third revolution; the information revolution. ${ }^{63}$ This move to information is described by Bell as:

The strategic resource and transforming agent of the post-industrial society ... just as the combination of energy, resources and machine technology were the transforming agencies of industrial society. ${ }^{64}$

Bell describes a move from 'pre-industrial' activities to 'industrial-fabrication' to 'post-industrial-information' activities. ${ }^{65}$ In his analysis of this information society, Bell separates and keeps distinct culture, politics and economy, which he states 'respond to different norms, have different rhythms of change, and are regulated by different, even contrary, axial principles' ${ }^{66}$ He therefore does not allow his theory of the information society to move from the boundaries of the economic, commenting instead only on changes in the 'techno-economic structure'. ${ }^{67}$ In this sense, Bell sits in contrast to the majority of other information society commentators, who perceive the changes to be far more widespread throughout society.

\footnotetext{
${ }^{61}$ Ibid. pp.9-11

${ }^{62}$ Kumar, K. (2005) From Post-Industrial to Post-Modern Society: new theories of the contemporary world Blackwell; Oxford pp.34-35

${ }^{63}$ Ibid. However, Agar (2003) does argue against this, saying that information came first, providing a number of examples of information collecting and processing organisations in the 1930s. One specific example he provides is the Telecommunications Research Establishment at Malvern, which later housed Radar development.

${ }^{64}$ Bell, D. 'The social framework of the information society' in Forester, T. (1980) The Microelectronics Revolution: the complete guide to the new technology and its impact on society Oxford; Blackwell pp. 531-545

${ }^{65}$ Ibid. pp. 504-505

${ }^{66}$ Bell, D. (1976) The Cultural Contradictions of Capitalism Basic Books; New York p.10

${ }^{67}$ Ibid. p. 11
} 
For some, such as Masuda, the widespread changes are highly positive. Masuda envisages a future 'universal society of plenty', which is enabled by information technology, describing this society as a 'computopia'. Information technology will eradicate the need for labour, administration and centralised politics; 'citizen management systems' and participatory democracy will prevail. ${ }^{68}$ For Stonier, the information society is also a highly democratic society, with the diffusion of information throughout society, widely distributed and not centrally controlled. ${ }^{69}$ Critics of the information society, for example Webster, argue that change is overemphasised, that a restructuring of society and a new era has not occurred; 'If there is just more information then it is hard to understand why anyone should suggest that we have before us something radically new' ${ }^{70}$ Webster argues that there is far more continuity with the past than is proposed by proponents of the information society - that society is still first and foremost capitalist, pursuing wealth creation. He does distinguish between various forms of capitalism; laissezfaire $\left(19^{\text {th }}\right.$ century), corporate capitalism $\left(20^{\text {th }}\right.$ century) and informational capitalism ( $21^{\text {st }}$ century), yet stresses continuity in change, rather than a break with the past. ${ }^{71}$ Fuchs also describes a restructuring of capitalist society, rather than the emergence of a new type of society:

Computer networks are the technological foundation that has allowed the emergence of global network capitalism, that is, regimes of accumulation, regulation, and discipline that are helping to increasingly base the accumulation of economic, political, and cultural capital on transnational network organizations that make use of cyberspace and other new technologies for global coordination and communication .... . The need to find new strategies for executing corporate and political domination has resulted in a restructuration of capitalism that is characterized by the emergence of transnational, networked spaces in the economic, political, and cultural system and has been mediated by cyberspace as a tool of global coordination and communication. Economic, political, and cultural space have been

\footnotetext{
${ }^{68}$ Kumar, K. Op.cit. p.15

${ }^{69}$ Ibid.

${ }^{70}$ Webster, F. (2002) (2nd ed.) Theories of the Information Society Routledge; London p.259

${ }^{71}$ Webster, F. (2006) (3rd ed.) Theories of the Information Society Routledge; London
} 
restructured; they have become more fluid and dynamic, have enlarged their borders to a transnational scale, and handle the inclusion and exclusion of nodes in flexible ways. ${ }^{72}$

This is similar therefore to what Castells and others have termed the 'network society', Fuchs however assigns the term 'transnational network capitalism', where he argues that capitalism has entered an 'informational mode of development'. ${ }^{73}$ This continuity is also emphasised by Beniger, who argues that the information society 'has not resulted from recent changes....but rather increases in the speed of material processing and of flows through the material economy that began more than a century ago' ${ }^{74}$

For Castells, information has enabled the emergence of the network society:

One of the key features of informational society is the networking logic of its basic structure, which explains the use of the concept of 'network society'... . As an historical trend, dominant functions and processes in the Information Age are increasingly organized around networks. Networks constitute the new social morphology of our societies, and the diffusion of networking logic substantially modifies the operation and outcomes in processes of production, experience, power, and culture'. ${ }^{75}$

The network society therefore results from this increase in information. Castells, however, does emphasise the formation of a new type of society, and therefore stands in contrast to Bell et al. as mentioned above. Although arguing that the network society has been enabled by information, Castells argues against the theory of the emergence of an information society:

\footnotetext{
${ }^{72}$ Fuchs, C. (2008) Internet and Society: Social Theory in the Information Age Routledge; London pp.110-119

${ }^{73}$ Ibid. p.118

${ }^{74}$ Beniger, J. R. (1985) The Control Revolution: technological and economic origins of the information society Harvard University Press; Cambridge p.435

${ }^{75}$ Castells, M. (2000) ( $2^{\text {nd }}$ ed.) The Rise of the Network Society Blackwell; Oxford pp. 21 - 500
} 
We are not in the information or knowledge society. At least no more than we have been in other historical periods. Knowledge and information have always been essential sources of productivity and power. If, by emphasizing the knowledge component of our world, we imply that we know now and were ignorant in earlier times, a little modesty would be welcome. Knowledge is always historically relative ... . Information and knowledge are indeed essential, in the economy and in society at large. But they are not specific as dominant components of our kind of society. What is specific is that, on the basis of a new technological paradigm (informationalism), a new social structure has emerged, a structure made up of electronic communication technologies - powered, social networks. So, what is the difference? It is the technology, of course. But it is also the networked social structure, and the specific set of relationships implied in the networking logic Therefore, in my view, we must let the notion of an information society or of a knowledge society wither, and replace it with the concept of the network society. ${ }^{76}$

Castells argues that theories of the information or knowledge society simply emulate earlier arguments of a shift from nomadic to agricultural to industrial societies; a technologically deterministic argument of human progress as based in technological development. He argues that these arguments are based on the idea of technology as progress, as opposed to thinking about 'organizational transformation' and the 'emergence of a globally interdependent social structure, with its processes of domination and counter-domination', found in the theory of a network society. ${ }^{77}$ For Castells, the network society is:

A society whose social structure is made of networks powered by microelectronics-based information and communication technologies. By social structure, I understand the organizational arrangements of humans in relations of production, consumption, reproduction,

\footnotetext{
${ }^{76}$ Castells, M. 'Informationalism, networks, and the network society: a theoretical blueprint' in Castells, M. (2004) (ed.) The Network Society: A Cross-cultural perspective Edward Elgar; Cheltenham p.41

${ }^{77}$ Ibid. p.42-43
} 
experience, and power expressed in meaningful communication coded by culture. $^{78}$

Increased volumes of information and advances in information technologies are also used as the basis for arguments proposing that we have now become a surveillance society. Studies of the surveillance society concentrate on the fact that technological advances have also culminated in increases in the collection and processing of data in regard to individuals. With regard to this, Lyon says:

All societies that are dependent on communication and Information Technologies for administrative and control processes are surveillance societies ... one intrinsic aspect of all so-called Information Societies is that they are, by the same token, Surveillance Societies. $^{79}$

The term 'surveillance society' was coined in 1985 by the sociologist Gary T. Marx, when he referred to the surveillance society as an Orwellian situation in which:

With computer technology, one of the final barriers to social control is crumbling - the inability to retrieve, aggregate, and analyze vast amounts of data. Inefficiency is losing its role as the unplanned protector of liberty. ${ }^{80}$

The surveillance society is said to exist due to the details of individuals being 'collected, stored, retrieved and processed every day within huge computer databases' ${ }^{81}$ Lyon adds to this by arguing that as surveillance systems grow, they are becoming less apparent and far more efficient, structured and elusive. ${ }^{82}$ These examples are based in the technological, rather than ideological; that the

\footnotetext{
${ }^{78}$ Ibid. p.3

${ }^{79}$ Lyon, D. (2001) Surveillance Society: Monitoring everyday life Open University Press;

Buckingham pp.1-5

${ }^{80}$ Marx, G. T. (1985) 'The Surveillance Society: The threat of 1984-style techniques' The Futurist 19/3 pp.21-26 (р.26)

${ }^{81}$ Lyon, D. (1994) The Electronic Eye: the rise of the surveillance society University of Minnesota Press; Minneapolis p.3

${ }^{82}$ Lyon, D. (2001) Op.cit. p.2
} 
technology exists is enough to produce a new type of society. However, the development of surveillance is far more complex than that, and whether the increase in surveillance means we have entered a new type of society is debatable.

Latour describes the claims of the network, information, and surveillance society, as operating under an assumption that the society provides the context in which things are to be understood. He argues, however, that the actors, actants, and actions, need to be followed - that the actions need to be looked at first in order to explain the society. He proposes a need to open up the 'black-box' in order to explore the issues inside. ${ }^{83} \mathrm{I}$ argue in this thesis that the theories of the information society, network society, and surveillance society are insufficient to explore the rise of CCTV in the UK. The assumption that is made that we have entered and exist in a certain type of society neglects important social, historical, economic and political factors contributing to the development and usage of the technology. To situate CCTV as simply being a part of the network, information, or surveillance society is not enough.

Furthermore, in order to present a more rounded and less technologically deterministic analysis, I include ideas of the public in relation to CCTV. Next, I focus on the public sphere, and the public and media.

\subsection{The public sphere}

Prior to more focused and empirical research later in the thesis, I will provide a theoretical context describing a history of ideas of the public, the public sphere and public space, the public and the role of the media, situating this in a framework of an understanding of liberal democracy.

In his conceptualisation of the public sphere, Aristotle declared that 'friendship also seems to hold political communities together'; a 'concord', working for the good of the community. ${ }^{84}$ This is reiterated by Habermas in his theory of the

${ }^{83}$ Latour, B. (1987) Science in Action Open University Press; Milton Keynes

${ }^{84}$ Williams, R. (1876) tr. The Nicomachean Ethics of Aristotle Longmans Green and Co.; London 
'discursive public sphere'; an ideal of the public sphere as a place of democracy and debate. This concept of the public sphere is bound up with politics. From this point of view, the fundamental basis of democracy is that public opinion, and active participation in democratic and deliberative processes, is vital in shaping the future of society. This concept of an active public is based on an Athenian model - active, informed and participatory (rather than the Roman model of a passive public; simply recipients of information). Habermas describes the public sphere as follows:

By 'the public sphere' we mean first of all a realm of our social life in which something approaching public opinion can be formed. Access is guaranteed to all citizens. A portion of the public sphere comes into being in every conversation in which private individuals assemble to form a public body. They then behave neither like business or professional people transacting private affairs, nor like members of a constitutional order subject to the legal constraints of a state bureaucracy. Citizens behave as a public body when they can confer in an unrestricted fashion-that is with the guarantee of freedom of assembly and association with the freedom to express and publish their opinions-about matters of general interest. ${ }^{85}$

Arendt describes a loss of the public sphere, under modernity. In The Human Condition she describes a decline of public space and the disappearance of the public realm, referring to what she describes as the ideal in the Ancient Greek Polis. However, even though Arendt describes this traditional version of the public realm as something ideal, it was in fact an exclusionary and elitist form of participation in political life for the select few. Habermas also describes a decline of the public sphere, although laying blame with the rise of the consumer culture, rather than modernity more generally, as is the case with Arendt. Habermas argues that in the industrial society, the media and elites control the public sphere. He also holds a historically idealised version of the public realm (in the $18^{\text {th }}$ and $19^{\text {th }}$ centuries), and describes its decline in the $20^{\text {th }}$ century, with the rise of

\footnotetext{
${ }^{85}$ Habermas, J. 'The Public Sphere: An encyclopaedia article' in Bronner, S. E. and Kellner, D. M. (1989) (eds.) Critical Theory and Society: A reader pp.136-42
} 
capitalism, consumption, and industry. He sees the public as consumers first and foremost, with government taking control of the public sphere. ${ }^{86}$

This stands in contrast to another view of the media; namely that its political function is a democratic one, allowing public participation in government and political decisions, particularly once the print media became a mass medium at the end of the $19^{\text {th }}$ century (through the rise of the new middle class and cheaper papers through advertising income, which will be described next). At the same time, the freedom of the press had become an established civil right. ${ }^{87}$ Although Habermas argues that control of the public sphere has passed to the media, his normative ideal is one where the public sphere allows criticism of the state. Fraser states that this model 'designates a theatre in modern societies in which political participation is enacted through the medium of talk'. ${ }^{88}$ She also sees the press as the most important institution of the public sphere in its ideal form. ${ }^{89}$

Although newspapers first appeared in Britain during the $16^{\text {th }}$ century, ${ }^{90}$ they did not become widespread until the nineteenth century, when newspapers took on a new role, which Chapman describes as follows:

In essence, newspaper reading was a form of participation in politics. Throughout the nineteenth century the role of the media in the process of democracy was being continually tried and tested. The extension of political power to a wider number of people required the means to give them knowledge of politics: in the nineteenth century, of necessity this entailed newspapers free from government control as public argument became an instrument of social transformation. ${ }^{91}$

\footnotetext{
${ }^{86}$ Habermas, J. (1987) The structural transformation of the public sphere : an inquiry into a category of bourgeois society Polity Press; Cambridge

${ }^{87}$ Volkmer, I. (1998) Covering News John Libbey Media; Luton

${ }^{88}$ Fraser, N. 'Politics, Culture, and the Public Sphere: Toward a postmodern conception' in Nicholson, L. and Seidman, S. (1995) (eds.) Social Postmodernism: Beyond Identity Politics Cambridge University Press; Cambridge pp.287-314 (p.287)

${ }^{89}$ Gregory, J. and Miller, S. (1998) Science in Public: communication, culture, and credibility Plenum Trade; New York and London

${ }^{90}$ For a detailed early history of the British newspaper see Clarke, B. (2004) From Grub Street to Fleet Street Ashgate; Aldershot

${ }^{91}$ Chapman, J. (2005) Comparative Media History, An Introduction: 1789 to the present Polity Press; Cambridge p.12
} 
At the same time there were changes in the production technology in order to keep up with increasing demand for newspapers, described as a period of 'rapid industrialization' within the newspaper industry. ${ }^{92}$ The late $19^{\text {th }}$ and early $20^{\text {th }}$ century was an era of 'technological inventiveness', during which time 'increased urbanization and literacy created a new mass market for the media, pioneered by newspapers'. ${ }^{93}$ By the early $20^{\text {th }}$ century, the 'growth of the press had become so phenomenal ... that newspaper production was now a major industry in its own right'. 94

The First World War had the impact of a greater demand for more efficient communication methods. During this time there was an increase in broadcasting in general, with Chapman describing this period (1918-39) as an 'age of ideology and politics aimed at manipulating the masses', during which time 'the role of the media became multi-faceted' in terms of entertainment, propaganda, cultural influence, and nationalism'. ${ }^{95}$ During the Second World War, there was also a rise in newspaper sales; 'War makes us hungry for news' notes Seymour-Ure. ${ }^{96}$ By 1945, the number of people reading a London edited national newspaper had increased substantially, in which most of the content was news rather than features. ${ }^{97}$

During the 1960s and 1970s, competition for advertising revenue meant that 'the appeal of [newspapers] had to be widened in order to retain advertising, ${ }^{98}$ The term 'mass media' came into widespread usage during this time. ${ }^{99}$ The general enthusiasm that was felt for science and technology after World War Two fluctuated during the 1960s and 1970s, showing itself in the lack of funding for primary research. This lack of enthusiasm laid the foundations for the rise of the Public Understanding of Science movement (PUS). The general idea behind the

\footnotetext{
${ }^{92}$ Ibid. p.57

${ }^{93}$ Ibid. p.71

${ }^{94}$ Ibid. p.81

${ }^{95}$ Ibid. pp.178-179

${ }^{96}$ Seymour-Ure, C. (1991) The British Press and Broadcasting since 1945 Blackwell; Oxford p.16

${ }_{97}^{9}$ Ibid. p.1

${ }^{98}$ Chapman, J. Op.cit. p.235

${ }^{99}$ Seymour-Ure, C. Op.cit. p.6
} 
movement was that lack of enthusiasm and interest from the public for science and technology was due to a lack of understanding and ignorance (the deficit model of public understanding). If this ignorance could be combated, public enthusiasm for science would increase, as would funding. ${ }^{100}$ This idea of the public assumed a direct correlation between people reading and knowing about science and technology and an increased enthusiasm for it. This 'deficit model' relied on a passive audience, taking in information relayed by the media. Although this model has been criticised strongly in the academic literature, in practice, elements of the deficit model still remain, which I will discuss in relation to CCTV in chapter 7.

This idea of a public deficit of knowledge was not a new one. In 1922, Lippmann argued that the public lack the knowledge required to participate in forming public policy, describing them as a 'bewildered herd' who require the media to help them understand events. Within his argument, the media therefore shape public opinion and public perceptions of the world around them. ${ }^{101}$ A few years later he also argued that the public are a 'mere phantom', incapable of acting competently to direct policy and unable to direct events. ${ }^{102}$ In this work he refers to the public as a 'deaf spectator in the back row', more interested in themselves than the bigger issues that determine the course of society. ${ }^{103}$

In contrast, Dewey (1927) argues for a revival of the concept of 'the public'. He argues against Lippmann (1922) by stating that the public are 'in eclipse' rather than a 'mere phantom' and that increased public communication is required in order to revive 'the public'; that there is the potential for the public to be a participant in democracy again. He looks to the local community to become the 'great community':

Without such communication the public will remain shadowy and formless ... . Till the Great Society is converted into a Great

\footnotetext{
${ }^{100}$ Gregory, J. and Miller, S. Op.cit.

${ }^{101}$ Lippmann, W. (1922) Public Opinion Allen \& Unwin

${ }^{102}$ Lippmann, W. (1925) The Phantom Public Harcourt Brace \& Co. p.77

${ }^{103}$ Ibid. p.13
} 
Community, the Public will remain in eclipse. Communication can alone create a great community. ${ }^{104}$

Dewey therefore argues that in order for democracy to exist, there must also be the existence of an active public. This notion of an active public has evolved more recently into the notion of an active citizen, or active citizenship. This idea of an active citizen was deployed in Britain during the Thatcher years (although this was in accordance with the idea that 'there is no such thing as society'). I look at active citizenship and self-governance in relation to crime control and CCTV in chapters 7 and 8.

In this section I have looked at the history of the public sphere and ideas of the public. Further, I have looked at theories the public and its relationship to the media. In the next section I extend the discussion of the media and public via theories of media effects and moral panics, which will be referred back to once again during chapter 7 .

\subsection{Media effects and moral panics}

In this section, I will provide a brief overview of the concept of moral panic, its relationship to the mass media and media effects research, and its connection to the risk society. Although I will look specifically at certain 'panics' that have arisen in the media over recent years, and the relationship of CCTV to these panics, I also want to situate my analysis in the wider context of risk society, in order to analyse and assess whether moral panics research can add anything to our understanding of risk society and vice versa.

The concept of moral panics was originally developed by Cohen (1972), although the term was introduced by Jock Young in $1971 .{ }^{105}$ Cohen describes the concept as follows:

${ }^{104}$ Dewey, J. (1927) The Public and its Problems George Allen \& Unwin; London p.142

105 The term appeared in an essay by Jock Young in 1971 in Cohen's Images of Deviance. 
Societies appear to be subject, every now and then, to periods of moral panic. A condition, episode, person or group of persons emerges to become defined as a threat to societal values and interests; its nature is presented in a stylized and stereotypical fashion by the mass media ... . Sometimes the panic passes over and is forgotten ... at other times it has more serious and long-lasting repercussions and might produce such changes as those in legal and social policy or even in the way the society conceives itself. ${ }^{106}$

Although a lot of emphasis is placed on what Cohen describes as 'folk devils' regarded as an individual, or a group of individuals, by many moral panics commentators. Cohen also refers here, however, to a 'condition' or 'episode', not just the wrongdoings of people. ${ }^{107}$ In this sense, the concept can be linked more readily with the theory of risk society. In the context of risk society, anxiety and concern about risk is based around events rather than individuals (although the risk is human-made). For the purpose of this thesis, the 'risk' is fear of crime, and the moral panic is perceived notions of crime derived from individual events portrayed in the media. I will think about how crime is constructed in the media, and whether CCTV is seen as the solution.

In terms of understanding how the public react to issues presented in the media, Cohen argues that:

A crucial dimension for understanding the reaction to deviance both by the public as a whole and by agents of social control, is the nature of the information that is received about the behaviour in question ... . In industrial societies, the body of information from which such ideas are built, is invariably received at second hand. That is, it arrives already processed by the mass media and this means that the information has been subject to alternative definitions of what constitutes 'news' and how it should be gathered and presented ...

\footnotetext{
${ }^{106}$ Cohen, S. (1972) Folk Devils and Moral Panics: The Creation of the Mods and Rockers MacGibbon \& Kee; London p.10

${ }^{107}$ Ungar, S. (2001) 'Moral panic versus the risk society: the implications of the changing sites of social anxiety’ in British Journal of Sociology 52(2) pp.271-291
} 
.The student of moral enterprise cannot but pay particular attention to the role of the mass media in defining and shaping social problems. The media have long operated as agents of moral indignation in their own right: even if they are not self-consciously engaged in crusading or muck-raking, their very reporting of certain 'facts' can be sufficient to generate concern, anxiety, indignation or panic. When such feelings coincide with a perception that particular values need to be protected, the preconditions for new rule creation or social problem definition are present. ${ }^{108}$

Although I believe that Cohen's focus on social control is overemphasised, how the public receive information is an important issue. This issue of media effects has a long history, with a huge number of theories put forward. Research in this area has been conducted since the 1920s, amassing a considerable amount of literature to which I cannot pay sufficient attention here. ${ }^{109}$

For my purposes, I will simply note here that media discourse must influence, at least to some extent, how people think about issues (and in relation to this thesis, CCTV). I do not suggest that public opinion is moulded by the media but do think that the media play an important role in shaping public beliefs and opinions. Besides this, it is an avenue through which the public receive information and so the slant taken by the media must surely have some effect on the feelings of the public towards issues reported. I agree with Chapman when she says; 'The media make the world even as the world makes the media'. ${ }^{110}$ Without entering into questions of public opinion formation or mass communication, I will undertake a discourse analysis concentrating on the framing of CCTV by the media, in chapter 7. More specifically and later in the thesis I am interested in the relationship between the press, the public and CCTV.

\footnotetext{
${ }^{108}$ Cohen, S. (1972) Op.cit. p.16

${ }^{109}$ Livingstone, S. (1996) 'On the Continuing Problem of Media Effects Research’ in Curran, J. and Gurevitch, M. ( $2^{\text {nd }}$ ed.) Mass Media and Society Edward Arnold; London pp.305-324 p.306

${ }^{110}$ Chapman, J. Op.cit. p.1
} 
Thompson argues that 'this is the age of moral panic', distinguishing from earlier panics over crime and the activities of the 'youth' to the nowadays rapid succession in which panics occur, alongside the 'all-pervasive quality of the panics' ${ }^{111}$ For him a moral panic is 'a high level of concern over the behaviour of a certain group or category of people and ... an increased level of hostility toward the group or category regarded as a threat'. ${ }^{112}$ Within this definition, the relationship between moral panics and risk is clear; as a slightly simplified explanation (neglecting other socio-economic and political factors for now), public concern over perceived risks, such as crime, is captured and heightened by the media in relation to specific events in such a way as to develop into a general anxiety over certain conditions. However, the public does already need to be 'receptive to discourses containing a demonizing message'. ${ }^{113}$ For example:

In 1993 The Economist described the publicity surrounding the murder of 2-year-old James Bulger by two 10-year-old boys as another case of 'moral panic'. In both cases public anxiety was amplified by publicity in the press, which portrayed these events as signifying a widespread and deeper moral malaise and as signs of social disintegration. ${ }^{114}$

The receptiveness can be explained by a generally heightened awareness or perception of risk(s) as described by Beck in his theory of risk society. This receptiveness therefore provides the foundation for the moral panics which derive from media reportage of incidents.

Waddington argues that a moral panic needs to be something that is not markedly different from what has occurred before, but where the reaction, both media and official, is on a far greater scale. ${ }^{115}$ He goes on to state that the problem with this definition is assessment of the scale of the problem in relation to the scale of the

\footnotetext{
111 Thompson, K. (1998) Moral Panics Routledge; London pp.1-2

112 Ibid. p.9

${ }^{113}$ Ibid. p.29

${ }^{114}$ Ibid. p.11

${ }^{115}$ Waddington, P. A. J. (1986) ‘Mugging as a Moral Panic: A question of proportion’ British Journal of Sociology 37(2) pp.245-259 pp.245-246
} 
response. ${ }^{116}$ I disagree that quantifying the scale of the response is always an issue. As an example, in the context of the James Bulger incident, the scale of the response was far greater than the one incident, provoking a reaction of increased anxiety about child snatchers etc. (There was also the major issue that the two boys who killed James Bulger were also children, but the public outcry was one centred on child snatchers). The problem of assessing proportionality is not an issue here, as the intensity of the reaction was far greater (in terms of the broader context of child snatching and homicide, I do not mean here that the reaction to the actual crime was overemphasised), in contrast to the increase in this type of crime - child homicide rates have remained broadly similar since the 1970s in the UK ${ }^{117}$ Reaction by the media and the public turned a single incident into a potentially society-wide and common problem. I discuss this further in chapter 7.

I will later refer back to this moral panics literature in my analysis of media reportage of CCTV, asking whether risk of crime and the moral panics caused by this fear is used as a rationale and justification for introducing CCTV.

\subsection{Conclusion}

In this chapter I have reviewed a range of literature, which I feel is relevant to my thesis. In the first section I explored the concept of risk and the idea that we currently live in a risk society. An increasing awareness of risk on the part of the public has led to risk management strategies and an ongoing reliance on technological solutions. This belief in the technological fix was looked at in section two of this literature review. The idea of technology as a solution to social problems leads to the notion of technology as the driving force behind social change. Literature concerned with technological determinism was therefore reviewed in the next section. I also discussed the idea of the social shaping of technology, as well as newer literature arguing for the co-production of society

\footnotetext{
${ }^{116}$ Ibid. p.246

${ }^{117}$ NSPCC -

http://www.nspcc.org.uk/Inform/resourcesforprofessionals/Statistics/KeyCPStats/4_wda48747.ht $\underline{\mathrm{ml}}$ (Accessed 16/09/2009)
} 
and technology. Following this, I explored ideas of a new era of social development; that we have entered a surveillance society, a network society, or an information society. In the final sections of the chapter, I discussed notions of the public and the public sphere, its relationship to the media, and the possibility of media effects culminating in moral panics.

I have therefore drawn on literature from a number of disciplines, which I refer back to when attempting to answer the main research question of this thesis why has the UK become so camera-surveilled? Prior to the analytical chapters of this thesis, I first explore the more specific literature concerned with CCTV in the UK and internationally, which is reviewed in the next chapter. 


\section{Chapter III:}

\section{CCTV Literature Review}

\subsection{Introduction}

In this chapter I will provide a comprehensive review of the literature on CCTV. I will concentrate on those with a focus on public space CCTV systems, rather than the workplace and private settings. I have split the literature into what I believe are the five main themes running throughout: effectiveness, social control, public opinion, privacy, and international studies. As I will show, the majority of UKbased literature is concerned with the themes of effectiveness and social control. In terms of the main research question of the thesis - why the UK has become so camera-surveilled - I believe a multi-disciplinary STS approach is necessary, which I will show is lacking in the current literature on CCTV. In this chapter I will review the literature and show what my thesis will add.

\subsection{CCTV and effectiveness}

\section{$\underline{\text { Home Office Studies }}$}

The impact of CCTV in reducing crime has been widely championed by the Government, local councils and the security industry in the UK. In terms of academic studies, the Home Office is the most vocal in publishing the benefits of CCTV with regard to crime reduction. These Home Office studies often concentrate dually on the issues of effectiveness of CCTV and public acceptability of the technology. A lot of the research concentrating on the effectiveness of CCTV is over ten years old (near the inception of its widespread dissemination). More recent studies still raise the same questions showing that the effectiveness debate has not yet been resolved. 
A very early Home Office commissioned study of CCTV effectiveness was conducted by Burrows in 1980, looking at the effect - on theft and robbery offences - of equipping the London Underground with CCTV. ${ }^{1}$ He begins his report by stating that, in terms of CCTV:

Costs are a severe limitation ... and effectiveness, even discounting the possibility of displacement, cannot be taken for granted ... where crime is relatively infrequent the level of vigilance required from those manning a CCTV system may be unrealistic. There may also be problems in controllers getting a quick enough reaction from other staff or being able to communicate a good enough description of the offender. $^{2}$

However, despite this lean towards possible problems that may arise through the use of CCTV, as well as mention of displacement effects and the possibility that crime has been reduced in the area through other measures (such as increased police presence), Burrows reverts to painting a positive picture of the impact of CCTV on crime with little reference to these earlier issues.

Two further early studies from the Home Office Police Research Group were conducted by Honess and Charman in 1992, and Tilley in 1993. The 1992 report describes the results of a survey concerned with public opinion towards CCTV and the use of these systems by those who install them. The survey asked questions surrounding issues of: public attitudes towards CCTV, public awareness of CCTV systems and any concerns about these systems, responsibility for the installation of systems, the views of the public on access to and use of tapes, and public perceptions of the purpose of CCTV. The report also includes crime statistics from four case study areas for the purpose of discussing the effectiveness of CCTV. The conclusions of this study are that CCTV has a

\footnotetext{
${ }^{1}$ Burrows, J. (1980) 'Closed Circuit Television and Crime on the London Underground' in Clarke, R. V. G. and Mayhew, P. Designing Out Crime. Home Office Research Unit. Her Majesty's Stationery Office; London.

${ }^{2}$ Ibid. p.75
} 
'broadly positive perception from members of the general public. Levels of concern are not high and CCTV is assumed to be effective in crime control'. 3

The authors point out, however, that these attitudes are held by a public without a sound knowledge of the capabilities and functions of CCTV in public places. They recommend greater provision of information and levels of public consultation, to minimise the potentially negative impact on civil liberties. The survey data is now over fifteen years old, as well as having been conducted by non-independent researchers. This call for public consultation has not yet been realised many years later. The issue of effectiveness was also researched by the Scottish Office in 1996, with a study which took place over four years and focused on questions of effectiveness and possible displacement effects. The main findings of this study showed a $21 \%$ fall in the total number of recorded crimes and offences in the area covered by CCTV in the two years following installation (the research was conducted over four years; two prior and two postinstallation) and a 16\% improvement in the detection of crime. They found no evidence of crime displacement. However, simply looking at crime statistics may be too simplistic, with some of the crimes recorded and cleared up being minor crimes which may otherwise not have been reported. Further, this evaluation, although long-term relatively to others, is still not conducted over a long enough time-period to gain a full picture.

This point about crime statistics is argued in a recent Home Office funded study outlining the findings from the 2005 national CCTV evaluation. The main areas of focus were: changes in crime, an analysis of other crime reduction initiatives, the design process of CCTV and other factors involved, the installation process; the economic impact of each system, control room operations, and public perceptions of CCTV. The findings from this evaluation point to CCTV having little or no effect on crime, as well as being ineffective in terms of making people feel safer or changing their behaviour. The authors argue that to come to these conclusions is too simplistic. They state that crime rates are a poor measure for assessing the effectiveness of CCTV, as success with one type of offence may be

\footnotetext{
${ }^{3}$ Honess, T. and Charman, E. (1992) 'Closed Circuit Television in Public Places: Its acceptability and perceived effectiveness’ Police Research Group Crime Prevention Unit Series Paper \#35
} 
swallowed in the overall statistics. They therefore call for a more balanced judgement of the success of CCTV, proposing that the UK is still learning how to use this technology to its best effectiveness. Although I agree that crime rates may not be the best measure for assessing the impact of CCTV on crime, there seems to be an element of excusing the negative results obtained from the evaluation.

\section{Independent Research}

Independent research studies tend to produce lower rates of effectiveness than those funded by the Home Office. For example, Bulos and Sarno conducted the first national evaluation of local authority CCTV initiatives in 1994, concentrating their survey on issues of the nature and scope of research into schemes and questioning the extent to which these schemes have extended into the public domain. ${ }^{4}$ The evaluation encompasses government studies, an independent evaluation by Liberty (an independent human rights organisation working in England and Wales), research from CCTV users and providers, and the media. The second part of the report surveys CCTV use by local authorities, concentrating on issues of; levels of CCTV use, the extent of planned CCTV schemes, and knowledge of research on CCTV to date. The authors conclude that their findings suggest a desire to expand CCTV (and the use thereof in public places) from local authorities and the police, with plans in place to develop and integrate systems. They point out that this desire to develop and extend CCTV use comes with no basis in evaluation or research, and therefore call for more long-term evaluation of CCTV, as well as the establishment of an agency to coordinate activities in public places. ${ }^{5}$ The authors suggest that there are gaps in knowledge regarding the effectiveness of CCTV systems and argue that there has been little independent research into this issue. Although this paper is useful in offering a critique of studies of CCTV and its effectiveness, a more recent and indepth evaluation of schemes is necessary.

\footnotetext{
${ }^{4}$ Bulos, M. and Sarno, C. (1994) 'Closed Circuit Television and Local Authority Initiatives: The first national survey’ Research Monograph, South Bank University.

${ }^{5}$ Ibid. p.21
} 
A year later, in 1995, a small-scale study was undertaken by Bulos to address issues of whether CCTV has had an impact on levels of crime in Sutton town centre (a suburban high street just South of London), the public perception of CCTV (which will be looked at again later), and how the Sutton scheme compares with others elsewhere. ${ }^{6}$ The main conclusions deriving from this study were that during the 4 month period after CCTV installation, vehicle crime in the 3 council owned car parks fell by 93\%, and that a 76\% reduction in vehicle crime on streets with CCTV occurred between June and September 1994. The report does describe some evidence of crime displacement to other locations. This study is a prime example of why the effectiveness issue has not yet been resolved. The study highlights the fact that the same questions are still being asked; however it itself is a small-scale and short-term study that fails to provide information on long-term effects and impacts.

A more recent Home Office study focused once more on these same questions. Welsh and Farrington undertook a review of 46 relevant studies of CCTV and a meta-analysis of 22 surveys from the UK and US on the effectiveness of CCTV in reducing crime. ${ }^{7}$ The study concludes that CCTV has a small impact on crime and is most effective in reducing incidents of vehicle crime in car parks. They add that it has little or no effect on city centre crime or public transport. Included in this paper is a critical analysis of the methodologies used in previous studies, as the authors point to what they believe to be necessary future areas of research. They argue the need for a control condition, longer-term evaluations with longer follow-up periods, as well as the need for evaluations to determine alternative methods of measuring crime. ${ }^{8}$ I would suggest that a funded study such as this may have been more useful in tackling some of the research suggested by the authors, as opposed to covering old ground which has been remarked upon time and time again in the literature on the effectiveness of CCTV.

\footnotetext{
${ }^{6}$ Bulos, M. (1995) 'Towards a Safer Sutton? Impact of closed circuit television on Sutton town centre’ London Borough of Sutton

${ }^{7}$ Welsh, B. C. and Farrington, D. P. (2002) 'Crime Prevention Effects of Closed Circuit

Television: a systematic review’ Home Office Research Study

${ }^{8}$ Ibid. p.9
} 
Moving away from the question of effectiveness, Tilley presents a study concentrating on how to improve the evaluation of CCTV schemes. He does briefly discuss the issue of whether CCTV really works arguing that the answers to this question fall into three camps; that of 'it doesn't work all the time', 'it does work some of the time', and thirdly that it is unclear whether it works or not, which Tilley states as being the answer from 'opportunistic academics' who argue that more research is necessary 'alongside the money to pay for it'. ${ }^{9}$ This statement seems too dismissive of academic work on this issue, particularly when it is known that Tilley has undertaken evaluation work for the Home Office. Furthermore, he goes on to state that there is enough academic work concentrating on the issue of effectiveness that there is no need for any more. To be dismissive of academic work, yet to then cite it as being sufficient is slightly contradictory. Nevertheless, Tilley goes on to suggest that the next question that needs to be addressed is - 'how does CCTV work in differing contexts to generate specific outcomes? ${ }^{\prime 10}$ He cites a study from himself and Pawson advocating their concept of 'realistic evaluation' (which will be looked at again in this chapter) to answer this question. To conclude, Tilley argues that:

Once the causal potential of CCTV to effect crime prevention is established, the real task is to find out how it triggers crime prevention mechanisms in what context .... What is now needed in the evaluation of CCTV effectiveness is a series of technically proficient studies in which we develop our understanding of what works for whom in what circumstances so that future decisions about where and how CCTV can be installed maximise the chances of intended positive outcomes and minimise unintended negative ones. ${ }^{11}$

Although making some useful suggestions, Tilley does seem too dismissive of evaluations preceding his own proposed methodology. Further, there are other important issues to address alongside the evaluation of effectiveness, which he

\footnotetext{
${ }^{9}$ Tilley, N. 'Evaluating the Effectiveness of CCTV Schemes' in Norris, C. Moran, J. and Armstrong, G. (eds) (1998) Surveillance, Closed Circuit Television and Social Control. Ashgate p.140

${ }^{10}$ Ibid. p.145

${ }^{11}$ Ibid. p.151
} 
disregards (such as public opinion etc. which should have an independent researcher perspective as well as that of funded research). A valid point to arise from this chapter, however, is that if Tilley is right in terms of the questions which should be being asked of the effectiveness of CCTV, then evaluations to this day have been ineffective. The same questions do arise time and time again with no clear answers.

Gill and Turbin use the concept of 'realistic evaluation' (developed by Pawson and Tilley 1997) to carry out their own evaluation of CCTV in two retail stores. ${ }^{12}$ The authors highlight the problems rife in evaluation of crime prevention measures, stressing the discrepancies between policy and academia in terms of short-term answers and a call for longer-term evaluations. A 'realistic evaluation' methodology is used also by Tilley in his study of car park crime. ${ }^{13}$ He looks at the impact of CCTV on crime in car parks, asking whether it reduces it, and if so why? He states that CCTV does not physically hinder car crime and that the reasons behind the reduction need to be known. This study does start with the assumption that CCTV does reduce crime and that it is common sense to assume this to be the case. He concludes that the data collected does show a reduction in car crime in these car parks however it can be argued that this is a short-term study that takes no account of displacement effects. Tilley also seems to run into problems in terms of answering the question he posed at the start of the paper (and which he criticises other researchers for not answering) - what is it about CCTV that reduces car crime?

As has been shown in this section, effectiveness is a widely recurring theme in the CCTV literature and has been for over fifteen years. Studies concentrating on assessing the effectiveness of CCTV in reducing crime show differing results, most often depending on whether they are independent or Home Office funded. Although the question of effectiveness is an interesting one, in terms of public perception and CCTV policy-orientation the results of these studies do not seem to have made an impact. CCTV has become widespread concurrently to the

\footnotetext{
${ }^{12}$ Gill, M. and Turbin, V. (1999) 'Evaluating 'Realistic Evaluation: Evidence from a study of CCTV’ Crime Prevention Studies Vol.10

13 Tilley, N. (1993) 'Understanding Car Parks, Crime and CCTV; Evaluation lessons from safer cities’ Police Research Group Crime Prevention Unit Series Paper 42.
} 
academic literature showing varying degrees of success in terms of efficiency. The varying results are interesting for this thesis, as I will show in chapter 7 that policy and media discourse relies heavily on the notion of an effective, crimepreventing technology, yet this has been shown to not necessarily be the case.

\subsection{CCTV and social control}

Another recurring theme in the CCTV literature to date is that of social control. Within this theme, there are varying emphases on different aspects of social control. Often, but not always, the emphasis is based on a Foucauldian notion of panoptic power. Other areas of interest are the use of CCTV in public space and its impact on this space, often bound with issues related to social control, including exclusion, discrimination and consumption.

Comparisons with the Panopticon are particularly prevalent in sociological research on CCTV. ${ }^{14}$ For example, Fyfe, Bannister and Kearns discuss the factors contributing to the rise of CCTV within their 'Closed Circuit Television and the City' chapter. ${ }^{15}$ They argue that this development is closely linked with the growth of the city and the differences (in terms of race, class, cultures) that have therewith arisen. The notion of public space as an 'arena for the celebration of difference' is described, whilst at the same time interaction and encounters with strangers bring a sense of danger and fear. The solution to this fear is then the (as previously mentioned) 'fortification of the city' (which, it can be argued, can be perceived to be a strategy of social control as well as a solution). This fear and subsequent fortification, they say, created the perfect environment for CCTV to be dispersed as a solution to the perceived danger arising in urban areas. They conclude that the city has become a Panopticon, provoking and ensuring conformity.

\footnotetext{
${ }^{14}$ Lyon, D. (1994) The Electronic Eye: The rise of the surveillance society Polity Press; Cambridge

${ }^{15}$ Bannister, J. Fyfe, N. R. and Kearns, A. 'Closed Circuit Television and the City' in Norris, C. Moran, J. and Armstrong, G. (eds) (1998) Surveillance, Closed Circuit Television and Social Control Ashgate
} 
McCahill echoes these thoughts, although adding a consumption focus to his argument. ${ }^{16}$ He analyses the growth of surveillance in relation to concepts of modernity, discussing CCTV within the realm of three themes: 'time-space distanciation', globalisation, and the 'risk society'. He argues that this 'timespace distanciation' has produced new forms of social interaction and new forms of social control. In terms of globalisation, he examines the social and economic forces driving forward the growth of CCTV and concludes that 'the growth and use of city centre CCTV surveillance systems is bound up with attempts to revive the economic fortunes of the entrepreneurial city and with attempts to manage out 'inappropriate behaviour' in the new territories of consumption'. ${ }^{17}$ Added to this, he states that the rise of CCTV is bound up with the emergence of the 'risk society', wherein CCTV has been proposed as an effective solution to combating crime (part of a 'strategy of risk management'), essentially suggesting that societies cannot be changed but only managed.

Reeve takes this idea of CCTV and consumption one step further when discussing surveillance and the town centre. ${ }^{18} \mathrm{He}$ draws upon empirical findings from interviews with town centre managers to look at the issue of access to public space, and states that there has been a 'transformation of significant parts of the public realm from civil space to consumer space', of which CCTV is partly involved (also involved are; design, management, policy and so on) in propelling the move of the town centre to 'a place which must privilege individuated spending', i.e. where certain types of behaviour are unacceptable (bringing this argument back into the realm of social control). He concludes that there is now a 'remote control of space' in the town centre, wherein certain types of behaviour are not accepted and the decision over who is allowed to use that space and in what way is made by those operating that system. This then is about democratisation and surveillance, and the extent to which CCTV impinges on this. This idea is also looked at by Norris in his discussion of the Panopticon and

\footnotetext{
${ }^{16}$ McCahill, M. ‘Beyond Foucault: Towards a contemporary theory of surveillance’ in Norris, C. Moran, J. and Armstrong, G. (eds) (1998) Surveillance, Closed Circuit Television and Social Control Ashgate

${ }^{17}$ Ibid. p.42

${ }^{18}$ Reeve, A. 'The Panopticisation of Shopping: CCTV and leisure consumption' in Norris, C. Moran, J. and Armstrong, G. (eds) (1998) Surveillance, Closed Circuit Television and Social Control. Ashgate
} 
the idea of all subjects becoming visible and equal, which will be looked at later on. ${ }^{19}$ Furthermore, the categorisation of individuals links with the work of Foucault on power.

There are also a number of studies which dispute the notion of CCTV as the Panopticon, with varying degrees of resistance and different emphases. Williams and Johnstone, for instance, although arguing that there is a definite potential for exclusion of certain groups from public space through the use of CCTV, also argue against the use of the Panopticon as a metaphor for surveillance. Their paper accounts for the rise of CCTV in Britain and discusses issues such as: the impact of the technology on the geographies of public space and the aforementioned exclusion of certain groups. The authors use empirical evidence (in the form of observation of meetings, semi-structured interviews, and observation of the operation of systems) to address questions of how CCTV cameras are used, how this use is governed and public reaction to this use. They emphasise that CCTV systems are highly selective, which they state is in contrast to Foucault's notion of the Panopticon to which CCTV is often equated, although they point to the social control aspect in a different way, i.e. through the selection of targets. ${ }^{20} \mathrm{I}$ am not sure that this argument stands however; the Panopticon could also be selective, in terms of the guards choosing what or who to watch.

Norris also uses Foucault's theory of the Panopticon as a starting point for discussion. However, he highlights that CCTV surveillance is not simply about the power to surveille but that power is maintained through a variety of methods. ${ }^{21}$ He argues that CCTV fundamentally alters the nature of surveillance and the 'surveillance gaze', in terms of an expansion of disciplinary social control. $^{22}$ However, he critiques the idea of the expansion of surveillance necessarily heralding panoptic control:

\footnotetext{
${ }^{19}$ Norris, C. 'From Personal to Digital: CCTV, the panopticon, and the technological mediation of suspicion and social control' in Lyon, D. (2003) Surveillance as Social Sorting: Privacy, Risk and Digital Discrimination Routledge; London

${ }^{20}$ Williams, K. S. and Johnstone, C. (2000) 'The Politics of the Selected Gaze: Closed Circuit

Television and the Policing of Public Space’ Crime, Law and Social Change 34 (2) 183-210

${ }^{21}$ Norris, C. (2003) 'From Personal to Digital: CCTV, the panopticon, and the technological mediation of suspicion and social control' Op.cit.

${ }^{22}$ Ibid. pp.252-253
} 
The power of the panopticon is not just embodied in its ability to subject all to a surveillance gaze, but in the ability to link observation to a named subject through an individualized record, which can then be used for the purposes of identification, bureaucratic codification, and eventual classification. This secondary element, which in the Foucauldian sense transforms mere surveillance into discipline, is largely absent in the routine operation of CCTV systems. The images produced by the multiplicity of cameras are generally anonymous. ${ }^{23}$

Norris also looks at the issue of the democratisation of surveillance by CCTV (which was mentioned earlier when looking at Reeve's analysis of consumption and CCTV), and disputes using the Panopticon as a metaphor for CCTV surveillance in terms of all subjects not becoming equally visible. He points to CCTV being portrayed as being impartial, with no deliberate monitoring taking place, only 'suspicious behaviour'. However, this is shown not to be the case as there are no guidelines as to what constitutes 'suspicious behaviour' as Norris draws on research studies conducted on the habits of CCTV operators to show that discrimination and targeting of certain and specific individuals does indeed occur. He concludes that:

Ironically ... it is the exclusionary potential of CCTV-mediated control that has become dominant in the semi-public spaces of the shopping mall and leisure centre ... in this privatized space there is little commitment to democratic ideals of public access and assembly; the commitment is to commercial success. If people and their associated behaviours, whether legal or not, disrupt this entrepreneurial mission, they are to be excluded. Moreover ... identity - not behaviour - is likely to be emphasised with the deployment of digital algorithmic systems for exclusionary purposes ... . In conclusion, it is the computer - not the camera - that heralds the panopticonization of urban space. ${ }^{24}$

\footnotetext{
${ }^{23}$ Ibid. p. 256

${ }^{24}$ Ibid. p. 260
} 
Taking this idea one step further, Yar also discusses the limitations of using the Panopticon as a basis for theorising CCTV surveillance. ${ }^{25}$ He argues that 'the logical adequacy of equating visual surveillance with effective subjectification and self-discipline' and suggests that philosophically 'the Foucauldian thesis may well 'pathologise' the relationship between subjectivity and visibility' and thereby overlooks 'other dimensions of our experience of vision'. In discussing the applicability of panoptic theory to surveillance studies, Yar suggests three types of response; on applicability (the panoptic is not totalising), decline of the conditions possible for the operation of the Panopticon, and the extension of the Panopticon through new technological systems. He goes on to suggest that there is a lack of understanding and analysis of what the gaze entails and examines sociologically the subjective experience of being 'under the gaze' in public spaces.

Moving away from the issue of the Panopticon, a number of studies emphasise social control and exclusion resulting from the installation of cameras. Fyfe and Bannister look at the economic and political restructuring of urban space, concentrating on the idea of the 'fortress impulse' in contemporary urban design. They highlight that there are numerous, complex, economic and political forces behind the rise of CCTV, which in turn means a change in social experience for those who occupy these spaces. The authors argue that those in charge of city centres and shopping areas install CCTV in a bid to emulate (for the public) the safety and security perceived of out-of-town retail parks and shopping centres. The use of CCTV systems therefore extends further than dealing with crime or the fear of crime, stating that they are used for dealing with inappropriate behaviour, 'suspicious youths' and so on, thereby privatising public space as commercial goals control who does and does not belong in that space. Fyfe and Bannister conclude that research on CCTV to date has primarily focused on evaluating the 'before and after impact of cameras on the level and distribution of crime' and whilst important they state that this 'research agenda has marginalised

\footnotetext{
${ }^{25}$ Yar, M. (2003) 'Panoptic Power and the Pathologisation of Vision: Critical reflections on the Foucauldian thesis' Surveillance and Society 1(3) 254-271
} 
the broader economic, political and socio-cultural issues surrounding the development of CCTV surveillance in public space'. ${ }^{26}$

The surveillance of inappropriate behaviour and target selection are also discussed by Norris and Armstrong in their study drawing on data from a twoyear study in the operation of CCTV control rooms. They examine how CCTV operates in practice and ask the question - 'who and what gets watched?' They question how operators select their targets with only visual information to base this choice on, as opposed to police officers on street level who also have sounds and communicative ability. Norris and Armstrong carried out three observational studies between May 1995 and April 1996: one in a busy city, one in the market square of a town, and one in a high street of an inner-city borough. Within the results the issue of the 'male gaze of CCTV' arose, showing CCTV as providing little to women in terms of protection and security (their results show that women accounted for only $7 \%$ of targets surveilled during the time of the study, and only one incident during this time was for protection) yet at the same time providing them with a visual image of security in terms of camera presence. Also of interest in terms of civil liberties implications are the results of the targeting of minorities and different age groups, highlighting the priority targets as young black males. Norris and Armstrong provide examples of black youths being targeted by CCTV operators, both as a matter of course (in terms of actual policy) and due to individual discretion. They conclude that:

This technologically mediated and distanced social interaction is, then, loaded with meaning. Moreover for literally thousands of black and working-class youths, however law-abiding, it transmits a wholly negative message about their position in society ... . If social groups experience CCTV surveillance as an extension of discriminatory and unjust policing, the consequential loss of legitimacy may have disastrous consequences for social order. ${ }^{27}$

\footnotetext{
${ }^{26}$ Fyfe, N. R. and Bannister, J. 'The Eyes Upon the Street: Closed-Circuit Television Surveillance and the City' in Fyfe, N. R. (1998) Images of the Street. Routledge; London.

${ }^{27}$ Norris, C. and Armstrong, G. 'CCTV and the Social Structuring of Surveillance' in Painter, K. and Tilley, N. (eds) (1999) Surveillance of Public Space: CCTV, Street Lighting and Crime Prevention Criminal Justice Press; New York p.176
} 
They go on to point out that this enhanced social control with discriminatory aspects may ironically be the thing which causes social disorder. ${ }^{28}$

Still in the realm of power and social control, Newburn and Hayman embarked on a study of a recent experiment to introduce CCTV into the custody suite of Kilburn police station. This book extensively covers the narrow topic of the use of CCTV in police custody suites, and raises issues of the treatment of suspects in custody, the experiences of suspects in custody (through empirical research) and the impact of the introduction of cameras on the police officers themselves. Although Newburn and Hayman treat the custody suite as public space in this study, it is not traditionally defined as such. This study does usefully highlight, however, the complicated power relations arising from police officers being filmed and watched whilst 'doing the watching' ${ }^{29}$

The issue of CCTV and policing is also looked at by Goold in his 2004 study of the shift from 'on the street' police surveillance to public area CCTV surveillance, and the impact of this on the organisation and practice of policing. He analyses the integration of CCTV into policing practices, as well as looking at the effects on the police of themselves being under surveillance, concluding that CCTV has had little impact on policing practices and organisation, contrary to popular expectation. Goold states that, for a variety of reasons, the police are either unable or unwilling (or both) to make greater use of CCTV. The main reason provided for this lack of uptake is that the police are inflexible and unwilling to change their policies in order to incorporate this new technology. Goold then poses the question - if CCTV has had little effect on policing practices, why then is there a common perception that a police state is hovering around the corner? He provides a variety of explanations for this, including; a general unease over the use of CCTV by the police and the want of civil libertarians to prevent any further spread of police powers. He then offers an explanation of what he terms 'a less obvious explanation' of 'Orwellian

\footnotetext{
${ }^{28}$ Ibid.

${ }^{29}$ Newburn, T. and Hayman, S. (2002) Policing, Surveillance and Social Control: CCTV and police monitoring of suspects Willan Publishing
} 
nightmares' and 'visions of dystopia'. This doesn't seem to be a less obvious explanation but one that makes sense in terms of popular culture. Orwell's vision of the future has been used many times as a metaphor in academic writings concerning the surveillance society. If Goold was searching for a less obvious explanation, he might have used another example of dystopian literature, such as Kafka's The Castle. Goold does conclude by making an important point - CCTV is not in itself an intrusive technology, it is the purposes to which we put them which have this impact. He suggests moving away from a deterministic and dystopian view of public area CCTV to one which takes a more neutral standpoint when questioning the relationship between the police and technological change. ${ }^{30}$

This section has given an overview of the CCTV literature concentrating on social control and Foucauldian notions of power and discipline. Some of the literature outlined above discusses CCTV and its impact on public space; fear of crime leads to urban fortification and consumption of CCTV to combat fear. Of interest to my thesis is taking this idea further, to ask - who are the public who consume CCTV, and how has CCTV been portrayed to this public via policy and the media? I will look at these questions in chapters 7 and 8 . I also want to step away from the umbrella of social control, to delve more deeply into the complex social, economic, and political reasons behind the introduction of CCTV and its subsequent widespread use.

\subsection{CCTV and the public}

One issue of particular interest to this thesis is that of the public and public engagement in relation to CCTV. This arises most often in the literature in the form of public opinion surveys of the technology, generally concentrating on acceptability, privacy issues and effectiveness. However, concentrated research in this area is lacking, with public attitudes incorporated into the literature as a sideline to other issues. When public opinion surveys are the main focus, it is often the methodology not ideas of the public that is discussed at length. I will

\footnotetext{
${ }^{30}$ Goold, B. J. (2004) CCTV and Policing: Public area surveillance and police practices in Britain Oxford University Press; Oxford
} 
refer to the literature overviewed below during discussion of my empirical results in chapter 8 and throughout analysis of local and national government discourse on CCTV in chapter 7.

Ditton, for example, provides some possible explanation for the discrepancy between amateur and professional surveys of public support for CCTV as he finds that amateur surveys usually find $90 \%$ in favour of CCTV, and those carried out by professional researchers find around 60\%-70\% acceptability. He argues first that sampling is a major factor and likewise survey/questionnaire design. He provides a couple of examples of similar surveys conducted in the same area at around the same time to highlight the reasons he provides.

Fyfe and Bannister make mention of public acceptance of CCTV during their discussion of public spaces and access entitlement. They enquire into levels of public resistance to public space CCTV surveillance and state that support for CCTV seems mainly to arise from the belief that it reduces crime and increases public safety. A further small-scale survey (although large in terms of sample size relatively to town populations) carried out by Williams and Johnstone in Wales shows interesting results in terms of attitudes towards CCTV and its perceived effectiveness in tackling crime, particularly as they ask respondents to think about this issue in relation to the bigger picture of crime prevention, rather than as an isolated method. ${ }^{31}$ More police officers and increasing investment in activities for teenagers prove to be as popular as using CCTV in the town centre when people spoke about ways to cut crime. The results of this survey are very interesting particularly when compared with surveys conducted by researchers funded by the Home Office, as they set questions within the wider context and tackle issues wider than that of only CCTV and its perceived effectiveness or acceptability. Recently, Gill et al. conducted a study of public perceptions of CCTV in residential settings (pointing out that only limited research has looked at this issue in a residential context, most has been done in town and city centres). ${ }^{32}$ This study

\footnotetext{
${ }^{31}$ Williams, K. S. and Johnstone, C. (2000) 'The Politics of the Selective Gaze: Closed Circuit Television and the Policing of Public Space' Crime, Law and Social Change 34 (2) 183-210

${ }^{32}$ Gill, M et al. (2007) Public Perceptions of CCTV in Residential Areas: "It Is Not As Good As We Thought It Would Be.” International Criminal Justice Review 17; 304-324
} 
takes a particular interest in levels of fear of crime and feelings of safety and whether these levels are impacted upon by CCTV and its introduction. Interestingly, this report shows levels of support for CCTV reducing following the installation of the cameras/systems due to little or no reduction in their fear of crime.

Davies mentions the absence of public debate in the area of CCTV and says that it has been shown that once the public embark upon discussions of CCTV and are given a chance to voice their opinions and hear those of others, there is less unconditional support for the systems. ${ }^{33}$ A recent paper from Hood (2003) discusses CCTV and the public in the context of risk regulation. ${ }^{34}$ The author questions why investment in CCTV has continued to rise, when the results over its effectiveness are so ambiguous. Further to this, and within the context of his case study within Greater Easterhouse (Scotland), he asks why public perception of the effectiveness of CCTV is so at odds with the empirical findings of academics on this issue. This leads on to questioning why there has been little or no policy discourse on CCTV and why the public have so readily accepted this lack of debate. Davies concludes that, despite uncertainty within the official statistics over the true effectiveness of CCTV as a crime reduction tool, the residents within his case study area welcome the technology and perceive it to be effective. Although this paper states that an answer to the issue of why public perception is so at odds with empirical research on CCTV effectiveness will be sought, it does not provide a conclusion on this. Instead, the author offers the opinion that 'there is a strong desire to make it [CCTV] work' from the police and the public, without really delving into the question of why this is the case.

In 2005, the Home Office funded a series of public attitude surveys, forming part of their National CCTV Evaluation. ${ }^{35}$ These surveys were conducted in one town, two city centres and nine residential areas (over 4,000 people), prior to the installation of CCTV systems. The report surveyed: levels of victimisation, fear

\footnotetext{
33 Davies, S. (1996) 'The Case Against: CCTV should not be introduced' International Journal of Risk, Security and Crime Prevention Vol.1 No.4 p.328

${ }^{34}$ Hood, J. (2003) 'Closed Circuit Television Systems: a failure in risk communication?’ Journal of Risk Research 6 (3) 233-251

${ }^{35}$ Spriggs, A. et al. (2005) 'Public Attitudes Towards CCTV: results from the pre-intervention public attitude survey carried out in areas implementing CCTV’ Home Office Online Report.
} 
of crime, feelings of safety, and levels of avoidance of particular areas, awareness of existing CCTV systems, beliefs about capabilities of CCTV, support for CCTV and privacy concerns. Some interesting results arise from this, highlighting important issues such as the level of public knowledge surrounding CCTV and its capabilities with $30 \%$ believing that CCTV is watched all the time (which is incorrect). The results of any privacy concerns may be skewed as the survey is slanted towards CCTV and its effects on crime, as well as fear of crime, which it has been argued (for example by Ditton, detailed previously) may produce different results than a survey with questions phrased differently. This issue of public knowledge of CCTV systems is also found in the 1992 Honess and Charman report (mentioned previously in this chapter). ${ }^{36}$ They also found that there is a lack of awareness of the capabilities of CCTV systems and their functions in public places. They recommend a greater level of public consultation to combat this problem. It can be argued that any level of public consultation would be an improvement on the current situation. To date, there has not been a national public consultation on CCTV in the UK.

This section has shown that the question of the level of public acceptance of CCTV has not been resolved; much in the same way as the effectiveness debate. In both cases there are differing results, which, as was pointed out by Ditton earlier, may simply be the nature of social research in terms of the wording of questions. Of particular interest to my thesis is the issue of why the public have apparently accepted the deployment of CCTV. I will refer back to the results of the public opinion surveys outlined above during chapter 7 when I analyse policy and media discourse surrounding CCTV and the public.

\subsection{CCTV, privacy, and human rights}

Although most of the literature focusing on CCTV deals with issues of social control and effectiveness, there is some literature discussing privacy issues in relation to the technology and its use. Davies (who is an activist and campaigner

\footnotetext{
${ }^{36}$ Honess, T. and Charman, E. (1992) 'Closed Circuit Television in Public Places: Its acceptability and perceived effectiveness' Police Research Group Crime Prevention Unit Series Paper \#35
} 
as well as an academic), for example, gives an account of the lack of public resistance to CCTV and its rise during the early 90s, as well as assessing the threats to privacy, civil liberties and public life which he associates with CCTV. ${ }^{37}$ His paper argues that the period up to 1996 was a time when civil liberties objections to CCTV were largely ignored. This, the author states, is due to a number of factors; not least images made public of Jamie Bulger's killers and the inference that anyone opposing the technology was in support of 'baby killers'. The paper goes on to describe the rise in voices of dissent from those in opposition to CCTV, and the resulting shift in public attitudes. This paper is very interesting in terms of accounting for the rise of CCTV with mass public acceptance; however it does seem that Davies may be overstating the case of later public resistance.

Previously, Davies had argued his case against CCTV being introduced in a 1996 paper, which came about as a response to a paper in the same journal by Horne arguing for the introduction of CCTV.$^{38}$ In this paper Davies argues that:

If CCTV is introduced to saturation levels, the matter should be seen as a vitally important issue for democratic rights and public policy. It would be folly to neutralise debate by characterising critics as privacy fanatics or 'friends of criminals'. And yet, that is so often the response..$^{39}$

A more detailed look at CCTV and privacy legislation comes from Gallagher in his 2004 paper looking at the landmark decision by the European Court on Human Rights in 2003. The UK was judged to have breached Article 8 of the European Convention on Human Rights (ECHR) when CCTV footage of a suicidal man was passed to the media for broadcast. The author asks why CCTV tends not to be perceived as a human rights issue, to which he suggests that the reasons are multiple. Firstly, that the reasons given for installation of CCTV

\footnotetext{
${ }^{37}$ Davies, S. 'CCTV: a new battleground for privacy' in in Norris, C. Moran, J. and Armstrong, G. (eds.) (1998) Surveillance, Closed Circuit Television and Social Control Ashgate

${ }^{38}$ Davies, S. (1996) Op.cit.

${ }^{39}$ Horne, C. (1996) 'The Case For: CCTV should be introduced' International Journal of Risk, Security and Crime Prevention 1(4)
} 
systems are generally neutral and unthreatening, such as 'for the public good' and secondly that regulation is lagging behind technological advances in this area. Thirdly, he suggests that arguments against CCTV as a human rights issue state that as they operate in public places the citizen 'waives his rights when he chooses to walk by them'. Lastly, he argues that people do not see the right to privacy as a universal one, applicable to all, but only to certain groups in society. He concludes that CCTV in Britain is poorly regulated, as well as finding that:

Privacy is a nuanced context-specific concept, and that certain acts, such as suicide attempts, can be inherently private, regardless of whether they take place on a public street rather than in a private dwelling. ${ }^{40}$

In terms of government funded studies looking at the area of privacy and civil liberties, there is very little literature, although there is brief mention in a couple of studies. In their published guide offering answers to CCTV installation questions, Edwards and Tilley mention privacy issues in terms of providing to installers a good practice outline. ${ }^{41}$

Although there is little literature concerned with CCTV and privacy, the few examples outlined above do show that the Data Protection Act is not sufficient to provide privacy in terms of the technology, and that the ECHR also falls short in a domestic setting. I look at privacy and data protection in chapter 9, also discussing the international context with reference these issues.

\subsection{International CCTV research}

In terms of international literature focusing on CCTV some studies have served the purpose of looking at the issue of legal regulation. As an example, a 2004 paper by Gras looks at recent legislative changes surrounding CCTV systems and questions whether these changes can be seen as providing effective regulation,

\footnotetext{
${ }^{40}$ Gallagher, C. (2004) 'CCTV and Human Rights: The fish and the bicycle? An examination of Peck v. United Kingdom (2003) E.H.R.R. 41' Surveillance and Society 2 (2/3) 270-292

${ }^{41}$ Edwards, P. and Tilley, N. (1994) ‘CCTV: Looking Out for You’ HMSO
} 
concentrating particularly on numbers of cameras. It also covers the regulatory systems in France, the Netherlands and Germany. ${ }^{42}$ She looks at changes since the Human Rights Act came into force in 1998 when a person's 'right to privacy' became a priority, stating that 'even British subjects have a right to privacy, also in public places'. Looking at the actual regulation of CCTV in Britain, she argues that 'it is difficult to conclusively declare the British situation as compatible with or in breach of European legislation. Thus the search for European regulation becomes a question of whether other European countries have regulated CCTV at a national level'. Gras looks at Denmark first, for the purpose of her analysis, showing that there is far stronger regulation of CCTV there than in Britain, to the extent that 'CCTV surveillance is generally forbidden there', although there are exceptions to this for the police, certain businesses and public authorities. This stronger regulatory environment is also seen in France, Germany and the Netherlands, with Germany taking the lead in evaluating the need for and continual reviews of CCTV systems. Wiecek and Sætnan also look at the issue of CCTV regulation in a comparative analysis of Denmark and Norway. ${ }^{43}$ They ask 'Is CCTV more highly regulated in Denmark than in other countries studied in a European policy context?' Their findings suggest that there are major differences in the legal regulation of systems, but their analysis provides no firm conclusions as to why this difference has occurred. They do propose cultural differences, differences in strategic decisions taken, influenced by the British path, differences in public discourse, and so on. However, Wiecek and Sætnan do not offer any firm conclusions.

Sutton and Wilson step away from a looking purely at legislation, to include the extent of CCTV systems in Australia, they describe their paper as 'the first systematic attempt to document and assess the extent of open-street CCTV systems in Australia'. ${ }^{44}$ This summary takes place in the context of a comparison between the UK and Australia, with the authors disputing that the 'surveillance

\footnotetext{
${ }^{42}$ Gras, M. (2004) 'The Legal Regulation of CCTV in Europe' Surveillance and Society 2(2/3) 216-229

${ }^{43}$ Wiecek, C. and Sætnan, A. R. (2002) 'Restrictive? Permissive? The Contradictory Framing of Video Surveillance in Norway and Denmark’ UrbanEye RTD-Project www.urbaneye.net/results/ue_wp4.pdf ${ }^{44}$ Sutton, A. and Wilson, D. (2004) 'Open-Street CCTV in Australia: The politics of resistance and expansion’ Surveillance and Society 2(2/3) 310-322
} 
revolution' will follow the same lines in Australia as the UK. In their overview of open-street CCTV systems in Australia, thirty-three are identified across the country, with New South Wales having the highest concentration and the Northern Territories having none. They state that these low levels are not due to any legislative barriers. In contrast to the UK, funding for CCTV in Australia has mainly come from private sources, as opposed to the central government funding in the UK, and is far more local authority led in terms of policy. This is changing slightly in the current climate with more state funding becoming available in certain parts of the country for public space CCTV systems; however this is mainly on an ad-hoc basis. The authors conclude that political concerns about crime remain in the local context, rather than mirroring global patterns.

Another comparative analysis, but this time focusing on Europe and the use of CCTV in public space and the public perception of the technology, is a 2004 paper by Hempel and Töpfer (for the EU $5^{\text {th }}$ Framework Programme). ${ }^{45}$ They use a number of research methods including: media analysis, observation, surveys, interviews with CCTV operators and managers, interviews with citizens, and a workshop with CCTV experts. They argue that the 'operation and impacts [of CCTV systems] have to be understood as the outcome of the interplay between technological, organisational and cultural factors'. They found the scale of the use of CCTV across Europe varied greatly, as did the public perception of the technology; with Britain showing the highest levels of acceptance, and Germany and Austria the least.

Much more so than UK research on CCTV, the international literature focuses specifically on rationales for the introduction of cameras, the locations and how they are chosen, and the impacts of the cameras on the space into which they are introduced. For example, Klauser researches the positioning of cameras in Geneva, which he terms the 'spatial logic', differentiating between CCTV used for 'preservative' or 'protective' purposes; the former for anti-social behaviour and the preservation of public order, and the latter for the protection of buildings and specific objects. He also focuses on the impact of CCTV on public space,

\footnotetext{
${ }^{45}$ Hempel, L. and Töpfer, E. (2004) ‘CCTV in Europe’ UrbanEye RTD-Project www.urbaneye.net/results/ue_wp15.pdf
} 
concluding that there is a low rate of awareness of cameras by the public. ${ }^{46}$ Müller and Boos also focus on the rationale for the introduction of cameras into Zurich's main railway station, and the impact of the installation of CCTV on this 'semipublic' space, building up 'typology' of various purposes for which the cameras are placed. ${ }^{47}$

Observational work is also found in the international literature. Helten and Fischer, for example, conducted research via observation of the work of CCTV operators in Berlin shopping malls. Their research looks at the objectives of the systems as seen by those who run them, which is mostly vocalised as being 'to guarantee the safety of the customers', although what is specifically meant by this is not made clear. The authors conclude that the CCTV systems are there in order to maintain order and problem-free operation rather than for social exclusion or control purposes; 'the observation order in malls resembles that of a public transport system', i.e. the flow of people and traffic. ${ }^{48}$ In contrast to this (and echoing similar UK research), Lomell's observational study of control room practices finds that social exclusion does occur, with a high level of targeting of 'undesirables'. ${ }^{49}$

An observational study of four control rooms in Norway and Denmark reiterates these conclusions. Sætnan, Wiecek and Lomell question whether practices differ in other countries, looking at previous work from the UK on control room practices. $^{50}$ They find that 'scruffies' (scruffy looking individuals) are often ejected from 'transport centres' and shopping malls, with ethnic discrimination also being an issue. These observations are also found in a study by Martinais and Bétin of the city centre in Lyons, where they find that there is huge pressure from

\footnotetext{
${ }^{46}$ Klauser, F. (2004) 'A Comparison of the Impact of Protective and Preservative Video Surveillance on Urban Territoriality: the case of Switzerland' Surveillance and Society 2(2/3) $145-160$

${ }^{47}$ Müller, C. and Boos, D. (2004) 'Zurich Main Railway Station: A Typology of Public CCTV Systems' Surveillance and Society 2(2/3) 161-176

${ }^{48}$ Helten, F. and Fischer, B. (2004) 'Reactive Attention: Video Surveillance in Berlin Shopping Malls’ Surveillance and Society 2(2/3) 323-345

${ }^{49}$ Lomell, H. M. (2004) 'Targeting the Unwanted: Video Surveillance and Categorical Exclusion in Oslo, Norway' Surveillance and Society 2(2/3) 346-360

${ }^{50}$ Sætnan, A. R. Lomell, H. M. And Wiecek, C. (2004) ‘Controlling CCTV in Public Spaces’: Is privacy the (only) issue? Reflections on Norwegian and Danish Observations' Surveillance and Society 2(2/3) 396-414
} 
shop owners to rid the area of 'undesirables' and 'imported delinquency' (by which they mean migrant youths) and to tackle 'deviant' and 'anti-social' behaviour, and the exclusion of youths who do not fit in with the 'desired image'.51

In terms of a theme found regularly in UK literature on CCTV; that of effectiveness, the same topic does not often arise in the international literature. A US research study from 1997 focuses on this issue detailing private and public usage of CCTV systems and questioning their effectiveness as a crime prevention tool. ${ }^{52}$ From the same author, a study in 2002 also looks at the issue of effectiveness, stating that (in the context of the US); 'we find that there have been very few studies of the effectiveness of the CCTV surveillance systems....Despite their increasing use, there is limited evidence that CCTV camera surveillance programs are successful crime-prevention tools'..$^{53}$

A couple of European studies also look at the issue of effectiveness. Flight et al. evaluated three CCTV schemes in Amsterdam, in which they state that their findings confirm previous research on displacement effects in terms of some displacement occurring but that 'only rarely can complete displacement be observed. The net result has therefore always been positive' ${ }^{54}$ They are also positive with regard to the effectiveness of CCTV in cutting crime. In an evaluation of the effectiveness of CCTV at Oslo central railway station, Winge and Knuttson look at the impact on public order, criminality and the levels of public feelings of safety. ${ }^{55}$ They found that 'among the categories of crime, the only reduction occurred in robbery/theft from persons' and found that in a victimisation survey of targeted businesses perceptions of crime, disorder and

\footnotetext{
${ }^{51}$ Martinais, E. and Bétin, C. (2004) 'Social Aspects of CCTV in France: the case of the city centre of Lyons’ Surveillance and Society 2(2/3) 361-375

${ }^{52}$ Nieto, M (1997) Public Video Surveillance: Is it an Effective Crime Prevention Tool?

Californian Research Bureau; Sacremento

Research Bureau. http://www.library.ca.gov/CRB/97/05/

${ }^{53}$ Nieto, M, Johnston-Dodds, K. and Simmons, C. (2002) Public and Private Applications of Video Surveillance and Biometric Technologies Californian Research Bureau; Sacramento p.13 http://www.library.ca.gov/crb/02/06/02-006.pdf

${ }^{54}$ Flight, S. Heerwaarden, Y. van and Soomeren, P. van 'Does CCTV Displace Crime? An evaluation of the evidence and a case study from Amsterdam' in Gill, M. (ed.) (2003) CCTV Perpetuity Press p.93

${ }^{55}$ Winge, S. and Knuttson, J. 'An Evaluation of the CCTV Scheme at Oslo Central Railway Station’ in Gill, M. (ed.) (2003) CCTV Perpetuity Press p.127
} 
safety did not significantly change once the scheme had been introduced. The findings showed that 'respondents still had faith in the effectiveness of the CCTV scheme, but to a lesser extent than before its introduction'. In terms of European CCTV literature there seems to be the assumption that the UK has solved the effectiveness debate.

\subsection{Conclusion}

Though the CCTV literature outlined in this chapter is interesting and useful, I believe there are gaps which this thesis will fill, using a multi-disciplinary STS perspective. Of particular interest is the public acceptability literature, which will be followed up in an analysis of how the public are constructed in the context of CCTV, the portrayal of CCTV by the media and in political discourse. Also of interest is the literature detailing the rise of CCTV in the UK, which is firmly situated in the realm of social control. I want to develop a more in-depth sociohistorical and techno-political analysis of the growth of CCTV, without the assumption of power and social control as elements accounting for its widespread nature. The specificities of CCTV, rather than surveillance generally, are the issues I want to explore in this thesis. However, prior to embarking on this more concentrated analysis, I first provide an overview of the social and political history of Britain in the $20^{\text {th }}$ Century, focusing particularly on issues of surveillance and policing. I believe that in order to carry out a robust analysis of CCTV in the UK, the wider social and political context in which the technology was developed, must first be understood. I explore this history in chapter 5. Prior to this I give an overview of my methodology in the next chapter. 


\section{Chapter IV:}

\section{Methodology}

\subsection{Introduction}

This thesis has aimed to explore the ubiquitous nature of CCTV in the UK using a range of approaches and methods. I have attempted to go beyond traditional surveillance studies explanations of social control, Foucauldian notions and questions of effectiveness, to provide a socio-technical historical narrative and analysis of the political climate, specific social conditions and technological developments that have led to the UK becoming the most surveilled nation in the world in terms of cameras. Moving past these explanations presented me with a challenge: to find a way of encapsulating historical and social research, alongside empirical research, which would demand multiple methodologies. In this chapter, I will describe my general approach and analytical framework, the main research questions of the thesis, and the methods of data collection and analysis I have used.

\subsection{Analytical framework}

My overall approach has been one of social constructionism, questioning the social and historical roots of CCTV and its development in the UK. A social constructionist approach necessitates taking a critical look at the idea that the nature of the world can be understood through objective observation; it therefore stands in contrast to positivism. ${ }^{1}$ Working within a social constructionist mindset also allowed a mixed-methods approach to methodology to be undertaken; this is explained in further detail on p.78. Essentially mixed methods also favours an interpretivist approach, rather than one based in positivism.

\footnotetext{
${ }^{1}$ Burr, V. (2003) ( ${ }^{\text {nd }}$ ed.) Social Constructionism Routledge; London and New York p.3
} 
A review of relevant literature has been presented in chapter 2 in order to frame the findings of the thesis. The literature review I have developed is what Cooper terms 'integrative', ${ }^{2}$ essentially 'summarizing broad themes in the literature'. ${ }^{3}$ In my literature review I have given an overview of other studies related to my topic, situating my thesis in the larger ongoing dialogue of surveillance and CCTV literature. ${ }^{4}$ Through the literature review I have also pointed out the areas in which my STS perspective can play a crucial role in providing a more sophisticated analysis of CCTV in the UK. The STS approach favours a mixed methods approach due to its exploratory nature, allowing research to be conducted in the manner most appropriate to the research questions. The particular mix I have drawn together is based on history, media studies, and an empirical approach.

First, historical and archival research makes up a large component of my thesis. My approach to the history of policing has been to provide an account of the developments that led to the creation and subsequent evolution of a police force in Britain. For this purpose I used a variety of sources, including archival sources at the Open University. For the history of surveillance and the history of CCTV parts of my thesis I used a range of academic literature, media sources, and legal and policy documents. Using these sources, I undertake a documentary analysis, under the viewpoint that documents are social texts, produced in social settings and therefore useful for social research. ${ }^{5}$ I employed an iterative and reflexive approach to research, allowing movement between the literature, historical and archival, and the empirical. ${ }^{6}$

Second, I take on a constructionist stance in my media analysis. I do not argue that media discourse decides public opinion or that I can make an assumption about public opinion on CCTV in the UK through an analysis of media content. However, I do believe that the media has some influence on the public, that it is part of the process of the public formulating ideas about issues. I also believe this

\footnotetext{
${ }^{2}$ Cooper, H.M. (1984) ( $2^{\text {nd }}$ ed.) The Integrative Research Review Sage; London

${ }^{3}$ Creswell, J. (2003) Research Design: Qualitative, quantitative and mixed methods approaches

Sage Publications; London p.32

${ }^{4}$ Ibid. p.30

${ }^{5}$ Prior, L. (2003) Using Documents in Social Research Sage; London p.26

${ }^{6}$ Jupp, V. (2006) Sage Dictionary of Social Research Methods Sage; Londonp.258
} 
to be a two-way process, with the media mirroring existing ideas from the public about certain issues. In this context the media is placed in a complex role. Gurevitch and Levy describe the media as 'a site on which various social groups, institutions and ideologies struggle over the definition and construction of social reality'. ${ }^{7}$ I also believe that media content is a 'social construction of reality'. ${ }^{8}$

Frame building within the media occurs when journalists 'select some aspects of a perceived reality and make them more salient in a communicating text, in such a way as to promote a particular problem definition, moral evaluation, and/or treatment recommendation for the item described'. ${ }^{9}$ Journalists do this by the 'presence or absence of certain key words, stock phrases, stereotyped images, sources of information, and sentences that provide thematically reinforcing clusters of facts or judgements'.$^{10}$ Frames can therefore 'provide context that is communicated with the text, and also can shape the way text is received', although the effects and reception of communication is varied. ${ }^{11}$ This concept of frame building and construction of facts and judgements forms the framework for the media analysis, and is looked at in more detail in chapter 7.

This constructionist approach to the media is complementary to the wider social constructionist school of thought found in the thesis in general. Alongside a social constructionist approach, I have avoided relying on overtly technical or socially determinist explanations (discussed in greater detail in the literature review) and have instead taken the view that technology and society are co-produced; that society is ‘constructed' alongside technology and that to understand CCTV within this context means to understand the technological, social, political and economic webs that have enabled, or been enabled by, its development.

\footnotetext{
${ }^{7}$ Gurevitch, M. and Levy, M. R. (1985) (eds.) Mass Communication Review Yearbook Vol.5 Sage; California p.19

${ }^{8}$ Tuchman, G. (1978) Making News: A study in the construction of reality Free Press; New York

${ }^{9}$ Entman, R. M. (1993) 'Framing: Towards Clarification of a Fractured Paradigm' Journal of Communication 43 pp.51-58 p.52

${ }^{10}$ Ibid.

${ }^{11}$ Kerr, P. A. and Moy, P. 'Newspaper Coverage of Fundamentalist Christians, 1980-2000' in Franzosi, R. (2008) Content Analysis vol.3 Sage Publications; London pp.258-276 p.260
} 
This mixed methods approach is designed to answer the research questions of my thesis, which have been presented in the introduction to my thesis. I will now provide more detail on the empirical content of my thesis.

\subsection{Selection of methodological approach and research instruments}

This thesis utilises a mixed methods approach: a mixture of elements of both qualitative and quantitative research methods in order to provide both numerical and textual data for analysis. To provide a brief history, the mixed methods approach was born out of the 'paradigm wars' - a debate between quantitative and qualitative research as the best method for conducting research into people and society which has been ongoing throughout most of the $20^{\text {th }}$ century and still remains of academic importance today. The argument for quantitative methods relies on a positivist approach, arguing that people and social behaviour can be studied as part of objective reality, identifying facts to produce theories of behaviour. On the other hand, the argument for qualitative methods relies on an interpretive approach, arguing that the social is made up of and constructed through meanings; it is subjective and unpredictable and therefore cannot be studied using quantitative methods. ${ }^{12}$ However, out of this debate has arisen a new framework for social research, described by Tashakkori and Teddlie as the 'pragmatic paradigm'; it concerns itself with results and 'what works' rather than epistemological questions centred on truth or reality. Someone working within this framework is therefore able to research 'what interests you and is of value to you, study it in the different ways you deem appropriate, and utilize the results in ways that can bring about positive consequences within your value system' ${ }^{13}$ What used to be viewed as an ideal in social research; 'In the best of all possible worlds, your own research design should bring more than one research method to bear on the topic', ${ }^{14}$ is now 'discussed, planned, and conducted as a routine

\footnotetext{
${ }^{12}$ Hesse-Biber, S. N. and Leavy, P. (2008) (eds.) Handbook of Emergent Methods Guilford; London pp.32-35

${ }^{13}$ Tashakkori, A. and Teddlie, C. (1998) Mixed Methodology: Combining qualitative and quantitative approaches Applied Social Research Methods Series vol. 46 p.30

${ }^{14}$ Babbie, E. R. (1979) ( $2^{\text {nd }}$ ed.) The Practice of Social Research Wadsworth Publishing Co.; California p.110
} 
matter, part and parcel of normal science'. ${ }^{15}$ It has become an accepted and increasingly used methodology in the social sciences. ${ }^{16}$

I chose to use a mixed methods approach for the purpose of 'complementarity'; that is to seek a 'broader, deeper, and more comprehensive' understanding of CCTV and the public by 'using different methods that tap into different facets or dimensions of the same complex phenomenon', whereby the results are used to 'elaborate, enhance, deepen and broaden the overall interpretations and inferences from the study'. ${ }^{17}$ Due to its complexity, the research on CCTV and the public fits well into a complementarity mixed methods design. ${ }^{18}$ Further, the diversity of data that could be obtained through a mixed methods approach was also appealing to me when choosing my methodological approach. ${ }^{19}$

I therefore used a mixed investigation: 'simultaneously using both types of data collection (qualitative and quantitative) and both types of data analysis (statistical and qualitative analysis)'. ${ }^{20}$ The questionnaire I designed is a quantitative investigation with some elements of qualitative exploratory questions. The analysis undertaken with data obtained from the questionnaire is both quantitative (statistical analysis and inference) and qualitative (of open questions). The interviews I conducted are qualitative and analysed purely qualitatively. Including both open- and closed-ended questions within the questionnaire, alongside statistical analysis and analysis of text, followed by a qualitative method, situates my research design in the mixed methods approach. ${ }^{21}$

I used an overall sequential explanatory approach to mixed methods research, which is 'characterized by the collection and analysis of quantitative data

\footnotetext{
${ }^{15}$ Brewer, J. And Hunter, A. (2006) Foundations of Multimethod Research: Synthesizing Styles Sage Publications; London p.14

${ }^{16}$ Brewer, J. and Hunter, A. (1989) Multimethods Research: A synthesis of styles Sage Publications; California

${ }^{17}$ Greene, J. C. (2007) Mixed methods in social inquiry Wiley p.101

${ }^{18}$ Ibid.

${ }^{19}$ Brewer, J. And Hunter, A. (2006) Op.cit.

${ }^{20}$ Tashakkori, A. and Teddlie, C. (1998) Op.cit. p.149

${ }^{21}$ Creswell, J. (2003) Research Design: Qualitative, quantitative and mixed methods approaches Sage Publications; London p.17
} 
followed by the collection and analysis of qualitative data'. ${ }^{22}$ However, within this approach is also a concurrent nested strategy, due to quantitative and qualitative data being collected simultaneously. This approach allows the embedding of one data collection method within another more predominant method. ${ }^{23}$ In this case, this embedding took the form of the inclusion of open ended questions (for the purpose of qualitative analysis) within a quantitative questionnaire design. The adoption of this approach allowed a broader perspective to be gained from the results of the questionnaire, than would have been possible with only a quantitative approach. The qualitative element therefore allowed an elaboration and extension of the quantitative findings. The findings of the research are first presented as quantitative findings, followed by qualitative findings, as is the structure for a sequential research design. ${ }^{24}$

\subsection{The questionnaire}

During the early stages of my PhD, I read a small piece in The Register detailing a new development in Hackney, described as 'Europe's largest broadband expansion'. ${ }^{25}$ Included in this development was a CCTV installation, which would allow the residents of two estates access to footage from CCTV cameras on their estate, through their television - the 'community safety channel' (More specific detail on the Digital Bridge project can be found in chapter 8). Due to my interest in diffuse methods of community self-policing, the impact of CCTV on communities, the social atomisation of communities, peer-to-peer surveillance and CCTV in relation to public engagement and public consultation, I decided the Digital Bridge project would be an extremely interesting development to research for the empirical aspect of my thesis. The project had also received no academic attention to date.

\footnotetext{
${ }^{22}$ Ibid. p. 215

${ }^{23}$ Ibid. p. 218

${ }^{24}$ Ibid. p.222

${ }^{25}$ http://www.theregister.co.uk/2005/12/30/shoreditch_digital_bridge/
} 
Originally, I had intended to include the developers of the project, the Shoreditch Trust, in my research. I was interested in finding out their views on the inclusion of CCTV in the development, who and what had been involved, how and whether consultation and public engagement had occurred, and the results of any consultation with residents. However, I contacted the Shoreditch Trust, in person, by telephone, and via email a number of times, but did not receive a reply or any further information. I therefore decided to concentrate on the public aspect of the project, researching the residents’ views only.

As information on the Digital Bridge was hard to come by, the first stage of my empirical research needed to include as many residents as possible in order to gain a more detailed picture of the project. Broad issues that I wanted to address and gain an understanding of were: the uptake and usage of the community safety channel, residents' feelings on safety and CCTV, residents' feelings on privacy, and their involvement and thoughts on consultation with regard to the project. A quantitative method (with an element of qualitative) was therefore the most appropriate in terms of covering as many people's views as possible. The issue of sampling by demographic was not relevant in the case of this questionnaire as every household would receive a copy. The sample was therefore the two estates involved in the Digital Bridge project.

The first stage was to design a pilot questionnaire in order to ensure that the questions included were understandable and that there was no technical or ambiguous language. ${ }^{26}$ The questions were separated into four sections - the first concentrating on television usage and uptake of the digital bridge television service; the second on feelings about CCTV and involvement in consultation prior to the installation of cameras; the third concentrating on issues of safety and privacy; and the fourth section asked for biographical information. The questions I designed therefore included those concentrating on people's behaviour (for example, television usage) those concentrating on people's beliefs (for example,

\footnotetext{
${ }^{26}$ Payne, G. and Payne, J. (2004) Key Concepts in Social Research Sage Publications; London p.186
} 
feelings of safety) and those concentrating on people's attitudes (for example, whether people want to be engaged or consulted). ${ }^{27}$

The questionnaire contained both continuous scales (strongly agree to strongly disagree) and categorical scales (yes/no, rank from highest to lowest importance). ${ }^{28}$ The pilot questionnaire was given to twenty people living in Hackney in similar living environments to the Charles Square and Haberdasher estates. Following collection of the completed pilot questionnaires, the survey was redrafted and finalised (The questionnaire is included in Appendix II).

Due to the use of human subjects and possibly sensitive data (regarding their experiences as victims of crime, fear of crime, and violence on the estates), ethical approval from the Ethics Committee at University College London (UCL) was sought. ${ }^{29}$ This involved providing a detailed description of steps in my empirical research and how the data would be used. Once my application was approved, I applied to the data protection committee in UCL, who provided details of compliance with the Data Protection Act, as well as information to provide within the covering letter concerning protection of respondents' data.

The closed questions were coded, as these would later be analysed using Excel. An identification number was also included on each questionnaire. A covering letter was included in the envelope (with instructions for the return of the questionnaire), detailing the purpose of the questionnaire, my details and a statement of my undertaking of an independent research project (The covering letter is included in Appendix I). The purpose of the identification number was also explained, as well as the inclusion of a data protection and confidentiality guarantee. I also included an assurance that all cooperation in the research is voluntary. ${ }^{30}$ A stamped addressed envelope was also included. The questionnaire was sent out to 400 households.

\footnotetext{
${ }^{27}$ Vaus, D. A. de (1991) ( $3^{\text {rd }}$ ed.) Surveys in Social Research Allen and Unwin; London p.82

${ }^{28}$ Creswell, J. (2003) Op.cit. p.157

${ }^{29}$ http://ethics.grad.ucl.ac.uk/

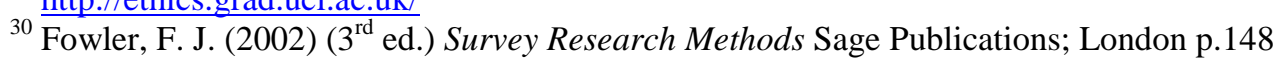


One of the major limitations of using a postal questionnaire is the low response rate that is traditionally associated with this method of research. ${ }^{31}$ Despite this, it still remained the most appropriate method as it would reach the largest number of people. A further limitation on acquiring a higher return of completed questionnaires was the financial constraint, which meant I could not send out a reminder. This may have increased the number of responses. However, I made the choice to include a SAE with each questionnaire, as opposed to using that budget to send a reminder. The possibility of low levels of literacy on the estates, as well as the potential for many people without English as their first language, may also have affected the response rate. Using a postal questionnaire also meant that I could not seek clarification on any unclear answers. However, this did not take place more than a couple of times. My analysis of the data derived from the questionnaires involved using quantitative and qualitative approaches on different parts of the material collected. For the closed-questions, the pre-coded responses were entered into Excel, within a spreadsheet designed to include filters on each question column. These filters allowed subsequent data and values to be temporarily filtered out. The results were tabulated to produce numerous graphs. The aims of this part of the analysis were to clearly show the results obtained from the questionnaires and to produce statistical evidence of answers. The next step was to analyse the data in order to assess any correlation between various answers. As an example, the relationship between gender and fear of crime, and gender and feelings of safety from CCTV, were looked at. I also analysed the data in comparison with the results of an official pilot study conducted in the area, focusing on uptake and usage of the system. The open-questions contained in the questionnaire were analysed qualitatively and were not entered into Excel as data.

\subsection{The interviews}

I chose to use a semi-structured interview approach, developing questions, themes and topics to explore within the interview but also allowing room for the interviewee to direct the discussion. I felt that a semi-structured interview would be less restrictive than a structured interview, allowing the interviewee the

${ }^{31}$ Bryman, A. (2001) Social Research Methods Oxford University Press; Oxford pp.128-135 
opportunity to engage with the topic from their perspective. I felt this to be particularly important due to my project's focus on public engagement. I therefore produced a number of questions but did not have in my mind that these would be followed in a particular order. The semi-structured interview approach also allowed me to clarify certain answers to questions, or to add in further questions when appropriate. I chose not to follow an unstructured interview methodology due to wanting to compare findings for the purpose of later analysis. This would not have been possible with an unstructured approach. ${ }^{32}$ The nature of my thesis as an inductive and exploratory piece of research meant it would benefit from a qualitative element. A qualitative methodology is interested in issues of interconnection and change, as well as the process of implementation, rather than simply the outputs. ${ }^{33}$ My thesis is concerned with the development and implementation of CCTV in a broad social, political and historical context, concentrating on various actors, policies and processes and therefore a qualitative element was seen to be necessary. Furthermore, the choice to use mixed methods and therefore adding a qualitative element to previous quantitative data collection meant that I could expand on the 'hard' data that had been collected, developing a dialogue and obtaining richer data during the interviews. ${ }^{34}$ Lastly, the semistructured interview method is highly flexible and allowed the interviewees to express themselves reasonably freely, whilst still allowing myself to maintain enough control and structure to elicit the information required for the aims of the thesis. $^{35}$

The semi-structured interview schedule was formulated from a number of sources, including the findings from the quantitative element of my research, the qualitative open-ended questions within the questionnaire, previous academic research on public perceptions of crime and fear of crime (which are included in the CCTV literature review earlier in this thesis), and my ongoing media analysis. Due to already having the results from the questionnaire, no scoping interviews

\footnotetext{
${ }^{32}$ Grix, J. (2001) Demystifying Postgraduate Research University of Birmingham Press; Edgbaston pp.76-77

${ }_{33}$ Bryman, A. (1998) Quantity and Quality in Social Research Unwin Hyman; London p.66

${ }^{34}$ May, T. (1997) ( ${ }^{\text {nd }}$ ed.) Social Research: Issues, methods and process Open University Press; Buckingham

${ }^{35}$ Ackroyd, S and Hughes, J.A. (1992) (2nd ed.) Data Collection in Context Longman; London, Berg, B.L. (2001) Qualitative Research Methods for the Social Sciences Allyn and Bacon; Boston p.76
} 
were undertaken prior to writing the interview schedule. The first stage in deciding the interview questions was to draw up a list of themes in relation to CCTV, in order to create an outline from which to develop the interview guides. ${ }^{36}$ These themes were then developed into interview questions, with the schedule providing for three main sections for discussion.

Included in the interview outline were possible elements of sensitive research (if participants answered yes to having been a victim of crime and questions centring on peoples' fear of crime), therefore I required ethics committee approval before proceeding. 'Sensitive research' is defined as requiring 'the disclosure of behaviours or attitudes which would normally be kept private or personal', in this case personal experience of crime and violence, fear of crime and so on. ${ }^{37}$

I contacted the ten residents who had agreed in their questionnaire response to take part in further research, either by email or telephone as requested. Of the ten people who had agreed to take part, eight then agreed to a face-to-face interview. I decided a face-to-face interview would be the best method due to the sometimes sensitive nature of the issues I wanted to discuss. I felt that a more familiar method than telephone would be preferable. I met with people at a time and place of their convenience, with most of the interviews being carried out in public places such as coffee shops, although a couple were conducted in people's homes due to their lack of mobility. The interviews averaged at about an hour, which provided fairly large amounts of material for subsequent analysis.

The interviews were recorded with the full consent of the interviewees. I also took notes during the interviews, although these were limited as I wanted to concentrate on non-verbal gestures as well as the words spoken. ${ }^{38}$ The tape recording has also allowed for direct quotations to be used in my thesis. I did promise anonymity prior to starting the interviews, although all the participants stated that would not be necessary. However, due to data protection issues, as

\footnotetext{
${ }^{36}$ Berg, B.L. (2001) Qualitative Research Methods for the Social Sciences Allyn and Bacon; Boston p.74

${ }^{37}$ Wellings, K. et al. (2000) 'Discomfort, Discord and Discontinuity as Data: Using focus groups to research sensitive topics’ Culture, Health and Sexuality 2(3) pp.255-67 p.256

${ }^{38}$ May, T. Op.cit.
} 
well as names being unnecessary for research purposes, the interviewees remain anonymous. I have, however, stated whether the interviewees were male or female as this has been shown to have some impact on views of CCTV and fear of crime and is therefore useful for analytical purposes. All the interviews were subsequently transcribed in full.

In terms of conducting the interviews, all participants were willing and interested in the subject and I found the experience an enjoyable one. The main problem that arose was some expectation that I would be able to influence the council in relation to security issues that were discussed during the interviews. As an example, one elderly interviewee was particularly distressed that her security gate had been broken for two years, and believed that I would be able to get someone to fix it, despite having received information about who I was and the purpose of my research. A further issue that arose was the negotiation of the phrasing of interview questions for different participants. There were those who understood terms such as 'public engagement' and 'public consultation' and those who did not. I had to ensure I explained the terms in simple and concise language. A disappointing aspect was the apparent willingness of some respondents to the questionnaire to take part in further research, however not providing their contact details, or providing an email address which bounced back when an email request for an interview was sent out.

In terms of analysing the data, I transcribed each interview in full and decided against using any sort of computer package for qualitative data analysis. I felt this was unnecessary due to the relatively small number of interviews carried out. During the interview process I had wanted interviewees to disclose feelings and beliefs, rather than purely factual information, therefore the interview guide was followed (and amended at times) in various ways, with questions being asked in a different sequence during each interview to allow a natural and flowing discussion to occur between myself and the interviewees. The first stage in analysis of the data obtained had to therefore focus on grouping the answers thematically, in order to provide a structured account of what had been said. As I transcribed I was able to pick out common themes, words and phrases used by participants. I grouped the answers within two main themes: in relation to CCTV 
in principle and in relation to CCTV on the estate (or at a more practical and local level). Within these main themes, I grouped the issues raised under a number of headings. Under the main theme of CCTV in principle, the issues were: awareness of CCTV and feelings of safety, impact on personal actions, negative and positive feelings towards CCTV, and public debate and CCTV. Under the theme of CCTV on the estate, the issues were: fear of crime, experience as a victim of crime, other uses for CCTV, and security on the estate. These answers were then analysed in order to extract the overriding and main issues to come out of the interviews.

The major limitation in this part of the research process was the fact that I was only able to interview a small number of people; therefore wider claims about the public have not really been possible. However, in terms of numbers of people on the estate it is still a useful and valid piece of social research, allowing an indepth perspective of people's thoughts and beliefs regarding CCTV and its use in their local area.

\subsection{Media analysis}

In this section, I describe my method and process of media analysis, the results of which are included in chapter 7. Alongside the quantitative and qualitative research described previously in this chapter, an important aspect of the mixed methods approach chosen for this thesis is the analysis of media content. At a general level I have familiarised myself with the main themes and topics arising in the press from surveillance issues in the UK. Over the course of my $\mathrm{PhD}$ I have continuously collected print media material focusing on CCTV, in the form of newspaper clippings and saving stories found online. I also set up a Google alert for the following key terms: 'ID cards', 'Surveillance + technologies', 'Surveillance + society', 'CCTV', 'CCTV + privacy', and 'CCTV + public' in order to keep up to date with broad surveillance issues in the news. 
More specifically for the empirical aspect of my thesis analysing media content, I used the online newspaper archives available at the British Library and UCL. The online archives available through UCL allow a search of full-content articles from The Guardian and The Times from the last twenty years (although The Times archive goes back to 1785). The British Library allows a search of full-content articles from the Daily Express and the Daily Mirror from the beginning of the $20^{\text {th }}$ Century. These four newspapers were therefore chosen due to the size of their archives and their political affiliations or leanings; The Guardian is left of centre and a broadsheet paper, The Times is right of centre and also a broadsheet, the Daily Mirror is a mass-market tabloid, left-wing and historically pro-Labour, and the Daily Express is a mid-market tabloid and leans to the right politically.

The keyword search terms I used were 'CCTV' and 'Closed-circuit television' and I once again used a mixed methods approach. This is for many of the same reasons as previously stated in relation to my questionnaire and interview design. Using only quantitative or qualitative methods would not have allowed for such broad research. The quantitative element was essential for deciding which years would be suitable for further qualitative analysis. Further, I was interested in the quantity and increase or decrease in coverage, as well as the narratives and discourse at play. One method without the other would not have worked.

For the quantitative element I searched for the keywords and then produced a graph of the results in order to see peaks in coverage in The Times, The Guardian, the Daily Express and the Daily Mirror. Once the peaks in coverage were known, I also searched across all other tabloid and broadsheet newspapers from the available archives (from the year 2000) in order to produce a quantitative summary of coverage in graph form. The other newspapers used are the remaining national broadsheet and tabloid newspapers in the UK: The Independent, The Telegraph, the Daily Mail and the Mail on Sunday, The Sun, the Daily Star and Sunday Star, the Morning Star, The News of the World, and The People.

Following this and for the qualitative element of my press analysis I undertook an in-depth content analysis of the peak years of CCTV coverage in The Times, The 
Guardian, the Daily Express and the Daily Mirror. This content analysis provided the information needed to answer the question - what are the broadsheet and tabloid print media saying about CCTV? I then took a closer look at the print media coverage of the 7 July 2005 London Underground bombings (which are explained in more detail in chapter 7) with particular reference to CCTV, in order to discuss how large-scale crimes are framed by the print media in their portrayal of CCTV to the public.

Content analysis is described as 'an empirically grounded method, exploratory in process [and] entails a systematic reading of texts' ${ }^{39}$ The research questions set out above were answered 'through inferences drawn from texts', looking at terminology used and assessing and discussing emphasis and meaning from the wording of newspaper articles. ${ }^{40}$

My media research utilises both a quantitative and qualitative content analysis. Although some suggest that a content analysis cannot be qualitative, ${ }^{41}$ others, such as Bauer and Gaskell, argue that:

Content analysis is the only method of text analysis that has been developed within the empirical social sciences. While most classical content analyses culminate in numerical descriptions of some features of the text corpus, considerable thought is given to the 'kinds', 'qualities' and 'distinctions' in the text before any quantification takes place. In this way, content analysis bridges statistical formalism and the qualitative analysis of the materials. In the quantity/quality divide in social research, content analysis is a hybrid technique that can mediate in this unproductive dispute over virtues and methods. ${ }^{42}$

Using a qualitative methodology in relation to media articles necessarily meant that interpretation played a part in my analysis. Judgement also played a part

\footnotetext{
${ }^{39}$ Krippendorf, K. (2004) ( $2^{\text {nd }}$ ed.) Content Analysis: An introduction to its methodology Sage Publications; London pp.xvii-3

${ }^{40}$ Ibid. p.31

${ }^{41}$ For example Neuendorf, K. A. (2002) The Content Analysis Guidebook Sage Publications;

London p.14

42 Bauer, M. W. and Gaskell, G. (eds) (2000) Qualitative Researching with text, image and sound Sage Publications; London p.132
} 
when I assessed which articles placed CCTV in a prominent position (and were therefore of use in my thesis) and those in which CCTV played a minor role. I could have only included those articles in which CCTV appeared as a term in the headline, however I felt that in order to really analyse media discourse surrounding CCTV a more in-depth (and time consuming) process was necessary. I wanted to find out the contexts in which CCTV appeared, not simply when it became headline news.

I wanted to gain an in-depth insight into the portrayal of CCTV by the press and therefore decided to approach the task in a traditional and paper based manner. Prior to printing out articles, I made the judgement as to whether CCTV played enough of a role to warrant analysis. I then printed out the remaining articles, summarising developments and reportage according to year. I also went through the articles manually to pick out any pertinent, repeated, and common phrases and words used in association with CCTV. Once an analysis according to year had been undertaken, as well as a specific focus on the language used in CCTV articles, an overarching analysis was conducted, detailing the changes in reportage over the past fifteen years.

\subsection{Conclusion}

In this chapter I have explained my overall approach, methodologies and design to researching CCTV in the UK. I have explained my interest in moving away from traditional surveillance studies accounts of why CCTV has become so widespread, into an STS centred-approach, based in a social constructionist school of thought. I have described my research questions and research aims, as well as the methodologies applied in order to answer these questions and achieve these aims. I have also described my methods of data collection, the manner in which the data collected was analysed and what I hoped to achieve through this analysis.

A mixed methods approach is employed in chapters 5 and 6, based on media sources, legal and policy documents and archival resources. This mixed methods approach serves the purpose of allowing me to answer research questions 
necessitating a multi-disciplinary and multi-methodological investigation. In chapter 7 , I continue the use of documentary analysis, extending this into a media content analysis, once again using a mixed methods research design. In chapter 8, I describe the results of my mixed methods research, using a combination of questionnaires and interviews.

My overall approach is one based in social constructionism, using an exploratory, objective, and interpretivist framework. I use a variety of sources and literature from a number of disciplines throughout my thesis, in order to develop an indepth analysis of why the UK has become so camera-surveilled. 


\section{Chapter V:}

\section{A Social and Political History of Britain in the $20^{\text {th }}$ and Early $21^{\text {st }}$ Centuries}

\subsection{Introduction}

In this chapter I provide a concise history of the social, economic, and political changes, Britain has undergone in the $20^{\text {th }}$ Century. I focus particularly on developments in science and technology, policing, surveillance, and the public sphere, as these have specific implications for the history of CCTV and the question of why Britain has become so camera-surveilled. In order to understand the history of CCTV the wider social and political context, in which the technology was developed and later extensively disseminated, needs to be looked at.

This chapter aims to answer the research questions set out previously:

How has policing and crime control evolved since the formation of a police force in Britain?

What can this tell us about surveillance and CCTV in Britain?

What is the broader context of surveillance in which CCTV has developed?

\subsection{Britain in the $20^{\text {th }}$ and early $21^{\text {st }}$ centuries}

Central state (and non-covert) surveillance began in earnest at the start of the $20^{\text {th }}$ century. ${ }^{1}$ In England the 'combination of warfare and welfare' (military conscription and NHS cards) created the basis of the surveillance we see presently (although we no longer have military conscription or NHS cards). ${ }^{2}$ Improvements in transport also increased the need for national forms of

\footnotetext{
${ }^{1}$ Lyon, D. (2003) Surveillance after September 11 Polity Press; Cambridge p.24

${ }^{2}$ Ibid. p. 25
} 
identification, such as the driving licence, which was introduced in $1903 .^{3} 1915$ saw the introduction of the passport, which included details of the individual, a photograph and signature. ${ }^{4}$ Surveillance had by this point become a way to prove citizenship, rather than as a method of exclusion for certain elements of society, which it had been prior to this time. ${ }^{5}$ In this sense surveillance had become an inclusionary, as well as an exclusionary phenomenon. ${ }^{6}$

However, it still remained an exclusionary method. To illustrate, one of the earliest examples of state surveillance can be seen in the covert photographing of the Suffragettes, which can be seen as an exclusionary method of surveillance. It is likely that this is the earliest example of an 'activist' (or what some commentators have deemed terrorist) organisation being subjected to covert surveillance photography.

Fig. 5.1 Known Militant Suffragettes (1914)

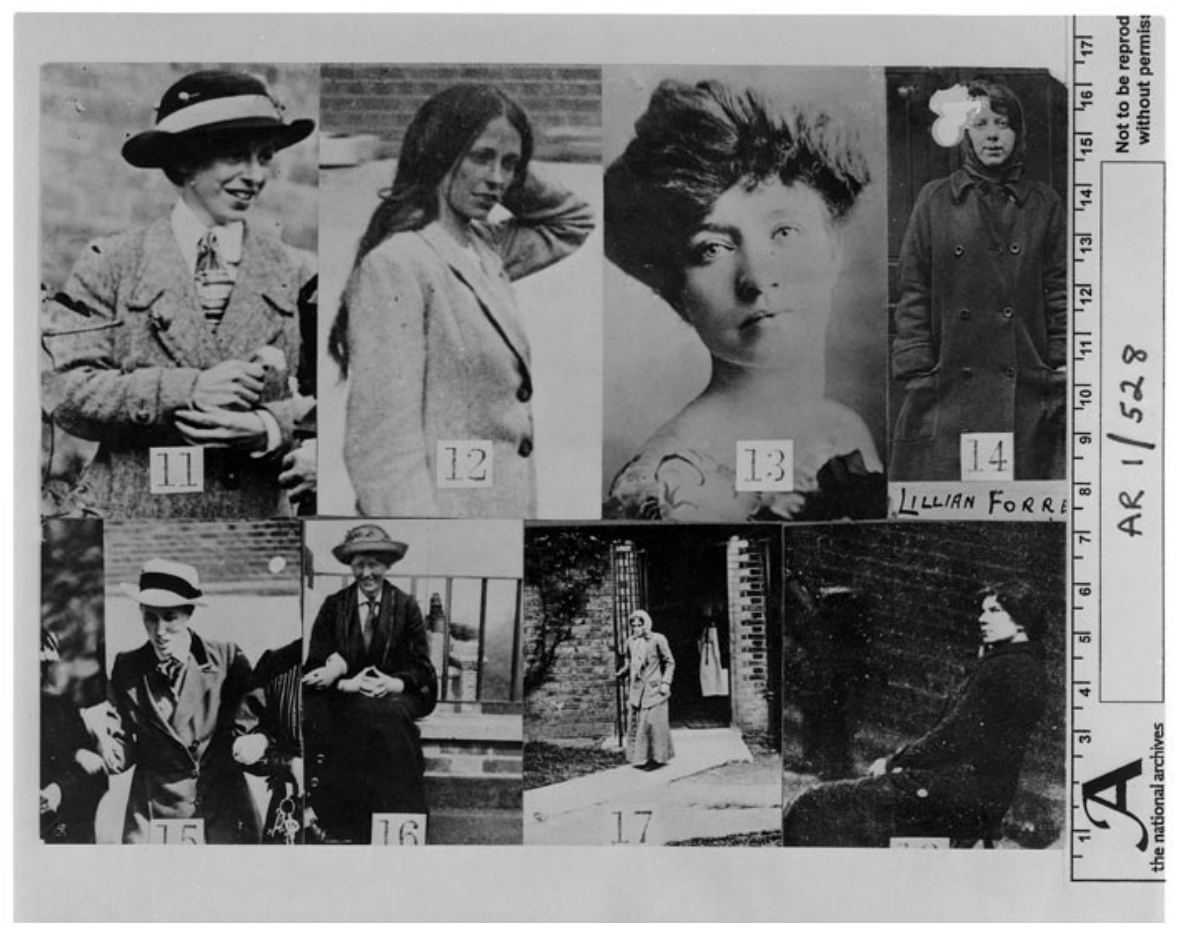

\footnotetext{
${ }^{3}$ Leeuw, K. De and Bergstra, J. A. (2007) The History of Information Security Elsevier; Amsterdam p.9

${ }^{4}$ Ibid. p.9

${ }^{5}$ Ibid.

${ }^{6}$ When I talk about exclusionary methods of surveillance I am referring to the introduction of routine surveillance of working class areas by on the beat policemen, which began during the early $19^{\text {th }}$ Century. Alongside this routine surveillance, Storch (1980) describes the introduction of the 'move on' system, which hindered the traditional freedom of assembly on the streets.
} 


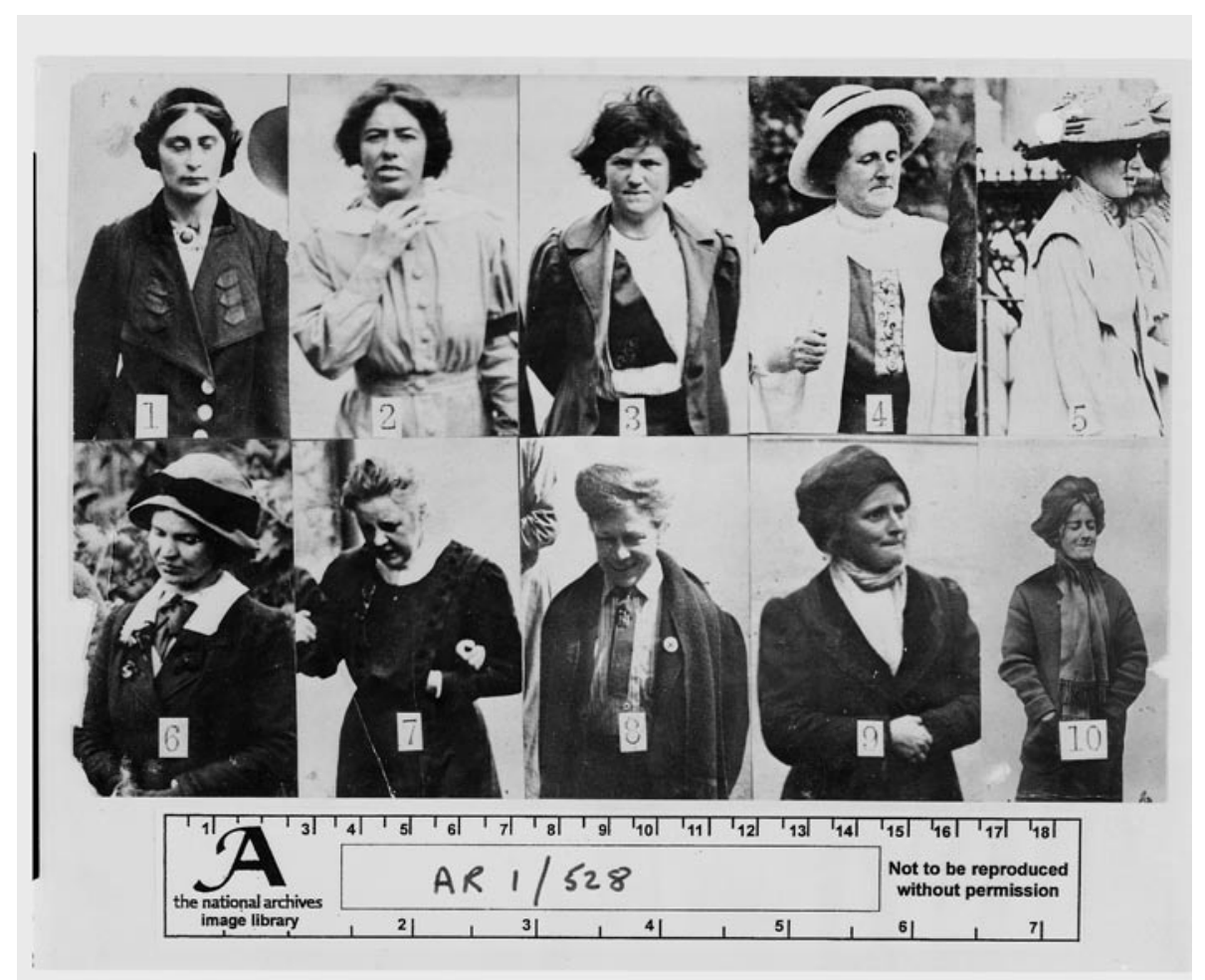

The above photographs were issued by the Criminal Records Office under the title 'Known Militant Suffragettes' in 1914. The photos were a mix of studio portraits, press pictures taken at public demonstrations, police photographs taken at the time of arrests and those taken in the exercise yards at Holloway prison. The photographs taken in the exercise yards were taken covertly. Forced photographs in other situations were also taken. ${ }^{7}$

The first British Identity Card was introduced in 1915 and abandoned in 1919. The second was introduced in 1939, with the system in existence until 1952. ${ }^{8}$ The first identity card was used for the purpose of national registration, in order to determine the amount of males in the population available for conscription. ${ }^{9}$ Agar points out that this was not the reason why the card was introduced yet did become the reason for its use. The original intention had been to join up

\footnotetext{
${ }^{7}$ Hamilton, P. and Hargreaves, R. (2001) The Beautiful and the Damned: The creation of identity in nineteenth century photography National Portrait Gallery; London p.55

${ }^{8}$ Agar, J. (2005) 'Identity Cards in Britain: Past experience and policy implications' History and Policy http://www.historyandpolicy.org/papers/policy-paper-33.html

${ }^{9}$ Ibid.
} 
numerous personal registers of information on individuals held by government agencies. ${ }^{10}$ The second was introduced for three purposes, specified as being; 'for the duration of the present emergency: co-ordinating national service, national security and the administration of rationing'. Once the war had ended there was significant public and political opposition to the cards, which were withdrawn in 1952. $^{11}$

Winston Churchill had been the British Prime Minister for the majority of the Second World War, leading a coalition government (although he was a Conservative). This wartime government came to an end on 23 May 1945 (after the end of the war on 7 May 1945). ${ }^{12}$ Churchill was succeeded by Clement Attlee, and a Labour government. Sked and Cook describe this change from a Conservative to a Labour government as surprising at the time however explain the changes in Britain and British people as:

People of widely differing social backgrounds had found it possible to live and work together when faced with common tasks and common dangers. They had accepted the need for control and restrictions and had been impressed by the results of their common effort. They assumed quite naturally that after the war they would share in common rewards, that is, in better housing and better social services. And if these entailed continuing government planning and interference, they were more than ready to put up with it. They knew that these benefits were more likely to be provided by Labour than the Tories. $^{13}$

In the aftermath of the Second World War, Britain has been described by Hollowell as 'economically exhausted', facing continuing rationing and near bankruptcy. ${ }^{14}$ Marwick describes Britain as a country seeking a 'new future

\footnotetext{
${ }^{10}$ Ibid.

${ }^{11}$ Ibid.

${ }^{12}$ Sked, A. and Cook, C. (1993) (4 ${ }^{\text {th }}$ ed.) Post-War Britain: A political history Penguin Books;

London p.13

${ }^{13}$ Ibid. p. 18

${ }^{14}$ Hollowell, J. 'From Commonwealth to European Integration' in Hollowell, J. (ed.) (2003)

Britain Since 1945 Blackwell Publishing Ltd. p.61
} 
involving state planning and a comprehensive welfare state'. ${ }^{15}$ In terms of greater state involvement, the coal, gas, transport, and electricity industries were nationalised under Attlee's government. ${ }^{16}$ The National Health Service was established on 5 July 1948, providing universal and free healthcare. ${ }^{17}$ Production levels rose during this time, reaching their highest ever level by 1950. Exports also increased - by 77\% between 1945 and 1950 - and having reached their prewar level by $1946 .{ }^{18}$ Despite this rise in production levels, most basic foods remained rationed and there were demands from the middle-class, coming to the end of an almost full decade of employment, for higher standards of living. ${ }^{19}$ This demand for improved standards of living, coupled with a feeling that levels of taxation for the middle-class were too high, meant that support for Labour decreased. ${ }^{20}$ Labour did win the 1950 election, with Attlee remaining as Prime Minister. However, their majority had significantly lessened, with only a residual five seat majority. The following year, in October 1951, Winston Churchill became Prime Minister once again under a Conservative government. The Conservatives remained in power from this time until October 1964.

Under Churchill (October 1951 - April 1955) domestic policy took a back seat to foreign policy, with Britain's involvement in the Korean War. $^{21}$ There was no return to the pre-war laissez-faire and the Welfare State remained in place. Rubinstein states that:

The electoral risks, above all from the deliberate creation of greatly increased unemployment, were so immense, given the government's small majority, that it simply could not be tried. ${ }^{22}$

\footnotetext{
${ }^{15}$ Marwick, A. (1996) (3 ${ }^{\text {rd }}$ ed.) British Society Since 1945 Penguin Books; London p.7

${ }^{16}$ Glynn, S. And Booth, A. (1996) Modern Britain: An economic and social history Routledge; London and New York p.268

${ }^{17}$ Mullard, M. (1995) Policy-making in Britain Routledge; London p.183

${ }^{18}$ Childs, D. (1995) Britain Since 1939: Progress and Decline Macmillan; London p.89

${ }^{19}$ Ibid. p.89

${ }^{20}$ Ibid. p.89

${ }^{21}$ MacDonald, C. (1990) Britain and the Korean War Blackwell; Oxford

${ }^{22}$ Rubinstein, W. D. (2003) Twentieth-century Britain: A political history Palgrave Macmillan p. 254
} 
Alongside the enduring welfare system, the majority of industry remained nationalised. ${ }^{23}$ Despite the Conservative government facing a 'serious balance of trade situation', the early 1950s were a time of increasing affluence (with full employment until the 1970s). ${ }^{24}$ There was also a sense of increasing freedom, which had been an election promise of the Conservatives prior to the 1951 election when they stated a promise to 'set the people free'. ${ }^{25}$ Broadcasting was deregulated in 1954, and following this, commercial television was introduced in $1955^{26}$

Wakeman calls the period from 1953 - 1973 the 'golden age of prosperity': a time of massive economic expansion across Europe (although for Britain the economic expansion occurred primarily after the war and during the early 1950s) At this time there was a rise in production and consumption, an increase in jobs, and rising standards of living. ${ }^{27}$ Wakeman argues that 'a consumer revolution swept through Europe completely transforming everyday culture with a cascade of commodities from washing machines to telephones and televisions' ${ }^{28}$ The average wage rose by 34\% between 1955 and 1960, whilst the cost of consumer technologies fell. ${ }^{29}$ However, for Britain this economic prosperity had started to wane by the mid-1950s.

In the years immediately following the war, policing had remained largely organised along a beat system (as had been the case since the $19^{\text {th }}$ century). A move to motor vehicles for the police was rejected for a number of reasons, including that it would 'diminish that contact with the public which is so useful to the police and to the public itself'. In its interim report, the Royal Commission discussed the disadvantages of moving from a beat to a motorised system of

\footnotetext{
${ }^{23}$ Ibid.

${ }^{24}$ Ibid.

${ }^{25}$ Francis, M. "Set the people free'? Conservatives and the state, 1920-1960' In Francis, M. and Zweiniger-Bargielowska, I. (eds) (1996) The Conservatives and British society, 1880-1990 University of Wales Press; Cardiff pp. 58-77

${ }^{26}$ Television Act 1954 (Accessed at the British Library - 01/10/2009)

${ }^{27}$ Wakeman, R. (2003) Themes in Modern European History Since 1945 Routledge; London and New York p.45

${ }^{28}$ Ibid.

${ }^{29}$ Holden, A. (2005) Tourism Studies and the Social Sciences Routledge; London p.35
} 
patrol. Affection towards beat policing, both within and outside the police force, remained strong well into the 1960 s. $^{30}$

By 1959, there were over 70,000 policemen in Britain. The 1960 Commission, which had been set up to review police pay and administrative issues surrounding the constitutional position of the police force in Britain, also recommended the appointment of a Chief Inspector of Constabulary responsible for scientific research, development and planning. Manwaring-White states that this development 'paved the way for...more technopolicing' ${ }^{31}$ Manwaring-White coined the term 'technopolicing', which she describes as: the 'technology of policing and the 'science of policing and its tools'. ${ }^{32}$ By 1951, radio was being used to enhance police efficiency, especially in relation to the use of motor vehicles, whilst Criminal Record Offices were set up in order to allow a flow of information between forces. ${ }^{33}$ The telephone was also being used to a greater degree. ${ }^{34}$ Of these technological developments, Manwaring-White says:

No checks or balances however were advocated by which the spread of this new scientific approach to policing could be evaluated. The dangers to the fragile freedoms of civil liberties, posed by sophisticated eavesdropping, electronic surveillance and computer information gathering were not considered. Technopolicing was embraced wholeheartedly as the new scientific aid to better policing. ${ }^{35}$

The Commission also recognised the importance of the trusting and confident relationship between the British public and the police force. This was voiced as the 'British police advantage' by the Commission and was heralded as unique. However, it is argued by some that this notion came to be re-examined during the 1960s as technological and societal developments took effect. Sir Philip Knight said:

\footnotetext{
${ }^{30} \mathrm{Ibid}$.

${ }^{31}$ Manwaring-White, S. Op.cit. pp.20-22

${ }^{32}$ Ibid. p.17

${ }^{33}$ Ibid. pp. 18

${ }^{34}$ Ibid. pp. 19

${ }^{35}$ Ibid. p.22
} 
Not only did the police get into cars, but so did the public. It was only one of the new problems of a society which changed enormously in the '60s. We used to talk to people over the garden fence, now the fence is twenty storeys up in a high-rise building. It wasn't only the police withdrawing, but society developing in an insular way. ${ }^{36}$

These developments meant that informal surveillance between the police and members of the public could no longer occur as easily, if at all. This new system of reducing the number of police officers on foot and putting them into cars was known as 'unit beat policing', a new system encouraged by the Home Office. ${ }^{37}$ However, this system, designed to improve police-community relations had the opposite effect. $^{38}$ Newburn argues that this was due to a concentration by the police on the 'action' element of their role, rather than the 'service' element. ${ }^{39}$ Chibnall describes this development as:

The dominant image of the honest, brave, dependable, (but plodding) 'British Bobby' was recast as the tough, dashing, formidable, (but still brave and honest) 'Crime-Buster'. ${ }^{40}$

Bradley et al. reiterate this point and argue that:

The introduction and spread of the unit beat system in the 1960s is now regarded as at worst an unmitigated disaster, which hastened the growing divorce between the police and the public, at best a desperate stop gap form of fire-brigade policing. ${ }^{41}$

\footnotetext{
${ }^{36}$ Sir Philip Knight, Chief Constable of the West Midlands quoted in Manwaring-White p.23

${ }^{37}$ A Home Office Circular was released in 1967 encouraging this new system, which allowed coverage of a much wider geographical area over a 24 hour basis. This system developed alongside the issuing of personal radios to policemen (for more on this see Newburn, T. (2005))

${ }^{38}$ Newburn, T. 'Policing since 1945' in Newburn, T. (ed.) (2005) Handbook of Policing Willan Publishing Ltd. pp.84-105 (p.85)

${ }^{39}$ Ibid.

${ }^{40}$ Chibnall, S. (2003) ( $2^{\text {nd }}$ ed.) Law-and-Order News: An analysis of crime reporting in the British press Tavistock Press

${ }^{41}$ Bradley, D. et al. (1986) Managing the Police: Law, Order and Democracy Harvester Wheatsheaf; Brighton p.16
} 
Fire-brigade policing was the term given to the police responding to crime, rather than seeking to prevent it. ${ }^{42}$

The aforementioned withdrawal of society occurred alongside a rise in relative poverty. Although, as described earlier, there was a rise in wages and a fall in the price of consumer goods, the gap between those becoming more affluent and those with little widened and became more pronounced throughout the $1970 \mathrm{~s}^{43}$ Housing estates, which had been built during the 1950s and 1960s to provide a solution to a lack of housing after the Second World War, had become, Marwick argues:

Heartless public housing estates ... now stuck on a descending spiral into Hades as, a natural target for frustration and vandalism, they increasingly became dumping grounds for problem families. ${ }^{44}$

Hanley describes council housing in Britain as having become 'housing for the working class (and the non-working class)' and that 'a wall exists unbroken throughout every estate in the land'. ${ }^{45}$ This divide, which started to occur in the 1950s and 1960s in Britain with the building of high-rise and sprawling council estates, meant that certain sections of society (mentioned previously in terms of policing) were becoming more isolated and detached. ${ }^{46}$

It was also during this time that the numbers involved in trade union membership grew substantially. Membership continued to grow until 1979, when it reached its peak. ${ }^{47}$ During the late 1960 s and early 1970s, alongside a rise in inflation, there was also a return to major mining disputes, culminating in a period of 'higher than usual levels of strikes' (in particular the coal-mining, docks, shipbuilding, car manufacturing, and iron and steel industries). ${ }^{48}$

\footnotetext{
${ }^{42}$ Emsley, C. (1995) Op.cit. p.140

${ }^{43}$ Marwick, A. Op.cit. pp.224 - 225

${ }^{44}$ Ibid. p. 232

${ }^{45}$ Hanley, L. (2007) Estates: An Intimate History Granta; London

${ }^{46}$ For more on the development of an insular society through the growth of housing estates, see Hanley, L. (2007) Estates: An Intimate History

${ }^{47}$ Wrigley, C. (1997) British Trade Unions 1945 - 1995 Manchester University Press; Manchester p.29

${ }^{48}$ Ibid. p.26
} 
By the mid-1970s the British economy was showing signs of distress. Sked argues that:

The economic failures of the 1960s and 1970s - growing unemployment, rising inflation, balance of payment crises, the 1967 devaluation and the 1976 IMF crisis - had forced almost everyone interested in the fate of the country to re-examine the assumptions behind the consensus. The behaviour of the trade unions - now largely seen as the cause of 'Britain's relative decline' - also helped the process. $^{49}$

Of the trade unions, Sked goes on to argue that:

Their refusal to co-operate with Wilson's In Place of Strife proposals of 1969; their opposition to Heath's industrial courts and other pieces of legislation designed to bring them within the law; Arthur Scargill's emergence as a would-be maker and breaker of governments after the miners' strikes of 1972 and 1974; and, finally, the 'winter of discontent' of 1978-9 which completely undermined the Callaghan government, meant that Thatcher could campaign openly against them in the general election of 1979 and succeed in winning a mandate to reform them and sort out the economy. ${ }^{50}$

The Conservatives, with Margaret Thatcher at the helm, won the 1979 general election. During the previous years, with Labour in power and James Callaghan as Prime Minister (1976 - 1979), relations between the government and trade unions had worsened and eventually broken down during the Winter of Discontent (1978 - 1979). Ironside and Seifert argue that the Winter of Discontent was caused by Labour's 'shift to the monetarist right ... and its turn

\footnotetext{
${ }^{49}$ Sked, A. 'The Political Parties' in Hollowell, J. (ed.) (2003) Britain Since 1945 Blackwell Publishing Ltd. p.48

${ }^{50}$ Ibid.
} 
away from social democracy', which in turn paved the way for the election of the Conservatives under Thatcher. ${ }^{51}$

The Thatcher government stayed in power until 1990 (winning three elections in 1979, 1983, and 1987). During her three terms Thatcher introduced increases in Value Added Tax (VAT), cuts in direct taxation, and decreases in public spending. ${ }^{52}$ There was also a move towards deindustrialisation and privatisation of industry, reducing the activities undertaken by the state. Deregulation was supposed to increase competition, and it was for this reason that private businesses were encouraged. Along the same lines, there was a move to gradually reduce eligibility for state benefits, in an attempt to encourage people to return to work. ${ }^{53}$ However, at this time there was also a rise in unemployment (particularly in the manufacturing industries). ${ }^{54}$

During the late 1970s and throughout the 1980s social divisions deepened in Britain with regard to wealth, race, and class. ${ }^{55}$ Throughout the 1980 s there were also a number of social and political disturbances, which will be looked at in greater detail later in the thesis. In 1981, for example, there were a number of outbreaks of rioting in London, Liverpool, and Manchester (for some these riots reflected local issues between residents and the police, for others the riots told of a deeper sense of alienation from society). ${ }^{56} \mathrm{~A}$ few years later, the government faced a year-long strike by the mining industry (I return to this in chapter 6). Throughout the 1980s there was also a continuing threat of violence from the IRA (the armed paramilitary campaign had started in 1969 and continued through the 1970s). To provide one specific example, during the 1984 Conservative Party annual conference an IRA bomb was planted in the venue. Five people, including one Member of Parliament (MP), were killed (this incident has particular

\footnotetext{
${ }^{51}$ Ironside, M. and Seifert, R. V. (2000) Facing up to Thatcherism: the history of NALGO 1979 1993 Oxford University Press; Oxford p.47

52 Black, J. (2004) Britain Since the Seventies: Politics and Society in the Consumer Age Reaktion Books; London p.126

${ }^{53}$ Childs, D. Op.cit. p.196

54 Strath, B. (1987) The Politics of De-industrialisation Croom Helm; London p.153

${ }^{55}$ Marwick, A. Op.cit. p.201

${ }^{56}$ Black, J. Op.cit. p.128
} 
relevance for the history of CCTV, and I return to this issue in greater detail in chapter 6). ${ }^{57}$

At this time there was also a rise in crime, prompting criticism of the fire-brigade manner of policing, which had arisen during the 1960s and which I mentioned earlier. ${ }^{58}$ Following a 1965 report from the Committee on the Prevention and Detection of Crime, a number of specialist crime departments had been set up. Until the 1980s, responsibility for crime prevention remained under the control of these specialist departments, treated as 'a peripheral specialism of low status and interest when placed alongside crime-fighting'. The continuing rise in crime during the 1980s, however, meant that 'one of the key messages emanating from the police was they could not be expected to carry responsibility for the prevention of crime unaided, 59

Following the Brixton riots in 1981, the Scarman report provided the following recommendations:

i) the need for a concerted, better co-ordinated attack on the problems of the inner city; ii) recognition of and action to meet the special problems and needs of the ethnic minorities, based on an acceptance of them as full and equal members of a culturally diverse society; iii) the need to involve not just black people, but all the community, both nationally and locally, in a better directed response to these problems. It is essential that people are encouraged to secure a stake in, feel a pride in and have a sense of responsibility for their own area; iv) the role of the police as essential participants in any effective response by the community. ${ }^{60}$

\footnotetext{
${ }^{57}$ Childs, D. Op.cit. p.196

${ }^{58}$ Emsley, C. (1996) (2 ${ }^{\text {nd }}$ ed.) The English Police: A political and social history Longman; London p.141

${ }^{59}$ Newburn, T. (2005) 'Policing since 1945' Op.cit. p.87 This is interesting in terms of thinking about CCTV and surveillance technologies. Were these first implemented as a way of sharing responsibility for crime prevention, and in order to shoulder part of the burden of 'fighting crime', or was there another reason for their early implementation? This will be looked at in more detail in the history of CCTV section, in relation to archival research into the Association of Chief Police Officers files.

${ }^{60}$ Ibid. p.175
} 
The Scarman report led to a number of reforms in police management techniques; however the outcome was not a positive one. The late 1980s saw 'all-time record crime increases, renewed public disorder, spectacular scandals involving miscarriages of justice and plummeting public confidence in the police'. ${ }^{61}$ Ackroyd argues that the underlying cause of the lack of public confidence in the police and the problems between the police and public is new technology, its impact on the organisation and a managerial failure on the part of the police to deal with these developments.

Although there was a rise in techno-policing, at the same time efforts were made to enhance community policing. The 1980s saw the rise of community policing and inter- or multi-agency cooperation, ${ }^{62}$ as well as a change in the tasks to which the police were put forward, such as the involvement of the Metropolitan Police in the Brixton Riots of 1981, which has been described as them being involved in the 'largest civil disturbance in this century'. ${ }^{63}$ In 1983, Sir Kenneth Leslie Newman (appointed as Commissioner of the Metropolitan Police in 1982) developed a new statement of the Principles of Policing, redirecting a number of the primary objectives of policing developed in $1829 .{ }^{64}$ Newman's strategy was based on the idea that the public must be involved in order to combat crime successfully. He extended the idea of policing by consent to one involving a 'notional social contract' between the public and the police; which was to be realised through greater involvement of the public in consultative committees and crime prevention panels. Multi-agency working was also emphasised in this strategy. ${ }^{65}$

The 1980s also witnessed the birth of the Neighbourhood Watch schemes. Emsley describes these schemes as 'link[ing] back to traditional, informal modes

\footnotetext{
${ }^{61}$ Reiner, R. 'Policing a postmodern society' Op.cit. p.690

${ }^{62}$ Newburn, T. 'Policing since 1945' Op.cit. p.87

63 'Metropolitan Police History’ www.met.police.uk/history/timeline

${ }^{64}$ http://www.met.police.uk/history/timeline1970-1989.htm

65 Brake, M. and Hale, C. (1992) Public Order and Private Lives; The politics of law and order Routledge; London p.75
} 
of community behaviour', which 'encourage[s] watchfulness and suspicion' ${ }^{66} \mathrm{He}$ goes on to suggest that the schemes can be seen as a failure of preventive policing and argues 'by their formal creation, the police are implicitly admitting that, after years of insisting they were the experts in crime prevention and detection, they cannot solve the problem of crime alone' ${ }^{67}$

The Police and Criminal Evidence Act was set up in 1984; a legislative framework governing the powers and duties of the police, and providing codes of practice for the exercise of those powers. ${ }^{68}$ The aim of the Police and Criminal Evidence Act was to balance the powers of the police to bring offenders to justice with the rights of the public. ${ }^{69}$ In 1987, Sir Peter Imbert took over as Commissioner; he continued to emphasise the need for police-public cooperation and consultation.

By 1987, the state sector under the Conservatives had been cut by a third. Fourteen large companies had also been privatised (mostly public utilities, and telecommunications), amassing $£ 11$ billion for the Treasury. ${ }^{70}$ Continuing this path of privatisation, the Conservatives also brought in legislation designating a 'right to buy' for council tenants wishing to buy their homes, allowing them to do so at a discounted price. This increased the number of homeowners substantially, yet, at the same time, meant that fewer council houses were available for others. The number of council houses fell, increasing the number of homeless people. ${ }^{71}$

The Conservatives retained power in the general election of 1992, with John Major as Prime Minister (having won the leadership election in 1990). They remained in power until 1997. By the time Major stepped in as Prime Minister,

\footnotetext{
${ }^{66}$ Pre-modern crime control was essentially based on self-regulation by the community rather than the state. The stranger was regarded with suspicion, informal social control was exercised by local communities and families, and sanctions imposed on those who strayed from the norm. For more on this see Emsley, C. (1995) and Lea, J. (2002). I also return to the issue of neighbourhood watch schemes in chapter 6.

${ }^{67}$ Emsley, C. (1995) Op.cit. p.141

${ }^{68}$ Police and Criminal Evidence Act 1984 http://www.statutelaw.gov.uk/content.aspx?activeTextDocId=1871554

${ }_{69}$ Zander, M. (1990) ( ${ }^{\text {nd }}$ ed.) The Police and Criminal Evidence Act, 1984 Sweet \& Maxwell; London p.vii

${ }^{70}$ Ibid. p. 210

${ }^{71}$ Ibid. pp.211 - 212
} 
Britain had gone into recession. Unemployment at this time was also rising, after a number of years of improvement. This situation began to change in the latter half of the 1990s, with employment levels rising once again, and an increase in weekly earnings. ${ }^{72}$

During the 1990s there were also major advances in Information Technology (IT), computerisation and the storage and collection of information on a mass scale. These changes had been occurring since the end of the Second World War in terms of analogue technology, which enabled the storage of data for the first time. This in turn was superseded by the advent of digital technology, which allowed for greater volumes of data to be stored at lower cost. Technologies such as the microchip and GPS have allowed for tracking of individuals, as well as the advancement of other surveillance technologies. In terms of computer technology, advances have been threefold: Firstly, the amount of information stored has increased, secondly, the speed at which this information can be transferred has increased and thirdly, improvements in search facilities have occurred, allowing specific information stored to be found more easily. In terms of everyday use, Agar states that:

Until the 1970s few people in Britain would have seen a computer, yet by the 1990s they could be bought in supermarkets. The appearance of smaller and cheaper machines, and new techniques for connecting computers together, made possible the entry of computers into new settings, particularly the front office and the home. ${ }^{73}$

At this time there were also important changes in the relationship between science, technology and society. These changes entailed greater public participation in policy processes on science and technology, and an end to the traditional top-down information policies. ${ }^{74}$ Public consultation started to be

\footnotetext{
${ }^{72}$ Llg, R. E. and Haugen, S. E. (2000) 'Earnings and Employment Trends in the 1990s' in Monthly Labour Review 123(3) p.22

${ }^{73}$ Agar, J. 'Science and Information Technology’ in Hollowell, J. (ed.) (2003) Britain Since 1945 Blackwell Publishing Ltd. p.353

${ }^{74}$ Callon, M. et al. (2008) Science and Governance: Taking European Knowledge Society Seriously: report of the expert group on science and governance to the Science, Economy and Society Directorate IPOC; Milan p.97
} 
viewed as an important part of the development of science and technology, with public opinion being used to drive policy in these areas. Prior to this, public participation in decisions on science and technology had been minimal. I return to this later in this chapter, and also in the conclusion to this thesis. The lack of public participation prior to this time has important implications for the study of CCTV in the UK.

In terms of policing, the objectives of the Metropolitan Police were designed for the first time by government in $1994 .^{75}$ The Police and Magistrates' Court Act (1994) legislated that the Home Secretary may issue Codes of Practice, which 'regulate the manner in which police authority pursues policy objectives'.76 During the same year, the Home Office and Association of Chief Police Officers issued the National Strategy for Police Information Systems, essentially an information technology strategy. ${ }^{77}$ The 1996 Police Act extended the powers of the Home Secretary, allowing them to 'make regulations for the government, administration and conditions of service of police forces' ${ }^{78}$

Labour, with Tony Blair as leader, won the 1997 general election subsequently also winning the 2001 and 2005 elections. The leadership of the Labour Party changed hands in 2007, with Gordon Brown, former Chancellor of the Exchequer, taking over. Under Tony Blair there were notable changes in human rights legislation, with the Human Rights Act 1998 brought into force in 2000, promoting further the rights and freedoms granted to citizens under the European Convention on Human Rights. However, during this period there have also been developments in the area of identity cards, with the Identity Cards Act 2006 planning the introduction of a National Identity Card (linked to a National Identity Register database, which is still in the developmental stage). The Labour government, under Blair, also introduced the role of Mayor of London (in 2000), concurrently developing the Greater London Authority, the governing body for Greater London.

\footnotetext{
75 'Metropolitan Police History' www.met.police.uk/history/timeline

${ }^{76}$ Barnett, H. (2004) Constitutional and Administrative Law Cavendish; London p.717

${ }^{77}$ Hoey, A. (1998) 'Techno-cops: Information Technology and Law Enforcement' International Journal of Law and Information Technology 6(1) pp.69-90 p.69

${ }^{78}$ Barnett, H. Op.cit. p.718
} 
During the late 1990s and early $21^{\text {st }}$ century, and under a Labour Government, there has also been a huge increase in the number of Government databases, as well as an increase in the amount of information stored in these databases. These have ranged from databases to determine eligibility for services to those designed for welfare reasons. The National Identity Register (linked to the National Identity Card - due to be issued from 2012) was established by the Identity Cards Act 2006, and it is planned that it will contain information on each British citizen including biometric information. Of this development, the Information Commissioner stated:

My anxiety is that we don't walk into a surveillance society. ${ }^{79}$

The National DNA database was set up in 1995 and now holds profiles of over 4 million people. ${ }^{80}$ DNA samples are taken from crime scenes and from individuals in police custody, the profiles of which are held on the database. ${ }^{81} 5.2 \%$ of the population of Britain are on the database, making it the largest of any country in the world. ${ }^{82}$ ContactPoint is a planned national database, which will hold details of all children under 18 years old in the UK. This database was created under the Children Act 2004, an amendment to the 1989 Act, largely in response to the Victoria Climbié inquiry. ${ }^{83}$ The purpose of the database is to allow the sharing of information between children's service providers. $^{84}$ The NHS National Programme for IT is also a planned initiative, this time from the Department of health, to bring all NHS patients records under one central electronic database.

Political campaigners have also been subject to surveillance, with their details stored on the database Crimint, which is used by the police to catalogue criminal

\footnotetext{
${ }^{79}$ The Times 16 August 2004 'Beware rise of Big Brother state, warns watchdog'

${ }^{80}$ National DNA Database Annual Report 2005-06

http://www.homeoffice.gov.uk/documents/DNA-report2005-06.pdf?view=Binary

${ }^{81}$ Ibid.

${ }^{82}$ Ibid.

${ }^{83}$ This inquiry was set up to investigate the death of 8 year old Victoria Climbié, who was abused and died from her injuries inflicted by her great-aunt and her great-aunt's boyfriend. A number of people were in contact with her prior to her death, including the police, social workers and doctors.

${ }^{84}$ http://www.everychildmatters.gov.uk/deliveringservices/contactpoint/about/
} 
intelligence. The information collected, which includes names and political meetings and/or demonstrations attended, is kept for up to seven years. Furthermore, photographs and video surveillance footage of campaigners (taken covertly) is also stored on the database. ${ }^{85}$

The Government is currently (2009) planning a national database of travel, which will hold the records of all journeys made in and out of the UK. These details will be kept on the database for 10 years. Of this planned database, Chris Grayling, the Shadow Home Secretary, stated:

The government seems to be building databases to track more and more of our lives. The justification is always about security or personal protection. But the truth is that we have a government that just can't be trusted over these highly sensitive issues. We must not allow ourselves to become a Big Brother society. ${ }^{86}$

In response, the Minister of State for borders and immigration, Phil Woolas, was quoted as saying:

Our hi-tech electronic borders system will allow us to count all passengers in and out of the UK and [it] targets those who aren't willing to play by our rules. Already e-Borders has screened over 75 million passengers against immigration, customs and police watchlists, leading to over 2,700 arrests for crimes such as murder, rape and assault. $^{87}$

Targeting crime has also played an important role in terms of policing. In 1998 the Crime and Disorder Act had been created which, Newburn states:

Placed a statutory duty on chief police officers and local authorities, in co-operation with police authorities, probation committees and

\footnotetext{
${ }^{85}$ The Guardian 7 March 2009 'Revealed: police databank on thousands of protestors’ p.1

${ }^{86}$ BBC News 8 February 2009 'Government plans travel database'

${ }^{87}$ Ibid.
} 
health authorities, to formulate and implement a 'strategy for the reduction of crime and disorder in the area, including undertaking and publishing an 'audit' of levels and patterns of crime locally'. The language of the late 1990s was dominated by talk of 'partnership', of multi-agency working and of joint responsibilities, and it was in the area of community safety that this was perhaps most visibly seen. ${ }^{88}$

This focus on partnership and communities has continued in the early part of the $21^{\text {st }}$ century. Within their 2004 White paper 'Building Communities, Beating Crime', the Home Office emphasised good police-public relations ('a new relationship between the police and the public - trust and confidence') as an essential part of policing practice. ${ }^{89}$

Anti-terrorism work has become a major part of the police role during the early part of the $21^{\text {st }}$ century, since the 11 September 2001 attacks in the United States, the Bali night club bombings in 2002, the Madrid Bombings in 2004 and the London Underground bombings in 2005. ${ }^{90}$ Although the police in Britain have had to deal with terrorism previously (such as the IRA from 1969 to 1999), the government response to recent attacks has made it a requirement of the police to plan and train for the possibility of terrorist attacks, including chemical and biological agents. ${ }^{91}$ Of police training for terrorist attacks, Edwards states that it may only be 'extremely expensive window-dressing to persuade the public that police are doing something to counter the fear of terrorist attacks’. ${ }^{92}$

The early part of the $21^{\text {st }}$ century has also seen further advances in computerisation, digital technologies, and the Internet, leading to changes in the workplace, consumption, and everyday interaction with others. The Internet has also allowed an increase in public participation in decisions on science and technology, in terms of online consultations, citizen participation exercises, and

\footnotetext{
${ }^{88}$ Newburn, T. 'Policing since 1945' in Newburn, T. (ed.) (2005) Handbook of Policing Willan Publishing Ltd. pp.84-105 (p.87)

${ }^{89}$ Home Office (2004) 'Building Communities, Beating Crime - A better police service for the $21^{\text {st }}$ century’ HMSO; London

${ }^{90}$ Edwards, C. J. (2005) ( $2^{\text {nd }}$ ed.) Changing Policing Theories for $21^{\text {st }}$ Century Societies

Federation; Annandale p.283

${ }^{91}$ Ibid. p.285

${ }^{92}$ Ibid. p.292
} 
other forms of E-democracy. ${ }^{93}$ Although the idea of public participation is not new (having evolved during the 1960s and 1970s), earlier forms were restricted to certain areas of society on the whole. The current trend of participation is far more widespread and inclusionary. ${ }^{94}$ However, this cannot be said of all technologies, and I will show later in my thesis that participation in policymaking on CCTV has been limited in the UK.

\subsection{Conclusion}

In this chapter I have provided a short history of Britain in the $20^{\text {th }}$ and early $21^{\text {st }}$ centuries, focusing particularly on changes in politics, society, information and communication technologies, surveillance, and policing. I have also introduced the changing role of the public in terms of participation in policy-making on science and technology, and the changing nature of the relationship between science, technology, and society, which has major implications for the rest of this thesis.

In the context of CCTV, the history of the police force, particularly with reference to technological developments, is important. In this chapter I have given an overview of developments and changes in policing during the $20^{\text {th }}$ and early $21^{\text {st }}$ centuries, with a particular emphasis on technological aspects of policing. Since the end of World War Two, there has been extensive change in terms of British policing. This has included three Royal commissions, set up to debate various aspects of policing, as well as a number of other inquiries on the reform of the police. There has also been an enormous amount of legislation regarding policing, new technologies implemented and utilised, and an ongoing debate concerning the role of the police. ${ }^{95}$ The responsibility for crime prevention is now shouldered by numerous institutions, through partnership working. A part of this sharing of responsibility also seems to have been the introduction of

\footnotetext{
${ }^{93}$ Chopyak, J. and Levesque, P. (2002) 'Public Participation in Science and Technology Decision Making: trends for the future’ Technology in Society 24(1-2) pp.155-166

${ }^{94}$ Ibid. p.158

${ }^{95}$ Newburn, T. 'Policing since 1945' in Newburn, T. (ed.) (2005) Handbook of Policing Willan Publishing Ltd. pp.84-105 (pp.84-85)
} 
technologies, such as CCTV. In this sense, the technology is heralded as another pair of eyes, and another policeman on the beat.

Policing became tantamount to crime prevention in the latter part of the $19^{\text {th }}$ century, and I have shown in this chapter how this changed during the $20^{\text {th }}$ century, with other duties such as traffic control taking the police away from this role of crime prevention. I will show in chapter 6 that this was one of the reasons CCTV was first implemented - for traffic management purposes. I have also described the introduction of new technologies and societal changes occurring in the 1960s; a withdrawal of society and decrease in on the beat policing. The detrimental effect on police-community relations and an increased focus on 'crime reaction' rather than prevention, coupled with this decrease in on the beat policing meant that CCTV could fit into the gap left by the policeman on the street. During the 1980s, the idea that the police could not tackle crime alone meant that there was another place for CCTV as a tool for crime prevention. In light of further changes in information technology, technological advances, and a push for the police to 'fight crime', alongside a lack of confidence on the part of the public and rising crime, it can easily be seen where CCTV fits in as a technological solution to social problems. However, it is not enough to suggest that the technology was implemented for this reason alone. A more detailed look at the political climate at the time, and the social and economic reasons for its introduction must also be considered in order to develop a more sophisticated analysis of the reasons for its introduction than are currently available. I develop a history of CCTV, taking all these things into account, in chapter 6.

I have also shown the changes that have occurred in the area of surveillance, surveillance technologies, and information and communication technologies. I have shown that the history of surveillance in this country is linked to various developments: welfare services, conscription, and travel and citizenship. The increase in surveillance and the gathering of personal information on a mass scale during the $20^{\text {th }}$ and early $21^{\text {st }}$ centuries has been picked up by commentators as heralding the beginning of an 'information age' or 'information society'. The increase in collection of personal information alongside the storage of this information by the Government has led some to believe that we have entered a 
'surveillance society'. I have looked at literature concerned with these issues in chapter 2, and will return to these issues again later in the thesis. 


\section{Chapter VI:}

\section{A History of CCTV in the UK}

\subsection{Introduction}

In this section I will undertake an analysis of the history of CCTV in terms of the social, economic, political and technological factors that have shaped its history in the UK. This will include an overview of criminal justice and crime control policies (the next section) in order to show the wider context in which CCTV (as a crime prevention technology) developed, and to attempt to show the wider policy networks and decisions that have shaped its development. I then develop an in-depth historical analysis of the rise of CCTV.

Much of the research on CCTV to date has concentrated on theoretical analysis of the technology, which, although important, does not help us fully understand how we have arrived at the present situation of surveillance in the UK. Other research looks at future uses of the technology, neglecting the history behind it. In this chapter, I will develop and outline a history of CCTV and criminal justice policy in order to answer in part the question of why the UK has become so surveilled in terms of cameras. In order to understand our present situation it is important to look at past events and the changes and developments which have led us to where we are today.

CCTV is promoted by the government as a tool of crime control (this point is discussed in greater detail in chapter 7), and can therefore be analysed in the context of criminal justice. It is for this reason that it is important to look at criminal justice policies alongside the developments in the technology and the changes in usage of CCTV. However, this does not mean to say that I believe the reasons behind its widespread use are purely political and technological, and a subsequent chapter in this thesis will look at policy specifically on CCTV in relation to the public, public opinion and acceptance, and how it is portrayed by 
the media (and has been in the past). Thereafter, I present a thorough analysis of the reasons why CCTV was introduced and subsequently used in such a widespread manner.

\subsection{Criminal justice}

In this section, I look at criminal justice in terms of an overview of past and current policy and political trends in Britain since 1945 to give a context in which to situate a history of CCTV. Prior to embarking on a sketch of criminal justice policies, it is important to mention here that there is a debate surrounding what constitutes crime control/prevention and criminal justice. Van Dijk states that crime prevention is:

The total of all policies, measures and techniques, outside the boundaries of the criminal justice system, aiming at the reduction of the various kinds of damage caused by acts defined as criminal by the state. ${ }^{1}$

However, he adds that, in reality, the distinction between prevention and justice is not always as clear cut as this definition suggests, and there is often an overlap between the two areas. ${ }^{2}$ I am not going to enter into this debate in detail (based as it is in the discipline of criminology, as well as it being unnecessary to do so for the purpose of my thesis), although it is worth mentioning that there is a difference between the two areas as it impacts on my analysis of CCTV and my overview of the history of the police. The criminal justice system in the UK is made up of the Home Office (who lead on criminal policy), the police, the courts and the prison and probation services. ${ }^{3}$ Media and policy discourse situates CCTV in the role of crime prevention, however it is in often used in practice as a tool for securing prosecution after a criminal act, and is therefore a tool of criminal justice.

\footnotetext{
${ }^{1}$ Dijk, J. J. M. van 'Crime Prevention Policy: Current State and Prospects' in Kaiser, G. and Albrecht, H. J. (eds) (1990) Crime and Criminal Policy in Europe Max-Planck-Institute p.205 ${ }^{2}$ Crawford, A. (1998) Crime Prevention and Community Safety Longman Ltd. p.11

${ }^{3}$ Criminal Justice White Paper: Justice for All (2002) HMSO; The Stationery Office p.6
} 
After the end of the Second World War there was general agreement, politically, concerning the need to rebuild the economy alongside the creation of a welfare state. This agreement centred on shared goals of increasing employment, a mixed Keynesian economy and a strengthening of social security and an improvement in education and health services. During this time crime and criminal justice matters took a back seat. ${ }^{4}$ During the 1960 s these matters began to feature in political party manifestos, due to rising crime rates, although at this time the rise in crime was still not seen as attributable to any political party. ${ }^{5}$ It was not until the 1970s that criminal justice policy featured as a major issue in general elections. ${ }^{6}$ Nonetheless, criminal justice policy did exist and needs to be looked at in order to gain an idea of the fuller picture of developments in Britain. Furthermore, Garland argues that criminal justice policy has become increasingly politicised, with changes based less on trends in crime than with the politics and culture surrounding it. Garland states:

It is clear enough that criminal conduct does not determine the kind of penal actions a society adopts. For one thing, it is not 'crime' or even criminological knowledge about crime which affects most policy decisions, but rather the ways in which 'the crime problem' is officially perceived and the political positions to which these perceptions give rise. ${ }^{7}$

This notion is an interesting one and may also be the case with CCTV. The use of CCTV is less to do with tackling crime and crime rates, and more to do with perceptions of and fear of crime. I will return to this point later in the thesis.

Downes and Morgan reiterate this point concerning the convergence of politics and criminal justice:

\footnotetext{
${ }^{4}$ Downes, D. and Morgan, R. 'No Turning Back: The Politics of Law and Order into the Millenium' in Maguire, M. et al. (2007) The Oxford Handbook of Criminology Oxford University Press; Oxford pp.201-240 (р.203)

${ }^{5}$ Ibid.

${ }^{6}$ Pierre, J. (2006) Handbook of Public Policy Sage; London p.374

${ }^{7}$ Garland, D. (1993) Punishment and Modern Society: A Study in Social Theory University of Chicago Press; Chicago p.20
} 
Compared with the contested party politics of the economy, foreign affairs, health, education, etc. those of 'law and order' are of remarkably recent origin. This absence from party political discourse seems now to be surprising .... . That law and order were relatively insulated from the realm of party politics for so long testifies perhaps to the strength of the belief that crime, like the weather, is beyond political influence; and that the operation of the law and criminal justice should be above it. ${ }^{8}$

Alongside this lack of linkage between politics, crime and criminal justice, a rehabilitative approach to the treatment of offenders can also be seen from the 1950s through to the 1970s. ${ }^{9}$ In 1948 the amended Criminal Justice Act was introduced, which abolished penal servitude (imprisonment with hard labour) and emphasised corrective training, preventative training and introduced detention centres as an alternative to the harsher borstals used previously. ${ }^{10} \mathrm{~A}$ year after this enactment, the Royal Commission on Capital Punishment (1949-1953) was set up by the then Home Secretary James Chuter Ede to discuss the possible limitation or modification of capital punishment. The Commission concluded that without overwhelming public support in favour of its abolition, the death penalty should not be abolished. ${ }^{11}$

The rehabilitative trend seen in the amended 1948 Criminal Justice Act could be seen again in the introduction of the Homicide Act in 1957, which restricted the use of the death penalty for murder. Three years later, the minimum age of imprisonment was raised from 15 to 17 under the 1961 Criminal Justice Act. Borstal training rather than imprisonment for offenders under the age of 21 was also encouraged. ${ }^{12}$ In 1965, the death penalty was abolished. The Criminal Justice Act was once again amended in 1967, abolishing preventive detention

\footnotetext{
${ }^{8}$ Downes, D. and Morgan, R. (2007) Op.cit. pp.201-202

${ }^{9}$ Blakemore, K. and Griggs, E. (2007) Social Policy: An introduction Open University Press; Maidenhead p.63

${ }^{10}$ Criminal Justice Act 1948

http://www.opsi.gov.uk/RevisedStatutes/Acts/ukpga/1948/cukpga_19480058_en_1

${ }^{11}$ Royal Commission on Capital Punishment 1949-53 (1965) HMSO; London

${ }^{12}$ Davies, M. et al. (2005) ( $3^{\text {rd }}$ ed.) Criminal Justice: An introduction to the criminal justice system in England and Wales Longman; Harlow and London p.xxviii
} 
(imprisonment without justification) and corporal punishment (the use of physical force to discipline). ${ }^{13}$

During the 1970s, the Conservatives began to make 'law and order' matters a political issue, implying that the Labour party was responsible for the rise in crime and arguing in their Conservative Party Manifesto in 1970 that 'the Labour government cannot entirely shrug off responsibility for the current situation'. ${ }^{14}$ The Conservatives began arguing that Labour needed to do more to tackle rising crime rates, placing themselves in the role of what Dunbar and Langdon describe as the 'traditional upholder of equality under the law, in contrast to the Labour party, which was implied to be selective in its view of the law' for the remainder of the decade. ${ }^{15}$ The 1979 general election saw the first major post-war difference in Conservative and Labour manifestos on crime issues, as Labour focused on 'dealing with crime through its social and economic programme for tackling inequality, poverty and deprivation' and the Conservatives 'raised the profile of law and order to rank as one of the party's five major tasks'. ${ }^{16}$

Alongside this issue of responsibility for crime into the political realm, Garland argues that there has been a break with what he terms 'penal welfarism' since the end of the $1970 \mathrm{~s},{ }^{17}$ with (amongst others) the:

Decline of the rehabilitative ideal ... the re-emergence of punitive sanctions ... the return of the victim ... the expanding infrastructure of crime prevention and community safety. ${ }^{18}$

These developments, he argues, are:

Puzzling because they appear to involve a sudden and startling reversal of the settled historical pattern .... . The re-appearance in

\footnotetext{
${ }^{13}$ Ibid.

${ }^{14}$ Downes, D. and Morgan, R. (2007) Op.cit. p.203

${ }^{15}$ Dunbar, I. and Langdon, A. (1998) Tough Justice: Sentencing and Penal Policies in the 1990s Blackstone Press Ltd; London p.99

${ }^{16}$ Ibid. p.100

${ }^{17}$ Garland, D. (2001) The Culture of Control: Crime and Social Order in Contemporary Society Oxford University Press; Oxford p.3

${ }^{18}$ Ibid. p.3
} 
official policy of punitive sentiments and expressive gestures that appear oddly archaic and downright anti-modern tend to confound that standard social theories of punishment and its historical development. ${ }^{19}$

This view appears to be the consensus in the literature on criminal justice in Britain. The argument stands that UK policy on crime prevention and criminal justice was severed during the last few decades by a reversal of what had become traditional methods of dealing with crime, with restorative and reformative policies taking a central role. ${ }^{20}$ More recently, criminal justice has centred on punitive policies and punishments. ${ }^{21}$

This does seem to be the case in terms of 1980s and early 1990s policy on criminal justice. The 1982 Criminal Justice Act reduced the timeframe of eligibility for parole from 12 to 6 months, as well as replacing borstal training with youth custody. ${ }^{22}$ The 1991 Criminal Justice Act remained in line with the previous stance on sentencing and punishment, outlining a strategy based on parole, rehabilitation, community sentences and alternatives to incarceration. ${ }^{23}$ However, a couple of years later, Michael Howard (the newly appointed Home Secretary) announced during the 1993 Conservative Party conference that 'prison works'; outlining a new strategy based on rights for victims, loss of rights for criminals, new powers of arrest for the police, and effectively abolishing the right to silence. ${ }^{24}$ Of the 27 measures outlined by Howard, 18 were included in the amended 1994 Criminal Justice Act. ${ }^{25}$

\footnotetext{
${ }^{19}$ Ibid.

${ }^{20}$ For further reading on the development of these methods see Rodman, B. (1968) 'Bentham and the Paradox of Penal Reform' Journal of the History of Ideas 29/2 pp.197-210

${ }^{21}$ Garland, D. (1996) 'The Limits of the Sovereign State: Strategies of crime control in contemporary society’ The British Journal of Criminology 36/4 pp. 445-471 (p.445)

${ }^{22}$ Davies, M. et al. (2005) Op.cit. p.xxviii

${ }^{23}$ Dunbar, I. and Langdon, A. (1998) Tough Justice: Sentencing and Penal Policies in the 1990s Blackstone Press Ltd; London p.1 and Criminal Justice Act 1991 http://www.opsi.gov.uk/Acts/acts1991/ukpga_19910053_en_1

24 The Independent 19 October 1993 'Flood of prisoners alarms Governors'

${ }^{25}$ Ferguson, I. (1994) 'Containing the Crisis: Crime and the Tories’ International Socialism Journal 62
} 
It seems then that the criminal justice situation changed fundamentally with the appointment of Michael Howard to position of Home Secretary and the introduction of a far more repressive criminal justice policy. ${ }^{26}$ At this time there was also a change in the opposition party's view of crime and criminal justice. A year before the Conservative election win of 1992, Tony Blair (as leader of the Labour party and at the 1992 Labour party conference) had stated:

When young men and women seek but do not find any reflection of their hopes in the society around them, when the Tories create a creed of acquisition and place it alongside a culture without opportunity ... [when] people feel they have no chance to improve and nothing to strive for ... [then] in the soil of alienation, crime will take root. ${ }^{27}$

A year later and as Shadow Home Secretary, Blair said:

There is no excuse for crime. None. ${ }^{28}$

A few years later, during the 1997 general election, the main promise New Labour made to the electorate was one based on crime control. ${ }^{29}$ It is interesting that at this point both parties were taking such a hard line on crime, particularly as Labour had traditionally looked to the underlying causes of crime (such as social factors). The White Paper 'No More Excuses', published in 1997, set out a strategy for the improvement of the youth justice system in combating youth offending. Jack Straw (then Home Secretary) stated in the White Paper that:

An excuse culture has developed within the youth justice system. It excuses itself for its inefficiency, and too often excuses the young offenders before it, implying that they cannot help their behaviour because of their social circumstances. Rarely are they confronted with their behaviour and helped to take more personal responsibility for

\footnotetext{
${ }^{26}$ Norris, C. and Armstrong, G. (1998) The Maximum Surveillance Society: the rise of CCTV p.34

${ }^{27}$ Cohen, N. 16 December 2002 'How Blair put 30,000 more in jail’ New Statesman

${ }^{28}$ Ibid.

${ }^{29}$ Hoyle, C. and Rose, D. (2001) 'Labour, Law and Order’ Police Quarterly (72/1) pp.76-85 (p.76)
} 
their actions. The system allows them to go on wrecking their own lives as well as disrupting their families and communities. This White Paper seeks to draw a line under the past and sets out a new approach to tackling youth crime. It begins the root and branch reform of the youth justice system that the Government promised the public before the Election. It will deliver our Manifesto pledge to halve the time it takes to get persistent young offenders from arrest to sentencing. All those working in the youth justice system must have a principal aim to prevent offending. ${ }^{30}$

A year later, the 1998 Crime and Disorder Act introduced Anti-Social Behaviour Orders. It also gave greater responsibility to local authorities to develop strategies for dealing with crime, in accordance with the police and other local criminal justice authorities. ${ }^{31}$ From the early 90s, there has been an emphasis on crime prevention networks involving state and non-state actors. ${ }^{32}$ Garland argues:

The intended result is an enhanced network of more or less directed, more or less informal crime control, complementing and extending the formal controls of the criminal justice state ... . The key phrases of the new strategy are terms such as 'partnership', 'public/private alliance, 'inter-agency co-operation, 'the multi-agency approach', 'activating communities', creating 'active citizens'. ${ }^{33}$

This does seem to be the case in terms of recent policy on CCTV in terms of a partnership approach to policy. For instance, the 1996 White Paper 'Protecting the Public' emphasises a 'co-ordinated approach to tackling crime' ${ }^{34}$ However, as will be discussed further in chapter 7 the public is often portrayed as a 'passive public' rather than an 'active' one. This is interesting as there has not been any work on examining the relationship between the rise of participatory democracy

\footnotetext{
${ }^{30}$ Home Office (1997) No More Excuses: A new approach to tackling youth crime in England and Wales HMSO; London

${ }^{31}$ Crime and Disorder Act 1998 http://www.opsi.gov.uk/acts/acts1998/ukpga_19980037_en_1

${ }^{32}$ Garland, D. (2001) Op.cit. p.125

${ }^{33}$ Ibid.

${ }^{34}$ Home Office Leaflet (1997) 'Protecting the Public: The Government's Strategy on Crime in England and Wales'
} 
and representations of the public in policy on CCTV. Work on the public understanding of science has moved from the 'deficit model' (described in the literature review) to advocating an active and involved public in decisions on science and technology. Policy on CCTV focuses strongly on the need to protect what they deem to be a 'passive' public (this point is returned to in chapter 7).

Looked at in a broader context, this partnership approach seems to be a general trend of crime prevention in recent years, including using partners who are not in the traditional criminal justice realm. ${ }^{35}$ Although historically, crime prevention was carried out by a range of people, more recently it was seen as being the main function of the police. ${ }^{36}$ However, crime prevention is not just carried out by the police, but involves communities, local authorities, technologies, architecture, urban planning and so on.

The 2001 White Paper - 'Policing a New Century' - emphasised, amongst other things; 'Better partnership working' ${ }^{37}$ A year later, the 2002 Criminal Justice White Paper - 'Justice for All' - once again put more emphasis on the victim, as well as pushing for increased conviction rates, ${ }^{38}$ stating 'This White Paper aims to rebalance the system in favour of victims, witnesses and communities'. ${ }^{39}$ The previous year, the White Paper 'Criminal Justice: The Way Ahead' had already proposed; 'putting the needs of victims more at the centre of the CJS [Criminal Justice System]'.40

Also in 2001, the Anti-terrorism, Crime and Security Act was formally introduced, two months after the terrorist attacks in New York. ${ }^{41}$ The Act allowed government departments to collect and share information on terrorist activities, and enhanced police powers to deal with those in custody unwilling to share their

\footnotetext{
${ }^{35}$ Crawford, A. (1998) Crime Prevention and Community Safety Longman; Harlow p.11

${ }^{36}$ This point is discussed in greater detail in my analysis of the police

${ }^{37}$ Home office (2001) Policing a New Century: A Blueprint for Reform HMSO; The Stationery Office p.9

${ }^{38}$ Home Office (2002) Criminal Justice White Paper: Justice for All HMSO; London

${ }^{39}$ Ibid. p. 4

${ }^{40}$ Home Office (2001) Criminal Justice: The Way Ahead HMSO; The Stationery Office p.10

${ }^{41}$ The terrorist attacks in New York took place on $11^{\text {th }}$ September 2001. They were a series of coordinated suicide attacks by al-Qaeda (a Sunni Islamist terrorist group) on a number of buildings in the United States.
} 
identity. ${ }^{42}$ The 2001 Act was replaced by the 2005 Prevention of Terrorism Act, allowing the Home Secretary the right to apply a control order (with the effect of restricting an individual's liberty) on any individual suspected to be involved with terrorism.

In this section I have provided an overview of criminal justice in the UK since the end of the Second World War. From the end of the Second World War until the 1970s, rehabilitation and treatment were high on the agenda. At this time, responsibility for crime was moved onto the political agenda by a Conservative government keen to place the blame for rising crime rates on the Labour government. From a period of political consensus regarding crime and criminal justice, sprang a divergence of policies and promises, with the Conservatives promising 'law and order' and Labour intent on tackling social reasons behind crime. This departure from consensus remained during the 1980s, although rehabilitation, in terms of penal punishment, remained the order of the day. The start of the early 1990s witnessed change with both parties taking a hard line view and stance on crime and criminal justice matters. From this time, a co-ordinated network approach to crime prevention began, with the responsibility for crime prevention falling under the remit of a number of organisations and institutions (this was also shown in chapter 5 with the history of policing at this time). In the next section I will detail the history of CCTV since the 1950s; the social, economic, political and technological reasons for its inception and usage, finally situating this in an analysis of CCTV and criminal justice in the UK.

\subsection{History of CCTV}

\subsubsection{Early uses}

Goold, who has studied public space CCTV, suggests that it is necessary to look back to the early 1990s in order to explain the enthusiastic uptake of CCTV in the UK and that:

\footnotetext{
${ }^{42}$ Davies, M. et al. (2005) ( $3^{\text {rd }}$ ed.) Criminal Justice: An introduction to the criminal justice system in England and Wales Longman; Harlow and London p.xxviii
} 
Viewed in this way, the rise of CCTV in Britain begins to look less like an accident and more like the inevitable consequence of a gradual but significant shift in thinking about crime and issues relating to criminal justice. ${ }^{43}$

I believe there is also scope for looking at the uptake of CCTV in Britain during the 1980s, at the same time as tracing the politics and decisions made. I also take a further step back, tracing the history of CCTV from the 1950s, in order to chart the development of the technology from what I will show to have been a tool for the education, transport and medical sectors, to one of crime prevention and control. The early uses of CCTV have been neglected in the literature to date. I look at what the technology was originally used for, and analyse when it turned into a technology for surveillance, situating this analysis in an overview of the social, political and economic climate of the time.

In an international context, other European countries also faced problems of rising crime, recession and social order problems; none, however, took up CCTV as a solution to these problems as enthusiastically as the UK and with as little public opposition and legislation standing in its path. ${ }^{44}$ It is therefore fair to deduce that the UK and its specific combination of social, economic and political factors have led to the flourishing of CCTV and its applications. An analysis of the uptake of CCTV internationally is undertaken in chapter 9.

One interpretation suggests that the history of CCTV starts from the use of photographs for crime control purposes. ${ }^{45} \mathrm{I}$ agree that CCTV is partly an extension of photographic surveillance; however, in outlining the history of CCTV in this chapter, I will look at the use of moving images and closed-circuit cameras rather than photographs. I have discussed photographs, as a surveillance method, during my analysis of the history of surveillance in chapter 5 .

\footnotetext{
${ }^{43}$ Goold, B. (2003) CCTV and Policing Oxford University Press; Oxford p.27

${ }^{44}$ Goold, B. Op.cit. pp.20-24. Hempel, L. and Töpfer, E. (2002) 'Inception Report' UrbanEye RTD-Project pp.4-9 http://www.urbaneye.net/results/ue_wp1.pdf

${ }^{45}$ Norris, C. and Armstrong, G. (1999) The Maximum Surveillance Society: The Rise of CCTV. Berg; Oxford. P.13
} 
I did a search in The Times, Daily Mirror and Daily Express newspaper archives and I found reports of CCTV being used during the post-war period for a variety of purposes, which do not seem to be acknowledged in the current literature. ${ }^{46} \mathrm{I}$ chose these newspapers due to the size of their digital archives, so that I could do a keyword search carried out across a number of years. Further, The Times leans to the right politically and is a broadsheet newspaper. The Daily Express is a midmarket tabloid paper, also leaning to the right politically, and The Daily Mirror is a mass-market tabloid, left-wing and pro-Labour. This selection of newspapers therefore covers the political spectrum, as well as including one of each of the variety of newspaper types in the UK. The first mention of the technology (in terms of the UK) is in an article in The Times detailing the transmission of an inauguration ceremony of a factory of the British Oxygen Company through a closed-circuit television link between London and South Wales in $1956 .{ }^{47}$ In November of the same year, CCTV is mentioned as relaying a ceremony with Princess Margaret in attendance at North Staffordshire University College, into adjoining buildings from the conference hall. ${ }^{48}$ This use of closed-circuit television as a point-to-point transmission technology occurs numerous times during 1956 and 1957, in a variety of contexts such as racing courses, boat clubs and auction houses, thus expanding the area within which spectators can witness significant events in real time. ${ }^{49}$

In January 1958, closed-circuit television was used by the Labour Party to test how they appeared on screen and to 'improve the quality of their political broadcasts', a form of CCTV for training purposes..$^{50}$ The same development is reported by the Daily Mirror, however they also describe CCTV being used by the Conservative Party for the last eighteen months. They describe CCTV used in this context as a 'vital force in politics' adding that 'five minutes on tv is worth

\footnotetext{
${ }^{46}$ This search involved looking for the keywords 'closed-circuit television' and 'CCTV' in The Times, Daily Mirror, and Daily Express newspaper archives.

${ }^{47}$ The Times 2 August 1956 'Large-Scale Oxygen Plant Opened’ p.5

${ }^{48}$ The Times 21 November 1956 'Princess Margaret at North Staffs College’ p.12

49 The Times 31 December 1956 'Innovations at Manchester’ p.2, The Times 20 February 1957 'No real clash of interest’ p.3, The Times 11 July 1957 ‘ $£ 26,520$ paid at Sotheby’s for modern masters' p.10

${ }^{50}$ The Times 23 January 1958 ‘Labour’s Own Television’ p.7
} 
more to the politicians than five years of speeches in draughty halls'. ${ }^{51}$ Throughout 1958, CCTV was reported as being increasingly used in the business and finance industries, to transmit information (such as from the Stock Exchange) to television receivers in offices, therefore using CCTV to send information. ${ }^{52}$ The technology is reported as being very expensive and it is for this reason that it was not put to greater use throughout the City of London. CCTV is also used during the same year to transmit on screen coach departures and arrivals to an air terminal in London. ${ }^{53}$ A few months later, in August 1958, closed-circuit television was installed in a church in order to transmit services to a hall for any overflow of congregation. ${ }^{54}$ In November 1958, the Daily Mirror report that CCTV has been used in the United States to detect shoplifters. However, the article reports this development as a failure as 'customers crowd round the cameras and wave wildly, thinking they are being televised by a national network. Result: Chaos in the store and a lot of indignant shoppers when they discover that no giveaway prizes are forthcoming. Management are now planning to hide the cameras'. ${ }^{55}$

In March 1959, a closed-circuit television system was installed at King's Cross station in order to transmit messages from the signal box to the public (by a member of staff receiving the transmission of information from the signal box, writing the information received on a board in front of the transmitting unit). This development is cited as 'the first time closed-circuit television has been used for this purpose'. ${ }^{56}$ Another article suggests that 'something similar is already used for relaying information on an American Air Force station in Britain, at a stockbroker's office and on a South African racecourse, but British Railways are the first railway undertaking to use it' ${ }^{57}$ At the end of the year, the Daily Express report a customer viewing his banking transactions via closed-circuit television. ${ }^{58}$

\footnotetext{
${ }^{51}$ Daily Mirror 23 January 1958 'Votes and Viewers' p.2

${ }^{52}$ The Times 16 May 1958 'Growing use of television in the City’ p.17, The Times $3{ }^{\text {rd }}$ November 1958 'Private television for share prices’ p.5

${ }^{53}$ The Times 26 May 1958 'Peaceful days at air terminal' p.4

${ }^{54}$ The Times 12 August 1958 'City temple restored' p.3

${ }^{55}$ Daily Mirror 16 November 1958 'Just look at me - on TV' p.14

${ }^{56}$ The Times 6 March 1959 'Television experiment at King's Cross’ p.10

${ }^{57}$ The Times 12 March 1959 'Television from the signal box' p.8

${ }^{58}$ Daily Express 4 December 1959 'First customer of a new era' p.15
} 
A number of articles during 1958 and 1959 report CCTV being used for educational purposes, in the medical sector. One article details an operation being filmed and transmitted to a medical conference in Liverpool (and in colour, which is a new development) ${ }^{59}$. Another article reports on the installation of a permanent closed-circuit television installation in Birmingham University Faculty of Medicine to transmit images from an operating theatre in a teaching hospital, to a lecture theatre in the university, to allow students to watch surgery demonstrations. ${ }^{60}$ The educational benefits of using CCTV in this way were praised in another article as allowing 'more realistic teaching of large groups of students' ${ }^{61}$ In these examples it can be seen that there is a mass aspect to the appeal and driving force of CCTV, even in education.

Closed-circuit television was also used from 1956 for the purpose of improving safety in a number of workplaces and for a number of jobs. It is reported that it was used by the nuclear industry to look for any defects within reactors. ${ }^{62}$ Another article mentions a 'mechanical eye' used to aid in the construction of buildings (to allow the assessment of the state of the earth within holes drilled without physically sending an engineer down). ${ }^{63}$

Two articles from 1959 mention the use of closed-circuit television for traffic control and monitoring purposes. ${ }^{64}$ This use of CCTV for road traffic control is described as occurring for the first time, anywhere in the world, in Durham in 1959. ${ }^{65}$ In 1959 an article appeared detailing the intention to install closed-circuit television onto public transport vehicles as a 'safety device'. The technology is described as an 'extra eye for the driver'. Although this article refers to the enhancement of passenger safety, the connotation of surveillance is also apparent, due to the 'extra eye' allowing the driver to surveille the passengers. ${ }^{66}$

\footnotetext{
${ }^{59}$ The Times 30 October 1958 'News in Brief - Operation on Television' p.6

${ }^{60}$ The Times 3 December 1959 'Surgery to be televised for students' p.6

${ }^{61}$ The Times 16 October 1959 'Middlesex Hospital prize giving’ p.6

62 The Times 17 October 1956 'Industrial television at Calder Hall’ p.ix, The Times 13 August

'Safety television for Harwell' p.4

${ }^{63}$ The Times 3 October 1957 'New giant building rising on the South Bank' p.5

${ }^{64}$ The Times 30 June 1959 'Plan to increase public garage accommodation’ p.14, The Times 16

November 1959 'Television used in traffic control' p.12

${ }^{65}$ Emmerson, A. (July 2000) 'Behind Big Brother’ Electronics World p.523

${ }^{66}$ The Times 18 June 1957 'Television on the upper deck' p.4
} 
Although the two articles mentioned previously detail the first use of CCTV for road traffic control as 1959, archival research using the Association of Chief Police Officers (ACPO) files from the 1950s has revealed that experiments with cameras for traffic management were conducted in August 1956. These experiments took place in Durham. ${ }^{67}$ During May 1957, the Lancashire Constabulary gave a demonstration of the uses of CCTV for traffic control and management, by installing cameras onto four main roads and allowing participants to view the images taken. This demonstration was described as the largest of its kind and was in partnership with a number of radio and television manufacturers. ${ }^{68}$ The ACPO files also detail the approval by the Minister of Transport for a permanent installation of CCTV cameras in Durham market square. The Minister of Transport is also said to have agreed to contribute towards the cost. ${ }^{69}$ There is no further information available about whether these cameras were installed. As early as 1953, the use of CCTV was being discussed at a Central Conference of the ACPO. ${ }^{70}$

During 1959, a couple of letters from industry to the ACPO show the potential uses of CCTV as described by the manufacturers. One manufacturer describes the uses as; 'road safety, teaching crime prevention to the public, various training uses within police departments, and recording and combating dangerous driving'. Only the last potential use has a significant real-time function and not one that seems to be developed for providing evidence, but more as an exemplary function. The response from the Secretary of the ACPO states 'I am particularly interested in film making for instructional and propaganda purposes'.$^{71}$ By July 1959, there are reports of exhibitions of equipment used by various police forces. Alongside a number of crime prevention films, Sheffield police offer a 'burgot cabinet camera' ${ }^{72}$ and the Metropolitan Police exhibit 'raised control posts' on the

\footnotetext{
${ }^{67}$ Association of Chief Police Officers Police Review 11/8/56

${ }^{68}$ Association of Chief Police Officers Police Review 07/05/57

${ }^{69}$ Association of Chief Police Officers Police Review 06/07/57

${ }^{70}$ Letter from Chief Constable ACPO, Monday 20 April 1953

${ }^{71}$ Letter from Rank Precision Industries ltd, cine and photographic division, to the Secretary of ACPO 12/12/ 1958

${ }^{72}$ A CCTV camera enclosed in a wooden box
} 
Chiswick flyover (including photographs). ${ }^{73}$ However, during this time there is not a great deal of enthusiasm shown for CCTV. A letter from one electronics company to the Chief Constable of Hertfordshire Police, details the advances in the technology and the benefits this can bring. The manufacturers do not detail crime prevention as a general application, but state that (amongst other examples) 'Traffic can be controlled: fire and theft can be detected from key positions in factories and warehouse' [sic]. They add that 'Closed Circuit television is already useful in hundreds of different ways. There may well be yet another application, to solve your particular problem'. The handwritten response on the back states that 'This is just another circular to bring to notice the latest developments in television which might be of use to us. I feel a visit and demonstration is unnecessary and suggest we file'. ${ }^{74}$

In August 1965, The Times published an article detailing the planned installation of closed-circuit television by Camden Borough Council in tall blocks of flats so that 'mothers can keep watch on their children in the playgrounds below'. Parents would be able to view the playgrounds through two cameras through a standard receiver and two extra channels on their television. ${ }^{75}$ I was not able to find any information about whether the planned installation went ahead.

Williams traces the use of CCTV by the police to the 1960s, arguing that pre1980s use of CCTV by the police is a neglected area of research, referring specifically to Moran and Davies as stating the first uses of CCTV in public areas being Bournemouth in 1985 and football grounds (also in 1985) respectively. ${ }^{76}$ Williams describes the use of two CCTV cameras, lent by EMI to the Metropolitan Police, during a state visit by the Thai royal family in Trafalgar Square in 1960. He adds a second example of the use of CCTV later that year on Bonfire night. Williams describes both of these attempts as being unsuccessful

\footnotetext{
${ }^{73}$ ACPO Police Efficiency Exhibition - schedule of exhibits

${ }^{74}$ Letter from DG Ashton Davies, Sales Manager, Instrument Division, EMI Electronics Ltd, Hayes, Middx, Oct 7th 1959 to the CC, Herts 8th Oct 1959

${ }^{75}$ The Times 21 August 1965 'Television 'eye’ for mothers' p.10

${ }^{76}$ Williams, C. A. (2003) 'Police Surveillance and the Emergence of CCTV in the 1960s' in Gill, M. (ed.) CCTV Perpetuity Press; Leicester p.10. See also Moran, J. 'A brief chronology of photographic and video surveillance’ in Norris, C. et al. (eds.) (1998) Surveillance, Closed Circuit Television and Social Control Ashgate; Aldershot and Davies, S. (1996) Big Brother: Britain's Web of Surveillance and the New Technological Order Pan Books; London
} 
due to technical difficulties. ${ }^{77}$ The ACPO files detail the minutes of a conference, held in October 1960, stating that 'no special advantages [had been] gained' from using CCTV in these situations. ${ }^{78}$

In 1964, four covert cameras were tested by the police in Liverpool, who insisted that the tests were successful in cutting crime, although finally admitting, alongside the Home Office stating that there were other reasons for the apparent success of the cameras such as the publicity surrounding the venture and an increase in plain-clothed policemen, that no arrests were made due to the cameras. $^{79}$ Throughout the late 1960s CCTV was installed at a number of temporary locations, some becoming permanent. Williams states that:

The Met concluded that for demonstrations: 'the value of CCTV ... is beyond question'. In public, though, they claimed that the cameras in central London were all intended for traffic control. ${ }^{80}$

However, a Times article from October 1965 refers to CCTV being introduced for crime control purposes (as opposed to purely for traffic control purposes as Williams states). The article focuses on a prediction of record crime levels forecast for 1965 and states (with reference to Liverpool):

Last year crime in the city increased by over 13 per cent and, because of this and the fall in detection rates, a special police commando force and closed-circuit television were introduced.

A year later, another Times article clearly states that, in the face of increasing rates of crime:

\footnotetext{
${ }^{77}$ Williams, C. A. Op.cit. pp. 13-14

${ }^{78}$ Association of Chief Police Officers 'No.6 District Conference 5/10/1960' at the Open University

${ }^{79}$ Williams, C. A. Op.cit. p. 14

${ }^{80}$ Ibid. p.17
} 
New methods of crime detection and prevention, including the experimental use of closed circuit television and infra-red equipment, are reported. ${ }^{81}$

In 1968, The Times once again reports CCTV being used for crime prevention and detection purposes, with:

The first experiment in London in the use of closed circuit television to detect and prevent crime has been started in Croydon by the Metropolitan Police ... . Unknown to the local public, the Croydon experiment has been going on since December $18 \ldots$. The cameras are controlled from a small room in Croydon police station by two operators who are also in radio contact with police patrolling the area ... . The police believe the main use of the cameras will be in detecting car thieves and pickpockets .... . Asked about possible criticism that the scheme had been started without the knowledge of the public, he [Chief-superintendent J. Hall] said: 'What is the difference between being looked at by a man in plain clothes whom the public do not recognize as a policeman, and a camera they do not see?' ${ }^{82}$

Within the first two Times quotes CCTV is viewed absolutely in terms of a crime prevention tool. The first quote in particular suggests that the efficacy of CCTV will not be called into question; the crime rates have risen, therefore CCTV is introduced to combat this rise. The second, although describing the use of CCTV as experimental, already situates the technology in the bracket of crime prevention and detection, prior to its effectiveness being assessed. The third quote shows ownership of the technology as seen by the police. The public are not involved in decisions over CCTV; the cameras are described as installed for crime prevention purposes, utilised, installed, controlled, and owned, by the police.

\footnotetext{
${ }^{81}$ The Times 27 July 1966 'More crime regardless of consequences’ p.10

${ }^{82}$ The Times 4 January 1968 'TV cameras help London fight against crime’ p.2
} 
Having been established in 1967, the company Photoscan was the first to introduce CCTV to British retailers. The British Security Industry Association, a trade association for the professional security industry, was also established in 1969. ${ }^{83}$ Although the technology was now more readily available to the mass market, Norris and Armstrong argue that:

The political climate retarded its introduction. The early 1970s and early 1980s saw a fierce political confrontation between elements of the local state, particularly Labour controlled local authorities, and the police regarding accountability. ${ }^{84}$

Furthermore, they argue that there also existed a financial reason why CCTV was not more rapidly introduced:

The early 1980s saw local authorities under the financial cosh of a Conservative administration committed to reducing public expenditure and curbing, what it saw as, the excesses of predominantly Labour controlled local councils ... . Faced with having to cut back on its most basic services [the cost of installing a CCTV system] could not be justified. ${ }^{85}$

Despite this, CCTV was installed during this period (November 1975) at Clapham Common, Stockwell, Clapham North and Brixton underground stations. ${ }^{86}$ These were installed to deal with assaults on staff and to combat theft in underground stations. ${ }^{87}$ The 1970s saw the introduction of video cassette recorders using analogue technology, with the capacity to record and store recordings on tape. This technology was not very effective in low light or at

\footnotetext{
${ }^{83}$ Moran, J. 'A brief chronology of photographic and video surveillance' in Norris, C. et al. (eds.) (1998) Surveillance, Closed Circuit Television and Social Control Ashgate; Aldershot p.279

${ }^{84}$ Norris, C. and Armstrong, G. (1999) Op.cit. p.35

${ }^{85}$ Ibid.

${ }^{86}$ Mayhew, P. et al. (1979) 'Crime in Public View’ Home Office Research Study No.49. HMSO; London p.21-23

${ }^{87}$ Webb, B. and Laycock, G. (1992) 'Reducing Crime on the London Underground: An evaluation of three pilot projects’ Crime Prevention Unit Paper No. 30 HMSO; London p.11
} 
night-time. However, there were improvements in terms of the general reliability of the technology. ${ }^{88}$

Charged Coupled Device cameras were brought into use during the 1980s, allowing low light and night-time recordings. The introduction of these solid-state CCTV cameras was a significant development, replacing most of the tube type cameras by the early 1990s. ${ }^{89}$ Advances in Digital Multiplexing allowed recordings on multiple cameras, as well as new capabilities such as time-lapse. More recently (and since the late 1990s), digital technology has lowered the cost of cameras, in addition to providing greater clarity and extra capabilities such as zoom. $^{90}$

The Data Protection Act came into force during 1984, the same year that cameras were used for the purpose of crowd control during the miner's strike. ${ }^{91}$ This was not a permanent CCTV system installation, yet I argue that it signifies the beginning of a more widespread use of video surveillance. I take a closer look at the miners' strike next, before moving on to discuss the rest of the 1980s in relation to the history of CCTV. A closer look at the strike is necessary as it is a pivotal moment in the history of the technology.

\subsection{Surveillance of the miners' strike}

In this section, I provide an overview of the surveillance used during the miners' strike of 1984-85, concentrating particularly on video surveillance. For this purpose, I use historical sources and archival diary extracts in order to build up a picture of a minimally documented event in the context of surveillance. I chose to present this example due to the miners' strike being (to the best of my knowledge) the first time CCTV cameras were used for the purpose of crowd control in the UK.

\footnotetext{
${ }^{88}$ Fennelly, L. J. (2003) ( $3^{\text {rd }}$ ed.) Effective Physical Security Elsevier; London p.210

${ }^{89}$ Ibid.

${ }^{90}$ Roberts, L. P. (2004) 'The History of Video Surveillance - from VCRs to eyes in the sky' Evaluseek Publishing - http://EzineArticles.com/?expert=Lucy_P_Roberts

${ }^{91}$ Kirkby Times News Section September 2002 http://www.kirkbytimes.co.uk/news_items/cctv_sept_2002.html
} 
I will show that surveillance in this context was used for exclusionary purposes, other examples of which have been shown in the British history chapter preceding this. Not only were surveillance methods, including surveillance cameras, used for exclusionary purposes in terms of disallowing access to certain areas for the miners believed to be involved in the strike, but they were also used to target other citizens.

The miners' strike of 1984-1985 was a year-long industrial dispute involving the British coal industry. On 6 March 1984, the National Coal Board announced the closure of 20 pits with the loss of 20,000 jobs. On the 12 March, Arthur Scargill, then president of the National Union of Mineworkers (NUM) called a national strike against the pit closures, resulting in the year-long strike that followed. Deemed illegal by the Government, due to no ballot having been called prior to the strike, this allowed the police the right to sequester NUM funds and to intervene to allow those miners who did not want to strike to go to work, which in turn lead to violence on the picket lines. ${ }^{92}$ The Union was referred to by Prime Minister Thatcher as 'the enemy within', in her $19^{\text {th }}$ July 1984 speech to the 1922 Committee. She stated:

We had to fight the enemy without in the Falklands. We always have to be aware of the enemy within, which is much more difficult to fight and more dangerous to liberty. ${ }^{93}$

The miners' strike has a complicated history and there are conflicting accounts of the union. Milne argues that it showed the strength of the union, whereas Richards argues that there was internal division and conflict within the union itself, weakening working class solidarity and culminating in a 'catastrophic defeat' for the miners. ${ }^{94}$ The case for a division within the union is argued strongly by Hall who says:

\footnotetext{
${ }^{92}$ For more on the background to the strike and the illegal ballot, see: Arkell, P. and Rising, R. (2009) Unfinished Business: The miners' strike for jobs 1984-5

${ }^{93}$ BBC 'Enemies Within: Thatcher and the Unions' http://news.bbc.co.uk/1/hi/uk_politics/3067563.stm

${ }^{94}$ For more on the strength of the union, see Milne. For more on the perception of a defeat for the miners, see Richards (1996).
} 
The miners' strike certainly contained a powerful 'class' dimension. But politically, it was not ... a 'class-versus-class' showdown because, far from 'the class' being united, it was deeply divided. ${ }^{95}$

It is generally agreed, however, that the strike was a pivotal moment in Britain's history. For Richards:

The strike ... was a momentous and unprecedented event in recent British political history .... . The strike challenged the very core of Thatcherism's strategy towards the nationalized industries in particular and trade union movement in general. ${ }^{96}$

Milne echoes this and says:

By any reckoning, the miners' strike of $1984-5$ was a watershed in postwar British history. Indeed, it has had no real parallel - in size, duration and impact - anywhere in the world. The dispute pitted the most powerful and politicized trade union in the country against a hard right administration bent on class revenge and prepared to lay waste to our industrial heartlands and energy sector, regardless of cost. It convulsed Britain, turned mining areas into occupied territory, and came far closer than was understood at the time to breaking the Thatcher government's onslaught on organized labour. The strike was a defensive battle to protect livelihoods and communities that the miners could not have avoided. But it was also a challenge to the destructive profit- and market led restructuring of economic life already then in full flow. ${ }^{97}$

During the miner's strike numerous methods of surveillance were employed by the police and intelligence agencies. The Home Office had assured the

\footnotetext{
${ }^{95}$ S. Hall (1988) The Hard Road to Renewal: Thatcherism and the crisis of the left Verso; London and New York p.204

${ }^{96}$ Richards, A. J. (1996) Miners on Strike: Class solidarity and division in Britain Berg; Oxford

${ }_{97}^{\text {p. }}$ Milne, S. (2004) ( $3^{\text {rd }}$ ed.) The Enemy Within: the secret war against the miners Verso; London p.ix
} 
Association of Chief Police Officers that resources for policing the strike would not be a problem. ${ }^{98}$ Furthermore, the Home Office announced that the police had the right to photograph miners in custody without their consent, providing they did not employ force. ${ }^{99}$ However, according to reports from miners, photographs were taken without consent at roadblocks, at which time vehicle registration details were also taken. ${ }^{100}$ These vehicle registration details were then entered into the Police National Computer at Hendon, in order to keep records of cars of interest to the police. ${ }^{101}$ Miners recalled the experience:

My car has been checked when we were picketing in Leicestershire...we were outside Bagworth colliery ... we were outside picketing ... nothing was going on. I was standing there and one policeman came walking up along the side, looking at my car, my tyres, my tax and looking at my number plate, and he radioed it through on his radio. You could see him looking at my number plate and speaking straight through on his radio ... He was telling them the number of my car. Other pickets had their cars checked and all. All the pickets' cars were parked in one line and this policeman went up past them and we tackled him about it. He said 'I'm entitled to do it. I'm checking the cars'. And he checked the number and radioed them through on his radio.

On the way to Leicester our car was stopped by the police and we were threatened with arrest. They took the number of our car. ${ }^{102}$

\footnotetext{
${ }^{98}$ Marsh, I. et al. (2004) Criminal Justice: an introduction to philosophies, theories and practice Routledge; London p.145

${ }^{99}$ Armstrong, G. and Giulianotti, R. 'From another angle: police surveillance and football supporters' in Norris, C. et al. (1998) Surveillance, Closed Circuit Television and Social Control Berg; Oxford p.122

${ }^{100}$ WCCPL (Welsh Campaign for Civil and Political Liberties) and NUM (1985) Striking Back WCCPL; Cardiff p.59

${ }^{101}$ East, R. and Thomas, P. 'Road-blocks: The experience in Wales' in Fine, B. and Millar, R. (1985) Policing the Miners' Strike Lawrence \& Wishart; London p.140

${ }^{102}$ Ibid. p.60
} 
Reports of photographs at picket lines and video surveillance from miners are also numerous. The official position from David East, then Chief Constable of Wales, was as follows:

It is not the usual practice of this Constabulary to take photographs at demonstrations. However, where there is good reason to anticipate a breach of the peace or the commission of other offences, the police are justified in obtaining photographic evidence. Film is sometimes taken for the training of officers in crowd control techniques. Of course, many people, including the media, take photographs on such occasions. ${ }^{103}$

The miners involved describe the situation as follows:

At Margam there was a photographer wandering around taking our pictures. Later we saw him at the police canteen eating sandwiches and drinking tea. He was laughing and joking with an inspector as if they had known each other for years.

At Margam video cameras were outside the gates. One was put in the bedroom of a private house, another in a Range Rover and another was seen on the hard shoulder of the M4.

At Port Talbot they had a video on us. At Bagworth Colliery in Leicester on top of the canteen they had a video going around all the time, watching you all the time.

In London, on the lobby of Parliament, we saw a police helicopter. We also saw police on office blocks with cameras with telephoto lenses. ${ }^{104}$

\footnotetext{
${ }^{103}$ Ibid. p.139

${ }^{104}$ Ibid. p.139
} 
The use of video surveillance is also mentioned in a diary extract (from Iris Preston, a member of one of the mining communities) detailing the records of a 'discussion in the community’ meeting on the 2 March 1985:

The camera. This is now being used at nearly every pit and is known as 'big brother'. The miners resent it. Even some scabs - they feel it is another intrusion and restriction in their lives. They were not sure whether it recorded continuous movement in the pit area and put it on film to be used against them. The women felt it could take photos of the homes of miners near to the pit. This pit has a public path running through it from one village to another. The camera restricted people from using this path. The old people in the village expressed a little fear of it. Most of the community was disgusted by the use of this camera and felt it was not just there to protect NCB property as the complement of police was heavy and not much damage was done at this pit. ${ }^{105}$

The use of the video camera is mentioned again further in the diary, alongside comments on the general nature of policing during the strike:

There are also constant police patrols, NCB security patrols. Video cameras fitted with intensifiers for use in the dark have been installed on the winding headgear. Resentment of the police presence on the tip is voiced by the strikers everyday ... . The brutality of the riot police drafted in from Southern Counties has left deep scars on the minds of the people of this village, and an inheritance of hatred and mistrust of the local police. This hatred will take until long after the strike is over to heal - not months, but generations. ${ }^{106}$

Another diary extract, this time from a pit delegate, details the technical nature and capabilities of the video cameras used:

\footnotetext{
${ }^{105}$ Samuel, R. et al. (eds) (1986) The Enemy Within: Pit villages and the miners' strike of 1984-5 Routledge; London pp.114-115

${ }^{106} I b i d$. p..121
} 
The next report involves our meeting with Deeming and his new razor sharp deputy manager ... a man who has been sent in 'to deal with us'. This meeting took place in the one time 'Special Branch Surveillance Room' which had just been cleared of its spy cameras and snatch squad devices. Incidentally we accidentally came across this equipment earlier and its power was far greater than we had thought. From the pit its trajectory was $360^{\circ}$ in all directions (including up and down) the most chilling thing however was its magnification. From the pit it could focus on every street on Broadway, individual houses, it could pick up clear details in back gardens in Hatfield and of course Stainforth had complete coverage. The Snatch Squad raids on individuals in the pit lane were obviously co-ordinated from here, as were the police attacks up certain streets and the filth laying in waiting on Broadway. ${ }^{107}$

Fig. 6.1 Miners at Orgreave. In this photograph, taken at the time of the miners' strike, the use of video surveillance and camera equipment can be seen in the top right hand corner. ${ }^{108}$

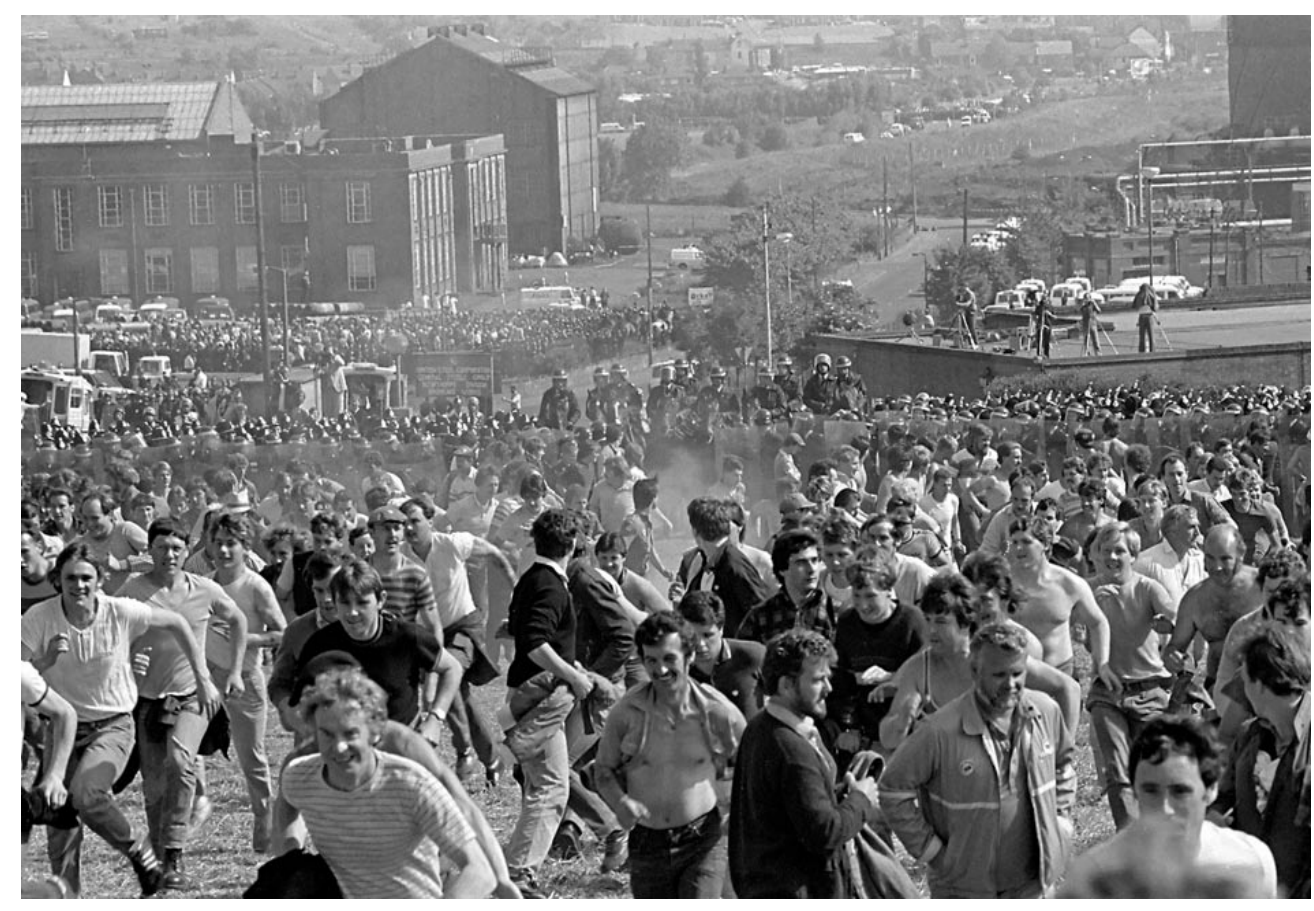

\footnotetext{
${ }^{107}$ Ibid. pp.228-229

108 This photograph was kindly provided for me to use by Martin Shakeshaft, who photographed the strike at the time
} 
The intelligence services were also allegedly involved in surveillance of the miners' strike. The methods employed involved telephone tapping, the use of agents provocateurs and at least one undercover agent in the National Union of Mineworkers. ${ }^{109}$ The security services also rented the building opposite the NUM headquarters in Sheffield for the duration of the strike. ${ }^{110}$ In terms of undercover police or agents provocateurs, extracts from interviews with miners describe the situation as follows:

It was dawn time. Three single-decker police buses, not private hire buses, were driving towards Cadley Hill pit, about three miles down the road. The first bus, with police stickers on the side and on the window, was full of uniformed policemen. The second police bus in the convoy was full of 'pickets' dressed in NCB donkey jackets with the orange flash on the back and with union stickers on their jackets. They had on flat caps. They looked more like bloody miners than miners. The third bus was full of uniformed police. Eight of us saw this convoy.

I recognised a detective, Stephen Evans from Glynneath. He was dressed like a picket. He was asking the boys if anything was about to happen and when is the next push.

I saw one 'picket' at Orgreave who I saw later on the line in Margam. He was in his police uniform the second time. ${ }^{111}$

The diary extracts therefore detail a number of surveillance methods employed during the miners' strike. These surveillance methods included: checking number plates (utilising other technologies alongside, such as radio and computer databases), photographs and video surveillance, phone tapping, and undercover police officers.

\footnotetext{
${ }^{109}$ Kelly, J. E. (1998) Rethinking Industrial Relations: Mobilization, Collectivism and Long Waves Routledge; London p.57

${ }^{110}$ Milne, S. Op.cit. p.342

${ }^{111}$ WCCPL (Welsh Campaign for Civil and Political Liberties) and NUM (1985) Striking Back WCCPL; Cardiff p.136
} 
In this section I have provided an example of surveillance carried out using a number of human and technological methods. Surveillance of the strike is interesting as it is an example of (and time of) the convergence of surveillance and criminal justice. Surveillance in this context was used for both exclusionary purposes, due to political reasons, as well as, to my knowledge, the first time for the purpose of crowd control. Video surveillance was used to restrict access to strike areas, as well as for control purposes once the miners were assembled. It was not only miners, however, who were affected. There are also reports of the alienation of residents of the mining towns, hindered from going about their everyday lives due to the appearance of surveillance cameras in the towns. Furthermore, other citizens stopped at roadblocks reported a sense of alienation due to police surveillance conducted to allow them access to mining towns.

Of particular interest to this thesis is the use of camera surveillance. In terms of its use during the miners' strike, it was installed in temporary and fixed positions within towns, as well as used at picket lines to surveille the crowds of miners. In this sense it becomes a tool for alienation. Following this section I continue to develop my history of CCTV, detailing its transition from an obvious tool of alienation and exclusion to one portrayed by the government and the media as a protective technology.

\subsection{CCTV after the miners' strike}

CCTV was also installed in the early 1980s at the Dartford Tunnel, which although initially used for purposes of catching stolen vehicles, was also used to monitor the movements of coal miners on strike travelling north from Kent. ${ }^{112}$ This use of cameras for monitoring people continued and expanded during the 1980s, and in terms of popular culture, the television programme 'Crimewatch' was aired for the first time in June 1984. The programme featured surveillance footage from CCTV cameras and photographs of suspects to the public. ${ }^{113}$

\footnotetext{
${ }^{112}$ Emmerson, A. (July 2000) 'Behind Big Brother’ Electronics World p.523

${ }^{113}$ The Independent $21^{\text {st }}$ April 2000 'Is Crimewatch best clear-up squad in Britain?'
} 
Davies notes that a year later, CCTV was installed in football grounds, which he suggests as being the beginning of the CCTV trend. ${ }^{114}$ Grants were allocated by the Football Trust to install these systems, for example Sheffield United was given £25,000 to install fifteen cameras. ${ }^{115}$ Alongside this, the police were also allocated funds to set up mobile CCTV units. ${ }^{116}$ In 1989 the Football Trust provided South Yorkshire Police with a grant of $£ 30,000$ for mobile CCTV cameras. ${ }^{117}$ Davies argues that a lack of legislative guidelines restricting how and where the cameras could be installed meant that the police found more uses for the systems. He goes on to suggest that word of mouth played a major part in CCTV being used by an increasing number of people involved in law enforcement. Davies states that it was this initial promotion and support for CCTV that explains why Britain has so much video surveillance. ${ }^{118}$

Although this may partly explain the beginning of the establishment of CCTV in Britain, there are other reasons for its rapid uptake and more widespread dissemination (in terms of the media, policy, funding environments, and so on, which will be looked at in this and other chapters) with regard to historical and later developments. Furthermore, Manwaring-White describes the use of video surveillance by the police at football matches as far back as 1977, so although 1985 may be the date of permanent installation into football grounds and a rise in funding for CCTV for this purpose, it seems it was routinely being used by the police prior to this date. ${ }^{119}$ Articles from The Times archive show that closedcircuit television was being used at football grounds even earlier than Manwaring-White suggests. The newspaper includes, as early as November 1968, a report detailing the installation of CCTV to combat hooliganism:

Closed circuit television is now working on some grounds: the police are able to scrutinize the crowd as they flood through the turnstiles. ${ }^{120}$

\footnotetext{
${ }^{114}$ Davies, S. (1996) Big Brother: Britain's Web of Surveillance and the New Technological Order Pan Books; London p.186

115 Armstrong, G. (2003) Football Hooligans Berg; Oxford p.117

${ }^{116}$ Davies, S. (1996) Op.cit. p.186

${ }^{117}$ Armstrong, G. (2003) Football Hooligans Berg Publishers p.117

${ }^{118}$ Davies, S. (1996) Op.cit. p.186

${ }^{119}$ Manwaring-White, S (1983) The Policing Revolution: Police, Technology, Democracy and Liberty in Britain The Harvester Press Limited: Sussex p.91

${ }^{120}$ The Times $26^{\text {th }}$ November 1968 'Football Hooligans' p.9
} 
In 1985, a CCTV system for monitoring public space was installed in Bournemouth. ${ }^{121}$ This development is noted by a number of commentators as being the first public space system in Britain. However, as I have shown earlier in this chapter, there are a number of earlier examples, such as; Liverpool in 1964 and Camden in 1965. Nevertheless, the reasons provided by Norris et al. for this temporary installation was the Conservative Party Conference being held in Bournemouth. At the party conference in 1984, an IRA bomb targeting Margaret Thatcher had exploded and killed 5 people (the then Prime Minister was unhurt). This installation of cameras, they argue, was a response to the IRA threat. ${ }^{122}$ Another commentator suggests that the local council in Bournemouth had concerns over street safety and that this is the reason the system was installed. ${ }^{123}$

In January 1986, Margaret Thatcher held a seminar on crime prevention resulting in a working group being established to conduct a study of how to reduce crime on the London Underground. One of the main recommendations was for further and improved installation of CCTV in stations. ${ }^{124}$

A year later, in 1987, a CCTV scheme began in King's Lynn in Norfolk, set up on an industrial estate in an attempt to control burglary rates. The second stage of this scheme was the introduction of 19 CCTV cameras to various sites in the town centres, including car parks and access to buildings. ${ }^{125}$ Five years later, thirty-two cameras were set up in car parks, and the scheme was extended out to housing estates and the city centre. ${ }^{126}$ Regarding this development, Davies argues that the rationale behind it is not readily apparent, due to King's Lynn having a relatively

\footnotetext{
${ }^{121}$ Moran, J. (1998) ‘A brief chronology of photographic and video surveillance’ Op.cit. p.280

${ }^{122}$ Norris, C. McCahill, M. And Wood, D. (2004) 'The Growth of CCTV: A global perspective on the international diffusion of video surveillance in publicly accessible space' Surveillance and Society 2(2) pp.110-135

${ }^{123}$ Ainley, R. 'Keeping an Eye on Them' in Munt, S. (2001) (ed.) Technospaces: Inside the New Media Continuum; London p.86

${ }^{124}$ Webb, B. and Laycock, G. (1992) 'Reducing Crime on the London Underground' Crime Prevention Unit: Paper No. 30 Home Office; London

${ }^{125}$ Brown, B. 'CCTV in Town Centres: Three Case Studies' Crime Detection and Prevention Series, Paper 68 Home Office; London (p.60) http://www.homeoffice.gov.uk/rds/prgpdfs/fcdps68.pdf

${ }^{126}$ Davies, S. (1996) Op.cit. p.176
} 
low crime rate (particularly in terms of a national comparison) and quotes the surveillance project director as saying:

What it comes down to is a perception of crime, rather than the crime itself ... the surveillance system has grown because of the 'feel-good' factor it creates among the public. ${ }^{127}$

This is an interesting focus for an analysis of CCTV in terms of its portrayal as a crime fighting technology as opposed to the actual results produced. I revisit this issue in chapters 7 and 8 .

The Safer Cities Programme was launched in 1988 and the organisation 'Crime Prevention' was established. ${ }^{128}$ In comparison with the rest of Europe, the introduction of CCTV and its subsequent growth during the 1980s and early 1990s in the UK met with little opposition. ${ }^{129}$ During this time there was a more general rise in levels of surveillance, including peer-to-peer surveillance. For example, the launch of 'Crime Stoppers' occurred in 1989, which encouraged people to anonymously report any details of crimes that were known to them, and the Department of Social Security (as it was known then) launched their benefit fraud hotline, which enabled people to anonymously report those they believed to be involved in benefit fraud. ${ }^{130}$

Goold argues that during the early 1990s the police in the UK were not heavily associated with CCTV systems for public space, preferring to wait for the public reaction before becoming involved. He says that the police were:

Keen to avoid being portrayed as a 'Big Brother' figure ... such fears eventually led the Association of Chief Police Officers (ACPO) to advise Chief Constables in 1993 to take a 'back-seat' role in the promotion of CCTV and to hold off committing resources to the technology until the police were better able to gauge the public

\footnotetext{
${ }^{127}$ Ibid. p.177

${ }^{128}$ Goold, B. Op.cit. p.32

${ }^{129}$ Goold, B. Op.cit. pp.20-24

${ }^{130}$ Norris, C. and Armstrong, G. (1999) Op.cit. p.30
} 
reaction to the introduction of cameras. As CCTV became increasingly popular with politicians and the media, however, police forces around the country ... [became] more actively involved in the promotion and installation of the technology. By the mid-1990s the police were leaders or active partners in CCTV schemes all over the country. ${ }^{131}$

Fay states that, during the 1990s:

The principal source of the diffusion of CCTV has been its promotion as a panacea for a wide range of social and economic problems by a variety of state agencies and commercial organizations, often working in partnership. ${ }^{132}$

This argument is supported by Goold, who argues that:

Public area CCTV [emerged] at a time when politicians and policymakers were in search of a new solution to the problem of crime and, perhaps more importantly, a way of convincing the public that they were serious about crime prevention. ${ }^{133}$

The first speed cameras in the UK were installed in West London in $1992 .{ }^{134}$ In the same year, a Home Office report on the effectiveness and acceptability of CCTV was published. ${ }^{135}$ The report showed that the public are generally unconcerned with the appearance of CCTV in public spaces. However, it also showed that fewer than half the people surveyed believed they would feel safer

\footnotetext{
${ }^{131}$ Goold, B. Op.cit. pp.19-20

${ }^{132}$ Fay, S. J. (1998) 'Tough on Crime, Tough on Civil Liberties: Some Negative Aspects of Britain's Wholesale Adoption of CCTV Surveillance During the 1990s' International Review of Law, Computers and Technology vol.12 pages 315-347 (p.316)

133 Goold, B. Op.cit. p.20

${ }^{134}$ Royal Society for the Prevention of Accidents. www.rospa.com/RoadSafety/advice/driving/speed_cameras.htm (Accessed: 8 July 2008)

${ }^{135}$ Honess, T. and Charman, E. (1992) 'Closed Circuit Television in Public Places: Its acceptability and perceived effectiveness’ Police Research Group Crime Prevention Unit Series Paper \#35
} 
following the installation of CCTV onto public streets, car parks and shopping centres. ${ }^{136}$

The murder of James Bulger in 1993 was an extremely important incident in relation to the history of CCTV. James Bulger (a two year old) was abducted in a Liverpool shopping centre in 1993 by Robert Thompson and Jon Venables (both ten years old at the time). His body was found two days later on a railway line in Bootle (a town a few miles away from Liverpool city centre). Robert Thompson and Jon Venables were charged with his murder. The CCTV images of the killers leading James away were shown on the news, and print media coverage repeatedly stated that the killers had been captured on CCTV. Although CCTV did not stop the incident occurring (it aided in identification and prosecution), following this time it was extremely difficult for anyone to oppose the technology and those that did were seen as being on the side of the killers. ${ }^{137}$

During the aftermath of the murder of James Bulger, John Major (the then British Prime Minister) announced in an interview with the Mail on Sunday that; 'Society needs to condemn a little more and understand a little less', ${ }^{138}$ and; 'My concern is to be considerate to the victim and protect the victim rather than be considerate to the criminal and forgive the criminal'. ${ }^{139}$ I revisit the media reportage of this incident (also in relation to the moral panics literature covered in chapter 2) in chapter 7.

The IRA detonated two bombs in the City of London, one in April 1992 and the other in April 1993. The first resulted in one casualty and $£ 350$ million worth of damage. ${ }^{140}$ The second (in Bishopsgate) also resulted in one casualty, forty injuries and $£ 650$ million worth of damage. ${ }^{141}$ As a result of these incidents more CCTV systems were installed within the City, roadblocks were put in place, and

\footnotetext{
136 Ibid.

${ }^{137}$ See Davies, S. (1996) Op.cit. pp.173-5 and Norris, C. and Armstrong, G. (1999) Op.cit. p.37

138 The Mail on Sunday 'Major on Criminals' 21 February 1993 p.8

139 The Mail on Sunday 'Major on Criminals' 21 February 1993 p.9

${ }^{140}$ International Herald Tribune 'City of London, an IRA Target, Starts to Relax' 1 June 1998 http://www.iht.com/articles/1998/06/01/ulster.t_0.php

${ }^{141}$ BBC 'On This Day'

http://news.bbc.co.uk/onthisday/hi/dates/stories/april/24/newsid_2523000/2523345.stm

(Accessed: 8 July 2008)
} 
there was an increase in visible policing and increased security at building entry points. This became known as the 'Ring of Steel' (July 1993). ${ }^{142}$

During the development of the 'Ring of Steel', the Chief Constable for City of London, Owen Kelly stated; 'If lives are to be saved by the use of these cameras, I cannot see that there can be any objection to them'. ${ }^{143}$ The Chairman of the Association of Chief Police Officers' committee on terrorism concurred, stating; 'There will be an increased use of video cameras in the future and what we are finding is that the pressure for them is coming from the local authorities'. ${ }^{144}$ The head of the Home Office Crime Prevention Unit stated that; 'You hear emotional pleas about Big Brother watching us but, in fact, there are very few objections from the public'. ${ }^{145}$

In September 1993, 'Camera Watch' - a scheme developed by the police to encourage more private CCTV systems to be set up in the City - was established, ${ }^{146}$ and by the end of the year CCTV systems were running in 39 UK towns and cities. ${ }^{147}$ Earlier in the year, on the back of Exeter and Birmingham City Councils disallowing two applications for CCTV systems, Davies describes:

Downing Street announced that laws would be passed prohibiting councils from blocking the installation of camera systems by making their installation exempt from the requirement to submit a planning application'. ${ }^{148}$

About this announcement, Fay suggests that:

\footnotetext{
${ }^{142}$ Coaffee, J. (2004) 'Recasting the "Ring of Steel”: Designing out Terrorism in the City of London' in Graham, S. (ed.) Cities, War and Terrorism: Towards an Urban Geopolitics Blackwell Publishing Ltd. P.278

${ }^{143}$ The Guardian 13 May 1993 'Big Brother is here'

${ }^{144}$ Ibid.

145 Ibid

${ }^{146}$ Coaffee, J. Op.cit. p.282

147 Goold, B. Op.cit. p.17

${ }^{148}$ Davies, S. (1996) Op.cit. p.187
} 
In essence, the change meant that cameras could be installed without the need for specific planning permission, thereby avoiding, in the words of one government minister, 'unnecessary red tape'. ${ }^{149}$

In 1994, the Home Office published its report: 'CCTV: Looking out for You' (which is looked at in more detail in chapter 7). On 5 July, as a 20 camera CCTV system was launched in Liverpool city centre, the junior Home Office Minister David Mclean announced:

This is a friendly eye in the sky. There is nothing sinister about it and the innocent have nothing to fear. ${ }^{150}$ It will put criminals on the run and the evidence will be clear to see. ${ }^{151}$

In October of the same year, the Home Office announced $£ 2$ million worth of funding for CCTV by way of a Challenge Competition. ${ }^{152}$ By the end of the year, the number of towns and cities with CCTV systems had risen to $79 .{ }^{153}$

By March 1995, this number had increased to 90. ${ }^{154}$ On 22 November 1995, Home Secretary Michael Howard launched a £15 million CCTV scheme competition, announcing at the same time the details of the Crime Prevention Agency set up to 'reduce the fear of crime'. ${ }^{155}$ This agency comprised the Home Office, the police and Crime Concern (a national crime reduction organisation). ${ }^{156}$ The competition was to 'encourage the expansion of CCTV', with 800 bids received. There had also already been a $£ 5$ million project six months earlier. ${ }^{157}$

\footnotetext{
${ }^{149}$ Fay, S. J. (1998) 'Tough on Crime, Tough on Civil Liberties: Some Negative Aspects of Britain's Wholesale Adoption of CCTV Surveillance During the 1990s' International Review of Law, Computers and Technology vol.12 pages 315-347 (p.317)

150 This is the same language that is used by advocates of Identity Cards

${ }^{151}$ The Times 6 July 1994 'Security cameras zoom in on crime'

152 Norris, C. and Armstrong, G. (1998) Op.cit. p.36

153 Goold, B. Op.cit. p.17

${ }^{154}$ Ibid.

155 The Guardian 23 November 1995 ’10,000 spy cameras for high streets’ p.4

156 Ibid.

${ }^{157}$ Jones, T. and Newburn, T. (1998) Private Security and Public Policing Clarendon Press; Oxford p.62
} 
CCTV was also installed for the first time in a residential area (in Newcastle) during this year. ${ }^{158}$

A further bomb in the London Docklands in February 1996 meant that security was immediately increased. ${ }^{159}$ Coaffee describes the situation from August 1994 (and the Provisional IRA ceasefire) to February 1996 as one of lessening security and even a call from one private business to disband the 'ring of steel' completely. ${ }^{160}$ Nevertheless, cameras and CCTV systems were continuously updated and improved (including a CCTV system at entry points into the City with number plate recognition capability) even with the declining IRA threat. ${ }^{161}$ Coaffee states that:

Camera technology was perhaps the single most important factor in the City of London Police’s counter-terrorist campaign. ${ }^{162}$

In March 1996, the Home Office published the White Paper 'Protecting the Public'. This report included the statement:

New technology is moving to the forefront of the fight against crime. Closed circuit television (CCTV) surveillance systems have proved very effective in preventing and detecting crime and in deterring criminals; CCTV is overwhelmingly popular with the operators, the police and the general public; Clearly CCTV works. ${ }^{163}$

It also promised $£ 45$ million additional funding for CCTV schemes and to provide 10,000 more cameras over the next three years. ${ }^{164}$ In terms of the Government's broader approach to crime prevention, the White Paper emphasised

\footnotetext{
${ }^{158}$ Moran, J. 'A brief chronology of photographic and video surveillance' in Norris, C. et al. (eds.) (1998) Surveillance, Closed Circuit Television and Social Control Ashgate; Aldershot p.283

${ }^{159}$ Coaffee, J. (2004) 'Recasting the "Ring of Steel”: Designing out Terrorism in the City of London' in Graham, S. (ed.) Cities, War and Terrorism: Towards anUrban Geopolitics Blackwell Publishing Ltd. p.286

${ }^{160}$ Ibid. p.285

${ }^{161}$ Ibid. p.285

${ }^{162}$ Ibid. p.286

${ }^{163}$ Ibid. pp.6-7

${ }^{164}$ Ibid. p.12
} 
a co-ordinated approach to reducing crime and a local and community partnership approach (including Neighbourhood Watch). ${ }^{165}$ It also stated that it will 'wage war on crime'. ${ }^{166}$ In the same year, the Scottish Office released their White Paper entitled 'Crime and Punishment' in which they wrote:

There is clear evidence that ... [CCTV] cuts crime ... The Government will foster the use of CCTV in many more communities in Scotland. ${ }^{167}$

The CCTV Challenge Competition round one results were also announced in 1996, by which time it has been estimated there were over 200 schemes in the UK. Following this, round two of the competition was for funding for the years 1996-97, round 3 for 1997-98, and round four for 1998-99. ${ }^{168}$

In October 1998, the first CCTV system with facial recognition capability was trialled in the London Borough of Newham. ${ }^{169}$ This system involved using 140 cameras to scan the faces of pedestrians and run them through a database in an attempt to match the images to those of known criminals. ${ }^{170}$ Algorithmic technology, which is carried out in real-time, is used to detect and identify human faces from images from the CCTV cameras. ${ }^{171}$

In August 2000, the Home Office published the results of an evaluation showing street lighting to be up to seven times more effective than CCTV in reducing crime. ${ }^{172}$ A year later the Home Office announced $£ 108$ million worth of funding for 300 new CCTV schemes. ${ }^{173}$ The following year, a $£ 3$ million CCTV control centre (controlling 400 cameras) was set up in Manchester's city centre. ${ }^{174}$

\footnotetext{
${ }^{165}$ Ibid. pp..8-9

${ }^{166}$ Ibid. p.54

${ }^{167}$ The Scottish Office (1996) Crime and Punishment HMSO: Edinburgh pp.13-14

${ }^{168}$ Hansard Written Answers (accessed 18/06/2008) 'Closed Circuit Television Challenge’ http://hansard.millbanksystems.com/written_answers/1996/dec/17/closed-circuit-television

${ }^{169}$ The Observer 11 October 1998 'As UK crime outstrips the US, a hidden eye is watching' p.5

${ }^{170}$ Brin, D. (1998) The Transparent Society Perseus Books; Massachusetts p.5

${ }^{171}$ Emmerson, A. (July 2000) ‘Behind Big Brother’ Electronics World p.522

${ }^{172}$ Farrington, D. P. and Welsh, B. C. (2002) 'Effects of improved street lighting on crime: a systematic review’ Home Office Research Study 251

173 The Independent 31 March 2001 '300 extra CCTV schemes planned’ p.6

${ }^{174}$ The Independent 29 June 2002 'Half CCTV schemes do not reduce crime rate’ p.7
} 
In November 2001, two months after the terrorist attacks in the United States, the Anti-terrorism, Crime and Security Act was formally introduced. ${ }^{175}$ The Act allowed government departments to collect and share information on terrorist activities, and enhanced police powers to deal with those in custody unwilling to share their identity. ${ }^{176}$ The 2001 Act was replaced by the 2005 Prevention of Terrorism Act, allowing the Home Secretary the right to apply a control order (with the effect of restricting an individual's liberty) on any individual suspected to be involved with terrorism. In 2003, the 'Ring of Steel' was extended into Holborn and Victoria Embankment. ${ }^{177}$

The Home Office published a report in 2005 outlining the results of evaluations of 14 CCTV systems. The findings showed that CCTV does not significantly reduce crime in public areas. ${ }^{178}$ On the 20 September 2005, Scotland Yard announced that CCTV filmed the 7 July bombers carrying out a 'dry run' on the London Underground just over a week before the attacks, essentially showing that CCTV in this case was ineffective in preventing a terrorist attack. ${ }^{179}$

However, in October 2007, the Home Office and Association of Chief Police Officers jointly published their National CCTV Strategy. The report stated that:

Closed circuit television plays a significant role in protecting the public and assisting the police in the investigation of crime ... CCTV in the UK enjoys significant public support. ${ }^{180}$

\footnotetext{
175 The terrorist attacks in New York took place on 11 September 2001. They were a series of coordinated suicide attacks by al-Qaeda (a Sunni Islamist terrorist group) on a number of buildings in the United States.

${ }^{176}$ Davies, M. et al. (2005) ( $3^{\text {rd }}$ ed.) Criminal Justice: An introduction to the criminal justice system in England and Wales Longman; Harlow and London p.xxviii

${ }^{177}$ BBC 'Ring of Steel Widened' 18 Dec. 2003

http://news.bbc.co.uk/1/hi/england/london/3330771.stm

(Accessed 8 July 2008)

${ }^{178}$ Gill, M. et al. (2005) ‘The impact of CCTV: fourteen case studies’ Home Office Online Report 15/05

http://www.homeoffice.gov.uk/rds/pdfs05/rdsolr1505.pdf

${ }^{179}$ The Times 21 September 2005 'CCTV shows 7/7 bombers on dummy run in June’ p.8

${ }^{180}$ Gerrard, G. et al. (2007) National CCTV Strategy HMSO; London
} 
The report goes on, however, to say CCTV has not been used to its full potential due to it being developed and operated in a 'piecemeal fashion', hence the need for a national strategy. ${ }^{181}$ The report also suggested that the location of cameras could be improved and that picture quality varied and was often poor. ${ }^{182}$

\subsection{Conclusion}

In this chapter I have outlined a history of CCTV in terms of the social, economic, political and technological developments contributing to its introduction and subsequent widespread use in the UK. I have charted the development of CCTV from a technology used for education, transport and medical sector purposes (which I mentioned was a neglected area of research), to a tool for surveillance, crime prevention and criminal justice. I have shown (using the ACPO files) that its potential as a crime prevention technology was described to the police by manufacturers as early as 1959. During this same year, CCTV was installed as an 'extra eye' on public transport vehicles. Its use as a surveillance method is shown again a few years later, in 1965 in a block of flats for reasons of surveilling the playground. During the 1960s CCTV was used by the police in public areas, although technical difficulties hindered the trials. I have shown through the ACPO archives, however, that the police at this time were beginning to see its potential as a crime preventing technology. I have described the technological developments of the 1970s, occurring alongside the introduction of cameras onto London Underground. The 1980s saw an increase in public space monitoring and the start of its use as a preventative and exclusionary technology; in the context of the miners' strike and at football grounds. I have shown that the 1990s saw a financial commitment from the government for increased CCTV, occurring alongside incidents such as the James Bulger murder, and a rise in fear of crime, which meant that the environment was ripe for increased use of the technology, if only to persuade the public that the government was tackling (perceived) rising levels of crime. More recently, the rationale for the use of

\footnotetext{
${ }^{181}$ Ibid. p.5

${ }^{182}$ Ibid. pp.15-16
} 
CCTV has centred on preventing crime and terrorism, with continued financial commitment from the UK Government for the technology.

In terms of key events the James Bulger incident was clearly a factor contributing to the rise of CCTV; a moral panic coupled with rising crime rates and increasing fear of crime by the public were certainly factors prompting an increase in budget for CCTV cameras. However, this was linked to a general redirection of criminal justice policy - CCTV, like any technology, does not develop in isolation. I showed in the criminal justice section that a hard line stance was adopted by both the Conservative and Labour parties during the 1990s in respect of crime and crime prevention. CCTV as a technology fitted into this promise of tackling crime, in terms of a technological solution to a wider societal problem. At least on the surface, both parties could announce that a something was being done. 


\section{Chapter VII:}

\section{CCTV and the Public}

\subsection{Introduction}

In this chapter I will seek to answer the research questions: How does the use of CCTV construct certain types of public and of society? Why have the public apparently accepted the deployment of surveillance technologies? What judgements have been made and by whom? What does this tell us about power structures in policy-making in society? What are the broadsheet and tabloid media saying about CCTV, and how is CCTV constructed in relation to reported crimes?

The background to my analysis will consist of looking at the promotion of CCTV by local city councils in the UK to gain an idea of how CCTV is portrayed to the public, and subsequently how the public are constructed and portrayed within this promotion. Next, I present an overview of the national marketing of CCTV by the government, also including within this section an overview of the Identity Cards (ID cards) consultation process in the UK over the last ten years. I include this section on ID cards in order to speculate on what a national consultation on CCTV in the UK might look like.

Next, I include a media analysis covering various peaks in coverage of stories centring on CCTV over the last fifteen years. I will look at how the media frame and represent CCTV to the public, and the media discourse that surrounds CCTV (I use newspapers as an indicator of press coverage). ${ }^{1}$

\footnotetext{
${ }^{1}$ For more on newspapers acting as indicators of media coverage, see Bauer, M. W. and Gaskell, G. (eds) (2000) Qualitative Researching with text, image and sound Sage Publications; London
} 


\subsection{Local government promotion of CCTV}

In terms of the method used, a keyword search was carried out on all city council websites in the UK. The search terms used were 'CCTV' and 'closed-circuit television'. A search of the crime and policing sections of each website was also conducted.

During research of the local marketing of CCTV the following four main themes emerged: a distinctive discourse from the Home Office regarding the advantages of CCTV; reduction of crime and enhanced public safety through CCTV, the public being watched/watched over and 'big brother' (with both negative and positive connotations), and the issue of civil liberties and privacy.

The London Borough Councils all emphasise CCTV as a technology that reduces crime and acts as a deterrent to criminals. It is often pronounced to be 'one of the best weapons against crime'. Public safety is also emphasised and the advantages of CCTV are strongly promoted:

'Combat crime and fear of crime' (Lewisham)²

'Crime prevention and detection...raising public confidence and feelings of safety' (Southwark) ${ }^{3}$

'Enhancing the community’s feeling of safety' (Hillingdon) ${ }^{4}$

'Increase community confidence' and 'improving quality of life' (Greenwich) $^{5}$

\footnotetext{
${ }^{2}$ www.lewisham.gov.uk (Accessed 07/10/2008)

3 www.southwark.gov.uk (Accessed 08/10/2008)

4 www.hillingdon.gov.uk (Accessed 08/10/2008)

5 www.greenwich.gov.uk (Accessed 08/10/2008)
} 
CCTV portrayed in this positive light is seen on most city council websites, often with an emphasis on participation in civil society, for example:

'To help provide a safer and more secure, user-friendly public environment in the City Centre and other areas covered by the scheme for the benefit of the whole community, including those who live, work, trade, visit and enjoy the facilities of these areas' (Peterborough $)^{6}$

'The purpose of our CCTV system is to make Cambridge a safer and more welcoming place at any time of the day or night - allowing all citizens and visitors the opportunity to participate fully and without fear in the life of the city'

(Cambridge $)^{7}$

'The main purpose of these cameras is to provide a safe public environment for the benefit of those who live, trade, visit, service and enjoy the facilities of the area covered by the CCTV scheme' (Lichfield) $^{8}$

'Closed circuit television (CCTV) is designed to take measures to prevent and detect street crime such as assault, vehicle theft, drugs offences etc. The CCTV System is a useful tool in aiding with crime prevention and ensuring that the streets of the city are a safe place' ${\text { (Lancaster })^{9}}$

'Canterbury City Council has a closed circuit television system to help provide a safer environment for everyone by: reducing the fear of crime, protecting property and deterring vandalism, assisting in the detection and prevention of crime, helping to catch and prosecute

\footnotetext{
${ }^{6}$ www.peterborough.gov.uk (Accessed 10/10/2008)

7 www.cambridge.gov.uk (Accessed 10/10/2008)

8 www.lichfield.gov.uk (Accessed 07/10/2008)

9 www.lancaster.gov.uk (Accessed 08/10/2008)
} 
those who commit crime or public order offences, assisting in the management of traffic and pedestrian flow' (Canterbury) ${ }^{10}$

Others base their marketing on quotes from the Home Office such as:

'People now feel safer when they are out and about' and 'CCTV is one of the best weapons against crime' (Barking and Dagenham) ${ }^{11}$

'People now feel safer when they're out and about' (Camden) ${ }^{12}$

'The introduction of Closed Circuit Television has been one of the best weapons in the fight against crime. It has been proved effective in both cutting crime and detecting crime and because of this people now feel safer when they're out and about' (Durham) $)^{13}$

'People now feel safer when they're out and about' (Hammersmith and Fulham $)^{14}$

'CCTV is a very effective tool for crime prevention and detection; it helps prevent the fear of crime and promotes public safety. It also has a positive impact on the local economy and the regeneration of the city' (Carlisle) $)^{15}$

Other councils use ideas of constantly being watched, or Big Brother (as a positive):

'Reassuring presence' (Kensington and Chelsea) ${ }^{16}$

'Like having an extra policeman on the street corner' (City of Westminster $)^{17}$

\footnotetext{
${ }^{10}$ www.canterbury.gov.uk (Accessed 08/10/2008)

11 www.barking-dagenham.gov.uk (Accessed 08/10/2008)

12 www.camden.gov.uk (Accessed 07/10/2008)

13 www.durham.gov.uk (Accessed 10/10/2008)

14 www.lbhf.gov.uk (Accessed 10/10/2008)

15 www.carlisle.gov.uk (Accessed 08/10/2008)

${ }_{16}$ www.rbkc.gov.uk (Accessed 08/10/2008)

17 www.westminster.gov.uk (Accessed 08/10/2008)
} 
'In safe hands. Ever felt like you're being watched? It's not surprising! Wherever you go these days, in shopping complexes, railway stations, car parks even just sitting by a fountain - you are often being watched. Closely....The Centre has fibre cable links to both the West Midlands and British Transport Police. So, the next time you're reading your paper by a fountain, be reassured about who's watching over you!' (Birmingham) ${ }^{18}$

'BIG brother is going 21st century after civic leaders in Leeds pledged to build a CCTV superhub in the city, Senior Councillors announced today that more than $£ 970,000$ will be injected into the Leedswatch CCTV system. It will replace the city's three existing and outdated analogue control centres with a single, state of the art digital CCTV supercentre. Bosses hope the ambitious new facility will not only act as a digital watchtower over the city, but the crisper pictures feeding will help police pounce on troublemakers quicker' (Leeds) ${ }^{19}$

'Smile...You're On CCTV! Stuart Stone is the City Council's Assistant Engineer with particular responsibility for parking and CCTV.

Broadminded? You bet I am, mostly because I've seen it all. By day, shoplifters, burglaries, drugs pushers, car break-ins, harassment, antisocial behaviour, rtcs (road traffic collisions), hold-ups, lost children, truants, street crime, the lot. By night, the falling-down drunks, the fights, and the kind of crazy antics people get up to when they think they're not being watched, particularly after the clubs have closed.

What they don't realise is that they are being watched. Better than that, it's being recorded right inside the police station in Castle Street' (Worcester) $^{20}$

\footnotetext{
${ }_{10}^{18}$ www.birmingham.gov.uk (Accessed 10/10/2008)

${ }_{19}$ www.leeds.gov.uk (Accessed 08/10/2008)

20 www.worcester.gov.uk (Accessed 10/10/2008)
} 
Other councils are more careful to dispel any civil liberties or privacy concerns, and others are careful not to portray CCTV as the only solution to crime:

'Arguably, Closed Circuit Television (CCTV) is one of the most powerful tools to be developed during recent years to assist with efforts to combat crime and disorder whilst enhancing community safety. Equally, it may be regarded by some as the most potent infringement of people's liberty. If users, owners and managers of such systems are to command the respect and support of the general public, the systems must not only be used with the utmost probity at all times, they must be used in a manner which stands up to scrutiny and is accountable to the very people they are aiming to protect. The Council is committed to the belief that everyone has the right to respect for his or her private and family life’ (Derby $)^{21}$

'With the increasing use of Closed Circuit Television cameras throughout City Centres and Housing Estates, strict procedures must be in place to ensure that cameras and footage are only used for the purpose stated in the Code of Practice. This will ensure that nobody's right to privacy is denied or encroached upon, whilst fulfilling the main aims of the installation, i.e.: to detect and prevent crime. All CCTV systems installed have safeguards built in to prevent cameras from looking into areas where they are not authorised to look, such as windows, gardens, conservatories etc. The cameras are all computer controlled, and the system set to prevent this type of intrusive surveillance. The Authority is committed to the rights of privacy, and ensures that all precautions are taken to ensure those rights are not infringed' (Leicester) ${ }^{22}$

'The ethos of CCTV in St Albans is that it is there for the protection of the public and not as a "Big Brother” tool spying on people'.

${ }^{21}$ www.derby.gov.uk (Accessed 08/10/2008)

22 www.leicester.gov.uk (Accessed 08/10/2008) 
However, they go on to suggest that the primary purpose of CCTV is not to combat crime, but as a tool for public health and safety:

'As an example, the priority would always be to assist with finding a missing child or direct emergency services to an elderly person who had fallen over, rather than targeting a suspected shoplifter' (St Albans) $)^{23}$

'Remember, CCTV may not be the best option for every area, and it is important to carry out a feasibility study before a CCTV project is introduced to an area' (Bristol) ${ }^{24}$

The local government promotion of video surveillance depicts a public with a fear of crime, who are offered protection by the Government through CCTV. CCTV is promoted as having a 'reassuring presence' for 'citizens' and the 'community'. CCTV is portrayed as providing absolute safety, albeit in a variety of ways. The technology is situated on its own, rather than in a socio-technical framework; it alone provides safety and reduces crime. It also raises feelings of safety and lessens fear, simply by being there. The benefits or effects are therefore twofold; crime is reduced and/or fear of crime is reduced.

The focus on citizens and the community is inclusionary for those not targeted by the cameras; the cameras are there to enhance and ensure the enjoyment of the city for the accepted members of the community, to enable participation in public life and civil society. The cameras are there to 'watch over' those citizens; 'you' or 'us'. However, for those members of society who do not abide by the rules of the community, the camera affects a different outcome - 'they are being watched'. This follows the lines of the traditional argument from advocates of surveillance technologies, that if you have done nothing wrong, you have nothing to fear.

\footnotetext{
${ }^{23}$ www.stalbans.gov.uk (Accessed 09/10/2008)

24 www.bristol.gov.uk (Accessed 09/10/2008)
} 
The Home Office discourse; 'People now feel safer when they're out and about' is repeatedly used on local government websites. Stated as fact, this quote is not backed up by evidence from public surveys or opinion polls. There is also a sense of freedom connoted in the phrase 'out and about'. Once again, safe participation in social and public life is provided by CCTV.

Having analysed how CCTV and the public are portrayed on local government websites, next I look at the consultation process in the UK on surveillance technologies and CCTV in order to establish how they are portrayed at a national level. Finding that there has not been a national consultation involving the public, I ask - where is the evidence for public support and how are the public portrayed in the policy process on CCTV? I look at past identity cards consultations in order to speculate about what a public debate and consultation on CCTV might look like.

\subsection{Consultation and public engagement}

Although there have been small-scale and local public attitude surveys funded by the Home Office, there has not yet been a national consultation open to the public on CCTV in the UK. However in 2007 there was a consultation for the 2007 National CCTV Strategy. This was described as:

A series of workshops were held to understand the current CCTV infrastructure, its use and where the main issues and problems lie from the perspective of key stakeholders and interested parties. The workshops were an opportunity for users of CCTV and stakeholders to air their experiences and views on current public space CCTV. The workshops were organised to bring similarly interested groups together as part of the consultation. These included representatives from the following stakeholder groups: Serious crime, transport, government departments, the criminal justice system, technology and town centre CCTV groups. ${ }^{25}$

\footnotetext{
${ }^{25}$ Gerrard, G. et al. (2007) National CCTV Strategy HMSO; London p.9
} 
Civil liberties representatives/groups and citizens were not asked to participate in the workshops or consultation. The consultation did not include an opportunity for debate on the relevance and need for CCTV in the UK, instead centring on how to improve the system in terms of the technology.

Recent consultations from the Home Office surrounding surveillance technologies and communications/information technologies have been:

Interception of communications in the UK consultation (1999)

Public consultation on Draft Code of Practice on Communications Data (2001)

Entitlement Cards and Identity Fraud consultation (2002)

Access to Communications Data- respecting privacy and protecting the public from crime consultation (2003)

Legislation on Identity Cards consultation (2004)

Revised Statutory Code for Acquisition and Disclosure of Communications Data consultation (2006)

National Identity Scheme: Delivery Plan 2008 (2008)

Compulsory Identity Cards for Foreign Nationals - Consultation on Code of Practice (2008)

Regarding consultations on surveillance technologies, identity cards (in one form or another), have received the most attention over recent years.

\subsubsection{The Identity Cards Scheme}

In 1995 an Identity Cards (ID cards) consultation document was published by Home Secretary Michael Howard. ${ }^{26}$ However, significant commons and public opposition meant that the proposal was abandoned. ${ }^{27}$ Following this, there have been four national consultations on Identity Cards in the UK over the last ten

\footnotetext{
${ }^{26}$ Home Office (1995) Identity Cards - A Consultation Document HMSO; London

${ }^{27}$ Privacy International (1997) 'History of ID cards in Britain' http://www.privacyinternational.org/article.shtml?cmd\%5B347\%5D=x-347-61886
} 
years. The first, entitled the 'Entitlement Cards and Identity Fraud consultation' took place in 2002.

In the aftermath of the terrorist attacks on the United States in $2001,{ }^{28}$ Prime Minister Tony Blair pushed for a review of British terrorism laws. ${ }^{29}$ Included in this review, Home Secretary David Blunkett revealed that he was seriously considering the introduction of ID cards. ${ }^{30}$ Blunkett is quoted as saying that the Government would have to consider:

How far anyone should expect to go in a democracy in being able to identify, being able to co-operate in terms of surveillance .... Those things are very difficult issues but they are ones we are going to have to address if we are actually going to protect the most basic freedom of all, which is to live in peace without fear.

In January 2002, David Blunkett announced that a consultation paper on the entitlement card (the name given to the identity card) was to be published during the summer. ${ }^{31}$ The civil liberties group Liberty responded to the proposal by arguing that the introduction of entitlement cards would be:

A very serious step .... . Not only would such a scheme be prohibitively expensive, but it would pose a real threat to civil liberties. People already have countless ways to prove their identity, whether they are using private or public services. ${ }^{32}$

In July 2002, the consultation paper 'Entitlement Cards and Identity Fraud' was launched. David Blunkett claimed that the entitlement card would help solve social problems and issues such as fraudulent activity and enable the relationship between the government and the citizen to develop in a positive and beneficial

\footnotetext{
${ }^{28}$ These terrorist attacks were a series of coordinated attacks on the United States on the $11^{\text {th }}$ September 2001 by al-Qaeda. The United States responded to these attacks with a 'War on Terror', which included the invasion of Afghanistan to fight the Taliban.

${ }^{29}$ The Times 15 September 2001 'Terrorism review may result in ID cards'

${ }^{30}$ The Times 15 September 2001 'Terrorism review may result in ID cards'

${ }^{31}$ The Times 6 February 2002 'Blunkett pushes benefits of compulsory ID cards'

32 The Independent 6 February 2002 'Blunkett clears the path for compulsory identity cards'
} 
manner, arguing that the Entitlement Card would prove to be 'a real weapon against some of the crimes undermining society'. ${ }^{33}$

In terms of the consultation, David Blunkett stated that:

I have made it clear that the introduction of an entitlement card would be a major step and that we will not proceed without consulting widely and considering all the views expressed very carefully. I want to see a far-reaching and meaningful public debate on the issue of entitlement cards, and a vigorous response from all parts of the community. $^{34}$

Responses for this consultation were due in January 2003. Following this, the consultation paper 'Legislation on Identity Cards: a Consultation' was launched in April 2004, with responses due by July 2004. The results of this consultation were published in October 2004, entitled 'A Summary of Findings from the Consultation on Legislation on Identity Cards'. On 24 November the 'Identity Cards Bill' was published, although the final version (presented to Parliament on 25 May 2005) was amended. ${ }^{35}$

The London School of Economics (LSE), in its report on the Identity Cards Bill, points out that throughout the consultation process the UK Government has presented results from opinion polls as showing 80\% public support for ID cards. They also describe the online portal - stand.org.uk - as collecting over 5,000 responses, $96.5 \%$ of which were opposed to ID cards and $1 \%$ in favour. These 5,000 responses were counted as one response in the summary of consultation responses by the Home Office. ${ }^{36}$ The LSE also points out that the wording of the questions within the consultation were sometimes framed as to draw a particular answer:

\footnotetext{
${ }^{33}$ The Times 4 July 2002 'It is perfectly possible to protect personal privacy and still establish our identities' p.20

${ }^{34}$ The Guardian 3 July 2002 'Blunkett unveils ID card proposals’

35 (2005) The LSE Identity Project: An assessment of the UK Identity Cards Bill and its Implications http://is2.lse.ac.uk/idcard/identityreport.pdf p.32

${ }^{36}$ (2005) The LSE Identity Project: An assessment of the UK Identity Cards Bill and its Implications http://is2.lse.ac.uk/idcard/identityreport.pdf p.34
} 
The consultation document asked respondents to say how an entitlement/ID card could help them. For example, granted that retailers selling restricted goods such as cigarettes and alcohol must verify the buyer's age, an honest question would be to ask what form of document would be the most help in establishing this. Instead, the question was more frequently framed as "Would an ID card help?" The answer is clearly likely to be 'yes'. The ID card was not presented as one of several alternative possible solutions among which respondents might pick. ${ }^{37}$

Although the Government portrayed those in favour of ID cards as an $80 \%$ majority during the consultation process, the results of the consultation present $48 \%$ as being in favour of their introduction.

Three civil liberties groups were represented in the consultation - NO2ID, Stand, and The Freedom Association. In this sense the consultation differs from the CCTV national strategy consultation, during which civil liberties groups were not asked to participate.

In 2004, the Home Affairs Committee (reporting on the Identity Card scheme) stated that:

The international experience clearly indicates that identity cards and population registers operate with public support and without significant problems in many liberal, democratic countries. In a number of these, the holding and even carrying of the card is compulsory and appears to be widely accepted. However, each country has its own social, political and legal culture and history: the nature of each identity scheme and population register reflects those

37 Ibid. p.36 
unique elements. We cannot assume that any particular approach can be applied successfully in the UK. ${ }^{38}$

An identity card scheme of the sort and on the scale proposed by the Government would undoubtedly represent a significant change in the relationship between the state and the individual in this country. ${ }^{39}$

Identity cards should not be ruled out on grounds of principle alone: the question is whether they are proportionate to the aims they are intended to achieve. Identity cards could make a significant impact on a range of problems, and could benefit individuals through enabling easier use of a range of public services. This justifies, in principle, the introduction of the Government's scheme. But the Government's proposals are too poorly thought out in key respects: in relation to the card itself, to procurement and to the relationship of the proposals to other aspects of government, including the provision of public services. $^{40}$

Similar issues were brought up during the National CCTV Strategy consultation, for example that of the need for effective management of the system. The issue of the relationship between the state and individual is one that could also equally be applied to CCTV and one which has arisen in the academic literature but not in policy discourse.

Two further consultations on ID cards were launched in 2008: the 'National Identity Scheme Delivery Plan' and the 'Compulsory ID Cards for Foreign Nationals'. The National Identity Scheme consultation seemed to consult more on practical issues rather than any focus on whether the ID card should or should not be introduced. The document describes itself as a 'consultation process on our proposals' and details:

\footnotetext{
${ }^{38}$ House of Commons Home Affairs Committee (2004) 'Identity Cards' The Stationery Office Limited; London p.69

${ }^{39}$ Ibid.

${ }^{40}$ Ibid. p.78
} 
The conversation which begins now with a wide constituency of stakeholders will enable us to take on a broad range of experiences and ideas for defining services.

This document sets out how the Government will deliver the National Identity Scheme, how the scheme will work and be operated. ${ }^{41}$

The consultation on ID cards for foreign nationals was also a consultation on process, rather than whether the scheme should be introduced. The UK Borders Act 2007 had already granted the Government the right to issue ID cards to foreign nationals. ${ }^{42}$

The present situation in the UK is that from 2012 the National Identity Scheme will 'begin to roll-out for the general population with identity cards issued in high numbers'. ${ }^{43}$

Recent research argues that:

Following on from the debates about the Identity Cards scheme, stories about privacy and surveillance have become increasingly high profile in British newspapers. The themes have also become the focus of a number of editorial statements in the leading broadsheet newspapers. ${ }^{44}$

This increased media interest, coupled with interest from other parties such as the Information Commissioner, means that (on the surface at least) ID cards have been increasingly debated in the public sphere. ${ }^{45}$ The media certainly play their

\footnotetext{
${ }^{41}$ Home Office (2008) National Identity Scheme: Delivery Plan 2008 pp.5-6

${ }^{42}$ Home Office (2008) 'Compulsory Identity Cards for Foreign Nationals'

http://www.ukba.homeoffice.gov.uk/sitecontent/documents/aboutus/consultations/closedconsultati ons/idcards/idcardsconsultationresult?view=Binary

${ }^{43} \mathrm{http}: / /$ press.homeoffice.gov.uk/press-releases/consultation-national-ID-scheme

${ }^{44}$ E. A. Whitley (2008) 'Perceptions of Identity Cards, Privacy and Surveillance' in A. Pickering (ed.) Knowledge Politics http://www.knowledgepolitics.org.uk/KP_Whitley.pdf ${ }^{45}$ http://www.ico.gov.uk/upload/documents/library/corporate/detailed specialist guides/id_cards bill__ico_concerns_october_2005.pdf
} 
part in ensuring that ID cards are debated in the public realm. Research has shown that ID cards are discussed (and the negative aspects included in these discussions) prominently in the press, however the situation with regard to CCTV is very different, as I will show later in this chapter.

During the consultation process on ID cards the public seem to be viewed by the Government as a more active and involved stakeholder than for the discussion of CCTV. They are asked numerous times for their opinions on whether ID cards should be introduced, in what form and how. It is assumed, at least in the early consultations, that the public are knowledgeable enough about the technology to form and share an opinion and to play a part in the consultation process.

In this sense then, a consultation on CCTV would look very different to one on ID cards. Although both technologies are described as crime prevention technologies (although targeting different crimes), CCTV seems to be something that is used to protect the public in a physical sense, whereas ID cards are used to prevent things like fraud.

In another sense, they are both surveillance technologies, and said to be used to protect the public from certain crimes, such as terrorism. Had CCTV been introduced more recently (as the possible re-introduction of ID cards was proposed during the 1990s) the consultation process may have looked similar.

In any case, despite the apparent consultation of a variety of stakeholders and the outcome of public opinion as a minority in favour of the introduction of ID cards, the current situation in the UK is that ID cards are due to be issued from 2012.

\subsubsection{National promotion of CCTV}

In this section I will look at the representation of CCTV by central government, and how the public have been portrayed in the literature.

The 2007 National CCTV Strategy states that: 
Transport hubs, shopping centres, shops, public houses and clubs, the role of CCTV cameras is widened .... . Often the primary role is not the detection and prevention of crime. The purpose of the CCTV scheme may be to monitor crowds, slips, trips and falls and staff crime. Often there is a public expectation that these systems are installed for their safety, but the CCTV may not be of sufficient quality for police to use in criminal investigations.

Despite this statement, CCTV on the London Underground, as an example, is promoted as a technology to enhance passenger safety. The announcement is repeatedly made that 'CCTV is installed on London Underground for your safety'. Furthermore, despite the admission that the prevention of crime is often not the primary role, the report also states that 'CCTV plays a significant role in protecting the public' ${ }^{46}$

Regarding public opinion, the Home Office argues that:

CCTV in the UK enjoys significant public support and year on year fear of crime surveys states that the public feels safer due to the presence of CCTV. ${ }^{47}$

However, the Home Office do not reference any crime surveys, nor do they give any indication as to where this information came from. ${ }^{48}$

The main crime survey in the UK is the British Crime Survey. ${ }^{49}$ The British Social Attitudes Survey also contains some information on crime and criminal justice. In terms of the claim that 'people now feel safer when they're out and about', the results of the last British Crime Survey (BCS) show that $65 \%$ of people thought that crime in the country as a whole has increased in the previous

\footnotetext{
${ }^{46}$ Gerrard, G. et al. (2007) National CCTV Strategy Home Office p.5

${ }^{47}$ Ibid. p.7

${ }^{48}$ I emailed the Home Office twice to ask them which crime surveys were used but did not receive any reply

${ }^{49}$ http://www.homeoffice.gov.uk/rds/bcs1.html
} 
two years. This result is unchanged from the survey in 2006/07. ${ }^{50}$ Furthermore, around $65 \%$ of people thought crime in the country as a whole had increased in the previous two years (unchanged from the results of the 2006/07 survey), with $35 \%$ believing that it had increased 'a lot', compared with 33\% in the last survey. ${ }^{51}$ Furthermore, the last British Social Attitudes Survey (BSAS) found that the proportion of people worried about violent crime fell from 24 to $17 \%$ between 2000 and 2004/05, but has since increased. ${ }^{52}$

I therefore argue that, at least in terms of these results, people's perceptions of, and fear of crime, have not decreased, making the claim that 'people now feel safer when they're out and about' an unlikely one. The Home Office also claims that 'the public feels safer due to the presence of CCTV', although this claim cannot come from the BCS or the BSAS as neither ask about feelings of safety from CCTV in their surveys. A recent Home Office Research Study also disputes this claim, as the findings show that CCTV does not make people feel safer, nor does it make them alter their behaviour. ${ }^{53}$

The national promotion of CCTV by the Government (in the same vein as local government) concentrates on: ‘freedom' for citizens and 'freedom and safety' for consumers. ${ }^{54}$ Both the local and national government marketing of CCTV seems to portray a public in need of protection. From the lack of opportunity to engage in the policy consultation process, I argue that the public are presumed to be passive and uninformed. They are not, and they should be included in the consultation process.

\subsection{Media analysis}

Next, I undertake an analysis of media coverage of CCTV during the last 15 years. In this analysis, I seek to understand how the media frames its portrayal of CCTV to the public, particularly in relation to crime. Over the last 15 years, there

\footnotetext{
${ }^{50}$ Kershaw, C. et al. (2008) 'Crime in England and Wales 2007/08: Findings from the British Crime Survey and Police Recorded Crime’ HMSO; London p.117

${ }^{51}$ Ibid. p.128

52 British Social Attitudes Survey 2008 http://www.statistics.gov.uk/cci/nugget.asp?id=1932

${ }^{53}$ Gill, M. et al. (2005) Assessing the Impact of CCTV HMSO; London

${ }^{54}$ Edwards, P. and Tilley, N. (1994) CCTV: Looking Out for You HMSO; London p.9
} 
has been a large increase in articles related to CCTV across all UK broadsheets. This increase presents itself in fluctuating terms, particularly in The Independent (all other broadsheets, although fluctuating slightly, generally increase with a few peaks).

In this section, I will present an overview of coverage involving CCTV in The Guardian (including The Observer), The Times (including The Sunday Times), the Daily Mirror and the Daily Express for the peak years: 1993, 1994, 1995, 1998, 2000, 2002, and 2005. An overview of 2006, 2007 and 2008 is also provided in order to give a recent picture of print media coverage (from The Guardian and The Times) of CCTV. The coverage during these years has shown a steady increase in frequency of mention of CCTV. The Guardian, The Times, the Daily Mirror and the Daily Express were chosen due to the size of their archives, in order to look at trends in reporting as far back as possible. Further, the four newspapers have different political leanings and different target audiences; The Guardian is left of centre and a broadsheet paper, The Times is right of centre and also a broadsheet, the Daily Mirror is a mass-market tabloid, left-wing and historically pro-Labour, and the Daily Express is a mid-market tabloid and leans to the right politically. This overview will show what is happening in terms of coverage of CCTV and trends in reporting and to answer the question - what are the broadsheet and tabloid print media saying about CCTV? I will then go on to undertake a more in-depth analysis of the events surrounding the 7 July 2005 bombings of the London Underground, looking at reports from the broadsheet and tabloid press, to tease out differences and/or similarities in reporting, terminology used, and the positive and/or negative light that CCTV is portrayed in. The tabloid and broadsheet newspapers used are all the UK national newspapers: The Guardian and The Observer, The Times and The Sunday Times, The Independent, The Daily Telegraph, the Daily Mirror and the Sunday Mirror, the Daily Mail and the Mail on Sunday, The Sun, the Daily Star and Sunday Star, the Morning Star, The News of the World, The People and the Daily Express. In concluding, I will look at how the use of CCTV in relation to crime is framed by the print media in its portrayal of the technology to the public. 
For the quantitative part of the analysis, I searched for the key terms 'CCTV' and ‘closed circuit television’ within The Times, The Guardian, Daily Express and Daily Mirror newspapers. After finding out where the peaks in coverage occurred, I then searched for the same terms in The Independent and The Telegraph during those peak years, producing graphs of the results. I then undertook a qualitative analysis of the articles printed during those times.

The Guardian (including The Observer) and The Times (including The Sunday Times) peaks in terms of CCTV mention are 1993, 1994, 1995, 1998, 2000, 2002, 2005, with figures doubling for the early 90s for both newspapers. The Independent and The Telegraph also have peaks in coverage in 2000, 2001, 2002 and 2005.

Fig. 7.1 Graph showing the results of a 'CCTV' keyword search in The Times and The Guardian

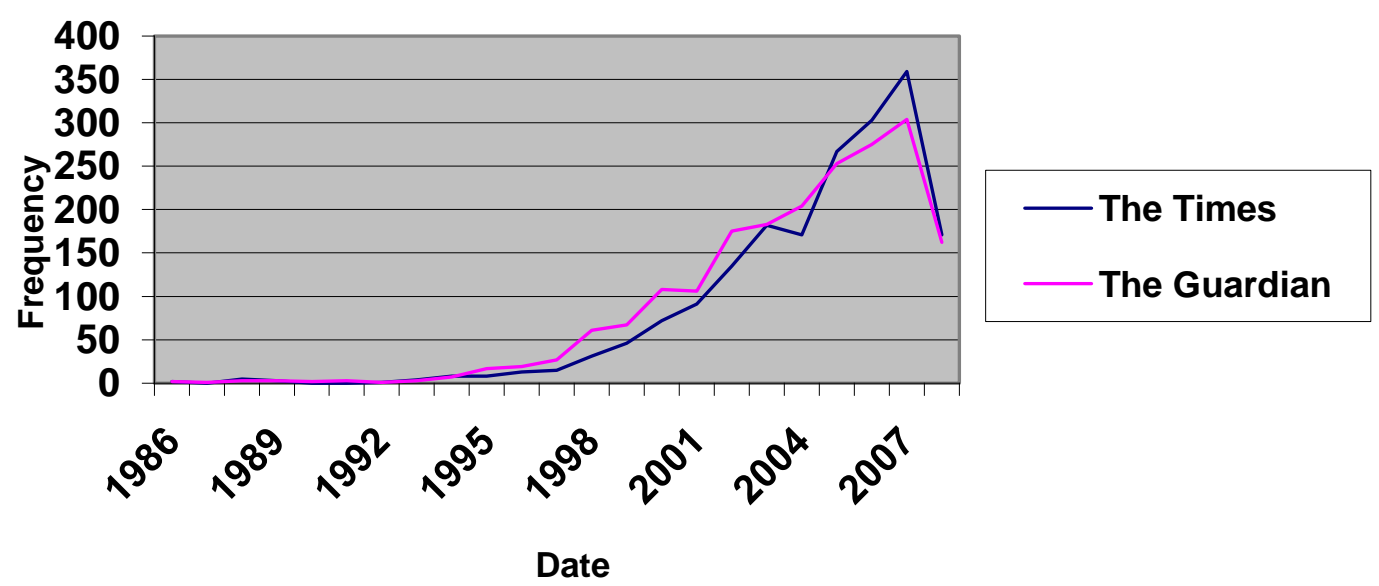


Fig. 7.2 Graph showing the results of a 'CCTV' keyword search in The Times, The Guardian, The Daily Telegraph, and The Independent

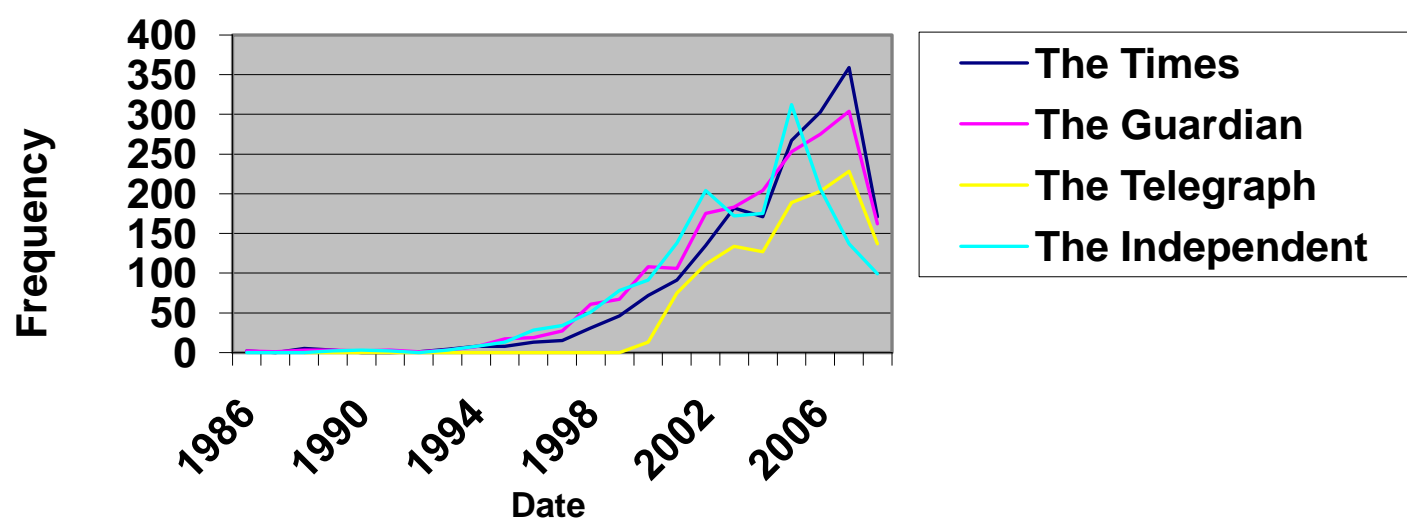

\subsubsection{Press coverage of CCTV during the 1990s}

The main stories involving CCTV during the early 1990s focused, in The Guardian and The Times, on the results of pilot schemes testing CCTV's effectiveness. In 1993, The Guardian reported some bad quality footage hindering prosecutions, whilst also focusing attention on the impact of CCTV on crime in city centres. The Times reported CCTV images as being too poor to be of any more use in the James Bulger case. Although the abduction of James Bulger and the image of his abductors leading him away on CCTV (and the role played by CCTV) meant that it was hard to be anti-CCTV at this time, there was not much press attention devoted to the images immediately after his abduction (although subsequently there are numerous mentions of the role played by CCTV in the case, at the time it hardly features). ${ }^{55}$ The Daily Express did not mention CCTV in any articles during 1993, whilst the Daily Mirror did not report on the James Bulger case or on the effectiveness of CCTV, but rather in the context of

\footnotetext{
55 There was media attention attached to the images in the form of the footage from the CCTV cameras repeatedly being shown on the news on TV
} 
the technology enhancing security at football games. ${ }^{56}$ The only mention during 1994 in the Daily Mirror was once again in the context of football security. ${ }^{57}$ In 1994, both The Guardian and The Times reported drops in crime due to CCTV, using phrases such as 'success' and 'raise hopes' in terms of cutting crime. David McLean, the junior Home Office Minister, was reported in The Guardian as saying that CCTV reduces shoplifting, car and drug related crimes, and Michael Howard, the Home Secretary announced $£ 2$ million CCTV competition for local authorities and estates. In late 1995, he was quoted in The Times as saying:

Criminals hate the cameras. They know that CCTV allows lawabiding people to reclaim their streets and public spaces. ${ }^{58}$

This was reported at the same time as the results of the first CCTV competition were announced. Terms such as 'spy cameras' and 'controversial spread' began to be used by The Guardian during 1995, signalling the start of criticism against CCTV by the newspaper (although this has not remained the case from this point onwards, which will be shown later in this analysis), at this point focusing mainly on issues of privacy, data protection, data security and effectiveness. ${ }^{59}$ At the same time, The Guardian also reported police backing of CCTV, and quoted David McLean as saying that CCTV is the 'friendly eye in the sky' ${ }^{60}$ The paper also reported some criticism from academic evaluations over success rates and reports some 'uneasiness' in terms of public feelings towards 'spy capabilities' ${ }^{61}$ One report in The Guardian at the beginning of the year suggested that there is general public acceptance of the rapid growth of CCTV cameras, finding this to be at odds with the traditional British approach to crime:

The lack of any marked reaction to the use of CCTV into public areas in 1994 came as a surprise to many inside and outside the security industry. 'Teams of journalists flocked out to see us,' says Tim

\footnotetext{
56 The Daily Mirror 9 March 1993 'Went for me’ p.31

57 The Daily Mirror 5 September 1994 'Fair deal league’ p.31

${ }^{58}$ The Times 23 November 1995 'TV cameras in towns to increase'

${ }^{59}$ The Guardian 22 March 1995 'Security: Someone’s Watching' p.2, The Guardian 21 September 1995 'Surveillance: Spies on the Streets’ p.4

60 The Guardian 30 January 1995 'Spy Cameras Become Part of Landscape’ p.6

${ }^{61}$ The Guardian 30 January 1995 'Spy Cameras Become Part of Landscape’ p.6
} 
Johnson, security manager for Liverpool Town Centre, 'All of them expected to come back with Big Brother horror stories. But people in Liverpool simply welcome the scheme.' The reaction of people in Liverpool may be partly explained by the city's proximity to the scene of the James Bulger tragedy. 'After the Bulger outrage,' says Fred Domenico, at Asprey in Bond Street, 'public feeling was Catch Them, and by association all criminals, by any means. Nevertheless in the UK we have traditionally taken a more laid-back approach' ${ }^{62}$

For the Daily Mirror, CCTV became a political issue during 1995, with the launch of an inquiry by the newspaper into the areas which received Home Office funding for camera installation. They reported that:

Home Secretary Michael Howard was accused last night of pouring crime-busting cash into Tory heartlands - and snubbing trouble spots packed with Labour voters.

The article goes on to argue that 'true-blue' areas (i.e. Conservative) received funding for CCTV when there is a low crime rate and cameras are already installed, at the expense of more deprived inner city areas. The general tone towards CCTV is positive though, in terms of the effectiveness of the technology. ${ }^{63}$ This positive tone is echoed in the Daily Express during 1995, with a number of articles detailing the success of CCTV in reducing crime and reporting on funding for the installation of cameras throughout the country. ${ }^{64}$

There was a definite shift in terms of coverage of CCTV in The Guardian during 1998. A critical look at the effects of CCTV on crime is taken, with one article detailing possible displacement effects and a rising fear of crime in places not covered by cameras, as well as referring to CCTV as 'Big Brother' ${ }^{65}$ Later in the year, The Observer raised concerns over civil liberties in terms of the proposed

\footnotetext{
${ }^{62}$ The Guardian 22 March 1995 'Security: Someone’s Watching’ p.2

${ }^{63}$ Daily Mirror 10 April 1995 'You've been framed Mr Howard' pp.8-9

${ }^{64}$ Daily Express 3 August 1995 'New tactics' p.40, 29 November 1995 'Big cash boost for crime war' p.4

${ }^{65}$ The Guardian 9 January 1998 ‘Demand for closed circuit TV triggers fear of crime’ p.8
} 
launch of CCTV with facial recognition capability in Newham, East London. They described a quote from a designer of the system as a 'chilling vision of the future':

Gradually this sort of technology will cover the whole country. Then it will become unprofitable to commit crime anywhere. ${ }^{66}$

The same development is described in The Guardian as 'spy camera[s]', once again raising concerns over possible civil liberties infringements. ${ }^{67}$ The Times also offered some criticism of CCTV during the year, reporting on the poor quality of footage for the purpose of identifying people. ${ }^{68}$ The Daily Mirror did not cover the civil liberties angle during 1998, focusing instead on the success of CCTV in prosecuting criminals after being 'in view of CCTV cameras', 'caught on camera' ${ }^{69}$ and 'tracked by CCTV cameras'. ${ }^{70}$

\subsubsection{Press coverage of CCTV from 2000 - 2005}

The shift in terms of negative coverage of CCTV in The Guardian and The Times continued in early 2000. There were numerous mentions in The Times of snooping and surveillance, as well as references to Big Brother. ${ }^{71}$ With reference to a new facial recognition technology - 'SatNet' - being used in conjunction with CCTV (used to match the faces of shoppers to known shoplifters on a database) The Guardian raised questions about privacy infringements and 'being watched' so closely. They also reported of 'excessive surveillance' and a call from Liberty (civil liberties group) for a public debate. ${ }^{72}$ However, although the number of articles mentioning privacy implications or other negative effects of CCTV rose during the first half of the year, the amount of coverage painting the

\footnotetext{
${ }^{66}$ The Observer 11 October 1998 'As UK crime outstrips the US, a hidden eye is watching' p.5

${ }^{67}$ The Guardian 15 October 1998 'Fears for civil liberties: Spy camera matches faces to police files' p.7

${ }^{68}$ The Times 27 March 1998 'CCTV identification 'error-prone’’ Home News

${ }^{69}$ Daily Mirror 6 March 1998 'Drunken thug teachers jailed for battering cop’ p.11

${ }^{70}$ Daily Mirror 26 August 1998 'Gang in van raid bungle’ p.14

${ }^{71}$ The Times 10 January 2000 'Looking for our fingerprints in cyberspace’, 11 January 2000

'Who's reading your email', 20 January 2000 'Is big brother already watching us?'

${ }^{72}$ The Guardian 10 February 2000 'In Your Face’ p.14
} 
technology in a positive light was still far greater. ${ }^{73}$ During this time, neither the Mirror nor the Express focused on the negative aspects of CCTV. The Daily Mirror started to report the checking of CCTV footage as a given, prior to knowing whether it will be of any use. As an example, in relation to a murder in Ireland, they stated that police 'will be looking at every inch of CCTV footage to spot Julie and see who she was talking to'. ${ }^{74}$ This reporting of CCTV being checked, prior to its usefulness being assessed, occurs numerous times - 'Police were checking CCTV footage from the club"75, 'Officers are studying CCTV footage for clues', ${ }^{76}$ '[Police] are searching film from Gloucester's CCTV for pictures of the rapist'. ${ }^{77}$ The police going through CCTV footage appears to be news in itself.

In July 2000, the court case of the Brixton nail bomber ${ }^{78}$ was reported by the Guardian, with the role that CCTV played in his identification mentioned in three articles - 'Police tracked him down through a series of leads, including calls from members of the public who recognised him from CCTV footage released following the Brixton bombing' ${ }^{79}$ The Times mentioned CCTV and its role in this case in one article. ${ }^{80}$ The Daily Mirror took a strong view on the role of CCTV in the case, reporting that 'Copeland was caught after a CCTV photograph of the Brixton bomber appeared in the press ${ }^{\text {, }}$ and 'A few hours later, he was arrested at his home after being identified by a workmate who recognised a CCTV shot of him taken at Brixton' ${ }^{82}$ The Daily Express did not mention CCTV in relation to the case.

\footnotetext{
${ }^{73}$ Between the 1 January 2000 and 1 July 2000, the Times contained thirty four articles mentioning CCTV. Of these, five contained negative terminology such as 'snooping', 'surveillance' and 'Big Brother'. During this time, the Guardian contained fifty nine articles mentioning CCTV. Of these, four articles depicted CCTV in a negative light, using terms such as 'excessive surveillance', 'monitored' and 'watched too closely'.

${ }^{74}$ Daily Mirror 5 February 2000 'MP's niece murdered at Giant's Causeway' p.17

${ }^{75}$ Daily Mirror 24 May 2000 ‘Has Sara murderer struck second time?’ p.11

${ }^{76}$ Daily Mirror 10 June 2000 ‘Cops quiz children over rail horror’ p.26

${ }^{77}$ Daily Mirror 19 August 2000 'Rapist in attack on aids girl' p.9

${ }^{78}$ David Copeland, known as the 'Brixton nail bomber' carried out a 13 day bombing campaign in London during April 1999

${ }^{79}$ The Observer 2 July 2000 'Nail bomber trapped by fake penpal' p.11

${ }^{80}$ The Times 1 July 2000 'Crucial tip-off came 24 hours too late'

${ }^{81}$ Daily Mirror 1 July 2000 'Lair of Hatred’ p.6

${ }^{82}$ Daily Mirror 1 July 2000 'Nothing excuses this evil’ p.2
} 
Also in July, The Observer reported possible privacy infringements from surveillance at work, through computers and the Internet, via CCTV, and loyalty cards. $^{83}$ A couple of months later, in September 2000, The Times focused on CCTV and the Human Rights Act, in relation to the launch of a 'Supervan' fitted with nine cameras on patrol in Westminster. ${ }^{84}$ Privacy was also mentioned in an article in the Daily Express in September, reporting on the inappropriate use of technologies in the workplace; in the case of CCTV, installed to protect employees from attack. The article argued that 'we all have a right to privacy'. ${ }^{85}$

On 27 November 2000, 10 year old Damilola Taylor was stabbed outside his block of flats in Peckham, London. The Times, The Guardian, Express and Mirror all mentioned CCTV as recording his last journey. ${ }^{86}$ The Guardian also reported that the children who were with Damilola Taylor shortly before he was stabbed had been identified through CCTV footage. Between 29 November and the end of the year (2000), The Guardian published 98 articles mentioning Damilola Taylor. Of these, CCTV was mentioned in nine. During this time, The Times published 71 articles mentioning Damilola Taylor, of which two mention CCTV. Within their report of CCTV footage showing Damilola's movements prior to his death, the Daily Express described the recording as showing him in a 'carefree mood', therefore using images with no sound to ascertain his feelings prior to the attack. ${ }^{87}$ This placing of CCTV into the role of body language expert occurs again numerous times during coverage of the London Underground bombings, looked at in more detail later in this media analysis.

At the beginning of 2002 (January), The Times reported that street crime had risen dramatically (giving the specific example of Harrow) in London boroughs since 9/11, due to many police being involved in anti-terrorism duties, leading to a fall in beat policing. ${ }^{88}$ A couple of months later (March), The Times reported on

\footnotetext{
${ }^{83}$ The Observer 30 July 2000 'The End of Privacy’ p.21

${ }^{84}$ The Times 19 September 2000 'If you feel that you are being watched...' Features

${ }^{85}$ Daily Express 15 September 2000 'Bosses spying on staff' p.26

${ }^{86}$ The Guardian 1 December 2000 'Witness clue in Damilola murder’ p.1, 2 December 2000 'Witness saw boy minutes before his death' p.2, 5 December 'Caught on camera: The last journey of Damilola Taylor’ p.1, Daily Mirror 1 December 2000 'Damilola on CCTV’ p.17, Daily Express $5^{\text {th }}$ December 2000 'Caught on camera, little Damilola's final living hour' p.3

${ }^{87}$ Daily Express 5 December 2000 'Caught on camera, little Damilola’s final living hour’ p.3

${ }^{88}$ The Times 10 January 2002 'Where are the police?'
} 
'Fortress Britain', detailing communities behind electric gates and gated developments. ${ }^{89}$ There was brief mention of CCTV, but The Guardian - in its reports of gated communities, during the first half of 2002 - was far more emphatic about the role of CCTV in enhancing security. ${ }^{90}$ The Daily Express included an article in April focusing on data trails, satellites, purchasing habits, home and mobile phone records and CCTV, entitled: 'There's no hiding place from this army of spies'. This article was included at a time when there was little or no reference in other newspapers to privacy issues in relation to surveillance technologies. The article stated that:

The nightmare scenario is that all the information held about you in different places could someday be joined together, giving whoever had access to it a total picture of your life, including many things you would rather keep to yourself ... . There are those that argue that people who live good, law-abiding lives have nothing to fear from CCTV cameras, identity cards and Government plans to share their information with private companies. They would do well to remember that things can, and do, go wrong when technology is used to record the behaviour of millions of people. Privacy is a valuable thing. ${ }^{91}$

In March 2002, Amanda Dowler, also known as Milly, was reported as missing. ${ }^{92}$ The Guardian mentioned CCTV numerous times, but it did not play a part in the investigation at first. ${ }^{93}$ In early April, CCTV footage of the girl was released. ${ }^{94}$ In July 2002, as a suspect was arrested, The Guardian mentioned CCTV numerous times even though the footage recorded was of no use - it was obscured by the glare of the sun. ${ }^{95}$ The Times mentioned CCTV the day after the body of Amanda Dowler was found, also in the context of the images recorded being of no use to the investigation:

\footnotetext{
${ }^{89}$ The Times 9 March 2002 'Fortress Britain’ Features

90 The Guardian 30 January 2002 'Laager Toffs’ p.2

${ }^{91}$ Daily Express 4 April 2002 'There’s no hiding place from this army of spies’ p.19

92 Amanda Dowler (aged 13) went missing on the 21 March 2002 on the way home from school. Her remains were found on the 18 September 2002.

${ }^{93}$ The Guardian 26 March 2002 'Police intensify hunt for missing teenager' p.5

${ }^{94}$ The Observer 7 April 2002 'New footage of missing teenager' p.12

${ }^{95}$ The Guardian 13 July 2002 ‘FBI to enhance possible video footage of Milly’ p.5
} 
A closed-circuit television camera swiveling on top of a Bird's Eye plant 50 yards away had surveyed the area, but such was the glare from the sun that for many months detectives were unable to make any use of the footage. Earlier this month, the FBI succeeded in enhancing that film and a black sports car with a spoiler could be seen stopping alongside a figure who may or may not have been Milly but who appeared to speak to the driver. The exchange lasted between 42 and 84 seconds, the time that the CCTV camera took to swivel back to survey the spot again. The next piece of footage showed that both the car and figure had gone. ${ }^{96}$

The Daily Mirror in particular frequently referenced CCTV in relation to the disappearance of Amanda Dowler. CCTV was mentioned as a potential aid to the investigation, describing it as possibly providing 'vital clues' and 'a vital lead'. ${ }^{97}$ The Daily Express also described its potential use, reporting that:

FBI scientists have made a potentially major breakthrough in the hunt for missing Amanda Dowler after discovering images of a mystery car on murky CCTV film ... previously marred by sun glare. ${ }^{98}$

A month earlier, in August 2002, Holly Chapman and Jessica Wells were also reported as missing. ${ }^{99}$ The Times reported CCTV footage showing the two girls at a sports centre near Holly's home before their disappearance. ${ }^{100}$ At this time, The Guardian described four potential witnesses captured on CCTV at the possible time and place of disappearance. ${ }^{101}$ The Guardian also speculated that the incident

\footnotetext{
${ }^{96}$ The Times 21 September 2002 'At last, Milly’s parents find a kind of relief' p.3

${ }^{97}$ Daily Mirror 26 March 2002 'I spotted Milly’p.5, 13 ${ }^{\text {th }}$ September 2002 'Is this Milly’ p.11, 9 November 2002 'Mazda driver link to Milly ruled out' p.32

${ }^{98}$ Daily Express 13 September 2002 'Milly: FBI find clue’ p.26

${ }^{99}$ Holly Chapman and Jessica Wells went missing on the 4 August 2002 in Soham, Cambridgeshire. Their bodies were found on the 17 August 2002.

${ }^{100}$ The Times 9 August 2002 'Sunday, teatime: Holly and Jessica pulled on Manchester United shirts, spent 29 minutes on their computer, then walked into town' p.1

${ }^{101}$ The Guardian 8 August 2002 ‘Abduction fear for missing girls’ p.2, 9 August 'Police trace moments girls vanished’ p.7, 9 August 'Captured on camera: Film of missing girls released’ p. 1
} 
would not have happened if plans to install seven CCTV cameras on the street where Holly and Jessica were last seen had not been delayed. ${ }^{102}$

At the same time as reporting the girls as missing and the final conclusion in the form of the arrest of Ian Huntley, there was mention in The Guardian of 'one of the biggest shake-ups ever of British policing' (due to calls to set up a specialist police unit similar to the FBI). ${ }^{103}$ Although Ian Huntley was not identified through CCTV, the technology was continuously mentioned in The Guardian both during the investigation and after his arrest. Interestingly, at the same time as numerous mentions of CCTV in the case of Holly and Jessica (even though the technology did not play a part in the investigation or subsequent conviction of Huntley), there were also a number of articles focusing on data trails, privacy, data protection, and 'Big Brother' in relation to surveillance technologies. ${ }^{104}$ The Daily Mirror and Daily Express also reported the questioning of the effectiveness of CCTV in cutting crime, through articles referring to the release of a report by the National Association for the Care and Resettlement of Offenders (Nacro) stated that there are more effective measures that can be taken to prevent crime, such as more street lights. The Daily Mirror went on to include a quote from the civil liberties organisation, Liberty, arguing that it was time for a reassessment of the worth of CCTV 'both financial and in terms of privacy'. ${ }^{105}$ The Daily Express, however, balanced the negative article with a positive about CCTV, stating that 'one of CCTV's successes was in helping to convict Jon Venables and Robert Thompson for the killing of toddler James Bulger after cameras spotted them abducting him from a Merseyside shopping centre in 1993'. ${ }^{106}$

In January 2005, The Times reported Sally Geeson as missing. ${ }^{107}$ CCTV was mentioned in terms of the police checking footage to see if she was captured on

\footnotetext{
102 The Guardian 12 August 2002 'CCTV plan 'could have foiled snatch”' p.4

103 The Observer 18 August 2002 'Holly and Jessica: The Search: Thirteen days of agony until hope finally died' p.4

${ }^{104}$ The Guardian 7 September 2002 'Big Brother: Your data trail’ p.12

${ }^{105}$ Daily Mirror 29 June 2000 ‘Bigger brother’s watching...but it’s just not working’ p.29

${ }^{106}$ Daily Express 29 June 2000 'CCTV does not stop crime’ p.10

107 Sally Geeson went missing on the 1 January 2005. Her body was discovered on the 7 January 2005.
} 
film. They did not state anything in the affirmative. ${ }^{108}$ Also in January 2005, The Guardian reported Amy Williams (14 years old and pregnant) as missing. CCTV footage of her final movements was released. ${ }^{109}$ Ten days later, The Guardian described a third person as having been arrested in connection with the murder of Amy Williams:

The latest arrest came hours after police released new CCTV footage which showed an unidentified man walking in the opposite direction to Amy soon after she was last seen. ${ }^{110}$

They did not explicitly state, but implied, that it was the CCTV footage that led to the identification of the man. The Daily Mirror also reported CCTV in connection with the case, saying that police were 'studying new CCTV film of her alone and fit and well'. ${ }^{111}$ Subsequently, they also detailed the release of CCTV footage showing her last movements, alongside reporting the arrest of a man in connection with her murder. The implication that the footage led to his arrest occurred once again. ${ }^{112}$

In February 2005, The Times reported the release of a Home Office study, which cast doubts on the effectiveness of CCTV in cutting crime. It was placed on page 36 of the newspaper. ${ }^{113}$ The Daily Mirror also placed their report of the study on page $31 .{ }^{114}$ The following month, an article describing the introduction of facial recognition technology by the police was included, and they state:

Police hope that this will make CCTV images as useful as fingerprinting and DNA evidence. ${ }^{115}$

\footnotetext{
${ }^{108}$ The Times 5 January 2005 'Missing girl sends desperate 'help me' texts to friends' p.11, Daily Mirror 5 January 2005 'Missing Sally’s desperate text message to pal’ p.13, Daily Express 5 January 2005 'Cry for help by text' p.5

${ }^{109}$ The Guardian 6 January 2005 'New arrest in hunt for teenager's killer’ p.6

110 The Guardian 16 January 2005 'Man held on Amy murder’ p.6

${ }^{111}$ Daily Mirror 3 January 2005 ‘Amy Quiz: Cops get more time’ p.22

112 Daily Mirror 6 January 2005 ' 'The Last Pictures’ p.21

113 The Times 25 February 2005 'CCTV cameras fail to cut crime’ p.34

${ }^{114}$ Daily Mirror 25 February 2005 'CCTV does not cut crime’ p.31

${ }^{115}$ The Times 14 March 2005 'Hi-tech rogues gallery puts police in picture’ p.7
} 
At the same time, The Guardian covered the introduction of car number plate recognition technology, using negative terminology, such as 'Little Brother' to describe the development. They stated that:

Britain, which already leads the world in terms of citizen surveillance, is about to tighten the screw. ${ }^{116}$

In May, The Times also featured an article describing the extent of surveillance cameras in Britain, using terms such as ‘intrusion' and 'loss of privacy' to argue strongly against the widespread nature of the technology. ${ }^{117}$ Two months later, The Times published an article arguing that too much information is given out with reference to loyalty cards, the Internet, and CCTV. ${ }^{118}$ A few days earlier, the Daily Mirror published an article reporting the Information Commissioner at the time, Richard Thomas, as stating that ID cards are 'an unnecessary and disproportionate intrusion of privacy'. Within this article, developments in the area of ID cards were placed alongside CCTV with facial recognition, number plate recognition and satellite tracking of vehicles, as another component of the surveillance society. ${ }^{119}$

Interestingly, this article occurred at a time when CCTV becomes a prominent feature in reports of the 7 July bombings of the London Underground. Coverage of the incident and aftermath repeatedly mentions CCTV as playing a major role in the investigation. I looked at this coverage across the broadsheet and tabloid press and I present my analysis of the differences in coverage next.

\subsubsection{Press coverage of the 7 July London Underground bombings and CCTV}

On 7 July 2005, four bombs went off in London - three of which exploded on tube carriages on the London Underground and one of which exploded on the

\footnotetext{
${ }^{116}$ The Guardian 25 March 2005 'Surveillance: Little brother’ p.27

117 The Times 14 May 2005 'Every move you make’ p.37

${ }^{118}$ The Times 1 July 2005 'Privacy on parade, at a price' p.24

${ }^{119}$ Daily Mirror 28 June 2005 ‘An unnecessary and disproportionate intrusion of privacy’ p.2
} 
No.30 bus at Tavistock Square. All of the bombs were carried in person by suicide bombers. In the immediate aftermath of the bombings, some newspapers focus on security on the Underground, although with different emphases.

On 8 July, The Times featured an article focusing on the possible permanent installation of body scan machines for the Underground. They mentioned that there are 1400 cameras on the tube and quote the managing director of QinetiQ (the developers of the technology) as saying:

After today, I expect the travelling public will be more prepared to put up with a greater level of surveillance. ${ }^{120}$

It seems that terrorism was seen as a marketing opportunity, at the same time as an assumption being made that public resistance up to this point had occurred.

The Mirror also focused on security on the Underground saying:

Security on the London Underground is fairly good, but the operators of CCTV cameras on the tube cannot look into every nook and cranny on each carriage. ${ }^{121}$

This suggests that the bombings were preventable, had CCTV operators been able to look into each carriage. However, later articles described the bombers as looking as though they were going on holiday, which suggests that CCTV operators would not have been able to spot anything unusual even with more cameras.

Despite the cameras not preventing the bombings, The News of the World still pushed the idea of CCTV as a crime fighting tool, reporting:

\footnotetext{
${ }^{120}$ The Times 8 July 2005 'Body scan machines to be used on tube passengers’ p.19

${ }^{121}$ Daily Mirror 8 July 2005 ‘07/07 War on Britain’ p.8
} 
Another vital component in tracking these bombers will be CCTV. It is a major tool in the fight against crime, and particularly terrorism. Think of the racist London nail bomber. ${ }^{122}$

Numerous articles in the days following the bombings report the seizure of 2,500 CCTV tapes from 2,000 CCTV systems, and describe the operation to go through the footage as:

Their [police] biggest search through the footage of surveillance cameras to try to identify the terrorists [and] the biggest CCTV recovery we have ever had. ${ }^{123}$

The Times reported that:

Examination of CCTV footage from the dozens of security cameras around King's Cross is a priority for investigators. ${ }^{124}$

With regard to terminology used for examination of footage, the phrases and words 'trawl through CCTV footage', 'scouring CCTV footage', and 'caught [on CCTV]' were used frequently. ${ }^{125}$

An article in the Mail on Sunday (the only paper to report this) included the claim that (with reference to the CCTV footage seized):

Advanced software can search for profile matches in domestic and international databases. ${ }^{126}$

In terms of reporting that the CCTV camera on the No.30 bus was not working, there was a clear distinction between the questioning nature of the broadsheet

\footnotetext{
122 The News of the World 10 July 2005 'Killers Leave Clues...Always'

${ }^{123}$ The Independent 9 July 2005 'Terror in London: The long intensive sifting of evidence to identify bombers'

124 The Times 11 July 2005 'Terror alert highest ever as police fear new attack’ p.1

${ }^{125}$ Daily Star 13 July 2005 'Blown up by 4 Brits’ pp.4-5, Daily Star 8 July 2005 'Bodies piled everywhere’ p.8, Daily Star 17 July 2005 'Together; Evil four on way to slaughter’ p.1, Morning Star 23 July 2005 'Britain - Police seeking bomb suspects'

${ }^{126}$ Mail on Sunday 10 July 2005 'All three tube bombs’ p.12
} 
articles and the coverage by the tabloid press. The Observer mentioned the broken camera a number of times over a range of articles (including the front page and second page devoted to the subject), and The Independent stated that:

There are questions, big and small, to be answered. They relate to intelligence, to the provision of support to survivors and to why the CCTV on the No.30 bus was not working. ${ }^{127}$

The Daily Mirror reported that:

The investigation received a serious setback when it was discovered that CCTV cameras on the bus that blew up were not working so detectives will not get vital images of the bomber ... but the antiterrorist squad are confident that other CCTV footage will help nail the three other terrorists. ${ }^{128}$

This conciliatory tone was echoed by the Mail on Sunday, which said:

Police admitted none of the CCTV cameras on the bus, which it had been hoped would yield vital clues, had been working since mid-June. But they are studying hours of very clear footage from traffic cameras. ${ }^{129}$

The Sun did not report that the camera was not working and instead states that:

CCTV footage retrieved from seven cameras on the bus has been handed to the police. ${ }^{130}$

\footnotetext{
${ }^{127}$ The Independent 12 July 2005 'Terror in London - A dignified political response to the bombs' p.26, The Observer 10 July 2005 'Attack on London: The Hunt for the Bombers’ p.2, The Observer 11 July 2005 'Bus bomb clues may hold key to terror attack' p.1

${ }^{128}$ Daily Mirror 9 July 2005 ‘07/07 War on Britain: The Hunt’ pp.6-7

${ }^{129}$ Mail on Sunday 10 July 2005 'All three tube bombs exploded at the same time' p.13

${ }^{130}$ The Sun 9 July 2005 'The Bus Driver: I thought I'd hit the kerb. I looked round...the back of the bus had gone'
} 
On 13, 14, and 15 July there were repeated mentions of the bombers caught on CCTV arriving at King's Cross on the morning of 7 July. Across the tabloid newspapers there were reports of the bombers looking like 'a group of happy hikers' ${ }^{131}$ 'completely normal' ${ }^{132}$ and 'looking happy and carefree, as if they were going on holiday'. ${ }^{133}$ It was also reported that the four men were 'chatting easily together', ${ }^{134}$ 'smiling and looking relaxed'135 and 'smiling and chatting'136 at King's Cross station. The Daily Mail suggested, somewhat contradictorily (in the same article that cites the bombers as looking relaxed), that one security source viewing the footage described the four men as looking 'like infantry going to war'. ${ }^{137}$ The same quote was also reported in The Telegraph. ${ }^{138}$

The Mail on Sunday reported the arrival of the four men at Luton as 'the bombers stroll into Luton'. ${ }^{139}$ The emphasis on how the men walked into Luton and the expression of the casual nature of their walk is interesting. In this case, it seems, CCTV plays the role of eyewitness, and the newspaper plays the role of body language expert. The Express also assumed the feelings of the four men from CCTV images captured in an article reporting the men as 'chatting easily together' ${ }^{140}$ With no sound from the CCTV footage, the assumption was still made that the conversation was of a casual nature.

There were also strong differences in terminology used to describe the bombers and the public. The Daily Star described one of the suicide bombers as an '18 year old killer'. ${ }^{141}$ The People described the CCTV footage from Luton train station as showing 'Four fiends stroll[ing] casually to a rendezvous in Hell', later

\footnotetext{
${ }^{131}$ Daily Express 15 July 2005 ‘On his way to kill: Bus bomber with his rucksack of death’ pp.2-3

${ }^{132}$ Daily Mirror 13 July 2005 '7/7 War on Britain: He has gone to London with some friends' pp.2-3

${ }^{133}$ Daily Mail 13 July 2005 'Killers who looked like they were on holiday’ p.2

${ }^{134}$ Daily Express 13 July 2005 'Four young men on a mission’ p.5

${ }^{135}$ Daily Mail 13 July 2005 'The suicide bomb squad from respectable homes’ p.4

${ }^{136}$ The Sun 13 July 2005 'The Boy Bombers'

${ }^{137}$ Daily Mail 13 July 2005 'The suicide bomb squad from respectable homes' p.4

${ }^{138}$ The Telegraph 13 July 2005 'Rucksack gang filmed at King’s Cross 'looked like infantry going to war' p.4

${ }^{139}$ Mail on Sunday 17 July 2005 '90 minutes before they wreaked unspeakable mayhem...the bombers stroll into Luton station' p.5

${ }^{140}$ Daily Express 13 July 2005 'Four young men on a mission’ p.5

${ }^{141}$ Daily Star 15 July 2005 ‘On his way to kill; TV film of rucksack bomb nut’ p.6
} 
describing the passengers on the Number 30 bus as 'innocents' ${ }^{142}$ This emphasis on 'victims' and 'evil doers' is of interest sociologically and I return to this issue later.

Prior to the identification of the four men, there was speculation across the tabloid and broadsheet newspapers that the CCTV images would hold an important role in the investigation. The Mail on Sunday contained an article by George Galloway, a Member of Parliament for the Respect party, saying:

I'm glad I never joined the knee-jerk liberal dislike of closed circuit television. CCTV is the most effective tool in crime-fighting. The CCTV camera doesn't lie and the clarity of the CCTV footage of suspects in the London bombings will soon see them brought in for questioning, I'm sure. ${ }^{143}$

The Express reported that:

CCTV has already played a vital role in the inquiry - capturing the four terrorists as they strolled through Luton and King's Cross together on the morning of the bombings. The identification of the suspects through CCTV film and documents found at the scene led to police raids on six addresses last week. ${ }^{144}$

After the identification of the four men, The Guardian reported that:

Among the unsung heroes of the tragedy of July 7 was the population of CCTV cameras in London and Luton, which played a key role in the identification of the bombers .... . Of all the weapons of surveillance, CCTV cameras have proved the least controversial ... .

\footnotetext{
${ }^{142}$ The People 17 July 2005 '89 mins from hell; first dramatic picture of 4 suicide bombers on way to slaughter' pp.4-5

143 Mail on Sunday 24 July 2005 'In London or Beirut, terror is universal’ p.29

${ }^{144}$ Daily Express 19 July 2005 'Police scour 25,000 CCTV tapes’ p.8
} 
They have been welcomed as the electronic guardian angels of our age. $^{145}$

In a later article focusing on the possible implementation of explosives-detecting technologies and more CCTV cameras, The Guardian described the CCTV pictures from the 7 July as 'invaluable in identifying the suicide bombers' ${ }^{146}$ The Times also mentioned the identification of the bombers from CCTV images numerous times throughout July and the beginning of August. ${ }^{147}$ At the same time however, and in contrast to The Guardian (which at this time write about CCTV in a positive light), The Times also voiced concerns that CCTV was replacing transport staff, arguing for more staff at stations and on buses. ${ }^{148}$ The results of a public opinion survey conducted by the Mail on Sunday were as follows:

More than three in four say the best way to prevent further attacks on London and other cities is to increase the number of CCTV cameras, with 68 per cent calling for the monitoring of car number plates at major road junctions. ${ }^{149}$

This strong sense of the effectiveness of CCTV in preventing attacks comes despite numerous reports describing the footage of the bombers caught on CCTV as 'normal'. The Mirror, for example, reported that:

The sense of ordinariness which the CCTV picture of Habib ${ }^{150}$ projects makes what he did even more horrific. For it means it is impossible to differentiate terrorists from the rest of us. ${ }^{151}$

\footnotetext{
145 The Guardian 18 July 2005 ‘CCTV cameras: Society’s little brothers’ p.19

146 The Guardian 23 July 2005 'Call for Underground scan system’ p.5

${ }^{147}$ The Times 27 July 2005 ‘Ready to strike again’ p.1, 28 July 2005 'Neighbours link ‘third bomber' to London flat' p.7

148 The Times 27 July 2005 'Transports cuts 'aid terrorists', p.5

${ }^{149}$ Mail on Sunday 10 July 2005 'Six out of Ten say: Execute bombers' p.11

${ }^{150}$ Habib Hussain was one of the bombers

${ }^{151}$ Daily Mirror 15 July 2005 ‘7/7 War on Britain: Spot the killer’ p.6
} 
The Guardian said:

It should be the most banal photograph in the world: four men entering a commuter railway station on a dreary Thursday morning. And yet you could stare at it for hours. Everything about it is ordinary ... . The picture itself gives nothing away ... . How often outside of our imaginations or the movies do we get to see criminals together, minutes before their crime? ... So this is the rarest kind of picture ... . The lesson of this picture is, change your nightmares - your fears are out of date. ${ }^{152}$

In general, both the tabloid and broadsheet newspapers report calls to enhance security across public transport, including increasing the numbers of CCTV cameras. The Independent said that:

The Government should immediately look into ways of toughening up security on London's transport system .... At the very least this should mean CCTV cameras on tube trains. ${ }^{153}$

These arguments for increased CCTV occur despite the fact that the bombings were not seen as preventable on the political scene (including in terms of surveillance and CCTV). Along the same lines as the previously mentioned Times article calling for more staff rather than technology, The Telegraph published one article arguing that, in terms of CCTV cameras, 'there are limits to how many can be actively monitored', adding that:

Besides, CCTV coverage is more of an aid as an investigating tool after events, rather than a device to prevent further attacks. ${ }^{154}$

\footnotetext{
152 The Guardian 18 July 2005 'Behind the banal street scene, a picture of devastation that will change our fears' p.5

${ }^{153}$ The Independent 23 July 2005 'London is under attack as never before, and fear is not a shameful response' p.38

${ }^{154}$ The Independent 24 July 2005 'Attacks on London: the best security is people, both staff and passengers' p.17
} 
On the 22 July 2005, Jean Charles de Menezes was shot by police as he boarded a tube at Stockwell Underground station in London. Coverage of this event focuses some attention on the footage captured by CCTV cameras in the station. In particular, reports suggested that eyewitness accounts differ from police descriptions of what Jean Charles de Menezes was wearing and how he was acting. CCTV footage is also reported as showing differences in police accounts regarding what he was wearing. ${ }^{155}$ The Independent Police Complaints Commission is reported as saying that they have all footage available, although there are some gaps. ${ }^{156}$

After the peak in coverage during July and August 2005, the rest of the year does not have any major reports involving CCTV in The Guardian, The Times, the Mirror or the Express. During September, there were a few articles in the Guardian, The Times and the Daily Express focusing on a 'dummy run' carried out by three of the four men who carried out the bombings on the Underground on 7 July. ${ }^{157}$ In November, The Guardian and The Times each contained one article reporting an announcement by Alistair Darling (Transport Secretary) concerning the testing of scanners, able to screen for concealed weapons and explosives, early in 2006. Both articles also mentioned that the number of CCTV cameras on London's Underground would double by 2010, from 6,000 to $12,000 .^{158}$

\subsubsection{Press coverage of CCTV from 2006 - 2008}

During 2006, the terminology used to describe footage from CCTV cameras as 'captured' continued. The coverage of the murder of Thomas ap Rhys Pryce, a lawyer robbed and murdered on his way home in Kensal Green on 12 January 2006, described CCTV footage as 'grainy pictures captured'. ${ }^{159}$ The Guardian

\footnotetext{
${ }^{155}$ For example - The Times 17 August 2005 'Leaked report lists 'blunders' as police shot bomb suspect' p.4

156 The Times 25 August 2005 'Footage of tube shooting has gaps' p.7

${ }^{157}$ The Times 21 September 2005 'CCTV shows 7/7 bombers on dummy run in June' p.8, The Guardian 21 September 2005 'London Bombings: Catalogue of clues’ p.9, Daily Express 21 September 2005 'Dress rehearsal for the 7/7 slaughter' p.9

${ }^{158}$ The Guardian 15 November 2005 'Bomb scanners to be tested on trains in new year' p.6, The Times 15 November 2005 'Smart CCTV could fight terrorist threat in stations’ p.27

${ }^{159}$ The Times 16 January 2006 ‘CCTV shows murdered solicitor’s last journey’ p.9
} 
reported that 'the murderers of Thomas ap Rhys Pryce were caught on CCTV apparently committing another knifepoint robbery in London only 20 minutes before the attack on the 31-year-old lawyer'. ${ }^{160}$ As was the case during the coverage of the London bombings, the use of the term 'captured' to describe images of the bombers or murderers implies a form of action. However, despite the 'murderers' being 'caught on CCTV' prior to the second attack, the second attack was not prevented.

A further report on the murder of Thomas ap Rhys Pryce described the CCTV footage as:

The grainy shots of Mr ap Rhys Pryce's last unsuspecting moments ride on top of an accumulation of other recent images in our minds. The banker John Monckton and his wife, struggling in vain to close their front door against a junkie on bail and a murderous thug on early release ... . Richard Whelan, 28, stabbed six times on the upper deck of the No. 43 bus for standing up and politely asking a black youth to stop to stop throwing chips at his girlfriend. Statistically, I know that these horrific events are still highly unusual. But they are amplified because they feel so close. They loom large in monochrome: black on white killings, fitfully sketched on CCTV. ${ }^{161}$

CCTV in this context therefore captures race issues, as well as class issues. The journalist earlier mentions 'London's professional class' against the 'hiphop culture'. The footage taken by the cameras is not, in this context, a crime fighting tool, but an encapsulation of images of social problems. The Daily Mirror also added a class element to reports, stating that 'A high-flying lawyer was stabbed to death by hoodie muggers just yards from his home', ${ }^{162}$ and 'CCTV clue in hunt for hoodie muggers who knifed lawyer'. ${ }^{163}$ Neither The Times, The Guardian, nor the Express mentioned the attackers as wearing hoods.

\footnotetext{
${ }^{160}$ The Guardian 17 January 2006 'Murder Clue: Stabbing suspects filmed in station’ p.4

${ }^{161}$ The Times 19 January 2006 'Murder in black and white’ p.20

${ }^{162}$ Daily Mirror 14 January 2006 'He gave muggers his possessions but they wanted more...His life’ p.5

${ }^{163}$ Daily Mirror 16 January 2006 ’19 minutes later he was murdered’ p.17
} 
CCTV is mentioned in many articles prior to it having been of use to an investigation. For example, at the beginning of February 2006, a police investigation of a car crash involving four minors is reported in The Guardian: '[checking] CCTV footage to try to establish where the car had been before the accident'. ${ }^{164}$ As another example, a couple of months later during an investigation into the stabbing of a nurse in hospital grounds, the police are reported as 'interviewing witnesses and examining CCTV images for any indication of what had led up to the attack'. The title of this article includes CCTV, implying that it will play a major role in the investigation - 'Nurse stabbed to death in hospital grounds: Colleagues find victim collapsed in parkland: Police check CCTV in hunt for killer' ${ }^{165}$ However, the following day, another article in The Guardian reports that 'speaking at the scene, Det Supt Langley said police had no eyewitnesses and no CCTV footage that covered the area of the attack' ${ }^{166}$ CCTV is also mentioned by the Daily Express despite there being 'no film of the attack'. ${ }^{167}$ Similarly, during the investigation of an attempted murder in Edinburgh, and prior to knowing whether or not CCTV footage existed, The Sunday Times stated that '[Detectives] think that the assailant may have been filmed by CCTV cameras in the Murrayfield area’. Furthermore, the title of the article stated that footage definitely exists - 'Police to study knifing footage'. ${ }^{168}$

During 2006, there was an increase from 2005 in the number of articles focusing on surveillance, control by the state, and the number of cameras in Britain. For example, in February the Daily Express reported that 'thanks to CCTV and speed cameras, we are the most watched people in the Western world. But, despite all this state surveillance, we also live in one of the most violent, terror prone and socially disordered societies in Europe' ${ }^{169}$ In April, The Observer Magazine carried an article focusing on the amount of CCTV cameras in the UK, stating that they have a negligible impact in cutting crime, yet continue to increase in

\footnotetext{
${ }^{164}$ The Guardian 2 February 2006 'Sisters aged 4 and 8 killed as four children die in car crash' p.8

${ }^{165}$ The Guardian 7 April 2006 'Nurse stabbed to death in hospital grounds: Colleagues find victim collapsed in parkland: Police check CCTV in hunt for killer’ p.6

${ }^{166}$ The Guardian 8 April 2006 'Man, 18, held over stabbing of nurse outside hospital’ p.6

${ }^{167}$ Daily Express 7 April 2006 'Nurse hacked to death’ p.5

168 The Sunday Times 29 January 2006 'Police to study knifing footage’ p.7

${ }^{169}$ Daily Express 13 February 2006 'Sinister system of state control must be stopped' p.12
} 
number. ${ }^{170}$ Also during this month, the Daily Mirror reported on 'The Spyway', detailing the number of CCTV and speed cameras on the M42. However, although terminology with negative implications in terms of privacy, such as 'spyway' and 'Big Brother' was used in the article, the overall tone was positive regarding the reduction of accidents and congestion. ${ }^{171}$ The Guardian reported on data sharing, stating 'like CCTV cameras that increasingly expose our every move to hidden viewers, mushrooming electronic data widens the scope to be a suspect and narrows that to act alone'. ${ }^{172}$ The Times also contained an article, written by Guy Herbert (General Secretary of the civil liberties group, NO2ID), on the amount of CCTV cameras, questioning whether they make people safer, and stating that they make people more fearful. He argued that 'Surveillance is not security, but it is control'. ${ }^{173}$ However, although there was an increase in the amount of articles, they were contained within the supplements or features sections of the newspapers, rather than making headline news. The exception to this was a short Guardian piece detailing the future of surveillance in Britain. ${ }^{174}$

During November and December 2006, a series of murders of female prostitutes occurred in Ipswich, Suffolk. The newspaper articles, at this time, once again focused strongly on CCTV and its possible role in the investigation. The Guardian reported that:

Officers are trying to find out what happened between the last sightings of the five young women and the discovery of their bodies by analysing CCTV footage, speaking to other prostitutes and drug workers who knew them. ${ }^{175}$

The Times also reported that CCTV footage will be examined:

\footnotetext{
${ }^{170}$ The Observer Magazine 2 April 2006 'Pan, Tilt, Zoom’ p.28

${ }^{171}$ Daily Mirror 4 April 2006 'The Spyway’ p.15

172 The Guardian 29 September 2006 'Personal Data Sharing: Monitoring Big Brother’ p.36

173 The Times 19 October 2006 'We are the watchers. We help you’ p.21

${ }^{174}$ The Guardian 2 November 2006 'Spy planes, clothes scanners and secret cameras: Britain's surveillance future' p.3

${ }^{175}$ The Guardian 14 December 2006 'Suffolk killings: Jewellery left on women's bodies’ p.4
} 
Footage will be studied in an attempt to identify suspicious cars or vans, especially vehicles that used the A14 between Copdock and Levington on the nights the murdered women disappeared. The two key cameras on the road will be those on high poles on both sides of Orwell Bridge. Intended for traffic management, they may be vital to the search for the killer. So too, police hope, will the 16 CCTV cameras in the red-light district close to Ipswich Town's football ground.

Subsequent articles repeatedly state that police will 'sift through hours of CCTV film' ${ }^{176}$ that 'thousands of hours of CCTV are being examined', ${ }^{177}$ that 'police are analysing more than 10,000 hours of CCTV footage', ${ }^{178}$ and that police are 'trawling through hours of CCTV footage and monitoring cameras which record number plates'. ${ }^{179}$ CCTV recorded images of one of the victims was also reported as having been released by police. ${ }^{180}$ The Daily Express also described more evidence coming to light after the release of CCTV footage of one of the victims. ${ }^{181}$

At the beginning of 2007, The Guardian contained an opinion piece within the technology section, reporting on advances in audio functions on CCTV cameras. The article described the numbers of CCTV cameras already in existence in Britain as being of little concern, and stated:

It is even possible that actual voice surveillance operating in troublespots in UK town centres might prove as uncontroversial as the omnipresence of CCTV cameras, an activity at which Britain leads the world. ${ }^{182}$

\footnotetext{
176 The Guardian 15 December 'The investigation: Manhunt is now national in all but name’ p.4

177 The Sunday Times 17 December 2006 'On the trail of the strangler' p.12

${ }^{178}$ The Sunday Times 17 December 2006 ‘CCTV images of victim’s last hours’ p.1

${ }^{179}$ Daily Express 15 December 2006 'Victims’ p.22

${ }^{180}$ The Sunday Times 17 December 2006 'CCTV images of victim’s last hours’ p.1

${ }^{181}$ Daily Express 18 December 2006 'Has strangler got clothes as sick trophies?’ p.15

${ }^{182}$ The Guardian 4 January 2007 ‘Big Brother sugars the surveillance pill’ p.4
} 
A number of other articles also at the beginning of the year focus on the potential intrusion and privacy impacts of CCTV cameras and increased surveillance by the Government. The Daily Express described a 'rash of CCTV cameras' ${ }^{183}$ A Times article used the title: 'Big Brother will be watching for ever', ${ }^{184}$ and The Sunday Times the phrase: 'Oy! Big Brother is talking to you' ${ }^{185}$ CCTV was also framed in a negative light within articles focusing on speed cameras and traffic control, referred to in this context as 'spy cameras', ${ }^{186}$ which 'monitor' the public. $^{187}$

Also at the start of the year, during the trial of the 21 July 2005 failed bombers, CCTV was reported as being used frequently, with the jury being shown footage of the various men involved. In this case, CCTV was used as evidence. The terminology used in the newspaper articles, once again implied a form of action by the cameras, with use of the word 'caught':

At Shepherd's Bush, Mr Osman's device also failed, as did those of Mr Ibrahim on the number 26 bus and Mr Omar at Warren Street, the court heard. When the devices failed the men are said to have fled, only to be caught on CCTV. ${ }^{188}$

He was caught on CCTV catching a No 220 bus towards Wandsworth, where he disembarked and was seen to make two telephone calls from a call box. ${ }^{189}$

Caught on CCTV: Boxes on trolley. This is the moment two alleged suicide bomb plotters laughed and joked as they collected more than 200 litres of the main explosive ingredient. ${ }^{190}$

\footnotetext{
${ }^{183}$ Daily Express 5 March 2007 'Now the all-powerful state is even prying on our young children' p.12

${ }^{184}$ The Times 6 March 2007 'Big Brother will be watching for ever' p.36

${ }^{185}$ The Sunday Times 4 March 2007 'Oy! Big Brother is talking to you' p.4

${ }^{186}$ The Sunday Times 18 March 2007 'Friend or foe? The roadside spies cluttering up Britain’ p.4

${ }^{187}$ The Times 20 March 2007 'A witness you can't trust' p.7

${ }^{188}$ The Guardian 16 January 2007 'July 21 bomb plot: Failure of devices foiled tube attacks, court told' p.2

${ }^{189}$ The Times 17 January 2006 'CCTV shows would-be bombers trying to blow themselves up' p.6

${ }^{190}$ Daily Mirror 20 January 2007 ‘Shopping for bombs’ p.19
} 
Footage of the men was also described as having been 'picked up' at various locations, once again implying action and adopting a phrase often used to describe a person being arrested by the police; i.e. 'picked up by the police':

On Stockwell Road in South London, the three men were picked up by CCTV cameras walking separately towards the Tube station .... . CCTV cameras on the platforms picked him up, a distinctive figure with cropped hair and the New York top - deliberately chosen, it is alleged, to refer to the events of $9 / 11 .{ }^{191}$

In the aftermath of Bob Woolmer's (the England cricket coach) suspected murder in Jamaica during the 2007 World Cup, CCTV was once again reported as being vital to the police investigation prior to any definite use of footage. One article in The Guardian went as far as to definitively state in the title that 'CCTV cameras will provide clues' ${ }^{192}$ A few days later, reports stated that the footage is of poor quality and would need to be enhanced before being used for investigative purposes. $^{193}$

The following month, after successful trials in Middlesborough, the imminent arrival of more 'talking' CCTV cameras was reported in both newspapers. The Times described the cameras as targeting 'yobbish behaviour'. ${ }^{194}$ A day later, The Times also included another article containing criticism levelled at the new development from the civil liberties organisation Liberty. ${ }^{195}$ The Guardian focused more strongly on the privacy aspects of the new development. One article began: 'The surveillance society found its voice yesterday' ${ }^{196}$ Within the Features section, an article stated that: 'The government may be tough on stray crisp packets and tough on the causes of stray crisp packets', thereby belittling the

\footnotetext{
${ }^{191}$ The Times 17 January 2006 'CCTV shows would-be bombers trying to blow themselves up' p.6

${ }^{192}$ The Guardian 24 March 2007 'Bob Woolmer murder: Yard veteran grapples with mystery of Room 374: Absence of signs of forced entry and nakedness of corpse will lead investigators to look at coach's associates. CCTV cameras will provide clues' p.14

193 The Times 27 March 2007 'Poor-quality tapes will need to be enhanced’ p.9

194 The Times 4 April 2007 'Big Brother Talks’ p.4

${ }^{195}$ The Times 5 April 2007 'Talking CCTV cameras will see crime and tick off louts’ p.27

${ }^{196}$ The Guardian 5 April 2007 'Cameras to tell off troublemakers’ p.6
} 
development as one that only tackles littering. ${ }^{197}$ The Daily Express targeted the development negatively, by dismissing it as 'another Labour gimmick' ${ }^{198}$ The Daily Mirror also focused on the negative implications, describing an Orwellian situation and constant surveillance, enhanced by the latest development of talking CCTV cameras. They stated: 'Big Brother really is watching you', and Simon Davies (Privacy International) was quoted as saying 'If something is not done soon to reverse this trend, privacy will be extinct within a decade'. ${ }^{199}$

Privacy issues come to the forefront again at the start of May 2007, with reports that Richard Thomas, the Information Commissioner, has submitted written evidence to the House of Commons inquiry into the surveillance society. ${ }^{200} \mathrm{~A}$ day later, The Guardian also published a features article arguing that Britain needs to look after its civil liberties. ${ }^{201}$ The Times did not publish an article focusing on this development. Concerns were reported in The Guardian over the installation of CCTV cameras into rural villages with low levels of crime, with reports of a possible 'Orwellian' situation arising in terms of surveillance. ${ }^{202}$ The Times focused on a report from CameraWatch (a national CCTV advisory body) stating that; 'the vast majority of CCTV is used incorrectly and could potentially be inadmissable $[$ sic $]$ in court' ${ }^{203}$

Just prior to this, CCTV was once again repeatedly mentioned (despite not playing a significant part in the investigation) in relation to the disappearance of Madeline McCann, who disappeared on the 3 May 2007 in Portugal from her family's apartment in the holiday region of the Algarve. One Times article discussed the lack of CCTV as causing problems for the investigation and stated; 'The country does not have the extensive CCTV network that blankets Britain, making kidnapping cases far more difficult to crack' ${ }^{204}$ Footage of three possible

\footnotetext{
197 The Guardian 5 April 2007 'Big Brother is watching, listening and talking to you’ p.3

${ }^{198}$ Daily Express 5 April 2007 ‘Talking CCTV? It’s just another Labour gimmick’ p.9

199 Daily Mirror 9 April 2007 '1984 comes true’ p.8

${ }^{200}$ The Guardian 1 May 2007 'New powers vital to avert surveillance society, says watchdog’ p.3

${ }^{201}$ The Guardian 5 May 2007 'Surveillance can save innocent lives, but we still need to stand up for our civil liberties’ p.11

${ }^{202}$ The Guardian 21 May 2007 'CCTV in shires alarms senior police officer: Benefits of wideranging surveillance questioned' p.6

203 The Times 31 May 2007 'Nearly all CCTV cameras 'are illegal' p.33

${ }^{204}$ The Times 9 May 2007 'Angry Portuguese ask why couple left the children alone’ p.7
} 
suspects was discussed a few days later, but the poor quality was reported in The Observer as hindering the investigation. ${ }^{205}$ The Daily Express, however, printed a front page story with the title 'Police have CCTV footage in new breakthrough'. Later in the article they stated that it was a 'possible sighting' of Madeleine. They did not mention the poor quality of the footage. The next day in The Times, this footage was disregarded. ${ }^{206}$

On the 27 August 2007, Rhys Jones, an 11 year old boy, was murdered in Croxteth Park, Liverpool. He was shot in the back at 7.30pm. CCTV was reported in both The Times and The Guardian as playing a significant part in the investigation. The Times stated that; 'There was a significant breakthrough last night in the hunt for the killer of Rhys Jones, when 12 people identified the same person after viewing closed circuit television footage of the alleged shooter' ${ }^{207}$ The footage was aired on the television programme Crimewatch, alongside a reconstruction of the incident. The Guardian focused on the footage of the suspect prior to the shooting, once again using the terminology 'captured on camera' and 'the camera caught him again 30 seconds later'. ${ }^{208}$ In terms of the response to the footage aired on Crimewatch, they do not treat is a 'breakthrough', but described the footage as 'grainy'. ${ }^{209}$ The Daily Mirror reported that 'the teenage killer of little Rhys Jones was captured on CCTV as he rode to and from the scene of the shooting', detailing later in the article that 'the actual shooting is not caught on film'. ${ }^{210}$ The Daily Express reported that 'the killer of Rhys Jones was caught on CCTV just three minutes before he gunned down the 11-year-old'. ${ }^{211}$

The last major story of 2007 involving CCTV was the release of a report from the Home Office, describing $80 \%$ of images from cameras as being of no use to

\footnotetext{
${ }^{205}$ The Observer 13 May 2007 'Madeleine: poor CCTV shots of suspects hamper police’ p.5

${ }^{206}$ The Times 14 May 2007 'Detectives in search for Madeleine admit they have no suspect' p.15

${ }^{207}$ The Times 27 September 2007 'Boost in hunt for Rhys's killer as 12 identify youth on CCTV' p.20

${ }^{208}$ The Guardian 27 September 2007 'Liverpool murder: CCTV captures a boy on a bike - thirty seconds later he had killed Rhys Jones: Locals believe they know who shot 11-year-old Mother renews appeal for witnesses to come forward' p.9

209 Ibid.

${ }^{210}$ Daily Mirror 30 August 2007 'Trail of Rhys Killer’ p.4

${ }^{211}$ Daily Express 30 August 2007 'Caught on film, boy who shot Rhys dead’ p.24
} 
police in identifying criminals. ${ }^{212}$ The placing of CCTV cameras was also reported as being ineffective in preventing terrorism or serious crime. ${ }^{213}$

A number of articles in The Times at the start of 2008 focused on the use of CCTV cameras. This coincided with the release of a new CCTV code of practice by the Information Commissioner’s Office. One article reported that:

SEVEN people out of ten oppose CCTV cameras being allowed to record their conversations, according to the Information Commissioner's Office (ICO) .... . The study also reveals that more than half the public don't realise that the use of CCTV is covered by the Data Protection Act. ${ }^{214}$

The next day, The Times published another article focusing on the negative aspects of surveillance technologies, with a particular emphasis on CCTV cameras. They stated:

Walk down any high street in Britain today and you will instantly be under surveillance. All around you, lampposts and shopfronts bristle with CCTV cameras, many of them privately operated and unregulated. ${ }^{215}$

A few days later, they also published an article describing how to 'escape the spies all around us'. ${ }^{216}$ Although not focusing specifically on CCTV as the article discussed:

${ }^{212}$ The Times 20 October 2007 'Eight out of ten CCTV images offer no help in solving crimes' p.2 2

${ }^{213}$ The Guardian 20 October 2007 'Police and CCTV: pictures too poor, cameras in wrong place: Networks are little use in fighting crime, says report: Authorities have no idea how many cameras exist' p.16

${ }^{214}$ The Times 5 February 2008 'CCTV under the spotlight' p.8

${ }^{215}$ The Times 6 February 2008 'Every breath you take, every move you make, a camera will be watching you' p.7

${ }^{216}$ The Times 9 February 2008 'Living off the grid - how to escape the spies all around us’ p.33 
Britain is the undisputed leader in the free world at snooping on its citizens. We are watched everywhere we go: driving to work, walking the dog, shopping, taking the train. We are constantly under surveillance, by camera, by the chips in our debit, credit or store cards. When we telephone or e-mail our friends, numerous agencies and private companies instantaneously know what we are doing and where we are doing it from. We can barely turn on a light or the oven without someone, somewhere, tracking our every move. ${ }^{217}$

During March, The Times published a number of articles criticising the use of CCTV for parking enforcement, naming it a 'devious revenue raiser' and that; 'local authorities use CCTV to boost their revenue'. ${ }^{218}$ The Daily Express also referred to the development as a 'money-making scam'. ${ }^{219}$ The Guardian, although reporting the development, did not provide any criticism of the use of cameras for this purpose. ${ }^{220}$

A few months later, however, The Guardian published an article stating that:

Pervasive security cameras don't substantially reduce crime ... . Overall, CCTV cameras aren't very effective. This fact has been demonstrated again and again. ${ }^{221}$

A month earlier, the Daily Express included an article entitled 'Big Brother is not working', describing CCTV as a waste of money and a failure as a preventative measure to crime. ${ }^{222}$ In their comment and debate pages, The Guardian and Observer published a couple of articles arguing strongly against CCTV and its prevalent use. The Guardian argued:

${ }^{217}$ The Times 9 February 2008 'Living off the grid - how to escape the spies all around us' p.33

${ }^{218}$ The Times 29 March 2008 'Stop this devious revenue raiser' p.3, 'Smile, your fine is in the post' p.6

${ }^{219}$ Daily Express 17 March 2008 'Uproar over new £120 parking fines' p.29

${ }^{220}$ The Guardian 31 March 2008 'Motorists face new traffic penalties' p.13

${ }^{221}$ The Guardian 26 June 2008 'CCTV doesn't keep us safe, yet the cameras are everywhere’ p.2 This article is referring to comments made by DCI Mike Neville, head of Scotland Yard's Visual Images, Identifications and Detections Office, stating that CCTV was ineffective at deterring criminals

${ }^{222}$ Daily Mirror 7 May 2008 ‘Big Brother is not working’ p.18 
Closed-circuit TV cameras are the crime-fighting tool so fiendishly sophisticated that they can be foiled by the wearing of a hood. Yet having stuck 4.2 million of the things around this country, with nary a consultation on the matter - nor any significant impact on crime statistics - efforts to pimp them to 2.0 status continue. ${ }^{223}$

The Observer focused more generally on surveillance and civil liberties, but of CCTV stated that there is:

[A] waste of public funds in local government surveillance operations and CCTV systems which Detective Chief Inspector Mike Neville, Scotland Yard's CCTV expert, declared an 'utter fiasco'. ${ }^{224}$

CCTV is mentioned in numerous articles in the four newspapers for the rest of the year, but did not play a major part in any stories.

\subsection{CCTV in the press}

Over the past 15 years, articles focusing on CCTV have increased dramatically. The early 1990s saw The Guardian approach the increased use of the technology with criticism, whilst The Times depicted the developments in a largely positive light. The Daily Mirror and Daily Express also represented CCTV in a positive light during the 1990s. A change in coverage in The Times occurred during 2000, with an increase in mentions of privacy and the implications of the technology. The Guardian also increasingly mentioned privacy and excessive surveillance. The Daily Express only reported on the possibly negative privacy implications of CCTV in 2002.

\footnotetext{
${ }^{223}$ The Guardian 28 June 2008 'This surveillance onslaught is draconian and creepy: The cameras, they are multiplying - and now they even have ears. But the state hasn't stopped to run the plan past us' p.30

${ }^{224}$ The Observer 29 June 2008 'We can't leave David Davis to carry the fight on his own: With Labour addicted to regulating how we live, the lone rebel deserves support if we want to our freedoms to remain intact' p.28
} 
Although all the newspapers continued to mention negative aspects of CCTV during the period 2002-2005, there was also an increase in the assumption that CCTV would be of use to investigations, with it repeatedly mentioned as a first port of call for the police. The print media coverage of the 7 July 2005 bombings and the aftermath was generally positive about the role played by CCTV. There was little mention of the technology not having stopped the bombings occurring, even though CCTV was pushed forward as a 'crime fighting' or 'crime prevention' technology by the Government. Instead the emphasis lay in the identification of the bombers after the event and the importance of CCTV footage in this task. The language used is extremely interesting: terms such as 'caught' by CCTV cameras implies some form of action. Juxtaposing this with the terms used in the event of the disappearance of Holly Wells and Jessica Chapman in 2002 shows a completely different set of terminology used. In this case, CCTV footage of the girls was described in terms such as: 'possible sightings', 'spotted', 'images of the girls'. ${ }^{225}$ In some ways the event of two little girls going missing frames the coverage as it can only be described as an 'awful thing to happen'. With regard to the coverage of CCTV in this case, it is placed in the role of protector, with the cameras following the girls. With regard to the 7 July bombers, the cameras follow the criminals, fulfilling the role of hunter rather than protector.

CCTV continued to be portrayed as indispensable during 2006 with reference to a number of murder investigations, even prior to assessment of the usefulness of footage, or whether footage even exists. However, at the same time there was an increase in the number of articles focusing on the negative implications of widespread CCTV and surveillance. This focus on possible negative repercussions extended into 2007, although there were also numerous articles discussing the use of CCTV in high profile crimes. During the first half of 2008, CCTV came under the spotlight in a discussion of the effectiveness of the technology, with The Times in particular launching an attack on the amount of money spent in relation to their impact on levels of crime.

\footnotetext{
${ }^{225}$ Daily Mail 6 August 2002 'How did they just vanish’ p.1, The Sun 8 August 2002 'Parents' vigil in church’, Daily Express 12 August 2002 'Jessica and Holly’ pp.4-5
} 
Overall, CCTV has been portrayed in a positive light in the press; it is depicted as a technology to 'capture' and 'protect' the law abiding public from 'fiends' and 'criminals'. An anthropomorphisation of CCTV occurs with the media portrayal of the technology as 'heroes' and 'guardian angels'. The technology was frequently reported as being 'vital' to investigations; the first port of call for the police who 'trawl' and 'scour' the footage recorded. The technology in this sense has been represented in the media as a tool to reduce risk. In its role as protector, CCTV was used to address the risk posed by terrorists after the 7 July 2005 bombings. Increased installation of CCTV was posed as a solution, by the media, to the continuing threat and risk of a repeat attack.

CCTV was also often referred to in reports of missing persons and possible abductions. In this context, CCTV was used to trace the last steps, movements, and actions of the person. Although, as has been shown, press coverage at the time of the murder of James Bulger did not focus heavily on the role of CCTV, later reports mentioned its place in this investigation as extremely important. Other media coverage did, however, thrust it into the spotlight, with the footage replayed on television during news broadcasts. The moral panic arising from this crime was surely heightened by advice from the Merseyside Police at the time:

Until this person is caught, parents must keep hold of their children because until we know who is responsible, we cannot guarantee their safety. $^{226}$

Later reports focusing on CCTV and its important role in the investigation, placed it in the role of a technology that will protect the public from similar incidents; a risk-mitigating technology to keep children safe.

\footnotetext{
${ }^{226}$ BBC 'Missing two-year old found dead' http://news.bbc.co.uk/onthisday/hi/dates/stories/february/14/newsid.2541000/2541171.stm
} 


\subsection{Conclusion}

In this chapter I have looked at local and national government promotion of CCTV, the issue of public engagement and consultation on CCTV, drawing also on the Identity Cards Scheme in order to speculate about what a national consultation on CCTV might look like. I have also explored media coverage of CCTV over the past fifteen years, focusing particularly on large scale crimes.

In a political context, policy on CCTV still takes a top-down approach. Although CCTV policy is formulated under a liberal democracy, public participation is very limited and in some cases (such as the 2005 National CCTV Strategy consultation) groups are excluded (as was the case for civil liberties representatives). The public is constructed as a passive consumer of surveillance, and one that needs to be looked after. This is reinforced in media discourse, describing CCTV as a protector of the public.

Policy discourse surrounding CCTV describes a public who 'feel safer when they are out and about'. I have shown that this statement and similar can be contested through recent public opinion surveys. Although the statement is presented as fact, there is no reference to empirical research to back this up. Therefore, although it may appear that the public have accepted and welcomed the deployment of CCTV in terms of enhanced feelings of safety, this may not be the case. The public have been judged as fearful, an entity that requires a feeling of safety and a strategy of risk reduction in order to go about their everyday lives. 


\section{Chapter VIII:}

\section{The Digital Bridge}

\subsection{Introduction}

In this chapter I present the findings of my empirical research. I explore in more detail the issue of CCTV and the public, particularly in the context of public engagement. I refer back to the research question posed at the beginning of the thesis: Why have the public apparently accepted the deployment of surveillance technologies? Within this research question, I look issues of privacy, public engagement, feelings of safety and fear of crime, communities, and peer-to-peer surveillance.

First, I provide background to the Digital Bridge project, discussing who was involved, funding and delivery, and political endorsements. Next, I move onto an exploration of literature concerned with communities, regeneration and selfgovernance, directing this analysis to the specificities of the Digital Bridge project. I then give an overview and analysis of the results of the questionnaire sent out to residents on the estates, before next exploring the findings from interviews with respondents.

\subsection{The Digital Bridge Project}

The Digital Bridge project was officially launched in Shoreditch on $8^{\text {th }}$ May 2006 by the Minister for London and Neighbourhood Renewal, Jim Fitzpatrick. The project was to involve bringing broadband to two estates in Hackney, East London: Charles Square estate and Haberdasher estate, through a PC on TV service. Included in the project was the installation of CCTV cameras onto the estates, and the inclusion of a television channel (the Community Safety channel), which residents could access to watch live images from the newly installed CCTV cameras. 
The service was delivered by the regeneration agency, the Shoreditch Trust, in partnership with Video Networks Ltd. and received funding from the Office of the Deputy Prime Minister (now the Department for Communities and Local Government), the European Union and private investment, totalling £12 million.

The following political endorsements about the project were made (at the $21^{\text {st }}$ Century Public Services: Putting People First, QEII Conference in June 2006):

Tony Blair (Prime Minister):

Digital Bridge is an immensely important project ... . It will allow people to report graffiti online ... And to be able to do that very, very easily through the technology. It's going to be fantastic for people and I think it is a really exciting project. And if it works as well as we hope then we can see that project extending in many different parts of the country. ${ }^{1}$

Gordon Brown (Chancellor of the Exchequer):

We are interested in how local authorities across the country can use the internet and web portals to allow people to ... receive the services they use. I have looked at Shoreditch ... at the Digital Bridge that allows people to alert residents as events happen, and residents to alert them about abandoned cars, about graffiti, about vandalism. $^{2}$

These political endorsements seem to be highly technologically deterministic in their approach. Although both quotes mention that people will be involved in the project (in terms of alerting the authorities about crimes) neither really situate the technology in a socio-technical network. I have also shown this to be the case with regard to media reports of the use of CCTV. The technology is portrayed as the solution - the rest simply follows. Furthermore, the project

\footnotetext{
${ }^{1}$ www.londonconnects.gov.uk/docman/digital-london/digital-bridge-presentation/download.html 2 www.londonconnects.gov.uk/docman/digital-london/digital-bridge-presentation/download.html
} 
was marketed by the Shoreditch Trust as a project tackling social and digital exclusion; however the political discourse at the time is about tackling crime.

The pilot results for the Digital Bridge project in Shoreditch stated that:

70\% regularly accessed and used the live webcam network

$46 \%$ of users were reporting crime through the Action Maps (an interactive application detailing where crime has been reported and where it is being cleared) ${ }^{3}$

An article in The Register detailed that the pilot results from Shoreditch were to be released in January 2008. The author describes the results of the pilot (which he reports as having closed in June 2007) as showing that the viewing figures of Shoreditch TV have the 'equivalent reach of prime time, week-day broadcast programming'. He adds that Phase Two of the project will be announced in January, with the model being promoted to councils nationwide. ${ }^{4}$

The description of the Digital Bridge project and its aims seem to fit in with wider Government policies focusing on the greater involvement of civil society in crime prevention and a more active public (along the same lines as Neighbourhood Watch during the 1980s), and the recent rhetoric of greater community cohesion, renewed communities and regenerated neighbourhoods.

In theory, the Digital Bridge project is a step towards self-governance, by providing individual and private access to public images from CCTV cameras. A privatisation of public space has occurred within the estates, due to the control of this space by the residents. This fits in with the issue of the 'fortress impulse' described in towns and cities, wherein Ellin argues that although this may make some people feel safer, it can also 'contribute to accentuating ... fear by increasing paranoia and distrust among people'. 5 The result could therefore be, as opposed to the possibility of community cohesion, a real possibility of isolation and mistrust within the community. Ellin states that:

\footnotetext{
${ }^{3}$ www.londonconnects.gov.uk/docman/digital-london/digital-bridge-presentation/download.html ${ }^{4}$ Ballard, M. The Register 11 November 2007 'Home snoop CCTV more popular than Big Brother'

${ }^{5}$ Ellin, N. (1997) Architecture of Fear Princeton Architectural Press; New York p.42 See also Bannister, J. (1991) and Tilley, N. (1995)
} 
The close of the $20^{\text {th }}$ century is characterized by the selfsegregation of social sectors that, inspired by fear and homogeneity, have ruled for an intense privatization of public space, the development of highly isolated community models and controlled realities and environments by means of surveillance technology. ${ }^{6}$

For Castells, this isolation comes from more deprived areas existing in a manner of 'tribalism of local communities, retrenched in their spaces', in contrast to the 'cosmopolitanism of the elite, living on a daily connection to the whole world'. ${ }^{7}$ However, in his study of high rise estates in Scotland, McGrail shows the existence of information technology and CCTV and states that:

Although the specific forms new technologies take in these areas do differ from wealthier districts (in terms of who owns the technology and how it is utilised), they are nonetheless an essential part of the information revolution. ${ }^{8}$

The Digital Bridge project under a New Labour government has been described as being situated in neo-liberal political thought:

From the perspective of neo-liberalism, it is the individual who is principally responsible for crime and disorder ... the solutions to rising crime and public disorder are seen in terms of fostering a sense of individual responsibility. ${ }^{9}$

This type of initiative may however have the reverse effect. Groombridge and Murji argue that the presence of CCTV makes the public assume that someone

\footnotetext{
${ }^{6}$ Benites, C. and Lyster, C. (September 2005) 'Regarding public space’ Architecture Journal http://www.gg-architects.com/306090\%20public\%20space.pdf

${ }^{7}$ Castells, M. (1989) The Informational City: Information Technology, Economic Restructuring and the Urban-Regional Process Blackwell; Oxford p.30

${ }^{8}$ McGrail, B. A. (1999) 'Communication Technology and Local Knowledges: The case of peripheralized high rise housing estates’ in Urban Geography 20(4) pp.303-333 p.303

${ }^{9}$ Fyfe, N. R. (1995) 'Law and order policy and the spaces of citizenship in contemporary Britain' Political Geography 14(2) pp.177-189 (p.178)
} 
else is watching and/or that it is someone else's problem - 'As they move about head down' - individual responsibility is diminished. ${ }^{10}$

Surette argues that:

The possibility of CCTV causing a reduction in informal citizen guardianship is not a trivial issue. Prior evaluative research suggests that CCTV reduces crime more effectively through a crime deterrent effect as opposed to a crime detection effect. In addition, CCTV systems have not been found to be able to independently reduce crime. Thus, continued citizen involvement in CCTV-surveilled areas is important ... A consensus that has emerged from the research literature is that CCTV systems need to be coupled with police involvement to be fully effective ... Therefore, if the installation of CCTV systems results in the reduction of vigilance by persons in the camera's field of view, the net effect on crime could be counterproductive. From this orientation, an untested hypothesis regarding CCTV is generated: Its deployment in public space results in the substitution of formal technological surveillance for traditional informal citizen surveillance. $^{11}$

This thought is echoed by Groombridge and Murji who suggest that:

Instead of worrying about 'Big Brother' watching them, the public may perceive that 'Big Father' has sorted everything out. ${ }^{12}$

The involvement of residents in policing their estates through access to CCTV footage may therefore be a way to bypass this issue of the loss of informal citizen guardianship. It would take, however, active involvement on the part of the residents.

\footnotetext{
${ }^{10}$ Groombridge, N. and Murji, K. (1994) ‘As Easy as AB and CCTV?’ Policing 10(4) pp.283-290 (p.289)

${ }^{11}$ Surette, R. (2006) 'CCTV and citizen guardianship suppression: A questionable proposition' Police Quarterly (9) pp.100-125 (pp.101-102)

${ }^{12}$ Groombridge, N. and Murji, K. Op.cit. p.288
} 


\subsubsection{Press coverage of the Digital Bridge project}

I found surprisingly little press coverage of the Digital Bridge project. The response from the few press articles available was as follows:

The Sunday Times:

Residents of a trendy London neighbourhood are to become the first in Britain to receive 'Asbo TV' - television beamed live to their homes from CCTV cameras on the surrounding streets. ${ }^{13}$

The use of the word 'trendy' in this article does not fit with the reality of the two estates chosen for this project. The project was part of the New Deal for Communities scheme at the time to regenerate poor areas.

The Times concentrated on the technological (the article was situated in the technology section):

A British-designed internet system promises to break the 'fourminute mile' of broadband technology by delivering the fastest web service on the planet to British households ... Introduced this month, the system will allow 20,000 households to surf the web and download material at speeds up to 2,000 times faster than present services. $^{14}$

The Daily Telegraph made a reference to popular culture and said that:

BIG BROTHER, the reality television show that attracts up to seven million viewers, is old hat. ${ }^{15}$ In the world of boundary-pushing television, it was surpassed yesterday by a group of East-enders who have become the first to monitor their own neighbourhood via a home CCTV channel. Shoreditch TV is an experiment in beaming live footage from the street into people's homes and promises to be every bit as fascinating as the courtship rituals of the Celebrity Big Brother contestants Chantelle and Preston. Viewers can watch the dog walkers

\footnotetext{
${ }^{13}$ The Sunday Times 8 January 2006 'Asbo TV helps residents watch out'

${ }^{14}$ The Times 6 March 2006 'World's fastest internet will send Britannica to Shoreditch in 7 sec'

${ }^{15}$ The TV show Big Brother is filmed only two miles away on the River Lea at Elstree Studios
} 
on the street below, monitor the appearance of new graffiti and keep an eye on the local pub. ${ }^{16}$

The BBC asked whether the scheme was a 'step too far' in terms of civil liberties, quoting Gareth Crossman, policy director of Liberty (Human Rights organisation in the UK), as saying that:

[CCTV footage] should remain within the control of the local authority. While we're all under a duty to help police as best we can, what this basically means is that people will simply be monitoring all sorts of activities whether they're criminal or not. It also means that some people are likely to demand the police take action against groups of kids hanging around who aren't actually doing anything illegal...It could [also] lead to vigilantism. ${ }^{17}$

The BBC also reported the spokesman of the Digital Bridge project, Daniel Hodges, as saying:

[The Digital Bridge was] requested by and set up by local residents...This project has very, very strong support within the local community. The reality is that, in many communities across the country, crime and fear of crime are a very real problem and people want to see their families protected as well as their civil liberties.

\subsection{Questionnaire results}

I sent a questionnaire out to the residents of Charles Square and Haberdasher estates. My aim was to find out about levels of usage of the Digital Bridge television service, residents' feelings of safety, their thoughts on CCTV, and the levels of consultation prior to the installation of cameras onto the estates.

\footnotetext{
${ }^{16}$ The Daily Telegraph 9 May 2006 'CCTV channel beamed to your home’ p.6

${ }^{17}$ BBC News 8 May 2006 'Is 'reality CCTV' a step too far'
} 
The questionnaire was sent out to 400 households. 35 responses were returned. I have discussed the strengths and weaknesses and my methodological approach in the methodology chapter.

\section{Number of Respondents}

I received responses from 19 females (54\%) and 15 males (43\%). One did not specify an answer.

Fig. 8.1 Number of respondents

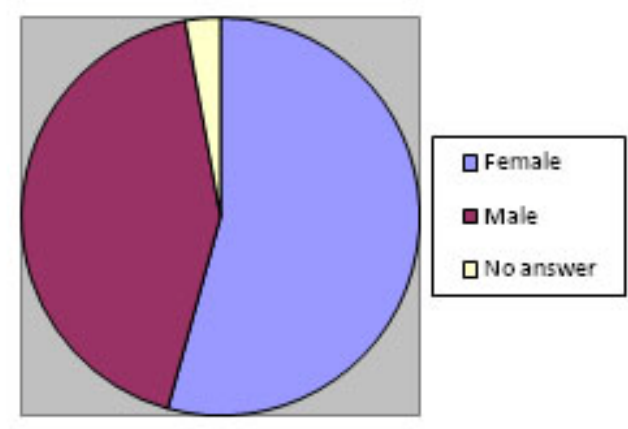

\section{$\underline{\text { Television Usage }}$}

32 of 35 respondents (91\%) have a television set in their house, of which 25 (78\%) responded that they watch it daily. 4 (12.5\%) stated that they watch their television four to five times a week, and one (3\%) replied that they watch it two to three times a week.

Fig. 8.2 Television use

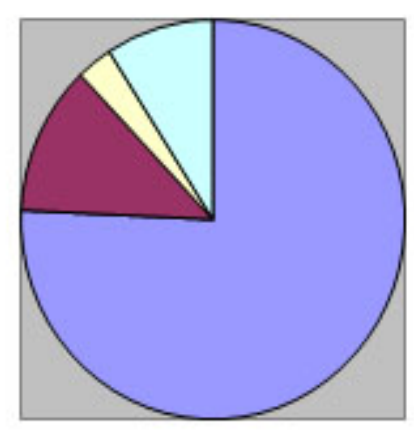

$$
\begin{aligned}
& \text { aDaily } \\
& \text { 口4-5 times } \\
& \square 2-3 \text { times } \\
& \square \text { NoTV }
\end{aligned}
$$


When asked whether they subscribe to the Digital Bridge television service, of the 32 respondents who stated they have a television set in their house, 2 (6\%) replied in the affirmative.

Regarding the Community Safety channel, 13 (37\%) answered that they were aware of the channel. Of these, 3 (23\%) answered that they had watched the channel; 2 during the evening and over 6 months ago, and one at various times and once a month. None of the respondents answered that they had witnessed a crime on the Community Safety channel.

\section{Feelings on CCTV and Consultation}

Of the 35 responses received 16 respondents (46\%) were aware of the CCTV cameras on their estate.

Fig. 8.3 Awareness of CCTV cameras

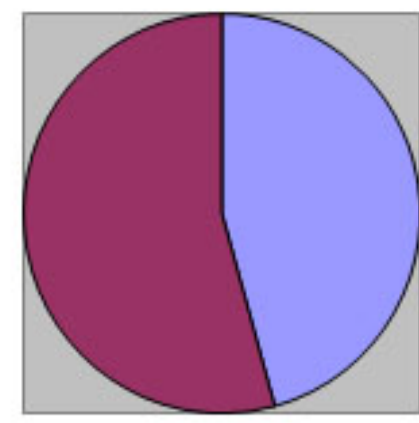

口Aware

a Not Aware

Of the 16 respondents who were aware of the CCTV cameras, 5 (31\%) stated that they were given some or a lot of information about the installation of CCTV on their estates.

Of the 35 responses received, 20 (57\%) answered that they had received no information about the installation of CCTV on their estates, and 8 (23\%) that they had received little information. 
Fig. 8.4 Information received regarding CCTV installation
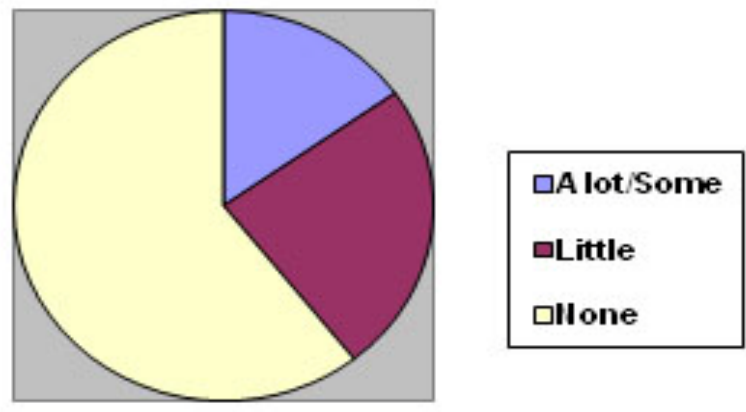

In terms of levels of satisfaction about how much information was received regarding installation of CCTV cameras, only one respondent (3\%) stated that they felt satisfied and two (6\%) stated that they were fairly satisfied. Of the remainder, 3 (9\%) declared themselves to be fairly unsatisfied and 7 (20\%) as unsatisfied. 16 respondents (46\%) answered that they were very unsatisfied with the amount of information they received.

Fig.8.5 Levels of satisfaction regarding information received about CCTV installation
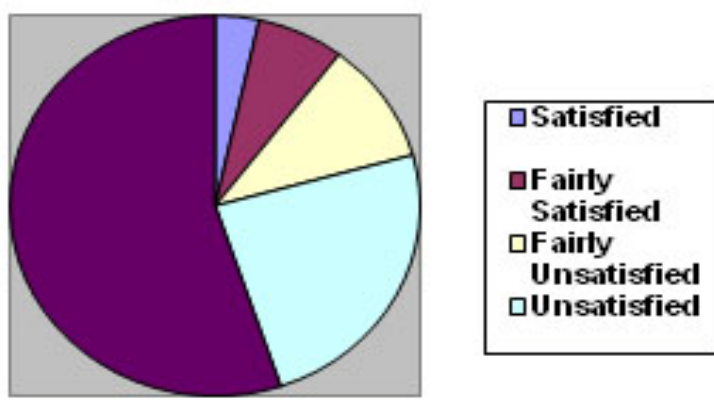

In terms of consultation, prior to the installation of cameras, one respondent (3\%) was asked to participate in a focus group by the Shoreditch Trust. 30 (86\%) stated that they had not been asked to participate, or asked their opinion in any other way (the remainder answered that they could not remember or did not know). 
Fig. 8.6 Consultation prior to CCTV installation
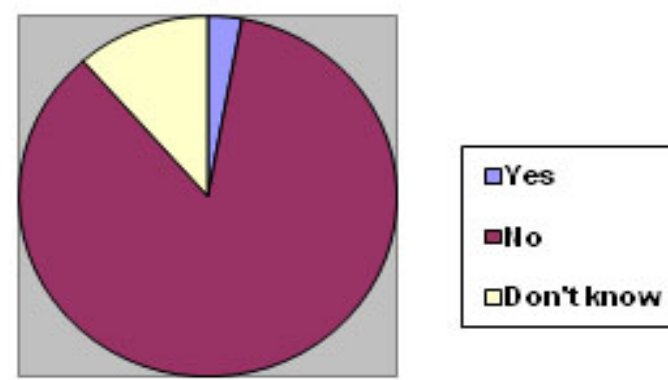

Of the 30 respondents who answered that they had not been asked their opinion in any other way, or been asked to participate in a focus group, 27 (90\%) stated that they would have liked to have been asked their opinion.

\section{$\underline{\text { Safety and Privacy }}$}

Of the 16 respondents who were aware of the CCTV cameras prior to the questionnaire, 3 (19\%) agreed or strongly agreed that they felt safer on their estate since the introduction of CCTV (these three respondents also all agreed or strongly agreed that CCTV helps prevent crime on the estate, and strongly disagreed or disagreed that CCTV invades residents’ privacy). (I disregarded those answers from respondents unaware of the cameras prior to the questionnaire). 4 respondents (25\%) strongly disagreed that the introduction of CCTV on their estate has made them feel safer. ${ }^{18}$

Fig. 8.7 CCTV and feelings of safety
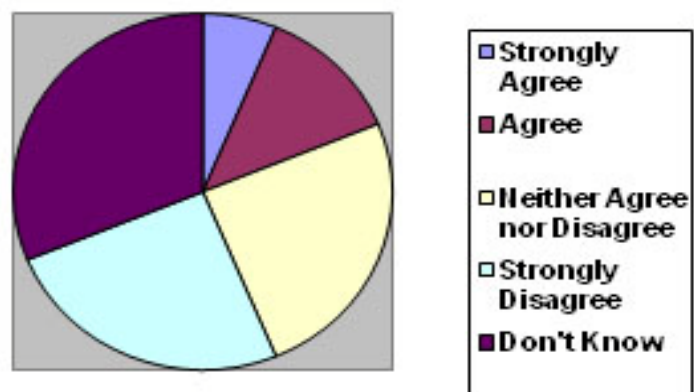

\footnotetext{
${ }^{18}$ These statistics are useful as being indicative of what the issues are. I am not using these numbers to infer statistical likelihood.
} 
Of the 35 respondents, 2 (6\%) strongly agreed and 7 (20\%) agreed that CCTV helps prevent crime on the estate. 7 (20\%) neither agreed nor disagreed. 5 (14\%) disagreed and 6 (17\%) strongly disagreed that CCTV helps prevent crime on the estate.

Fig. 8.8 CCTV and crime prevention
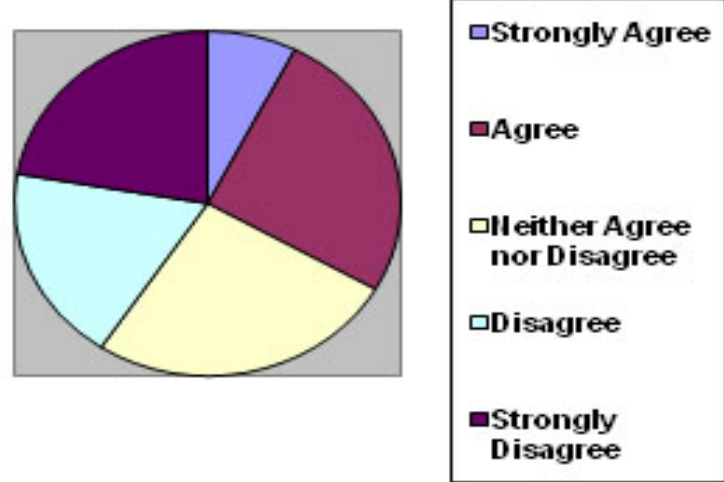

10 respondents (29\%) disagreed or strongly disagreed that CCTV on the estate invades residents' privacy. 10 respondents (29\%) agreed or strongly agreed that CCTV invades residents’ privacy. 9 respondents (26\%) declared that they neither agreed nor disagreed (6 stated that they don’t know).

Fig. 8.9 CCTV and privacy

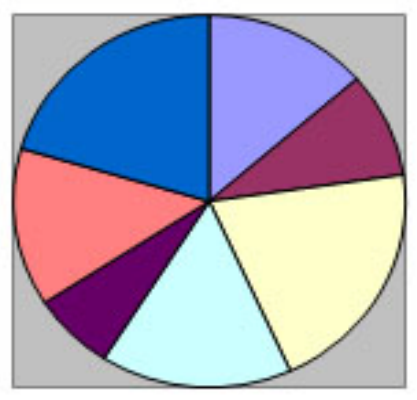

口Strongly Agree

a Agree

ㅁlleither Agree

nor Disagree

口Disagree

- Strongly

Disagree 
Of the 13 respondents (37\%) who were aware of the Community Safety channel, 7 (54\%) also stated that they felt there was an advantage to the facility. 6 (46\%) replied that they could not see an advantage to the channel.

Fig. 8.10 Advantages to the community safety channel
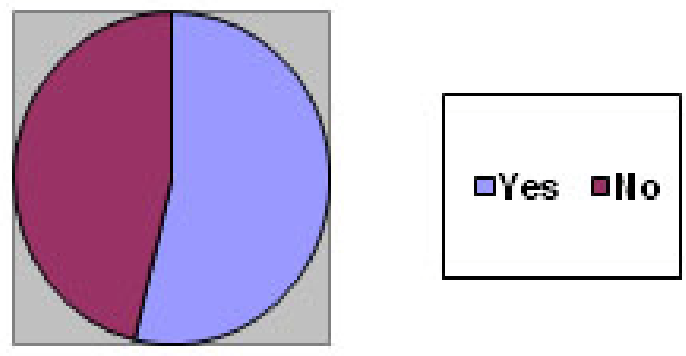

Of all respondents, 20 (57\%) stated that they have been a victim of crime, of which 9 (45\%) are female and 10 (50\%) are male (one respondent did not answer whether they were male or female). 13 respondents (37\%) answered that they have not been a victim of crime, and two did not answer.

Fig. 8.11 Victim of crime

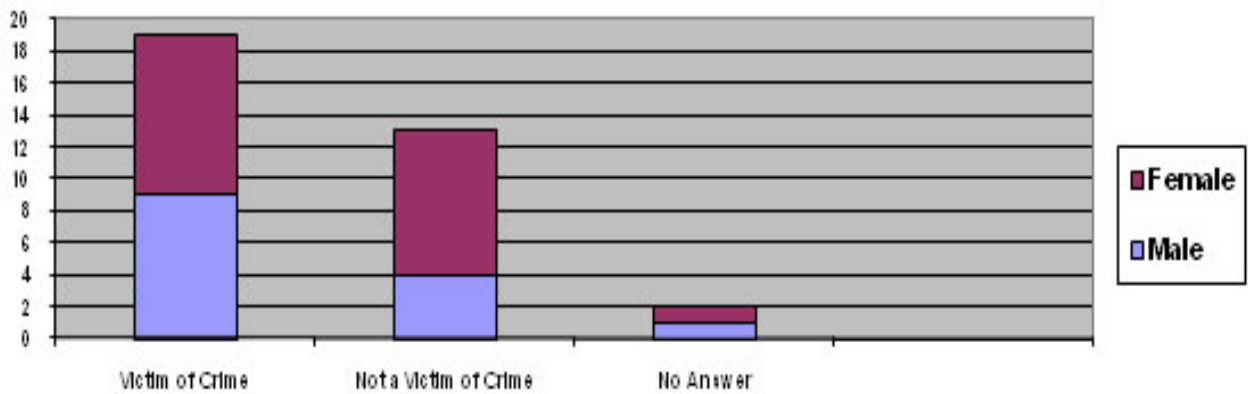




\subsection{Analysis of questionnaire responses}

\subsubsection{Closed questions}

Previous academic research has shown females to feel safer in areas with CCTV installed and to have fewer concerns than males about privacy implications of the technology. ${ }^{19}$ However, the results of this questionnaire show that of the 19 females who responded, 4 (21\%) agreed that they feel safer since the introduction of CCTV on their estate, whilst 4 (21\%) disagreed or strongly disagreed. 7 neither agreed nor disagreed and 4 answered that they did not know. These results therefore show that females in this context are likely to feel neutral in terms of safety after the installation of cameras. Of the male respondents, only 2 (14\%) agreed that they feel safer since the introduction of CCTV on their estate. 3 (20\%) males strongly disagreed that they feel safer since the installation of cameras. The remaining 10 male respondents answered that they neither agreed nor disagreed, or that they did not know. Within the results of this questionnaire the same therefore applies to males; they are more likely to feel neutral towards the technology in terms of safety, rather than having strong views one way or the other.

Of the female respondents, 4 (21\%) agreed that CCTV invades residents' privacy and 4 (21\%) disagreed or strongly disagreed. Of the 15 male respondents, 1 (7\%) agreed and 5 (33\%) strongly agreed that CCTV invades residents’ privacy. 6 (40\%) disagreed or strongly disagreed with the statement. These results do not show a difference in terms of male and female views concerning the privacy implications of CCTV.

When asked whether CCTV helps prevent crime on the estate, 7 females agreed or strongly agreed, whilst only 2 males agreed or strongly agreed. 7 females and 4 males disagreed or strongly disagreed with the statement. All females who agreed that they feel safer since the introduction of CCTV on the estate also agreed that CCTV helps prevent crime. Of those females who agreed that CCTV on the estate helps prevent crime 3 had been a victim of

\footnotetext{
${ }^{19}$ See for example, Honess, T. and Charman, E. (1992) 'Closed Circuit Television in Public Places: Its acceptability and perceived effectiveness’ Police Research Group Crime Prevention Unit Series Paper \#35
} 
crime. Of the 2 males who agreed or strongly agreed that CCTV helps prevent crime, both have been a victim of crime and both disagreed or strongly disagreed that CCTV invades residents' privacy. In terms of the perception of CCTV as a crime prevention technology, this research suggests that females have stronger views (either in the positive or negative) regarding this notion than males. Those females who felt safer since its introduction also saw CCTV on the estate as an effective crime prevention technology. A correlation also exists between males who have been a victim of crime and the belief that CCTV is a useful tool for crime prevention on the estate.

In comparison with the statistics presented by the Shoreditch Trust regarding usage and uptake of the Digital Bridge service, the results of the questionnaire show a different story. The pilot results showed that there was a $70 \%$ usage of the live webcam network; however of all residents who responded to the questionnaire only 2 (6\%) subscribe(d) to the Digital Bridge service. According to the questionnaire results, the usage of the live webcam is far less than stated in the official pilot results. 14 (40\%) residents were aware of the Community Safety channel, with only 4 (11\%) responding that they had watched it before. Only one respondent had been asked to participate in a focus group by the Shoreditch Trust, despite the claims made that the project was going ahead with 'very, very strong community support'.

30 out of 34 (88\%) respondents, who had not been asked to participate in a focus group or asked their opinion in any other way, stated that they would have liked to have been consulted prior to the installation of CCTV. 25 of the 30 respondents who would have liked to have been consulted were fairly unsatisfied, unsatisfied, or very unsatisfied with the levels of information provided prior to the installation of CCTV cameras on their estate. Of these respondents, 18 were provided with no information, 5 with little information and 1 with some information. Only 1 respondent was satisfied with the level of information (some information) but would still have liked to have been asked their opinion. Only 1 respondent, who was not asked to participate in a focus group, was provided with a lot of information about the installation of CCTV. The respondent who was invited to participate in a focus group also stated that they had received a lot of information regarding installation. Both respondents, 
despite stating that they received a lot of information, answered that they were fairly satisfied with the levels of information, rather than satisfied or very satisfied.

\subsubsection{Open questions}

When asked why they did not subscribe to the Digital Bridge service, the residents answered that they 'have not heard of it', 'don't know much about it', 'no one offered it to me' or 'too expensive/cannot afford it'.

One also answered that it is not in operation anymore, detailing that the Digital Bridge was removed over a year ago, arguing that:

Digital Bridge failed because it did not do its market research properly. Because of this area's proximity to the city and/or its high technology, we have NEVER been able to receive a decent TV picture without cable. Even in the 1970s everyone had a form of cable. Digital Bridge therefore was an additional expense on top of our normal cable expenditure. ALSO it would only operate on a BT line. Here again, most people had a cable package that included phone, broadband and TV. BT were their usual unhelpful selves and insisted on a new line number if we changed. Well, why bother! Another large sum of community money lined someone’s pockets.

When asked why they do not view the Community Safety channel, comments included; 'was not aware of it' and 'never heard of it'. One resident stated; 'because I don't want to spy on my neighbours like others do'. One other answered; 'no time, more important things to do'.

Those who answered that they had viewed the channel before detailed reasons such as; 'curiosity', 'to see the views and what areas were being monitored', 'to see what is going on in the streets'

In terms of possible benefits of the Community Safety channel, residents answered that; 'in theory a crime could be detected and reported', 'only if actively promoted and recordings are used', 'if it makes people feel more secure it can only be good' 'safety crime reduction, better type of policing', 
'only if people do something with it instead of just using it as another TV channel to view', 'a method of crime prevention'

Those who saw no advantage to the Community Safety channel stated that; 'even if you saw a crime being committed, the police wouldn't react for at least 2 hours - Shoreditch police are useless’

Concerns raised over the Community Safety channel included: 'intrusion of privacy', 'no one knows about it', 'invades privacy', 'don't know if images are strong enough to identify anyone engaging in criminal activity', 'if so many cameras were put in that they could be used to look inside people's flats then that would be an invasion of privacy', 'it is used by residents to spy on other residents', 'gross invasion of privacy - particularly so in the context of overall government collecting of personal data', 'not enough of them to cover our area'. In the context of concerns over the channel, the residents' views are therefore mixed. For some the issue of whether the channel and cameras are effective is a matter for concern, and for others it is the privacy implications that are the major issue.

I also included a space for other comments, which included a range of views. One person stated: 'I did subscribe to digital bridge when it was first installed and kept it until just before the cameras were taken down. No one told us they were to be taken down we just found out somehow'. This was the same person who had described the lack of market research causing the failure of the project. It was only through this respondent and one other that I found out that the project had failed. There was no information available to this effect from the Shoreditch Trust. The other respondent who had knowledge of the project and its failure stated that: 'I only heard about Digital Bridge through the media. I also heard that they had now been discontinued. No information was given to residents about the scheme or an update on what has happened to it'. I could not find any press articles that detailed the results, or the failure, of the project.

An additional comment was: 'CCTV breeds a culture of fear. Civil courage, rather than CCTV/surveillance should be encouraged'. This statement of the necessity of civil courage to combat crime relates back to academic literature on 
the subject of CCTV (discussed earlier in this chapter), describing a diminishing feeling of personal responsibility resulting from the installation of CCTV systems.

The last comment received also argues that residents' involvement is necessary to reduce crime, although is more positive about CCTV working alongside this: 'Any initiatives to help reduce crime are very welcome. CCTV is very useful to help monitor criminals [sic] activity and track movements of criminals. Swift and committed response to 999 calls from residents, even for smaller crimes, is key to establishing a culture of trusting the police system to deal with crime. In their way, residents become a part of the system of crime prevention, rather than just letting it happen (and also resenting the fact that it does happen!)'

\subsubsection{Summary}

The results from the closed questions show that only 2 of the 32 respondents with a TV subscribe(d) to the Digital Bridge service and that only 3 had ever watched the Community Safety Channel. Amongst other reasons, the results from the open questions show that the service was regarded as too expensive for residents (at $£ 3.50$ /month). Although described by one newspaper article as 'trendy', in reality the Charles Square and Haberdasher estates house lower income residents. Another reason for lack of uptake seems to be that the majority of residents had not heard of the service, and one suggested that it had been removed over a year ago. The initiative, as portrayed by the Shoreditch Trust was one consulted on and welcomed by residents, however only one respondent was asked to participate in any sort of research prior to installation.

Positives and negatives were raised with regard to the Community Safety channel. Those who saw potential positives described it as a method of crime prevention if used in certain ways - an active involvement on the part of the user was seen as necessary in order for it to be of use. A link between CCTV, the Community Safety channel and the local police was also made. The technology itself was not seen as enough. This point was reiterated and developed further 
when one resident described the requirement of a system of technology, police and resident co-operation in order to bring down levels of crime in the area. Concerns raised included the issue of the effectiveness of the cameras in terms of footage quality and the possible privacy infringements of the cameras and Community Safety channel.

\subsection{Interview results}

\subsubsection{CCTV in principle}

Eight of the questionnaire respondents agreed to be interviewed. All interviewees responded that they feel positive about technology generally. All use a computer, mobile phone, and the internet. All interviewees were also aware of CCTV as they go about their daily lives. However, reactions to feelings of safety produced by the cameras varied greatly. One respondent stated that the cameras 'make me feel a bit safer'. Another responded that they 'make me feel worried'. One interviewee, although having answered that a possible advantage to CCTV would be to deter criminals, responded that even if CCTV were installed she would still not walk in certain places:

If I'm out late at night (which I'm not very often) I'll walk in the middle of the road so there's no dark doorways, you know...

Another also replied that it would have little or no impact on where he went:

It doesn't have an impact on where I go ... I suppose most of the areas where CCTV is installed is fairly safe anyway, I mean you're not going to get a little back alley covered by CCTV, I wouldn't have thought ... it wouldn't change where I would go, or how I would act. 
Another stated definitively that CCTV would have no impact on where he went:

Nah, it makes absolutely no difference. I certainly wouldn't go somewhere because they had CCTV.

Another interviewee was more positive about the possible impact CCTV might have one where he would go:

Probably ... yeah ... possibly. You know there's a lot of places, you know rough areas or what have you that I wouldn't really go to, but I suppose if they had CCTV I might think about it.

In terms of negative aspects of CCTV, one respondent stated that:

I suppose the only ... part of the problem is that a lot of the CCTV footage is so poor, that it's not very useful for prosecuting people, so a lot of the time the justification given for it ... you wonder whether there are other reasons for it ... like with speed cameras, whether they're there to raise revenue ... it can be an issue ... They are there to protect property and to protect people, that's the main justification, but there could be other reasons as well...

Another interviewee responded that in terms of negatives, after becoming a victim of crime, the police did not check for any CCTV footage of the incident:

I mean, when you get mugged - it was the early hours of the morning, coming home from my friend's, and the police sort of shrugged his shoulders as if to say well being out at that time of the day, you're asking for it ... that's the impression he gave. I said well I've been walking home from my friend's in City Road for about 5 years ... because it wasn't worth me waiting around for 2 bus stops, it's just easier for me to walk down City Road and turn in ... I just happened to be in the wrong place at the wrong time. 
Another interviewee raised concerns about the lack of real-time watching of footage from CCTV cameras:

I think, umm, I think there are a lot of problems, they don't get checked as much as they should be ... you know what I mean, a lot of people ain't watching the cameras, so if someone doesn't report a crime the cameras won't get looked at.

The theme of the cameras not being watched was continued by another interviewee who stated:

They don't do anything, you don't know if they're working or being checked half the time. They don't prevent anything ... they just record what's happening to build up databases of data that doesn't mean anything. They're just pointless ... a waste of time.

In terms of any concerns over CCTV, the respondent went on to say:

Only that it's presented as being a kind of magic bullet and it isn't, so that's a concern ... because every time someone thinks you can just refer back to something and that'll give you the answer and therefore solves the problem ... then, there could always be the problem ... the problem's already been done, as such.

When asked whether CCTV cameras had any impact on their everyday lives, one interviewee responded that:

Yeah, if I'm like doing something, like smoking or whatever, and like don't want a camera to see me, I'll just go round a corner or something ... to be out of the view of the camera.

(IK - So, it doesn't actually stop you doing what you were going to do?) 
Nah, I'll just do it out of view

In terms of public debate, only one respondent described an active public debate on CCTV currently, although situating it in the larger issue of surveillance technologies:

I mean, yeah there's a debate going on about civil liberties type, the big brother society, where there are now so many CCTV cameras ... so I can see why people would have concerns about it ... and it's really the same debate about putting chips in your car so they can record how many miles you go, or road tax ... it's just that whole debate about big brother scenarios...

Another respondent replied that there is a public debate going on, but only for certain people:

[We're] excluded on purpose. They only include people who are going to support ... especially with public debate, they never seem to go to anybody who'll oppose what they're saying.

(IK - So, you think that people are involved?)

People are, just not the people who are actually involved in it, or who it might affect in any way.

Five of the six interviewees stated that, in one way or another, they would like to be involved in a public debate about CCTV. The one interviewee who did not state that he would like to be involved in public debate said:

I think there's very little, I mean I think that public opinion makes itself known through the media ... and the elect ... who you elect for your ... to be your government. But I don't see it becoming as big an issue as the economy, or Iraq ... it's not at the top of people’s agendas ... but if you had an objection to CCTV cameras going up, I don’t 
think many people would know how to go about ... I mean, presumably you would need some sort of planning permission to put a CCTV camera outside a shop but I think there's very little ... I would say there are more important issues in society than CCTV... I don't think it's a huge issue...

Of those interviewees who responded that they would like to be involved, one argued:

There should be some sort of ... way ... I mean, some forum to allow people to debate issues ... financially, you could argue this. (The interviewee in this instance was discussing tax payers' money)

Another interviewee stated that he would like to be involved but only under certain conditions:

It depends what for ... I mean if they're just going to say we want to know what you think but we're going to do it anyway, like with ID cards, then no I'd rather they put the money to better use than waste it...

\subsubsection{CCTV on the estate}

When asked whether they feared becoming a victim of crime on their estate, one interviewee responded:

Not enough to make me want to move away or to alter my behaviour or anything ... I mean obviously you do sensible things like not walking around flashing your mobile phone and ... I don't think our estate is particularly ... well I know there are far worse estates. I think mostly the issue is low-level crime, anti-social behaviour, graffiti ... that sort of thing ... not serious crime ... I mean, I know there are estates where people are regularly beaten up ... and that's not the sort of thing that happens on our estate. 
Another interviewee responded along the same lines:

Not particularly ... depends. There's some bits you wouldn't go for a wander at 4 in the morning, but that's like anywhere ... They'd rob my stuff and things like that, like if you left your bike outside they'd steal it ... if you left your whatever, if you left a box downstairs for a few minutes while you were doing something else it'd get nicked, it's more kind of like petty bollocks, opportunist crime.

Another responded that:

Immediately after I was mugged I felt nervous - I would walk past people and wonder whether it was going to happen again. But now, I don’t ... no.

Another interviewee responded that:

Definitely, I live in a rough area as it is. Cameras don't cover everybody. A lot of people don’t really care about the cameras.

This view was echoed, although more emphatically by another respondent who replied that:

Yes, all the time ... everyday. This estate isn't safe. I feel ... well ... unsafe.

When asked whether the introduction of CCTV cameras has had any impact on their fear of crime, one interviewee stated:

Well, if I knew where they were and whether they were working or not, then yes I would but ... no one seems ... there was no communication to make people aware of when they were going up, or what to do if there was a problem so... 
I would feel safer if I knew that they were there and where they were ... and pointing. Like in the back area where the garages are, where there have been quite a few problems ... I mean you do feel a bit unsafe when you're walking around there and there are drug addicts hanging around or what have you, so if I knew that there were cameras there I would feel safer.

Another interviewee replied:

No, because people just cover their faces and run off and it's no good ... or the cameras are facing the wrong way ... and no one watches the cameras ... just more reasons why it's of no use.

(IK - So, how would you like to see it being used?)

Yeah, watch the cameras if they're going to bother having them, instead of recording and watching once something's happened. I mean, there must be so many things that happen directly underneath a camera ... and it just never gets pulled up because they never bother to look at the footage for that time of day because there's no reason to ... so on that basis, you're saying 'oh we've brought down drug dealing', it's bollocks because as soon they realise that no one's watching the cameras you're back to normal.

Another stated that:

I didn’t realise we had it actually.

When asked how security on their estate might be improved, all suggested increased policing and fixing security gates. One interviewee said:

Well, I think the obvious things would be more police ... you do see them quite a bit on their bikes ... more on the beat policing, although 
having said that I have seen them quite a few times, so I think that's happening. More wardens ... you don't see the wardens very often ... and they are [important?] by a visible presence. Other than that, just general security, like for example there are gates that are supposed to block access to the garages, but they've been broken for about two weeks ... things like that ... a lot of the garages aren't secure ... things like improving visibility, making sure that there lights that go out are fixed ... for example a light went out on my walkway and it was pitch black for about three weeks ... so I think it's more the environmental factors ... making gates more secure, fixing things when they go wrong, removing things that have been dumped, litter that's been dumped, that sort of thing ... that makes for a better environment.

Another replied that:

Make the punishment more severe. More police on foot. CCTV doesn't get anyone there to your help ... when you think people can get mugged and no one takes any notice, you can get assaulted on a train or bus and people are afraid to interfere ... and CCTV doesn't help you then either. I see their point of view, if you were only going to get a sock on the jaw it would be easier than getting knifed wouldn't it? More policing would help ... I haven't seen a policeman down here for a long time....

She continues:

I come home sometimes and there's the Central Foundation boys school $^{20}$ sitting on my mat playing cards and I have to say 'excuse me' to get into my flat, and I wonder whether one day they're going to shove me in and grab my handbag but it hasn't happened yet. It will be nice when there's locks on the doors so as no one can get up

${ }^{20}$ The Central Foundation is a local school 
to my door unless they're visiting somebody - there'll be a door either end which we'll have keys to, as long as everybody shuts that you'll only get the genuine postman and if someone you're expecting you'll let them in. It would be much nicer if it were locked off. Although I don't know how it's going to keep everyone out as people are a bit absent minded about closing the door...

I mean, why didn't they get the keys ready before they put the gates up?

I mean, we're not tackling it [crime] in the right way are we? I mean, why don't they ask the people? It's all very well with people in these big houses, they have security.

Another respondent spoke about crime in Hackney more generally, and replied:

Errr, everyone's just really poor, so increase public spending ... spend it on people who need it when they need it. You kind of have to do something to fix 'the kids' in general because they don't have anything to do ... ummm ... so, like whether you like it or not you're kind of going to have to bite the bullet and take some pain in the short term and fix them because there's no way ... you can’t keep locking them up and you can't keep putting tags on them and Asbos ... 'cos, it's the same thing again, nobody enforces the Asbos ${ }^{21}$ and nobody bothers to check whether the tag's turned on and whether they're inside or outside the area they're meant to be in ... I dunno, just spend it on stuff that might work rather than stuff that's just punitive and just isn't going to result in any change other than people just thinking it's correct to behave the way they do because of the way they're treated .... and that's the problem you've got in Hackney - no one wants to help the police and nobody wants to help the council because

${ }^{21}$ Anti-Social Behaviour Orders 
the council and the police don't do anything to help them and it's true, they don't ... there's nothing you can see that they're doing to improve your life.

\subsubsection{Analysis of interviews}

Perceptions of crime, fear and safety varied greatly between the interviewees, although most felt relatively safe in the area they live in. In terms of the interviews conducted, there was a correlation between those who have a fear of being a victim of crime in the area they live and possible feelings of enhanced safety due to the installation of CCTV cameras. One interviewee described feeling very unsafe and that she would feel much safer if cameras were installed and known to be working. The rest of the interviewees who stated that they have some fear of crime in the area they live in were more cautious in answering that CCTV would definitely make them feel safer. Those who answered that they did not have a fear of crime had different answers to the question of CCTV enhancing feelings of safety. For some, CCTV would categorically make no difference to their everyday lives or feelings of safety. For others, feelings of safety from the installation of CCTV would possibly occur if they knew that the cameras were working.

Effectiveness - Not knowing whether the cameras are working or not continued as a theme throughout all the other interviews. If the CCTV were known to be working it seems it would make an impact on peoples' feelings of safety, although this would have to occur in conjunction with the cameras being watched in real-time. For the majority of interviewees, CCTV did not alter their everyday behaviour (for the reasons outlined previously - i.e. due to not knowing whether the cameras are working, feelings of safety do not change and therefore behaviour does not change either). The only exception to this was one interviewee who replied that if he were going to do something illegal he would do it out of the view of the cameras. It seems therefore to be a 'just in case they are working' mentality for someone doing something illegal, but for feelings of safety brought on by CCTV the prevailing belief is that the cameras are not working. 
Personal responsibility vs. Responsibility to look after you - Another theme emerging from the interviews was the issue of personal responsibility. One interviewee spoke about being mugged when walking home alone late one night and the police reaction having been one of 'you're asking for it'. The reaction of the police implied that it was her responsibility to be aware of what was safe and what was not safe. The interviewee does not suggest that it was her fault, nor that the police or CCTV should have stopped the incident occurring; she simply states that she was 'in the wrong place at the wrong time'. In a slightly different context, this theme arises again when one interviewee discusses people not helping the police because 'the police don't do anything to help them'. This viewpoint therefore suggests that there has been a failure on the part of the police to help residents, which in turn means policing of the area suffers due to lack of cooperation on the part of the residents.

Policing and other methods of preventing crime - When asked about other methods of crime prevention, all interviewees suggested more on the beat policing and a more visible presence of police or wardens on the estate and surrounding area. More emphatically stated, however, was the need for maintenance of existing security measures, such as fixing broken security gates and lighting. In this case, involving the community and asking for suggestions would have provided a number of possible solutions for improving security on the estates.

Punishment - The theme of punishment arose during the interviews, though with differing opinions expressed. For one interviewee a more severe punishment would act as a deterrent to crime. For another, the threat (or reality) of prison was not the way to tackle criminal behaviour. He suggested a less punitive method, with increased public spending into vulnerable and deprived areas, targeting in particular the younger population. In the context of these interviews, the younger respondents supported rehabilitation, education, and less severe punishment, whereas the older respondents favoured a stricter enforcement of the law. This divide did not have a correlation with feelings of fear of crime and safety. These 
feelings of fear of crime and safety varied across the age groups interviewed and did not correlate in terms of, for example, higher age groups feeling more fearful.

In this section I have presented the results of my interviews with residents on the Charles Square and Haberdasher Estates in Hackney. I first provided extracts of interviews based around issues of CCTV in principle and CCTV on the estate. I followed this with an analysis based around five themes, which arose during analysis of the interviews: perceptions of crime, fear and safety, effectiveness, personal responsibility, policing, and punishment.

\subsection{Conclusion}

In this chapter I have discussed the results of my empirical research based on the Digital Bridge project in Hackney. Although I only reached a small sample, the results are nevertheless important as a piece of social research. The lack of engagement and consultation prior to the installation of CCTV on the estates goes some way to answering why the public seem to have apparently accepted the deployment of surveillance technologies. The information is not readily available and there is a lack of forum for discussion. Without consultation the public do not have informed choice and cannot participate in decisions on surveillance. As has been discussed previously in this thesis, CCTV is therefore used as a method to protect a passive public without room for active involvement - a lack of information and engagement means that there is no other outcome. The Digital Bridge project, although showing potential in terms of community involvement in issues of crime and a promising step towards self-governance, eventually ended up delivering neither of these things due to a lack of research and consultation prior to the launch of the project. 


\section{Chapter IX:}

\section{CCTV Internationally}

\subsection{Introduction}

In this chapter I provide an overview of video surveillance activities in an international context. The purpose of this section is to further aid my analysis of why CCTV in Britain has become so widespread and will provide a comparative basis from which to advance conclusions. It will provide a wider context in which to look at CCTV and to further assess why the UK in particular has become so camera-surveilled. I start by looking at data protection legislation and privacy rights across the European Union, moving on to look at identity cards and video surveillance throughout the member states. I then take a closer look at three European Union countries: Germany, France and Spain, detailing the extent of CCTV in each and discussing the legislation governing its implementation. I also look at the examples of the United States and Canada, in order to provide a nonEuropean perspective.

\subsection{Right to privacy and data protection legislation}

Most of the member states of the European Union (EU) recognise the right to privacy within their constitutions. The exceptions to this are:

Austria (although data protection is recognised in their constitution) United Kingdom (no written constitution exists)

Czech Republic (although they do have a Charter for Fundamental Rights and Personal Freedoms, which covers privacy rights)

France (although in 1999, the constitutional court ruled that privacy rights are implicit in the constitution) Ireland (although their constitution does refer to the 'personal rights of the citizens') 
In order to be eligible to join the EU, all countries must reach the requirements of the Copenhagen Criteria, defined as:

Membership requires that the candidate country has achieved stability of institutions guaranteeing democracy, the rule of law, human rights and respect for and protection of minorities, the existence of a functioning market economy as well as the capacity to cope with competitive pressure and market forces within the Union. Membership presupposes the candidate's ability to take on the obligations of membership including adherence to the aims of political, economic and monetary union.

All EU countries also have to abide under the EU Data Protection Directive (1995/46/EC) for the processing and movement of personal data on individuals. ${ }^{1}$ This Directive was implemented by the European Commission in 1995, although implemented by individual countries at various times since. Article 1 of this Directive states:

1. In accordance with this Directive, Member States shall protect the fundamental rights and freedoms of natural persons and in particular their right to privacy with respect to the processing of personal data.

2. Member States shall neither restrict nor prohibit the free flow of personal data between Member States for reasons connected with the protection afforded under paragraph 1.

Under Article 2, the definitions for the purposes of the directive are provided as:

(a) 'personal data 'shall mean any information relating to an identified or identifiable natural person ('data subject'); an identifiable person is one who can be identified, directly or indirectly, in particular by reference to an identification number or to one or more factors specific to his physical, physiological, mental, economic, cultural or social identity.

\footnotetext{
${ }^{1}$ http://www.cdt.org/privacy/eudirective/EU_Directive_.html
} 
'Personal data' is therefore data that can be connected with an individual, for example: a credit card number, a bank statement, or an address.

(b) 'processing of personal data'('processing') shall mean any operation or set of operations which is performed upon personal data, whether or not by automatic means, such as collection, recording, organization, storage, adaptation or alteration, retrieval, consultation, use, disclosure by transmission, dissemination or otherwise making available, alignment or combination, blocking, erasure or destruction.

'Processing' in this context is therefore any action that is taken on the 'personal data’ detailed above, by a machine or by a person.

The definitions also include 'controller', described as the person (legal or not), public authority, agency or any other body which 'determines the purposes and means of the processing of personal data'. The 'processor' is the person (legal or not) which 'processes personal data on behalf of the controller'.

This Directive covers the processing of personal data by automatic means (either partly or wholly), or that data which is intended to be part of a 'filing system'. It does not apply to the processing of personal data for the purpose of state security, public security, defence, or criminal law. Video surveillance data for crime control and prevention purposes is therefore not covered by this Directive as it is used for purposes of criminal law, public and state security.

All Member States are also signatories of the European Convention on Human Rights (ECHR), under which Article 8 protects the right to privacy:

1) Everyone has the right to respect for his private and family life, his home and his correspondence.

2) There shall be no interference by a public authority with the exercise of this right except such as is in accordance with the law and is necessary in a democratic society in the interests of national security, public safety or the economic well-being of the country, for 
the prevention of disorder or crime, for the protection of health or morals, or for the protection of the rights and freedoms of others. ${ }^{2}$

Again, this convention does not necessarily cover video surveillance as it is used variously for public safety and the prevention of disorder and crime.

\subsection{Surveillance technologies across the European Union}

\subsubsection{Identity Cards}

In terms of identity cards, the countries within the European Union (EU) have different experiences. Compulsory ID cards are in operation in: Belgium, Bulgaria, Germany, Portugal, Cyprus, Czech Republic, Greece, Slovakia, Slovenia, Luxembourg, Netherlands, Romania, Spain and Poland. Noncompulsory ID cards are in operation in: Netherlands, France, Hungary, Austria, Finland, Italy, Estonia, Latvia, Lithuania, Malta and Sweden. Those currently without ID cards are: Denmark, UK (although they may be issued in 2012), and Ireland.

The ID card in Belgium is first issued at 12 years old and becomes compulsory at the age of 15. Belgium also launched its electronic ID programme in 2003. Normal card functionality and the e-ID card can be used to prove identity online. Bulgaria issues the compulsory ID card (introduced in 2000) at the age of 14 . Cyprus issues a compulsory ID card at the age of 12 and the Czech Republic at 15. In Luxembourg, the card is also issued at age 15 and is required to be carried at all times. They are also issued in Slovakia at age 15.In Spain, the ID card is issued at 14 and must be carried at all times. Romania's ID card is also issued at 14, but it is not compulsory to carry it at all times. Slovenia and Poland issue compulsory ID cards at 18.

\footnotetext{
${ }^{2}$ http://echr.coe.int/NR/rdonlyres/D5CC24A7-DC13-4318-B457-

5C9014916D7A/0/EnglishAnglais.pdf
} 
In Germany it is compulsory to possess a 'Personalausweis' (ID card) but not to carry it at all times. The card is issued at the age of 16 . This is also the case in Lithuania. Greece issues a compulsory ID card to all citizens over the age of 12, and like Germany it is compulsory to possess one but not to carry it at all times. In Hungary and Latvia it is necessary by law to possess either an ID card or passport.

The information contained on the identity cards varies from country to country. For example, Greek cards now only hold the person's name, date and place of birth, height, municipality, and mother and father's details and a photograph. Previous versions included religious denomination, ethnicity and fingerprints but were removed for reasons of being unnecessary for the purpose of personal identification. The ID card for Belgium contains more information, including a chip containing a digital signature which can be used in card-readers, much in the same way as the chip-and-pin system. Other countries plan to include biometric data, for example France, although some opposition to this scheme has occurred. ${ }^{3}$

\subsubsection{Video surveillance}

The EU countries also have vastly different levels of use of video surveillance and for various purposes. Video surveillance by public authorities is not affected by European data protection provisions and remains under the remit of national legislation. ${ }^{4}$

In terms of public transport, Belgium and Austria have CCTV installed on their underground networks in Brussels and Vienna. In Austria, the Wiener Linien, who manage public transport in Vienna, own more than 1000 cameras, which are installed on the underground. ${ }^{5}$ The 'Verkehrsleitzentrale' (traffic management controller) owns 60 cameras. Austria uses far less CCTV than the UK and there is no network of CCTV systems. The main use is for traffic management and minor

\footnotetext{
${ }^{3}$ (2005) 'Report demands that French ID card plans must be reviewed' Biometric Technology Today 13(7) pp.1-2 p.1

${ }^{4}$ Rosenberg, R. S. (2004) (3 ${ }^{\text {rd }}$ ed.) The Social Impact of Computers Elsevier; Amsterdam and Londonp.382

${ }^{5}$ Ney, S. And Pichler, K. (2002) ‘Video Surveillance in Austria’ Urbaneye Working paper Series No.7 p.3
} 
offences. ${ }^{6}$ Video surveillance is also in use to protect government and ministerial buildings; however the images are not recorded as the cameras are used for immediate security only. ${ }^{7}$ Belgium also uses CCTV for traffic management purposes and the Brussels ring road has been equipped with cameras since $1993 .{ }^{8}$ As far back as 1998, the European Commission of Human Rights commented that 'Surveillance by means of video cameras, both by public and private authorities, is developing very rapidly in Belgium'. ${ }^{9}$ There has also been an increase in the use of CCTV in the Czech Republic over recent years, from both private institutions and local government. ${ }^{10}$

In Denmark, the use of CCTV for surveillance purposes is generally forbidden, although exceptions to this are made for owners of certain types of property, such as petrol stations. However, if CCTV is used the owners of the property must abide by strong regulations to inform those being surveilled of the presence of cameras. These regulations are reportedly abided by in Denmark. ${ }^{11}$

Very few EU countries have regulation specifically governing the use of video surveillance. However, both France and Spain have specific regulation concerning the use of CCTV. The Netherlands legislated against the use of covert video surveillance in 2004, making it unlawful to install cameras without notification. ${ }^{12}$ The growth of video surveillance in the Netherlands has, however, been fairly rapid. The first public space cameras were installed in 1997 and by 2003, 80 of the 550 municipalities were using CCTV. ${ }^{13}$ Slovenia also enforces regulation of video surveillance, with their use covered in their 1999 Personal

\footnotetext{
${ }^{6}$ Ibid.

${ }^{7}$ Ibid. pp.4-5

${ }^{8}$ Parliamentary Assembly (2008) 'Video Surveillance of Public Areas' Council of Europe p.115

${ }^{9}$ European Commission on Human Rights (1998) 'Decisions and Reports' p.94

${ }^{10}$ Privacy International (2003) 'Silenced - Czech Republic' http://www.privacyinternational.org/article.shtml?cmd[347] =x-347-103758

${ }^{11}$ Gras, M. L. 'The Legal Regulation of CCTV in Europe' Surveillance and Society 2(2/3) pp.216-219 (p.218)

${ }^{12}$ Privacy International (2007) 'Kingdom of the Netherlands' http://www.privacyinternational.org/article.shtml?cmd[347] =x-347-559513

${ }^{13}$ Norris, C., McCahill, M. and Wood, D. 'Editorial: The Growth of CCTV: a global perspective on the international diffusion of video surveillance in publicly accessible space' Surveillance and Society 2(2/3) 110-135 p.113
} 
Data Protection Act and 2003 Private Protection Act. ${ }^{14}$ Video surveillance systems can only be operated under license, and the public must be informed that surveillance is taking place, for what reason, and where they can find information on data retention periods. Failure to notify the public of the presence of cameras carries the risk of fines. The last few years have seen the Information Commissioner take an active role in investigating unlawful video surveillance, leading to increased legal provisions and stricter enforcement of regulations in terms of the installation of cameras. ${ }^{15}$

In Germany, the deployment of CCTV in public space is repeatedly challenged. There are less than 100 cameras in public areas in Germany, in comparison with the UK, which has over 40,000 in 500 cities (although these are estimates). ${ }^{16}$ Private space video surveillance is, however, reportedly increasing. ${ }^{17}$ The Czech Republic has also seen an increase in CCTV in recent years, from private institutions and local government. ${ }^{18}$ In the capital, Prague, it is estimated that there are two hundred cameras in the city centre, which are now linked to an automatic facial recognition system. ${ }^{19}$ Over recent years, there has also been an increase in video surveillance in Lithuania, with little or no notice given to the public of their installation. There is no legal regulation governing the use of CCTV systems in Lithuania. ${ }^{20}$ Poland has also recently installed their largest system of CCTV, with 19 cameras installed into the city centre and to cover 4 schools, in June $2007 .^{21}$ Italy has seen an increase in CCTV systems installed into sports premises, as well as in certain areas of its cities. ${ }^{22}$

\footnotetext{
${ }^{14}$ Privacy International (2007) 'Republic of Slovenia' http://www.privacyinternational.org/article.shtml?cmd[347]=x-347-559492

${ }^{15}$ Ibid.

${ }^{16}$ Hempel, L. and Töpfer, E. (2002) 'Inception Report’ Urbaneye Working Paper Series No.1

${ }^{17}$ Goold, B. J. (2004) CCTV and Policing: Public area surveillance and police practices in Britain. Oxford University Press; Oxford p.24

${ }^{18}$ Privacy International (2003) 'Silenced - Czech Republic' http://www.privacyinternational.org/article.shtml?cmd[347]=x-347-103758

${ }^{19}$ Norris, C., McCahill, M. and Wood, D. 'Editorial: The Growth of CCTV: a global perspective on the international diffusion of video surveillance in publicly accessible space' Surveillance and Society 2(2/3) 110-135 p.117

${ }^{20}$ Privacy International (2004) 'The Republic of Lithuania' http://www.privacyinternational.org/article.shtml?cmd[347]=x-347-83771

${ }^{21}$ Privacy International (2007) 'Republic of Poland' http://www.privacyinternational.org/article.shtml?cmd[347]=x-347-559594

${ }^{22}$ Norris, C., McCahill, M. and Wood, D. 'Editorial: The Growth of CCTV: a global perspective on the international diffusion of video surveillance in publicly accessible space' Surveillance and Society 2(2/3) 110-135 pp.113-114
} 


\subsection{CCTV in Germany}

The first CCTV cameras used in Germany were for the purpose of traffic control and management, installed in Munich in 1958. During the following year, Hannover also installed a system for traffic management, specifically for a large industrial conference and aeronautics exhibition. ${ }^{23}$ Hannover was also the first German city to use CCTV to control 'fringe- and problem groups'. In this instance, 25 permanent CCTV cameras were installed in $1976 .^{24}$

The 'Recht auf Informationelle Selbstbestimmung' was developed by Germany’s Constitutional Court in 1983. Essentially, this concerns the right of the individual over control of personal data and to determine how it is applied and to whom it is given. ${ }^{25}$ This development derived from the right to personal freedom described in the 'Grundgesetz' (German Basic Law), and denotes that any unauthorised collection of data on an individual goes against their civil rights and is therefore unconstitutional. However, in cases where it is in the public interest this collection is allowed, although strongly regulated and proportional. ${ }^{26}$

Video surveillance in Germany now operates within the legal framework of the European Data Protection Directive, under regulation passed in 2001. This amendment of the 'Bundesdatenschutz' (Data Protection Act), which had first come into effect in 1977, incorporated the EU Directive into German law. ${ }^{27}$ Each state also has its own further data protection act, the 'Landesdatenschutz'. ${ }^{28}$ The use of CCTV in public space is strictly regulated, and accompanied by ongoing public discussion of the technology (including the use of CCTV by the police), ${ }^{29}$

\footnotetext{
${ }^{23}$ Weichert, T. (1998) 'Audio- und Videoüberwachung. Kontrolltechniken im öffentlichen Raum' Bürgerrechte \& Polizei 60 pp.12-19 (Author’s translation)

${ }^{24}$ Ibid. (Author's translation)

${ }^{25}$ http://www.datenschutz.de/recht/grundlagen/

${ }^{26}$ Töpfer, E. (2003) 'Watching the Bear: Networks and Islands of Visual Surveillance in Berlin' Urbaneye Working Paper Series No.8 p.6

${ }^{27}$ Nouwt, S. Vries, B. R. and Loermans, R. 'Analysis of the country reports' p.343 in Nouwt, S. et al. (2005) (eds.) Reasonable Expectations of Privacy? Eleven country reports on camera surveillance and workplace privacy TMC Asser Press; The Hague ${ }^{28}$ Ibid.

${ }^{29}$ Hempel, L. and Töpfer, E. (2004) ‘CCTV in Europe’ Urbaneye Working Paper Series No.15 p. 25
} 
the installation of open-street systems continues to be minimal, although it has been rising in recent years. ${ }^{30}$ Those open-street systems, which are in operation, are regulated by the state police acts, covering what is captured and the length of storage time. ${ }^{31}$ Due to these regulations, the open-street systems in Germany have been described as monitoring 'crime hot spots' and are, in the majority, operated by the police. ${ }^{32}$ In the context of CCTV in Germany, there is an awareness of the importance of civil liberties, perhaps to a greater degree than in other European country. $^{33}$

\subsection{CCTV in France}

In France, the installation of CCTV cameras must be agreed in advance by an administrative authority. ${ }^{34}$ The registration of systems for use in public space is also compulsory. ${ }^{35}$ It is estimated that around 300 towns in France have installed cameras for the purpose of monitoring public space. ${ }^{36}$ Over recent years this number has reportedly been rising. ${ }^{37}$ France maintains a centralised system of government and despite some devolution to regional authorities, the government holds tightly onto the reins of control over surveillance technologies and the police. $^{38}$

The first public space CCTV cameras were installed in 1994 in a Parisian suburb. $^{39}$ The business and financial district of Paris is continuously monitored by over 160 CCTV cameras. ${ }^{40}$ Presently, in France, public space CCTV can only legally be installed for specific purposes (such as the protection of property,

\footnotetext{
${ }^{30}$ Helten, F. And Fischer, B. (2004) 'What do people think about CCTV? Findings from a Berlin Study?’ Urbaneye Working Paper Series No.13

${ }^{31}$ Hempel, L. and Töpfer, E. (2004) 'CCTV in Europe' Urbaneye Working Paper Series No.15 p.38

${ }^{32}$ Ibid.

${ }^{33}$ Spencer, M. (1995) States of Injustice: A guide to human rights and civil liberties in the European Union Pluto Press p.185

${ }^{34}$ Hempel, L. and Töpfer, E. (2004) Op.cit. p.4

${ }^{35}$ Hempel, L. and Töpfer, E. (2002) 'Inception Report’ Urbaneye Working Paper Series No.1 p.3

${ }^{36}$ Hempel, L. and Töpfer, E. (2004) Op.cit. p.61

${ }^{37}$ Ibid. p.62

${ }^{38}$ Spencer, M. (1995) States of Injustice: A guide to human rights and civil liberties in the European Union Pluto Press p.181

${ }^{39}$ Hempel, L. and Töpfer, E. (2002) Op.cit. p.10

${ }^{40}$ Nieto, M. (1997) 'Public Video Surveillance: Is it an effective crime prevention tool?'

California Research Bureau http://www.library.ca.gov/CRB/97/05/
} 
traffic control and management, protection of public buildings) and must be authorised prior to installation. ${ }^{41}$ The interior of residential buildings is protected by this regulation, and the public have a right to access footage from CCTV cameras. $^{42}$

\subsection{CCTV in Spain}

The use of CCTV by the police in public space is strictly regulated in Spain. ${ }^{43}$ In 1997, legislation concerning the use of video surveillance by the police was passed. $^{44}$ In much the same way as in Germany, CCTV is used in Spain to monitor certain and limited locations (such as 'crime hot spots'). ${ }^{45}$ Any systems in use in public space must also be registered. ${ }^{46}$ According to the 1997 legislation any footage not used for a purpose after one month must be destroyed. Individuals also have the right to access to footage on which they have been recorded. ${ }^{47}$

In Spain, authorisation prior to installation of CCTV in public areas must be sought. Furthermore, any images from CCTV cameras in underground and railway stations are transmitted on monitors installed within that space, which are accessible to the public. ${ }^{48}$ There are no large networks of CCTV in Spain; instead the model is one of 'surveillance of limited but strategic locations'. 49

CCTV cameras have also been installed in public space in the Basque region in order to combat politically motivated vandalism by ETA supporters (an armed Basque nationalist and separatist organisation). ${ }^{50}$

\footnotetext{
${ }^{41}$ Parliamentary Assembly (2008) 'Video Surveillance of Public Areas' Council of Europe p.119

${ }^{4}$ Ibid.

${ }^{43}$ Hempel, L. and Töpfer, E. (2004) Op.cit. p.24

${ }^{44}$ Hempel, L. and Töpfer, E. (2002) Op.cit. p.10

${ }^{45}$ Hempel, L. and Töpfer, E. (2004) Op.cit. p.61

${ }^{46}$ Hempel, L. and Töpfer, E. (2002) Op.cit. p.3

${ }^{47}$ Statewatch Bulletin http://www.statewatch.org/news/ (Accessed 03/07/2009)

${ }^{48}$ Parliamentary Assembly (2008) 'Video Surveillance of Public Areas' Council of Europe p.119

${ }^{49}$ Hempel, L and Töpfer, E. (2004) Op.cit. p.6

${ }^{50}$ Nieto, M. (1997) 'Public Video Surveillance: Is it an effective crime prevention tool?'

California Research Bureau http://www.library.ca.gov/CRB/97/05/ p.9
} 


\subsection{CCTV in the United States}

The constitution of the United States (US) does not explicitly include the right to privacy. There is however a limited right to privacy granted by the Supreme Court, which states that an individual has a 'constitutionally protected reasonable expectation of privacy' from government surveillance. ${ }^{51}$ In terms of surveillance carried out by the government and private owners there is a large array of legislation centring on the use of technologies for this purpose. However, very little of this legislation applies directly to video surveillance. ${ }^{52}$ Even of the general surveillance legislation that exists in the US, one commentator remarks that it lacks 'clarity, coherence, consistency, compactness, and currency', adding that 'it cannot be a surprise, therefore, that the law governing video surveillance is uncertain'. ${ }^{53}$ Another commentator goes one step further and suggests that 'meaningful legal strictures on government use of public surveillance cameras in Great Britain, Canada and the United States are non-existent'. ${ }^{54}$ In much the same way as the UK, the United States has developed guidelines for the operation and installation of CCTV cameras in public space, but has not set up a method of enforcement. ${ }^{55}$ Although this quote indicates a similar situation to that of Canada, the analysis following next will show that in Canada, although having also only developed a set of guidelines, enforcement takes a different form, i.e. that of public opinion and lobbying by privacy rights campaigners.

CCTV with facial recognition software is increasingly being used in public space in the US, after being used for the first time at Tampa Bay, Florida, during the 2001 Superbowl. In this instance, it was used to compare faces in the crowd with a database of images in order to spot 'potential criminals', who were then

\footnotetext{
${ }^{51}$ Katz v. United States , 386 U.S. 954, 1967 http://supreme.justia.com/us/389/347/case.html

${ }^{52}$ R. Gellman 'A general survey of video surveillance law in the United States' in Nouwk, S. et al. (2005) (eds.) Reasonable Expectations of Privacy? Eleven country reports on camera surveillance and workplace privacy TMC Asser Press; The Hague p.7

${ }^{53}$ Ibid. p.8

${ }^{54}$ C. Slobogin (2002) 'Camera surveillance of public places' Mississippi Law Journal 72 pp.213233 p.233

${ }^{55}$ Ibid.
} 
removed from the stadium. ${ }^{56}$ This was a joint initiative between the stadium officials, the Tampa police department and the technical and installation experts.

The Lower Manhattan Security initiative was launched in 2005 in Manhattan, New York. This initiative has been compared with London's Ring of Steel. The initiative was launched as a network of CCTV cameras (alongside increased police presence and counterterrorism technologies) installed in order to increase public safety and monitor the business district. ${ }^{57}$ There are plans to introduce over 3000 cameras. As of November 2008 there were 156 cameras. ${ }^{58}$ In Washington, CCTV had originally been installed in commercial districts. However, legislation was passed in June 2006 to install cameras onto street corners in residential areas. $^{59}$

Funding for CCTV cameras is available from the Department of Homeland Security (DHS), which had requested over \$2 billion by 2005 to finance homeland security needs across the country. Some of this funding was used for setting up CCTV networks. ${ }^{60}$ For example, in May 2005 Chicago had a network of 2,250 cameras financed by the DHS. A further $\$ 48$ million for further cameras was expected over the next two years. ${ }^{61}$ Baltimore has also used DHS grants to set up a 'Watch Center' and network of cameras across the city. ${ }^{62}$ However, despite funding being available for the installation of CCTV, there are extremely few independent evaluations of video surveillance. ${ }^{63}$

\footnotetext{
${ }^{56}$ Bonner, J. (2001) 'Looking for Faces in the Superbowl Crowd' http://securitysolutions.com/mag/security looking_faces_super/

${ }^{57}$ New York Police Department (25/02/2009) Press Release http://www.nyc.gov/html/nypd/html/pr/pr_2009_005.shtml

${ }^{58}$ Daily News 24 November 2008 'Lower Manhattan Security Initiative up and running, safe from budget cuts'

http://www.nydailynews.com/news/2008/11/25/2008-11-

25_lower_manhattan_security_initiative_up_a.html

${ }^{59}$ The Washington Post 12 October 2006 'Street cameras are likely to stay' http://www.washingtonpost.com/wp-dyn/content/article/2006/10/11/AR2006101100733.html

${ }^{60}$ Electronic Privacy Information Center (May 2005) 'More cities deploy camera surveillance systems with Federal grant money’ http://epic.org/privacy/surveillance/spotlight/0505/

${ }^{61}$ Ibid.

${ }^{62}$ Ibid.

${ }^{63}$ Monahan, T. (2006) Surveillance and Security: Technological Politics and Power in Everyday Life Routledge; New York p.5
} 


\subsection{CCTV in Canada}

Canada began installing CCTV cameras into public spaces in $1992 .{ }^{64}$ Although it is utilised in a variety of settings, such as banks, restaurant, shops, and transport hubs, its use is nowhere near as widespread as in the UK. The number of surveillance cameras installed in Canada has been limited by active involvement of the Privacy Commissioner in campaigning against their overuse. ${ }^{65}$ Public opinion research conducted by marketing companies and political organisations show high levels of support for CCTV cameras in public and private spaces. However, research conducted by academics shows significantly lower levels of support, much in the same way as the UK. ${ }^{66}$ There are of course problems with public opinion surveys, as has been shown in previous discussions of CCTV literature, in terms of the wording of surveys influencing the outcome and levels of support recorded. ${ }^{67}$ Although cameras in spaces such as transport hubs and banks have been met with seemingly little resistance in Canada, the installation of cameras to surveille public space has been widely publicly debated and in turn resisted by privacy campaigners and privacy commissioners. ${ }^{68}$ One commentator suggests that due to this resistance 'it does not appear likely that Canada will be subject to the pervasive public monitoring in public places that is happening in Europe in the near future'. 69

Although there is no explicit right to privacy in Canada's constitution, there are two data protection laws in operation at the federal level. These are: the Privacy Act and the Personal Information Protection and Electronic Documents Act. ${ }^{70}$ Further, Section 8 of the Canadian Charter of Human Rights and Freedoms

\footnotetext{
${ }^{64}$ Nieto, M. (1997) 'Public Video Surveillance: Is it an effective crime prevention tool?' California Research Bureau http://www.library.ca.gov/CRB/97/05/

${ }^{65}$ Privacy International (2007) 'Video Surveillance' http://www.privacyinternational.org/issues/cctv/_index.html

${ }^{66}$ Deisman, W. et al. (January 2009) 'A Report on Camera Surveillance in Canada’ Surveillance Camera Awareness Network p.5

${ }^{67}$ See the reference to Ditton in the CCTV literature review

${ }^{68}$ Bennett, C. J. and Bayley, R. M. 'Video surveillance and privacy protection law in Canada' in Nouwt, S. et al. (2005) (eds.) Reasonable Expectations of Privacy? Eleven country reports on camera surveillance and workplace privacy TMC Asser Press; The Hague p.61

${ }^{69}$ Ibid.

70 The Right to Privacy and Parliament (2006) http://www.parl.gc.ca/information/library/PRBpubs/prb0585-e.htm
} 
provides protection against unreasonable search and seizure, thereby granting a form of privacy rights. ${ }^{71}$

Most of the CCTV in Canada is privately owned and cameras monitoring public spaces, such as residential areas, are relatively low in number. However, the number of cameras monitoring public transport hubs and airports has been increasing over the last few years. This rise has been attributed to rising fear of crime and terrorism in Canada since events such as the attacks on the World Trade Centre in New York in 2001 and the London Underground bombings in $2005 .^{72}$ Although relatively small in number in comparison to privately owned cameras, there has also been an increase during recent years in the number of open-street CCTV systems. This has been attributed to a rise in fear of crime. ${ }^{73}$ In 2007, the estimated number of cities which had installed open-street systems in Canada was $14 .^{74}$

\subsection{Analysis of CCTV in an international context}

In this section I ask: what has made the UK situation so different from other countries' experiences of CCTV? I will look at the recent political and social history of the European countries detailed above, teasing out any themes that will enable a conclusion to be drawn as to the different experiences. The detail provided earlier in this chapter will enable a thorough analysis to be undertaken.

Within the surveillance studies community, there is an argument that the reason CCTV has become so ubiquitous in the UK is due to the experience of 'transformation and restructuring' Britain experienced under Thatcher. It is argued that this lead to heightened risk perception, social polarisation and dislocation. ${ }^{75}$ The theme of CCTV as a tool for managing risk is also found

\footnotetext{
${ }^{71}$ Canadian Charter of Rights and Freedoms http://laws.justice.gc.ca/en/charter/

${ }^{72}$ Deisman, W. et al. Op.cit. p.3

${ }^{73}$ Ibid.

${ }^{74}$ Ibid. p.11

${ }^{75}$ Norris, C., McCahill, M. and Wood, D. 'Editorial: The Growth of CCTV: a global perspective on the international diffusion of video surveillance in publicly accessible space' Surveillance and Society 2(2/3) 110-135 pp.121
} 
elsewhere in the CCTV literature. ${ }^{76}$ However, other countries have also faced massive political and social upheaval, yet have not seen as rapid or large a growth in public space CCTV. Furthermore, risk (and the rising perception of it) is a global phenomenon, not confined to Britain.

Germany felt the after effects of the Second World War in terms of a complete restructuring of society. From the late 1960s through to the late 1990s the country also faced the threat of terrorism from the Red Army Faction (also known as the Baader-Meinhof group). With the fall of the Berlin Wall and German reunification there came yet another period of restructuring. However, this occurred alongside a strengthening of data protection laws and only limited increase in CCTV and surveillance for non-specific purposes. Germany was the first country to enact a privacy law, in 1970, concerned with the computerisation and centralisation of personal information. ${ }^{77}$ CCTV has been used by the German police to tackle terrorism since the 1980s. However, the general feeling has been, and remains one of, not wanting to use the cameras for more general surveillance purposes. ${ }^{78}$ This, coupled with the decision made by the Constitutional Court to provide the individual with the right to self-determination of personal information (1983), and a continual adjusting and strengthening of data protection laws, has meant that CCTV in public space has remained restricted in Germany. Public opinion has also remained largely unchanged since the early 1980 s. $^{79}$

Spain has also faced massive upheaval and the 'destabilising effects of transformation and restructuring', however does not have widespread CCTV and regulates stringently. Spain did not become a liberal democracy until the late 1970s, after the death of General Franco and the end of the dictatorial regime. The structure of society and the political system was therefore entirely reinvented during the late 1970s and early 1980s; however levels of surveillance in terms of cameras did not increase rapidly as they did in the UK. Spain has also faced

\footnotetext{
${ }^{76}$ McCahill, M. 'Beyond Foucault: Towards a contemporary theory of surveillance' in Norris, C. Moran, J. and Armstrong, G. (eds) (1998) Surveillance, Closed Circuit Television and Social Control. Ashgate. p.42

${ }^{77}$ Klosek, J. (2007) 'The War on Privacy’ Praeger; Conneticut p.78

${ }^{78}$ Goold, B. J. (2004) CCTV and Policing: Public area surveillance and police practices in Britain. Oxford University Press; Oxford p.22

${ }^{79}$ Ibid.
} 
numerous attacks by the Basque nationalist and separatist organisation ETA, since its founding in 1959. It has been estimated that the group have been responsible for over 800 deaths since their inception. ${ }^{80}$ Further, the Madrid train bombings, carried out by al-Qaeda occurred in 2004. Since the terrorist attacks on the US in 2001, Spain has strengthened its anti-terrorism laws, although a range of laws designed to combat terrorism were already in place prior to this time. For example, Article 54(1), together with 57(1) of the Law on Foreigners, allows the government to remove any foreign nationals who are believed to have participated in acts against the national security of Spain. ${ }^{81}$ In terms of CCTV, cameras have been installed in areas of the Basque region; however general public space video surveillance has not become prevalent.

France has also experienced numerous terrorist incidents over recent years from a variety of groups and organisations. During the 1980s those responsible for bombings in France included; the pro-Iranian Lebanese Hezbollah, the Popular Front for the Liberation of Palestine and Libyan intelligence (who were also responsible in 1986 for the bombing of the Pan Am flight 103 over Lockerbie, Scotland). During 1986 and 1987 a number of bombs went off in Paris, planted by a pro-Iranian militant group (this occurred at the same time as the height of the IRA bombings in the UK). The 1990s saw a number of terrorist attacks in France, carried out by the Armed Islamic Group, the GIA (Groupe Islamique Armé). However, despite these incidents, in 1986, the French National Committee on Computer Data and Individual Freedom (CNIL) lobbied the French government to regulate the use of CCTV in public space and to design regulation to prevent potential misuse. $^{82}$ Over the next ten years the CNIL campaigned for tight controls, and in 1995 legislation was passed strictly regulating the installation of CCTV and severely limiting its use. ${ }^{83}$ In December 2005, anti-terrorism legislation was passed allowing greater surveillance in areas seen as high-risk (such as airports and train stations). ${ }^{84}$ However, open-street CCTV systems are not included in this category.

\footnotetext{
${ }^{80}$ Klosek, J. (2007) ‘The War on Privacy’ Praeger; Conneticut p.89

${ }^{81}$ Ibid.

${ }^{82}$ Goold, B. J. Op.cit. p.21

${ }^{83}$ Ibid. p.22

${ }^{84}$ Op.cit. p.103
} 
Public opinion in France is also an important factor in restricting the use of public space CCTV. In 2003, for example, the decision to install 90 cameras in and around the entrances of schools in Paris sparked a public protest. ${ }^{85}$

Public opinion is an important factor in limiting the use of CCTV and ensuring regulation is put in place to prevent over- and misuse of the technology. France, Spain and Germany have all experienced resistance to CCTV from the public, or from an independent public body. In all three European countries, the public seem to play an active part in decisions taken over CCTV. Spain goes one step further, allowing immediate access to footage from cameras installed in underground and railway stations, thereby allowing an active public to take part not only in peer-topeer surveillance, but to take control of information captured about them.

In Canada, although research has suggested differing results in terms of public opinion, the Privacy Commissioner has played an important role in ensuring legislation is passed to regulate CCTV at various stages. Although during the last few years the Information Commissioner in the UK has begun to play an active role in warning of the dangers of 'sleepwalking into a surveillance society', the CCTV cameras have already been installed. The UK did have a Data Protection Registrar prior to the 1998 Data Protection Act; however they did not take an active role in campaigning against CCTV cameras, or the regulation thereof.

CCTV in the UK arose at a time when public participation in technology policy decisions was minimal (during the 1980s). In other European countries the wider dissemination and use of CCTV in public space has occurred at a later stage (during the 1990s), when public involvement in the policy process was already occurring. The use of CCTV was already established in Britain at this time, and public opinion of the technology seems to be positive (or if not positive, then neutral).

\footnotetext{
${ }^{85}$ Parliamentary Assembly Working Papers 2008 Ordinary Session ‘Video Surveillance of Public Areas’ 21-25 January p.116
} 
Legal situation - The differing legal situations, across the countries included in this chapter, have also had an impact on how CCTV has been installed, and to what extent. There is no constitution in the UK, and therefore also no right to privacy written into the constitution. Further, the UK does not have any specific legislation regulating the installation and operation of CCTV cameras. Even under the Data Protection Act, what is deemed to be collection of 'personal data' is debatable. The UK Information Commissioner has ruled that if CCTV cameras are not able to focus in on a particular individual, there is no contravention of the Data Protection Act and no need notify the use of the system to the Information Commissioner. ${ }^{86}$ The UK does have a Code of Practice for these systems, but it is largely ignored. ${ }^{87}$ Some more sophisticated systems are still subject to data protection controls, for example if footage is taken to learn about the activities of a specific individual, rather than footage taken of general scenes, data protection law is applicable. However, those cameras used for crime control and crime prevention purposes are exempt from data protection legislation as their purpose is concerned with national security and crime prevention. Furthermore, courts in UK are willing to accept evidence from illegally installed CCTV cameras. This does not promote good practice if images are accepted from cameras which should not be there. ${ }^{88}$

All three European countries, looked at more closely above, have either specific regulation governing video surveillance (France and Spain) or stringent data protection laws (Germany). In contrast to the UK, the legal situation surrounding the installation of public space CCTV systems was never left wide-open. As mentioned previously, Canada does not have specific regulation governing the use of CCTV systems; however, in this case, public involvement in the policy debate and an active privacy commissioner has meant that the widespread dissemination of the technology in public space has not occurred. The growth of public space systems has been greatest in the United States (from the above examples). It seems that the lack of legal regulation governing CCTV is leading

\footnotetext{
${ }^{86}$ Edwards, L. 'Switching off the surveillance society? Legal regulation of CCTV in the United Kingdom' in Nouwk, S. et al. (2005) (eds.) Reasonable Expectations of Privacy? Eleven country reports on camera surveillance and workplace privacy TMC Asser Press; The Hague p.96

${ }^{87}$ Moran, J. (2005) Reading the Everyday Routledge; London p.85

${ }^{88}$ Edwards, L. Op.cit. p.96
} 
to a similar situation to that of the UK; the growth of systems without enforceable guidelines.

Funding - A further similarity between the UK and the US is the availability of funding for CCTV systems. As detailed above, the US Department of Homeland Security has made available, over recent years, increasing levels of funds for video surveillance initiatives. A similar situation occurred in the UK (described in the history of CCTV section within this thesis), with a number of grants made available to local councils to install CCTV systems. This funding has been described previously in chapter 6 . The funding for CCTV in the UK has not been political party specific, commencing under a Conservative government, but continued under Labour.

Other surveillance methods - As detailed previously, the majority of countries in the European Union have a form of identity card. Public acceptance seems to come from a long history of identity card systems and opposition only increases when changes, such as the proposed inclusion of religious denomination in Greece, occur. Neither the United States nor Canada has an identity card in operation. In both countries the topic is publicly debated and various consultations and proposals have been put forward in recent years. Despite the levels of public acceptance of one method of surveillance - the identity card - no European country has the levels of dissemination of CCTV cameras of the UK. Furthermore, since events such as the terrorist attacks in the United States on the 11 September 2001, many countries have redesigned and strengthened their antiterrorism laws. As an example, Spain and France have now implemented a system to allow the deportation of individuals, described as radical Islamists, seen to be exhorting others to commit acts of terrorism. The revoking of citizenship can also occur in some cases. ${ }^{89}$ The UK government argues that CCTV is used as a tool to combat terrorism. However, despite redesigning their anti-terrorism laws, no other country has allowed the spread of video surveillance to the extent Britain has for the purpose of combating terrorism.

\footnotetext{
${ }^{89}$ Savitch, H. V. (2008) Cities in a Time of Terror: Space, Territory and Local Resilience M. E. Sharpe; London and New York p.145
} 


\subsection{Conclusion}

In this chapter I have looked at CCTV in an international context, detailing the use of the technology across the European Union, and in more specific detail in Germany, France, and Spain. Furthermore, the use of video surveillance in the United States and Canada was included in order to give a non-European perspective. This international context is useful in order to give a final set of perspectives to an analysis discussing what is different about the UK in terms of CCTV.

I have shown in this chapter that the UK does not have a constitution and therefore no written right to privacy. Although in general it must abide by the European Data Protection Directive (which protects the right to privacy), this directive does not necessarily cover the use of CCTV, as it is used for reasons of prevention of crime and public safety. I have explored the use of identity cards across the European Union, the use of which is widespread and generally accepted. However, in terms of video surveillance, there is far less than in Britain.

A closer look at Germany, France, and Spain, has revealed that there is more regulation, and enforceable regulation, regarding video surveillance than in the UK. In Germany, public challenges against, and discussion of, the installation of CCTV has meant that CCTV has not become as utilised as in the UK. The public are involved and consulted; there is informed choice and active participation in the policy process on CCTV. There is a similar situation in Spain and France, in terms of public involvement. There is also direct involvement in the surveillance process in Spain with regard to real-time access to CCTV footage taken in railway and underground stations. Public involvement and privacy campaigns in Canada have also meant that the situation regarding CCTV has remained less than the UK. However, in the United States a lack of public involvement, coupled with a lack of enforcement of CCTV regulations, and an availability of funding, has meant that video surveillance has increased rapidly over the last few years, following, it seems, in the footsteps of Britain. 


\section{Chapter X:}

\section{Conclusions}

\subsection{Introduction}

In this chapter I aim to bring together the various threads of the thesis. To start with, I look at CCTV in the context of theories of social change, arguing that these alone cannot explain the rise of CCTV in the UK. I then go on to focus more specifically on answering the research question I posed at the beginning of this thesis: why has the UK become so camera-surveilled, and what has the role of the public been in relation to CCTV? In answering this research question I will draw from each of the chapters and research questions that I have posed and answered along the way. Finally, I briefly reflect on the issue of CCTV and the public, in relation to public debate and engagement, and the democratic process.

\subsection{CCTV and theories of social change}

In recent times there have been major and rapid developments in information and communication technologies, alongside a general technologisation of security and surveillance. Technology has become the centrepiece of security systems, and there now seems to be a perception of, and a belief in, the possibility of attaining absolute security through technologies such as CCTV and biometrics.

For some commentators technological innovation and developments in information processing have meant our entry into an information society. For others we are now in a surveillance society, in which the monitoring of our day to day lives has become the norm. The rise of a network society has been heralded by some - the emergence of a new social structure, resulting from increases in information, wherein social structure is made up of networks enabled by 
information technologies. For others, a growing sense and awareness of risk (and how to manage these risks) has meant we now exist in risk society.

The growth of CCTV has been coupled with all of these theories of social change: theories of the emergence of a surveillance, risk, and information society. CCTV is a commodity; cameras are perceived to make people feel safer. In this sense (and in relation to the information society and network society) the cameras are affective - they do affective work. ${ }^{1}$ Following this line of thought, it could be argued that CCTV has a value as great as a technology that actually makes people safer. However, I argue against this in my thesis. The technology is portrayed by the Government as something which 'fights crime', and it is crime prevention money that is spent on it. If portrayed under these terms, the technology should have a real effect in terms of reducing crime rates, rather than only producing feelings of safety.

In terms of the aforementioned theories of social change (the emergence of an information or surveillance society), these can only go some way towards explaining the rise of video surveillance in Britain. The UK is not an isolated case with regard to these global phenomena. More is needed to really explore why the UK, in particular, is so camera-surveilled.

In answering this question, I purposely moved away from the technologically deterministic argument sometimes found in the literature, that the introduction and subsequent widespread use of CCTV was inevitable. Even when this is not stated directly, this notion is apparent in the lack of historical analysis and general acceptance that the UK has become a surveillance society, that this was inevitable, and that CCTV is simply a part of this surveillance era. Moving away from this traditional explanation means that the answer, as to why the UK has become so camera-surveilled, becomes more complicated. Coupled with this question, I have also explored the role of the public in relation to CCTV. This

\footnotetext{
${ }^{1}$ Affective information within this context is something that produces emotions. In the case of CCTV this is comfort and safety. For more on this see Masuda, Y. (1980) The Information Society as Post-industrial Society Institute for the Information Society; Tokyo
} 
role is interesting and multifaceted, especially when viewed in light of other technologies and public participation in policy on these technologies.

\subsection{Why is the UK so camera-surveilled, and what has been the role of the public?}

CCTV viewed in light of the questions of why it has become so widespread, and the role of the public, becomes a complex issue. The development of CCTV, and subsequent widespread dissemination in the UK, has involved the actions of various actors, and has been shaped by the various social and political contexts occurring during this development. It has fulfilled various roles over its history; at times it is a crime prevention technology, at others a tool for prosecution. It is variously portrayed as a technology that makes people feel safer and at other times as an effective technology in cutting crime (a technology that actually has an impact on peoples’ safety).

In chapter 5 I described the historical context in which CCTV has developed in the UK. In this chapter I focused particularly on the themes of surveillance, policing, science and technology, and the public sphere, as these are especially relevant for an analysis of CCTV. Following on from this, and in chapter 6, I developed a history of CCTV from the 1950s; something which has been neglected in the literature to date. The fact that CCTV has such a long history has implications for analysing why it has become so widely used, as well as for thinking about the role of the public in relation to its use.

I developed an analysis of policy discourse and consultation in relation to CCTV in chapter 7. I looked at the local and national promotion of CCTV, asking how the technology is portrayed to the public, and how, in turn, the public is portrayed in this promotion of CCTV. Following on from this, I conducted a media analysis, focusing on the last 15 years. In this section, I asked how CCTV is framed and represented to the public, and analysed the media discourse that surrounds the technology. In chapter 8 I presented the results of my empirical research, which studied the introduction of CCTV cameras onto two estates in East London, as part of a project concerned with digital expansion. Finally, I 
provided an overview of CCTV internationally, in chapter 9. This was presented in order to give a final, broader context, to my conclusions.

From these chapters the answer to why the UK is so camera-surveilled, and the role of the public in relation to CCTV, can be mapped out. In the first instance the history of surveillance in Britain can be seen to be linked to welfare, travel, conscription and citizenship. In some sense this remains the same presently. Technologies and documentation are used for access to services and to prove citizenship. The change in direction for CCTV has been far more dramatic. Early uses for the technology included those for educational purposes, and for the medical and transport sectors. This changed during the 1960s when it first became implemented for crime prevention purposes. This early history is important, and neglected in the literature to date. CCTV was not always a surveillance technology, and this is extremely important to remember when analysing its development and use. CCTV cannot simply be situated as part of a surveillance society with its use accepted as a given. Nor should it be viewed as a necessary technology due to its use as a prosecution tool or method of preventing crime. The reasons behind its implementation must be focused on, and the rationales given for its continued use. The argument that CCTV has simply been introduced to prevent crime, or that it is part of the surveillance society and therefore inevitable, is too simplistic.

The 1960s were an important time for CCTV in terms of its establishment as a crime prevention technology; if not for the public, then for the police. The police were increasing their use of technology and this, coupled with a move to cars, meant that the environment was ripe for the acceptance of new technologies and techniques. Alongside the development of an insular society, due in part to the spread of high-rise buildings (and the security and social problems which these brought), and less on the beat policing, came a time of the police reacting to crime rather than preventing it. This move away from crime prevention by the police meant that CCTV could be utilised to fill this gap. At this time there was also a push by manufacturers to increase the uses to which CCTV was put (shown by the ACPO files). The political climate at this time was one of a move towards criminal justice matters and crime entering the political agenda. Rising levels of 
crime meant that a solution would have to be presented in order to secure the vote in terms of law and order. I argue that it was during this time that CCTV changed from a technology for various sectors and purposes to a tool of politics. This development occurred at a time of a general technologisation of the public sphere and a greater infiltration of technology into the private lives of the public. The trend towards a technological solution was not confined to CCTV at this time.

The use of CCTV increased during the 1970s, particularly in relation to football grounds. Football hooliganism peaked at this time and CCTV seems to have been viewed as a solution (at least in terms of the politics of being seen to do something) to this. The more widespread use of CCTV during the 1980s was due to a variety of factors; the technology improved and became more cost-effective, there was increasing political interest in the use of CCTV, as well as a continued interest in crime prevention (and the involvement of the public in crime prevention issues, through the use of television programmes, such as Crimewatch). The use of CCTV escalated during the 1990s. Public opinion surveys reported a public unconcerned with the growth of video surveillance in public spaces and a judgement was made (seemingly not based on whether CCTV was an effective crime prevention measure) that the public felt safer with the presence of cameras. Media discourse at this time was largely positive about CCTV, gradually cementing its place in reports on missing persons, high-profile crimes, and murder investigations. This transition from a crime prevention technology to one of prosecution is interesting - CCTV is portrayed in policy discourse during the 1990s as something to prevent crime (and in this sense CCTV as a visible technology has an advantage), and in media discourse as something which aids investigation and prosecution.

There was another transition in terms of government promotion of, and discourse surrounding, the technology during the early $21^{\text {st }}$ century. The idea that the public feel safer after the installation of CCTV cameras became part of Home Office discourse ('makes the public feel safer'). As opposed to a technology purely for crime prevention, it became something to provide feelings of security and for 'reassurance'. The technology is not situated in a socio-technical network, despite numerous academic studies detailing that CCTV works best in conjunction with 
other crime prevention strategies; it alone provides safety and security. This is taken one step further in media discourse; CCTV is depicted as a 'protector' and a 'guardian angel', working alone against criminal activity. By both policy and media, the public are constructed as a passive entity in need of protection.

The answer to the question of why the UK has become so camera-surveilled is therefore not simple. It is more complex than simply situating CCTV as a result of the emergence of a surveillance society. The particular combination of factors that led to the introduction, and ensuing widespread installation and use of the cameras, have been detailed in this thesis and summarised in this conclusion. It is this particular combination of a situation allowing the installation of cameras without the need to operate within specific legal boundaries (which has had an impact on other countries in relation to installing cameras in public places), a police force looking for a shoulder to share the burden of fighting crime, the entry of criminal justice and crime onto the political agenda; and subsequently the need for a political solution to rising levels of crime, alongside a public constructed as passive and with no input in the policy process, frequent media mention of the successes of CCTV in criminal cases and continual technological developments, that have led to the UK becoming so camera-surveilled.

Furthermore, CCTV is not just a technology under the radar. It is a technology that developed under the radar in a pre-consultation era. We now live in a time when relics of this era have become institutionalised. CCTV is found in the 1970s and 1980s in Britain, a time when society was sluggish in terms of democracy, when the debates regarding privacy of the 1960s had disappeared, and social divisions were increasing. CCTV remains in this time, despite technological developments increasing its capabilities. The 1980s were not a time of public consultation, and the media was not a dissenting voice against new technologies. Furthermore, CCTV fitted in well into the political climate of the 1980s. CCTV is a divisive technology - it is for some and not for others (it is for the protection of those who are law-abiding). The use of CCTV fitted in well into the response to incidents such as the miners' strike, alongside the political discourse of the time focusing on 'the enemy within'. CCTV is used to exclude 'the enemy', and to protect the law-abiding public from those who are not. 
Alongside a growing and global awareness of risk, CCTV was implemented in Britain as a technology to manage the risks associated with crime. This occurred at the same time as the growth of a 'stranger society', a decline in communities, coupled with risk management strategies of gated communities, and the privatisation of public space. A lack of public consultation, coupled with changes in Britain towards a more insular society, meant that CCTV was able to grow into a tool of surveillance with little public focus or criticism. CCTV is now in place throughout Britain, and despite evaluations yielding negative results in relation to its effectiveness in preventing crime, no one is held to account with regard to public money being spent on what has been empirically proven to be an ineffective technology in terms of the purposes for which it is installed.

It is hard to argue against CCTV in terms of privacy, especially considering that most cameras are not watched constantly and are considered to be ineffective when studied empirically. However, I believe that the money spent on CCTV could be better spent elsewhere. Rather than funding a technology meant for crime prevention, but which in actuality is a tool for prosecution and evidence after the event, the allocated public money could be poured into education and areas with high levels of social deprivation. Finally, CCTV needs to be considered as part of a socio-technical network. On their own, the cameras do not function effectively. They require a solid and efficient network of actors in order to become something of use.

\subsection{Reflections on the issue of CCTV and the public}

At the start of my research on CCTV in the UK I was of the mindset that the biggest issue facing the public in terms of surveillance was one of privacy. However, research has shown that CCTV is not always effective due, in part, to poor quality footage and cameras being placed inefficiently. Although I still have concerns regarding the privacy implications of a technology that when installed and footage is recorded does not comply with the Data Protection Act, nor has any legal basis in terms of privacy protection, these have lessened somewhat. 
Individual profiles are not generally amassed on databases through footage recorded by CCTV cameras (unlike the proposed ID cards database).

However, the public are still surveilled via CCTV, and it is the issue of a lack of choice which has become more important to me throughout my research. I believe that the importance of the public and the public sphere in a liberal democracy cannot be overstated. Public debate and engagement define the public interest and form the basis of a democratic society, and a democratic society must maintain accountability and transparency, alongside the free flow of information. Public deliberation and input into political decisions is therefore necessary for a truly just and democratic process. My empirical research, which can still be viewed as a representative sample despite being a small-scale study, shows that the public do want to be consulted and engaged on issues of security, crime, and surveillance. I believe that the public are underrepresented in the policy-making process on CCTV, that this process happens away from the public realm, and that this is an issue that needs redressing. 


\section{Bibliography}

1954. Television Act 1954.

1965. Royal Commission on Capital Punishment 1949-53. London: HMSO.

1984. Police and Criminal Evidence Act.

1991. Criminal Justice Act 1991.

1998. Crime and Disorder Act 1998.

2002. Criminal Justice White Paper: Justice for All. London: HMSO.

2005. Report demands that French ID card plans must be reviewed. Biometric Technology Today 13 (7): 1-2.

2009. National DNA Database Annual Report 2005 - 2006.

Ackroyd S, and Hughes JA. 1992. Data Collection in Context. London:

Longman.

Ackroyd S. 1993. A case of arrested development? Some consequences of inadequate management in the British police. International Journal of Public Sector Management 6 (2): 5-16.

Agar J. 2003. Science and Information Technology. In Britain Since 1945, ed J Hollowell Blackwell.

-----. 2008. What happened in the Sixties. British Journal of Sociology 41 (4): 567-600.

Ainley R. 2001. Keeping an Eye on Them. In Technospaces: Inside the New Media, ed S Munt London: Continuum.

Alderson JC. 1978. Concepts of Preventive Policing.

Alpert H. 1993. Emile Durkheim and his sociology. Hampshire: Gregg Revivals.

Archer JM. 1993. Sovereignty and Intelligence: Spying and Court Culture in the English Renaissance.: Stanford University Press.

Arkell P, and Rising R. 2009. Unfinished Business: The miners' strike for jobs 1984-5. London: Lupus Books.

Armstrong G, and Giulianotti R. 1998. From another angle: police surveillance and football supporters. In Surveillance, Closed Circuit Television and Social Control, ed C Norris Oxford: Berg.

Armstrong G. 2003. Football Hooligans. Oxford: Berg. 
Babbie ER. 1979. The Practice of Social Research. California: Wadsworth.

Bailey V. 1981. Policing and Punishment in Nineteenth Century Britain. London: Croom Helm.

Bannister J, Fyfe NR, and Kearns A. 1998. Closed Circuit Television and the City. In Surveillance, Closed Circuit Television and Social Control, eds C Norris and G Armstrong Ashgate.

Barclay H. 1990. People Without Government: an anthropology of anarchy. London: Kahn and Averill.

Barker A, and Peters GB. 1993. The Politics of Expert Advice: Creating, using and manipulating scientific knowledge for public policy.: University of Edinburgh Press.

Barnett H. 2004. Constitutional and Administrative Law. London: Cavendish.

Bauer MW, and Gaskell J. 2000. Qualitative Researching with Text, Image and Sound. London: Sage.

Bauman Z. 1992. Intimations of Postmodernity . London: Routledge.

Beattie JM. 1977. Crime and the Courts in Surrey 1736-1753. In Crime in England 1550-1800, ed JS Cockburn Princeton: Princeton University Press.

Beccaria C. 1986. On Crimes and Punishment. Indianapolis: Hackett.

Beck U. 1992. Risk Society: Towards a new modernity. London: Sage.

-----. 2006. Living in the World Risk Society.

Bell D. 1976. The Cultural Contradictions of Capitalism. New York: Basic Books.

-----. 1980. The social framework of the information society. In The Microelectronics Revolution: the complete guide to the new technology and its impact on society, ed T Forester Oxford: Blackwell.

Benites C, and Lyster C. 2005. Regarding public space. Architecture Journal.

Bennett CJ, and Bayley RM. 2005. Video Surveillance and Privacy Protection Law in Canada. In Reasonale Expectations of Privacy? Eleven Country Reports on Camera Surveillance and Workplace Privacy, ed S Nouwt The Hague: TMC Asser Press.

Berg BL. 2001. Qualitative Research Methods for the Social Sciences. Boston: Allyn \& Bacon.

Bijker WE, Hughes TP, and Pinch TJ. 1987. The Social Construction of Technological Systems: New directions in the sociology and history of technology . Massachusetts: MIT Press. 
Bimber B. 1990. Karl Marx and the Three Faces of Technological Determinism. Social Studies of Science 20: 333-351.

-----. 1994. Three Faces of Technical Determinism. In Does Technology Drive History? The Dilemma of Technological Determinism , ed MR Smith, 79-100. Massachusetts: MIT Press.

Black J. 2004. Britain Since the Seventies: Politics and society in the consumer age. London: Reaktion Books.

Blakemore K, and Griggs E. 2007. Social Policy: An introduction. Maidenhead: Open University Press.

Bradley D. 1986. Managing the Police: Law, Order and Democracy. Brighton: Harvester Wheatsheaf.

Brake M, and Hale C. 1992. Public Order and Private Lives; The politics of law and order. London: Routledge.

Brewer J, and Hunter A. 1989. Multimethods Research: A synthesis of styles. London: Sage.

-----. 2006. Foundations of Multimethod Research: Synthesizing Styles. London: Sage.

Brin D. 1998. The Transparent Society. Massachusetts: Perseus Books.

Brogden M. 1987. The Emergence of the Police - The Colonial Dimension.

British Journal of Criminology 27 (1): 4-14.

Bryman A. 2001. Social Research Methods. Oxford: Oxford University Press.

Bulos M, and Sarno C. 1994. Closed Circuit Television and Local Authority Initiatives: The first national survey. South Bank University.

Bulos M. 1995. Towards a Safer Sutton? Impact of closed circuit television on Sutton town centre. London Borough of Sutton.

Burr V. 2007. Social Constructionism. London and New York: Routledge.

Burrows J. 2008. Closed Circuit Television and Crime on the London Underground. In Designing Out Crime, eds RVG Clarke and P Mayhew, 75-83. Her Majesty's Stationery Office.

Callon M. 2008. Science and Governance: Taking European Knowledge Society Seriously: report of the expert group on science and governance to the Science, Economy and Society Directorate. Milan: IPOC.

Castells M. 1989. The Informational City: Information Technology, Economic Restructuring and the Urban-Regional Process. Oxford: Blackwell.

-----. 2000. The Rise of the Network Society . Oxford: Blackwell. 
-----. 2004. Informationalism, networks, and the network society: a theoretical blueprint. In The Network Society: A Cross-cultural perspective, ed M Castells Cheltenham: Edward Elgar.

-----. 2009. The Rise of the Network Society The Information Age: Economy, Society and Culture, Volume 1.: Wiley-Blackwell.

Chambliss WJ, and Mankoff M. 1976. Whose Law? What Order? A conflict approach to criminology. New York: John Wiley.

Chan JBL. 2005. Police and New Technologies. In Handbook of Policing, ed T Newburn Willan.

Chant C, and Goodman DC. 1999. Pre-industrial Cities and Technology. London: Routledge.

Chapman J. 2005. Comparative Media History, An Introduction: 1789 to the present. Cambridge: Polity Press.

Chibnall S. 2003. Law-and-Order News: An analysis of crime reporting in the British press.: Tavistock Press.

Childs D. 1995. Britain Since 1939: progress and decline. London: Macmillan.

Chopyak J, and Levesque P. 2002. Public Participation in Science and Technology Decision Making: Trends for the future. Technology in Society 24 (12): $155-166$.

Clarke B. 2004. From Grub Street to Fleet Street. Aldershot: Ashgate.

Coaffee J. 2004. Recasting the "Ring of Steel": Designing out Terrorism in the City of London. In Cities, War and Terrorism: Towards an Urban Geopolitics, ed S Graham Blackwell.

Cohen S. 1972. Folk Devils and Moral Panics: The Creation of the Mods and Rockers. London: MacGibbon \& Kee.

Cooper M. 1984. The Integrative Research Review. London: Sage.

Coser LA. 1957. Social Conflict and Social Change. British Journal of Sociology 7 (3): 197-207.

Crawford A. 1998. Crime Prevention and Community Safety.: Longman.

-----. 1999. The Local Governance of Crime. Oxford: Oxford University Press.

-----. 2002. Crime and Insecurity. Devon: Willan.

Creswell J. 2003. Research Design: Qualitative, quantitative and mixed methods approaches. London: Sage. 
Critchley TA. 1967. A History of Police in England and Wales 900-1966.

London: Constable.

Dandeker C. 1990. Surveillance, Power and Modernity: Bureaucracy and discipline from 1700 to the present day. New York: St. Martin's Press.

Davies G, and Thasen S. 2000. Closed-circuit television: How effective an identification aid? British Journal of Psychology 91: 411-426.

Davies M. 2005. Criminal Justice: An introduction to the criminal justice system in England and Wales. Harlow and London: Longman.

Davies S. 1996. The Case Against: CCTV should not be introduced. International Journal of Risk, Security and Crime Prevention 1 (4).

-----. 1996. Big Brother: Britain's Web of Surveillance and the New Technological Order. London: Pan Books.

-----. 1998. CCTV: a new battleground for privacy. In Surveillance, Closed Circuit Television and Social Control, eds C Norris, J Moran and G Armstrong Ashgate.

Deisman W. 2009. A Report on Camera Surveillance in Canada. Surveillance Camera Awareness Network.

Deleuze G. 1990. Postscript to the Societies of Control. L'Autre Journal.

Dickson D. 1974. Alternative Technology and the Politics of Technical Change. Glasgow: Fontana Collins.

Dijk JJMv. 1990. Crime Prevention Policy: Current State and Prospects. In Crime and Criminal Policy in Europe, eds G Kaiser and HM Albrecht Max-PlanckInstitute.

Donajgrodzki AP. 1977. Social Control in Nineteenth Century Britain. London: Croom Helm.

Douglas M, and Wildavsky A. 1982. Risk and Culture: An essay on the selection of technological and environmental dangers. Los Angeles: University of California Press.

Douglas M. 1992. Risk and Blame: Essays in cultural theory. London: Routledge.

Downes D, and Morgan R. 2007. No Turning Back: The Politics of Law and Order into the Millenium. In The Oxford Handbook of Criminology, ed M Maguire Oxford: Oxford University Press.

Dunbar I, and Langdon A. 2009. Tough Justice: Sentencing and Penal Policies in the 1990s. London: Blackstone Press Ltd.

East R, and Thomas P. 1985. Road-blocks: The experience in Wales. In Policing the Miners' Strike, eds B Fine and R Millar London: Lawrence \& Wishart. 
Edwards CJ. 2009. Changing Policing Theories for $21^{\text {st }}$ Century Societies. Annandale: Federation.

Edwards L. 2005. Switching off the surveillance society? Legal Regulation of CCTV in the United Kingdom. In Reasonable Expectations of Privacy? Eleven Country Reports on Camera Surveillance and Workplace Privacy, ed S Nouwt The Hague: TMC Asser Press.

Edwards P. and Tilley N. 1994. CCTV: Looking Out for You. London: HMSO.

Ellin N. 1997. Architecture of Fear. New York: Princeton Architectural Press.

Ellul J. 1962. The Technological Order. Technology and Culture 3.

-----. 1964. La Technique.: Vintage Press.

-----. 1965. The Technological Society.: Cape.

Emmerson A. 2000. Behind Big Brother. Electronics World, 2000.

Emsley C. 1995. Preventive Policing: The path to the present. In Comparisons in Policing: An International Perspective, ed JP Brodeur Aldershot: Avebury.

-----. 2996. The English Police: A political and social history. London: Longman.

Entman RM. 1993. Framing: Towards Clarification of a Fractured Paradigm. Journal of Communication 43: 51-58.

Ewald F. 1993. Two Infinities of Risk. In The Politics of Everyday Fear, ed B Massumi Minnesota: University of Minnesota Press.

Fay SJ. 1998. Tough on Crime, Tough on Civil Liberties: Some Negative Aspects of Britain's Wholesale Adoption of CCTV Surveillance During the 1990s. International Review of Law, Computers and Technology 12 (2): 315-347.

Feenberg A. 1999. Questioning Technology. London and New York: Routledge.

-----. 1999. Questioning Technology. London: Routledge.

Fennelly LJ. 2003. Effective Physical Security. London: Elsevier.

Ferguson I. 1994. Containing the Crisis: Crime and the Tories. International Socialism Journal 62.

Fijnaut C, and Marx GT. 1995. Undercover: Police Surveillance in Comparative Perspective.: Kluwer.

Flight S, Heerwaarden Yv, and Soomeren P. 2003. Does CCTV Displace Crime? An evaluation of the evidence and a case study from Amsterdam. In CCTV, ed M Gill Perpetuity Press.

Foucault M. 1979. Discipline and Punish: The birth of the prison. Harmondsworth: Penguin Books. 
Fowler FJ. 2002. Survey Research Methods. London: Sage.

Francis M, and Zweiniger-Bargielowska I. 1996. The Conservatives and British Society 1880-1990. Cardiff.

Fraser N. 1995. Politics, Culture, and the Public Sphere: Toward a postmodern concept. In Social Postmodernism: Beyond Identity Politics, eds L Nicholson and S Seidman, 287-314. Cambridge: Cambridge University Press.

Fuchs C. 2008. Internet and Society: Social Theory in the Information Age. London: Routledge.

Fyfe NR. 1995. Law and order policy and the spaces of citizenship in contemporary Britain. Political Geography 14 (2): 177-189.

Fyfe NR, and Bannister J. 1998. The Eyes Upon the Street: Closed-Circuit Television Surveillance and the City. In Images of the Street, ed NR Fyfe London: Routledge.

Gallagher C. 2004. CCTV and Human Rights: The fish and the bicycle? An examination of Peck v. United Kingdom (2003) E.H.R.R. 4. Surveillance and Society 2 (2/3): 270-292.

Garfinkel S. 2001. Database Nation: The death of privacy in the 21st century. Cambridge: O'Reilly.

Garland D. 1993. Punishment and Modern Society: A Study in Social Theory. Chicago: University of Chicago Press.

-----. 1996. The Limits of the Sovereign State: Strategies of crime control in contemporary society. The British Journal of Criminology 36 (4): 445-471.

-----. 2001. The Culture of Control: Crime and Social Order in Contemporary Society. Oxford: Oxford University Press.

-----. 2003. The Rise of Risk. In Risk and Morality, eds RV Ericson and A Doyle Toronto: University of Toronto Press.

Gellman R. 2005. A General Survey of Video Surveillance Law in the United States. In Reasonable Expectations of Privacy? Eleven Country Reports on Camera Surveillance and Workplace Privacy, ed S Nouwt The Hague: TMC Asser Press.

Gerrard G. 2007. National CCTV Strategy. London: HMSO.

Giddens A. 1985. The Nation State and Violence. Cambridge: Polity Press.

-----. 1987. Social Theory and Modern Sociology. Oxford: Polity Press.

-----. 1991. Modernity and Self-Identity. Cambridge: Polity Press. 
-----. 1998. Conversations with Anthony Giddens: Making Sense of Modernity. California: Stanford University Press.

-----. 1999. Risk and Responsibility. Modern Law Review 62 (1).

Gill M, Bryan J, and Allen J. 2007. Public Perceptions of CCTV in Residential Areas: "It Is Not As Good As We Thought It Would Be". International Criminal Justice Review 17: 304-324.

Gill M, and Turbin V. 1999. Evaluating 'Realistic Evaluation: Evidence from a study of CCTV.

Gill M. 2005. Assessing the Impact of CCTV. London: HMSO.

Gilling D. 1993. Multi-agency crime prevention in Britain. In Crime Prevention Studies, ed RV Clarke New York: Monsey.

Glynn S, and Booth A. 1996. Modern Britain: An economic and social history. London and New York: Routledge.

Goold BJ. 2004. CCTV and Policing: Public area surveillance and police practices in Britain. Oxford: Oxford University Press.

Gould J, and Kolb WL. 1964. A Dictionary of the Social Sciences. London: Tavistock Publications.

Gras M. 2004. The Legal Regulation of CCTV in Europe. Surveillance and Society 2 (2/3): 216-229.

-----. 2008. The Legal Regulation of CCTV in Europe. Surveillance and Society 2 (2/3): 216-229.

Greene JC. 2007. Mixed methods in social inquiry.: Wiley.

Gregory J, and Miller S. 1998. Science in Public: communication, culture, and credibility. London and New York: Plenum Trade.

Grix J. 2001. Demystifying Postgraduate Research. Edgbaston: University of Birmingham Press.

Gurevitch M, and Levy MR. 1985. Mass Communication Review Yearbook. California: Sage.

Habermas J. 1987. The structural transformation of the public sphere :an inquiry into a category of bourgeois society. Cambridge: Polity Press.

-----. 1989. The Public Sphere: An encyclopaedia article. In Critical Theory and Society: A reader, eds SE Bronner and DM Kellner, 136-142.

Habib I. 2008. Black Lives in the English Archives 1500-1677. Aldershot: Ashgate. 
Hall S. 1998. The Hard Road to Renewal: Thatcherism and the crisis of the left. London: Verso.

Hamilton P, and Hargreaves R. 2001. The Beautiful and the Damned: The creation of identity in nineteenth century photography . London: National Portrait Gallery.

Hanley L. 2007. Estates: An intimate history . London: Granta.

Heilbroner RL. 1967. Do Machines make History? Technology and Culture 8 (3): 335-345.

Helten F, and Fischer B. 2004. Reactive Attention: Video Surveillance in Berlin Shopping Malls. Surveillance and Society 2 (2/3): 323-345.

Hempel L, and Töpfer E. 2004. CCTV in Europe.

Herskovits MJ. 1948. Man and his Works. New York: Knopf.

Hesse-Biber SM, and Leavy P. 2008. Handbook of Emergent Methods. London: Guilford.

Hetman F. 1974. Technology on Trial. In The Politics of Technology, eds G Boyle, D Elliott and R Roy London: Longman for the Open University Press.

Higgs E. 2001. The Rise of the Information State: The development of central state surveillance of the citizen in England 1500-2000. Journal of Historical Sociology 14 (2): 175-197.

Hoey A. 1998. Techno-cops: Information Technology and Law Enforcement. International Journal of Law and Information Technology 6 (1): 61-90.

Holden A. 2005. Tourism Studies and the Social Sciences. London: Routledge.

Hollowell J. 2003. Britain Since 1945.: Blackwell Publishing Ltd.

Home Office. 1995. Identity Cards - A Consultation Document. London: HMSO.

-----. 1997. No More Excuses: A new approach to tackling youth crime in England and Wales . London: HMSO.

-----. 1997. Protecting the Public: The Government's Strategy on Crime in England and Wales.

-----. 2001. Policing a New Century: A Blueprint for Reform. London: HMSO.

-----. 2002. Criminal Justice White Paper: Justice for All. London: HMSO.

-----. 2004. Building Communities, Beating Crime - A better police service for the $21^{\text {st }}$ century. London: HMSO.

-----. 2008. National Identity Scheme: Delivery Plan 2008. 
-----. 2008. Compulsory Identity Cards for Foreign Nationals.

Honess T, and Charman E. 1992. Closed Circuit Television in Public Places: Its acceptability and perceived effectiveness.

Hood J. 2003. Closed Circuit Television Systems: a failure in risk communication? Journal of Risk Research 6 (3): 233-251.

Horne C. 1996. The Case For: CCTV should be introduced. International Journal of Risk, Security and Crime Prevention 1 (4).

House of Commons Home Affairs Committee. 2004. Identity Cards. London: The Stationery Office Ltd.

Hoyle C, and Rose D. 2001. Labour, Law and Order. Police Quarterly 72 (1): 7685.

Hughes T. 1994. Technological Momentum. In Does Technology Drive History?, eds MR Smith and L Marx Cambridge: MIT Press.

Innis HA. 1951. The Bias of Communication. Toronto: University of Toronto Press.

-----. 1972. Empire and Communications. Toronto: University of Toronto Press.

Ironside M, and Seifert RV. 2000. Facing up to Thatcherism: the history of NALGO 1979 - 1993. Oxford: Oxford University Press.

Jary D, and Jary J. 1995. Collins Dictionary of Sociology. Glasgow: Harper Collins Publishers.

Jewkes Y. 2007. Handbook on Prisons. Cullompton: Willan.

Johnston L. 2000. Policing Britain: Risk, Security and Governance. London: Longman.

Joint Consultative Committee. 1990. Operational Policing Review.

Jones T, and Newburn T. 1998. Private Security and Public Policing. Oxford: Clarendon Press.

Jupp V. 2006. Sage Dictionary of Social Research Methods. London: Sage.

Kelly JE. 1998. Rethinking Industrial Relations: Mobilization, Collectivism and Long Waves. London: Routledge.

Kerr PA, and Moy P. 2008. Newspaper Coverage of Fundamentalist Christians, 1980-2000. In Content Analysis, ed R Franzosi, 258-276. London: Sage.

Kershaw C. 2008. Crime in England and Wales 2007/08: Findings from the British Crime Survey and Police Recorded Crime. London: HMSO. 
Klauser F. 2004. A Comparison of the Impact of Protective and Preservative Video Surveillance on Urban Territoriality: the case of Switzerland. Surveillance and Society 2 (2/3): 145-160.

Klosek J. 2007. The War on Privacy. Conneticut: Praeger.

Krippendorf K. 2004. Content Analysis: An introduction to its methodology. London: Sage.

Kumar K. 2005. From Post-Industrial to Post-Modern Society: new theories of the contemporary world. Oxford: Blackwell.

Laing RD. 1960. The Divided Self: An existential study in sanity and madness. London: Penguin Books.

Latour B. 1987. Science in Action. Milton Keynes: Open University Press.

Lea J. 2002. Crime and Modernity. London: Sage.

Leeuw KD, and Bergstra JA. 2007. The History of Information Security.

Amsterdam: Elsevier.

Lippmann W. 1922. Public Opinion.: Allen \& Unwin.

-----. 1925. The Phantom Public.: Harcourt Brace \& Co.

Livingstone S. 1996. On the Continuing Problem of Media Effects Research. In Mass Media and Society, eds J Curran and M Gurevitch, 305-324. London: Edward Arnold.

Llg RE, and Haugen SE. 2003. Earnings and Employment Trends in the 1990s. Monthly Labour Review 123 (3).

Lomell HM. 2004. Targeting the Unwanted: Video Surveillance and Categorical Exclusion in Oslo, Norway. Surveillance and Society 2 (2/3): 346-360.

Lord Scarman. 1982. The Scarman Report: The Brixton Disorders.: Penguin Books.

LSE. 2005. The LSE Identity Project: An assessment of the UK Identity Cards Bill and its Implications.

Luhmann N. 2003. Risk: A Sociological Theory .: Walter de Gruyter.

Lupton D. 1999. Risk. London: Routledge.

Lyon D. 1994. The Electronic Eye: The rise of the surveillance society. Minneapolis: University of Minnesota Press.

-----. 2001. Surveillance Society: Monitoring everyday life. Buckingham: Open University Press.

-----. 2003. Surveillance after September 11 . Cambridge: Polity Press. 
Macdonald C. 1990. Britain and the Korean War. Oxford.

MacIver RM. 1937. Society. New York: Farrar and Rinehart Inc.

Mackenzie D, and Wajcman J. 1985. The Social Shaping of Technology. Milton Keynes: Open University Press.

Malinowski BK. 1926. Anthropology. In Encyclopedia Britannica, 132. Encyclopedia Britannica Co.

Manwaring-White S. 1983. The Policing Revolution: Police, Technology, Democracy and Liberty in Britain. Sussex: The Harvester Press Ltd.

Marsh I. 2004. Criminal Justice: an introduction to philosophies, theories and practice. London: Routledge.

Martinais E, and Bétin C. 2004. Social Aspects of CCTV in France: the case of the city centre of Lyons. Surveillance and Society 2 (2/3): 361-375.

Marwick A. 1996. British Society Since 1945. London: Penguin Books.

Marx GT. 1985. The Surveillance Society: The threat of 1984-style techniques. The Futurist 19 (3): 21-26.

-----. 2005. Surveillance and Society. In Encyclopaedia of Social Theory, ed G Ritzer London: Sage.

Marx K. 1936. The Poverty of Philosophy. London: Martin Lawrence.

Marx K, and Engels F. 1967. The Communist Manifesto. London: Penguin Books.

Mawby RI. 1990. Comparative Policing Issues: The British and American Systems in Comparison. London: Unwin Hyman.

May T. 1997. Social Research: Issues, methods and process. Buckingham: Open University Press.

Mayhew P. 1979. Crime in Public View. London: HMSO.

McCahill M. 1998. Beyond Foucault: Towards a contemporary theory of surveillance. In Surveillance, Closed Circuit Television and Social Control, eds C Norris, J Moran and G Armstrong Ashgate.

McGrail BA. 1999. Communication Technology and Local Knowledges: The case of peripheralized high rise housing estates. Urban Geography 20 (4): 303333.

McLynn F. 1989. Crime and Punishment in Eighteenth-century England. London: Routledge. 
McQuail D. 1994. Mass Communication Theory: An introduction. London: Sage Publications.

Miller WA. 1975. Cops and Bobbies 1830-1870. Journal of Social History 9: 7388.

Miller WR. 1975. Police Authority in London and New York City 1830-1870. Journal of Social History 8: 81-101.

Milne R. 2004. The Enemy Within: the secret war against the miners. London: Verso.

Misa TJ. 1994. Retrieving Sociotechnical Change from Technological Determinism. In Does Technology Drive History, eds MR Smith and L Marx Cambridge: MIT Press.

Monahan T. 2006. Surveillance and Security: Technological Politics and Power in Everyday Life. New York: Routledge.

Moran J. 1998. A brief chronology of photographic and video surveillance. In Surveillance, Closed Circuit Television and Social Control, ed C Norris Aldershot: Ashgate.

-----. 2005. Reading the Everyday. London: Routledge.

Mullard M. 1995. Policy-making in Britain. London: Routledge.

Murphy T. 1999. The Admissibility of CCTV Evidence in Criminal Proceedings. International Review of Law, Computers and Technology 13 (3): 383-404.

Müller C, and Boos D. 2004. Zurich Main Railway Station: A Typology of Public CCTV Systems. Surveillance and Society 2 (2/3): 161-176.

Neuendorf KA. 2002. The Content Analysis Guidebook. London: Sage.

Newburn T, and Hayman S. 2002. Policing, Surveillance and Social Control: CCTV and police monitoring of suspects.: Willan Publishing.

Neyland D. 2004. Closed Circuits of Interaction? The mobilization of images and accountability through high-street CCTV. Information, Communication and Society 7 (2): 252-271.

Nieto M. 1997. Public Video Surveillance: Is it an Effective Crime Prevention Tool? Sacramento: Californian.

Nieto M, Johnstone-Dodds K, and Simmons C. 2002. Public and Private Applications of Video Surveillance and Biometric Technologies. Sacramento: Californian Research Bureau.

Nietzsche F. 1967. The Birth of Tragedy. New York: Vintage Books.

-----. 1968. The Will to Power. New York: Vintage Books. 
Norris C, and Armstrong G. 1999. The Maximum Surveillance Society: The rise of CCTV. Oxford: Berg.

-----. 1999. CCTV and the Social Structuring of Surveillance. In Surveillance of Public Space: CCTV, Street Lighting and Crime Prevention, ed N Tilley New York: Criminal Justice Press.

Norris C. 2003. From Personal to Digital: CCTV, the panopticon, and the technological mediation of suspicion and social control. In Surveillance as Social Sorting: Privacy, Risk and Digital Discrimination , ed D Lyon London: Routledge.

Nouwt S, Vries BR, and Loermans R. 2005. Analysis of the Country Reports. In Reasonable Expectations of Privacy? Eleven country reports on camera surveillance and workplace privacy, ed S Nouwt The Hague: TMC Asser Press.

NSPCC. 2009.

Palmer SH. 1988. Police and Protest in England and Ireland 1780-1850. Cambridge: Cambridge University Press.

Park RE, and Burgess EW. 1921. Introduction to the Science of Sociology. Illinois: The University of Chicago Press.

Parsons T. 1954. Essays in Sociological Thought. New York: The Free Press of Glencoe.

Payne G, and Payne J. 2004. Key Concepts in Social Research. London: Sage.

Petrow S. 1994. Policing Morals: The Metropolitan Police and the Home Office 1870-1914. Oxford: Clarendon Press.

Philips D. 1985. A Just measure of Crime, Authority Hunters and Blue Locusts: The Revisionist Social History of crime and the Law in Britain 1780-1850. In Social Control and the State: Historical and comparative essays, eds S Cohen and A Scull Oxford: Basil Blackwell.

Pierre J. 2006. Handbook of Public Policy. London: Sage.

Prior L. 2003. Using Documents in Social Research. London: Sage.

Privacy International. 2003. Silenced - Czech Republic.

-----. 2007. Kingdom of the Netherlands.

-----. 2007. Republic of Slovenia.

-----. 2007. Republic of Poland.

-----. 2007. Video Surveillance. 
Rabinow P, and Dreyfus H. 1983. Michel Foucault: Beyond Structuralism and Hermeneutics. Chicago: University of Chicago Press.

Radcliffe-Brown AR. 1935. On the Concept of Function in Social Science. American Anthropologist 37.

Radcliffe-Brown AR. 1959. Structure and Function in Primitive Society. London: Cohen and West Ltd.

Radelet LA. 1986. The Police and the Community. New York: Macmillan.

Radzinowicz L. 1956. A History of English Criminal Law and its Administration. London: Steven and Sons Ltd.

Rawlings P. 2002. Policing: A short history. Cullompton: Willan Publishing.

Reeve A. 1998. The Panopticisation of Shopping: CCTV and leisure consumption. In Surveillance, Closed Circuit Television and Social Control, eds C Norris, G Armstrong and J Moran Ashgate.

Reiner R. 1997. Policing and the Police. In The Oxford Handbook of Criminology, eds M Maguire, R Morgan and R Reiner Oxford: Clarendon Press.

-----. 2000. The Politics of the Police. Hemel Hempstead: Harvester Wheatsheaf.

-----. 2005. Policing a postmodern society. In Handbook of Policing, ed T Newburn Willan.

Reith C. 1938. The Police Idea: Its history and evolution in England in the 18th century and after. London: Oxford University Press.

-----. 1948. A Short History of the British Police. London: Oxford University Press.

Reynolds EA. 1998. Before the Bobbies: The Night Watch and Police Reform in Metropolitan London, 1720-1830. London: Macmillan.

Richards AJ. 1996. Miners on Strike: Class solidarity and division in Britain. Oxford: Berg.

Roberts LP. 2004. "The History of Video Surveillance - from VCRs to eyes in the sky." Available from http://EzineArticles.com/?expert=Lucy_P_Roberts.

Robinson CD, and Scaglion R. 1987. The Origin and Evolution of the Police Function in Society: Notes towards a theory. Law and Society Review 21 (1): 109153.

Robinson CD, Scaglion R, and Olivero JM. 1994. Police in Contradiction: The evolution of the police function in society. Conneticut: Greenwood Press.

Rodman B. 1968. Bentham and the Paradox of Penal Reform. Journal of the History of Ideas 29 (2): 197-210. 
Rosenberg RS. 2004. The Social Impact of Computers. Amsterdam and London: Elsevier.

Rubenstein WD. 2003. Twentieth Century Britain: A political history.

Ryberg J. 2007. Privacy Rights, Crime Prevention, CCTV, and the life of Mrs Aremac. Res Publica 13: 127-143.

Samuel R. 1986. The Enemy Within: Pit villages and the miners' strike of 1984-5. London: Routledge.

Savitch HE. 2008. Cities in a Time of Terror: Space, territory and local resilience. London and New York: M. E. Sharpe.

Sætnan AR, Lomell HM, and Wiecek C. 2004. Controlling CCTV in Public Spaces': Is privacy the (only) issue? Reflections on Norwegian and Danish Observations. Surveillance and Society 2 (2/3): 396-414.

Schwartz RT, and Miller JC. 1964. Legal Evolution and Societal Complexity. American Journal of Sociology 70 (1): 159-169.

Scott G, and Marshall J. 2005. Oxford Dictionary of Sociology. Oxford: Oxford University Press.

Seymour-Ure C. 1991. The British Press and Broadcasting since 1945. Oxford: Blackwell.

Short E, and Ditton J. 2008. Does Closed Circuit Television Prevent Crime? An evaluation of the use of CCTV surveillance cameras in Airdrie town centre. The Scottish Office Central Research Unit.

Silver A. 1967. The Demand for Order in Civil Society: A review of some themes in the history of urban crime, police, and riot. In The Police: Six Sociological Essays, ed DJ Bordua New York: John Wiley.

-----. 2005. The demand for order in civil society. In Policing: Key Readings, ed T Newburn Devon: Willan Publishing.

Simmel G. 1955. Conflict and the Web of Group Affiliations. Illinois: The Free Press of Glencoe.

Sked A, and Cook C. 1993. Post-War Britain: A political history. London: Penguin Books.

Sked A. 2003. The Political Parties. In Britain Since 1945, ed J Hollowell Blackwell.

Slobogin C. 2002. Camera Surveillance of Public Places. Mississippi Law Journal 72: 213-233.

Smart B. 1985. Michel Foucault. New York: Routledge. 
Smith MR, and Marx L. 1994. Does Technology Drive History? The Dilemma of Technological Determinism. Massachusetts: MIT Press.

Spencer M. 1995. States of Injustice: A guide to human rights and civil liberties in the European Union. Pluto Press.

Spitzer S. 1987. Security and Control in Capitalist Societies: The fetishism of security and the secret thereof. In Transcarceration: Essays in the Sociology of Social Control, eds J Lowman, R Menzies and T Plays Aldershot: Gower.

Spriggs A. 2005. Public Attitudes Towards CCTV: results from the preintervention public attitude survey carried out in areas implementing CCTV.

State Research Pamphlet. 1981. Policing the Eighties - The Iron Fist. London: Independent Research Publications Ltd.

Storch RD. 1980. Crime and Justice in $19^{\text {th }}$-Century England. History Today 30: 32-37.

Strath B. 1987. The Politics of De-industrialisation. London: Croom Helm.

Stunkel KR, and Sarsar S. 1994. Ideology, Values and Technology in Political Life. London: University Press of America.

Styles J. 2005. The emergence of the police - explaining police reform in eighteenth and nineteenth century England. In Policing: Key Readings, ed T Newburn Devon: Willan.

Surette R. 2006. CCTV and Citizen Guardianship Suppression: A Questionable Proposition. Police Quarterly 9 (1): 100-125.

Surgeon General's Conference on Agricultural Safety and Health. 1991. FarmSafe 2000: A National Coalition for Local Action.

Sutton A, and Wilson D. 2004. Open-Street CCTV in Australia: The politics of resistance and expansion. Surveillance and Society 2 (2/3): 310-322.

Tashakkori C, and Teddlie C. 1998. Mixed Methodology: Combining qualitative and quantitative approaches.

Taylor FW. 1967. Principles of Scientific Management. New York: Harper and Row.

The Scottish Office. 1996. Crime and Punishment. Edinburgh: HMSO.

Thompson K. 1998. Moral Panics. London: Routledge.

Tilley N. 1993. Understanding Car Parks, Crime and CCTV; Evaluation lessons from safer cities. 
Tilley N. 1998. Evaluating the Effectiveness of CCTV Schemes. In Surveillance, Closed Circuit Television and Social Control, eds C Norris, J Moran and G Armstrong Ashgate.

Tricomi AH. 1996. Reading Tudor-Stuart Texts through Cultural Historicism.:

University Press of Florida.

Tuchman G. 1978. Making News: A study in the construction of reality. New York: Free Press.

Turner JH, and Maryanski A. 1979. Functionalism. California: The Benjamin/Cummings Publishing Company.

Ungar S. 2001. Moral panic versus the risk society: the implications of the changing sites of social anxiety. British Journal of Sociology 52 (2): 271-291.

Vaus DA. 1991. Surveys in Social Research. London: Allen \& Unwin.

Vetter N, and Matthews I. 1999. Epidemiology and Public Health Medicine. Oxford: Oxford University Press.

Volkmer I. 1998. Covering News. Luton: John Libbey Media.

Waddington PAJ. 1996. Mugging as a Moral Panic: A question of proportion. British Journal of Sociology 37 (2): 245-259.

Wakeman R. 2003. Themes in Modern European History Since 1945. London and New York: Routledge.

Walby K. 2005. How Closed-Circuit Television Organizes the Social: An Institutional Ethnography. Canadian Journal of Sociology 30 (2): 189-214.

WCCPL, and NUM. 2009. Striking Back.

Webb B, and Laycock G. 1992. Reducing Crime on the London Underground: An evaluation of three pilot projects. London: HMSO.

Weber M. 1947. The Theory of Social and Economic Organization. London: William Hodge and Co.

-----. 1978. Economy and Society. California: University of California Press.

-----. 1985. The Protestant Ethic and the Spirit of Capitalism. London: Unwin.

Webster A. 1991. Science, Technology and Society. London: Macmillan Educational Ltd.

Webster F. 2002. Theories of the Information Society. London: Routledge.

-----. 2006. Theories of the Information Society. London: Routledge.

Weichert T. 1998. Audio- und Videoüberwachung. Kontrolltechniken im öffentlichen Raum. Bürgerrechte \& Polizei 60: 12-19. 
Wellings K. 2000. Discomfort, Discord and Discontinuity as Data: Using focus groups to research sensitive topics. Culture, Health and Sexuality 2 (3): 255-267.

Welsh BC, and Farrington DP. 2002. Crime Prevention Effects of Closed Circuit Television: a systematic review. HMSO.

Whitaker R. 1999. The End of Privacy: How total surveillance is becoming a reality. New York: The New Press.

Whitley E. 2008. Perceptions of Identity Cards, Privacy and Surveillance. In Knowledge Politics, ed A Pickering.

Wiecek C, and Sætnan AR. 2002. Restrictive? Permissive? The Contradictory Framing of Video Surveillance in Norway and Denmark.

Williams C. 2003. Police Surveillance and the Emergence of CCTV in the 1960s. In CCTV, ed M Gill Leicester: Perpetuity Press.

Williams KS, and Johnstone C. 2000. The Politics of the Selected Gaze: Closed Circuit Television and the Policing of Public Space. Crime, Law and Social Change 34 (2): 183-210.

Williams R. 1876. The Nicomachean Ethics of Aristotle. London: Longmans Green \& Co.

Winge S, and Knuttson J. 2003. An Evaluation of the CCTV Scheme at Oslo Central Railway Station. In CCTV, ed M Gill Perpetuity Press.

Winner L. 1980. Do Artifacts have Politics. Daedalus: 121-136.

-----. 1994. Three Paradoxes of the Information Age'. In Culture on the Brink: Ideologies of technology, eds G Bender and T Druckrey Seattle: Bay Press.

-----. 1994. Three Paradoxes of the Information Age. In Culture on the Brink: Ideologies of technology, eds G Bender and T Druckrey Seattle: Bay Press.

-----. 1997. Autonomous Technology: Technics-out-of-control as a theme in political thought.: MIT Press.

Wrigley C. 2009. British Trade Unions 1945 - 1995. Manchester: Manchester University Press.

Yar M. 2003. Panoptic Power and the Pathologisation of Vision: Critical reflections on the Foucauldian thesis. Surveillance and Society 1 (3): 254-271.

Young J. 1999. The Exclusive Society: Social exclusion, crime and difference in late modernity. London: Sage.

Zander M. 1990. The Police and Criminal Evidence Act, 1984. London: Sweet \& Maxwell. 


\section{Media Sources}

Ballard, M. The Register 11 November 2007 'Home snoop CCTV more popular than Big Brother'

BBC 14 February 2005 'On This Day - Missing two-year old found dead'

BBC 18 December 2003 'Ring of Steel Widened'

BBC 5 March 2004 'Enemies Within: Thatcher and the Unions'

BBC 'On This Day’ 24 April 2005 'On This Day - IRA Bomb Devastates City of London'

BBC News 8 May 2006 'Is 'reality CCTV’ a step too far'

BBC 8 February 2009 'Government plans travel database’

Daily Express 4 December 1959 'First customer of a new era’

Daily Express 3 August 1995 'New tactics’

Daily Express 29 November 1995 'Big cash boost for crime war'

Daily Express 29 June 2000 ‘CCTV does not stop crime’

Daily Express 15 September 2000 'Bosses spying on staff’

Daily Express $5^{\text {th }}$ December 2000 'Caught on camera, little Damilola's final living hour'

Daily Express 4 April 2002 'There’s no hiding place from this army of spies'

Daily Express 12 August 2002 'Jessica and Holly’

Daily Express 13 September 2002 'Milly: FBI find clue’

Daily Express 5 January 2005 'Cry for help by text'

Daily Express 13 July 2005 'Four young men on a mission’

Daily Express 19 July 2005 'Police scour 25,000 CCTV tapes’

Daily Express 15 July 2005 'On his way to kill: Bus bomber with his rucksack of death'

Daily Mail 6 August 2002 'How did they just vanish'

Daily Express 21 September 2005 'Dress rehearsal for the 7/7 slaughter' 
Daily Express 7 April 2006 'Nurse hacked to death’

Daily Express 13 February 2006 'Sinister system of state control must be stopped'

Daily Express 15 December 2006 ‘Victims’

Daily Express 18 December 2006 'Has strangler got clothes as sick trophies?'

Daily Express 5 March 2007 'Now the all-powerful state is even prying on our young children'

Daily Express 5 April 2007 'Talking CCTV? It’s just another Labour gimmick’

Daily Express 30 August 2007 'Caught on film, boy who shot Rhys dead’

Daily Express 17 March 2008 'Uproar over new £120 parking fines’

Daily Mail 13 July 2005 'Killers who looked like they were on holiday’

Daily Mail 13 July 2005 'The suicide bomb squad from respectable homes’

Daily Mail 6 August 2002 'How did they just vanish’

Daily Mirror 23 January 1958 'Votes and Viewers'

Daily Mirror 16 November 1958 'Just look at me - on TV'

Daily Mirror 9 March 1993 'Went for me’

Daily Mirror 5 September 1994 'Fair deal league’

Daily Mirror 10 April 1995 'You’ve been framed Mr Howard'

Daily Mirror 6 March 1998 'Drunken thug teachers jailed for battering cop'

Daily Mirror 26 August 1998 'Gang in van raid bungle’

Daily Mirror 5 February 2000 ‘MP’s niece murdered at Giant’s Causeway’

Daily Mirror 24 May 2000 ‘Has Sara murderer struck second time?’

Daily Mirror 10 June 2000 'Cops quiz children over rail horror’

Daily Mirror 19 August 2000 'Rapist in attack on aids girl'

Daily Mirror 1 July 2000 'Lair of Hatred’

Daily Mirror 1 July 2000 'Nothing excuses this evil’ 
Daily Mirror 29 June 2000 'Bigger brother’s watching...but it’s just not working’

Daily Mirror 1 December 2000 'Damilola on CCTV’

Daily Mirror 26 March 2002 'I spotted Milly’

Daily Mirror $13^{\text {th }}$ September 2002 'Is this Milly?'

Daily Mirror 9 November 2002 'Mazda driver link to Milly ruled out'

Daily Mirror 3 January 2005 ‘Amy Quiz: Cops get more time’

Daily Mirror 5 January 2005 'Missing Sally’s desperate text message to pal’

Daily Mirror 6 January 2005 '’The Last Pictures’

Daily Mirror 25 February 2005 'CCTV does not cut crime’

Daily Mirror 28 June 2005 'An unnecessary and disproportionate intrusion of privacy'

Daily Mirror 8 July 2005 ‘7/7 War on Britain’

Daily Mirror 9 July 2005 '7/7 War on Britain: The Hunt’

Daily Mirror 13 July 2005 '7/7 War on Britain: He has gone to London with some friends'

Daily Mirror 15 July 2005 '7/7 War on Britain: Spot the killer’

Daily Mirror 14 January 2006 'He gave muggers his possessions but they wanted more...His life'

Daily Mirror 16 January 2006 '19 minutes later he was murdered'

Daily Mirror 4 April 2006 'The Spyway’

Daily Mirror 9 April 2007 ‘1984 comes true’

Daily Mirror 20 January 2007 'Shopping for bombs’

Daily Mirror 30 August 2007 'Trail of Rhys Killer’

Daily Mirror 7 May 2008 'Big Brother is not working’

Daily Star 13 July 2005 ‘Blown up by 4 Brits’

Daily Star 8 July 2005 ‘Bodies piled everywhere’ 
Daily Star 15 July 2005 'On his way to kill; TV film of rucksack bomb nut'

Daily Star 17 July 2005 'Together; Evil four on way to slaughter’

The Daily Telegraph 9 May 2006 'CCTV channel beamed to your home’

Kirkby Times News $\quad$ Section 2002 http://www.kirkbytimes.co.uk/news_items/cctv_sept_2002.html

International Herald Tribune 1 June 1998 'City of London, an IRA Target, Starts to Relax’ http://www.iht.com/articles/1998/06/01/ulster.t_0.php

Mail on Sunday 'Major on Criminals’ 21 February 1993

Mail on Sunday 10 July 2005 'All three tube bombs’

Mail on Sunday 10 July 2005 'All three tube bombs exploded at the same time'

Mail on Sunday 10 July 'Six out of Ten say: Execute bombers’

Mail on Sunday 17 July 2005 '90 minutes before they wreaked unspeakable mayhem...the bombers stroll into Luton station'

Mail on Sunday 24 July 2005 'In London or Beirut, terror is universal’

Morning Star 23 July 2005 ‘Britain - Police seeking bomb suspects’

The Guardian 13 May 1993 ‘Big Brother is here’

The Guardian 23 November 1995 '10,000 spy cameras for high streets'

The Guardian 21 September 1995 'Surveillance: Spies on the Streets’

The Guardian 30 January 1995 'Spy Cameras Become Part of Landscape’

The Guardian 22 March 1995 'Security: Someone’s Watching’

The Guardian 9 January 1998 'Demand for closed circuit TV triggers fear of crime'

The Guardian 15 October 1998 'Fears for civil liberties: Spy camera matches faces to police files'

The Guardian 10 February 2000 'In Your Face’

The Guardian 1 December 2000 'Witness clue in Damilola murder'

The Guardian 2 December 2000 'Witness saw boy minutes before his death’ 
The Guardian 5 December 2000 'Caught on camera: The last journey of Damilola Taylor'

The Guardian 30 January 2002 'Laager Toffs’

The Guardian 26 March 2002 'Police intensify hunt for missing teenager’

The Guardian 3 July 2002 'Blunkett unveils ID card proposals’

The Guardian 13 July 2002 'FBI to enhance possible video footage of Milly’

The Guardian 8 August 2002 ‘Abduction fear for missing girls’

The Guardian 9 August 2002 'Police trace moments girls vanished'

The Guardian 9 August 2002 'Captured on camera: Film of missing girls released'

The Guardian 12 August 2002 ‘CCTV plan 'could have foiled snatch’’

The Guardian 7 September 2002 'Big Brother: Your data trail’

The Guardian 6 January 2005 'New arrest in hunt for teenager’s killer’

The Guardian 16 January 2005 'Man held on Amy murder'

The Guardian 17 January 2006 'Murder Clue: Stabbing suspects filmed in station'

The Guardian 25 March 2005 'Surveillance: Little brother'

The Guardian 18 July 2005 ‘CCTV cameras: Society’s little brothers’

The Guardian 18 July 2005 'Behind the banal street scene, a picture of devastation that will change our fears'

The Guardian 23 July 2005 'Call for Underground scan system’

The Guardian 21 September 2005 'London Bombings: Catalogue of clues’

The Guardian 15 November 2005 'Bomb scanners to be tested on trains in New Year'

The Guardian 2 February 2006 'Sisters aged 4 and 8 killed as four children die in car crash’ p.8

The Guardian 7 April 2006 'Nurse stabbed to death in hospital grounds: Colleagues find victim collapsed in parkland: Police check CCTV in hunt for killer' 
The Guardian 8 April 2006 'Man, 18, held over stabbing of nurse outside hospital'

The Guardian 29 September 2006 'Personal Data Sharing: Monitoring Big Brother'

The Guardian 2 November 2006 'Spy planes, clothes scanners and secret cameras: Britain's surveillance future'

The Guardian 14 December 2006 'Suffolk killings: Jewellery left on women's bodies'

The Guardian 15 December 2006 'The investigation: Manhunt is now national in all but name'

The Guardian 4 January 2007 'Big Brother sugars the surveillance pill’

The Guardian 16 January 2007 'July 21 bomb plot: Failure of devices foiled tube attacks, court told'

The Guardian 24 March 2007 'Bob Woolmer murder: Yard veteran grapples with mystery of Room 374: Absence of signs of forced entry and nakedness of corpse will lead investigators to look at coach's associates. CCTV cameras will provide clues'

The Guardian 5 April 2007 'Cameras to tell off troublemakers'

The Guardian 5 April 2007 'Big Brother is watching, listening and talking to you'

The Guardian 1 May 2007 'New powers vital to avert surveillance society, says watchdog'

The Guardian 5 May 2007 'Surveillance can save innocent lives, but we still need to stand up for our civil liberties'

The Guardian 21 May 2007 'CCTV in shires alarms senior police officer: Benefits of wide-ranging surveillance questioned'

The Guardian 27 September 2007 'Liverpool murder: CCTV captures a boy on a bike - thirty seconds later he had killed Rhys Jones: Locals believe they know who shot 11-year-old Mother renews appeal for witnesses to come forward'

The Guardian 20 October 2007 'Police and CCTV: pictures too poor, cameras in wrong place: Networks are little use in fighting crime, says report: Authorities have no idea how many cameras exist'

The Guardian 31 March 2008 'Motorists face new traffic penalties'

The Guardian 26 June 2008 'CCTV doesn't keep us safe, yet the cameras are everywhere' 
The Guardian 28 June 2008 'This surveillance onslaught is draconian and creepy: The cameras, they are multiplying - and now they even have ears. But the state hasn't stopped to run the plan past us'

The Guardian 7 March 2009 'Revealed: police databank on thousands of protestors'

The Independent 19 October 1993 'Flood of prisoners alarms Governors'

The Independent $21^{\text {st }}$ April 2000 'Is Crimewatch best clear-up squad in Britain?'

The Independent 31 March 2001 '300 extra CCTV schemes planned’

The Independent 6 February 2002 'Blunkett clears the path for compulsory identity cards'

The Independent 29 June 2002 'Half CCTV schemes do not reduce crime rate'

The Independent 9 July 2005 'Terror in London: The long intensive sifting of evidence to identify bombers’

The Independent 12 July 2005 'Terror in London - A dignified political response to the bombs'

The Independent 23 July 2005 'London is under attack as never before, and fear is not a shameful response'

The Independent 24 July 2005 'Attacks on London: the best security is people, both staff and passengers'

The Observer 11 October 1998 'As UK crime outstrips the US, a hidden eye is watching'

The Observer 2 July 2000 'Nail bomber trapped by fake penpal’

The Observer 30 July 2000 'The End of Privacy’

The Observer 7 April 2002 'New footage of missing teenager'

The Observer 18 August 2002 'Holly and Jessica: The Search: Thirteen days of agony until hope finally died'

The Observer 10 July 2005 'Attack on London: The Hunt for the Bombers'

The Observer 11 July 2005 'Bus bomb clues may hold key to terror attack'

The Observer 13 May 2007 'Madeleine: poor CCTV shots of suspects hamper police' 
The Observer 29 June 2008 'We can't leave David Davis to carry the fight on his own: With Labour addicted to regulating how we live, the lone rebel deserves support if we want to our freedoms to remain intact'

The Observer Magazine 2 April 2006 'Pan, Tilt, Zoom'

The News of the World 10 July 2005 'Killers Leave Clues...Always'

The People 17 July 2005 '89 mins from hell; first dramatic picture of 4 suicide bombers on way to slaughter'

The Sun 8 August 2002 'Parents’ vigil in church’

The Sun 9 July 2005 'The Bus Driver: I thought I'd hit the kerb. I looked round...the back of the bus had gone'

The Sun 13 July 2005 'The Boy Bombers'

The Sunday Times 8 January 2006 'Asbo TV helps residents watch out'

The Sunday Times 29 January 2006 'Police to study knifing footage’

The Sunday Times 17 December 2006 'On the trail of the strangler'

The Sunday Times 17 December 2006 ‘CCTV images of victim’s last hours’

The Sunday Times 4 March 2007 'Oy! Big Brother is talking to you’

The Sunday Times 18 March 2007 'Friend or foe? The roadside spies cluttering up Britain’

The Telegraph 13 July 2005 'Rucksack gang filmed at King's Cross 'looked like infantry going to war'

The Times 2 August 1956 'Large-Scale Oxygen Plant Opened'

The Times 21 November 1956 'Princess Margaret at North Staffs College’

The Times 31 December 1956 'Innovations at Manchester'

The Times 20 February 1957 'No real clash of interest'

The Times 11 July 1957 '£326,520 paid at Sotheby’s for modern masters’

The Times 23 January 1958 'Labour’s Own Television'

The Times 16 May 1958 'Growing use of television in the City'

The Times $3^{\text {rd }}$ November 1958 'Private television for share prices' 
The Times 26 May 1958 'Peaceful days at air terminal'

The Times 12 August 1958 'City temple restored'

The Times 6 March 1959 'Television experiment at King’s Cross’

The Times 12 March 1959 'Television from the signal box'

The Times 30 October 1958 'News in Brief - Operation on Television’

The Times 3 December 1959 'Surgery to be televised for students'

The Times 16 October 1959 'Middlesex Hospital prize giving'

The Times 17 October 1956 'Industrial television at Calder Hall'

The Times 13 August 'Safety television for Harwell'

The Times 3 October 1957 'New giant building rising on the South Bank'

The Times 30 June 1959 'Plan to increase public garage accommodation'

The Times 16 November 1959 'Television used in traffic control'

The Times 18 June 1957 'Television on the upper deck'

The Times 21 August 1965 'Television 'eye' for mothers'

The Times 27 July 1966 'More crime regardless of consequences’

The Times 4 January 1968 'TV cameras help London fight against crime'

The Times $26^{\text {th }}$ November 1968 'Football Hooligans'

The Times 6 July 1994 'Security cameras zoom in on crime'

The Times 23 November 1995 'TV cameras in towns to increase'

The Times 27 March 1998 'CCTV identification 'error-prone’

The Times 10 January 2000 'Looking for our fingerprints in cyberspace'

The Times 11 January 2000 'Who’s reading your email'

The Times 20 January 2000 'Is big brother already watching us?'

The Times 1 July 2000 'Crucial tip-off came 24 hours too late’

The Times 19 September 2000 'If you feel that you are being watched...' 
The Times 15 September 2001 'Terrorism review may result in ID cards'

The Times 15 September 2001 'Terrorism review may result in ID cards'

The Times 10 January 2002 'Where are the police?'

The Times 6 February 2002 'Blunkett pushes benefits of compulsory ID cards'

The Times 9 March 2002 'Fortress Britain’

The Times 4 July 2002 'It is perfectly possible to protect personal privacy and still establish our identities’

The Times 21 September 2002 'At last, Milly’s parents find a kind of relief'

The Times 9 August 2002 'Sunday, teatime: Holly and Jessica pulled on Manchester United shirts, spent 29 minutes on their computer, then walked into town'

The Times 5 January 2005 'Missing girl sends desperate 'help me' texts to friends'

The Times 25 February 2005 'CCTV cameras fail to cut crime’

The Times 14 March 2005 'Hi-tech rogues gallery puts police in picture’

The Times 14 May 2005 'Every move you make'

The Times 1 July 2005 'Privacy on parade, at a price’

The Times 8 July 2005 'Body scan machines to be used on tube passengers'

The Times 11 July 2005 'Terror alert highest ever as police fear new attack'

The Times 27 July 2005 'Ready to strike again’

The Times 27 July 2005 'Transports cuts ‘aid terrorists’”

The Times 28 July 2005 'Neighbours link 'third bomber' to London flat'

The Times 17 August 2005 'Leaked report lists 'blunders' as police shot bomb suspect'

The Times 25 August 2005 'Footage of tube shooting has gaps'

The Times 21 September 2005 'CCTV shows 7/7 bombers on dummy run in June'

The Times 21 September 2005 'CCTV shows 7/7 bombers on dummy run in June' 
The Times 15 November 2005 'Smart CCTV could fight terrorist threat in stations'

The Times 16 January 2006 'CCTV shows murdered solicitor’s last journey’

The Times 17 January 2006 'CCTV shows would-be bombers trying to blow themselves up'

The Times 19 January 2006 'Murder in black and white'

The Times 17 January 2006 'CCTV shows would-be bombers trying to blow themselves up'

The Times 6 March 2006 'World's fastest internet will send Britannica to Shoreditch in 7 sec'

The Times 19 October 2006 'We are the watchers. We help you'

The Times 6 March 2007 'Big Brother will be watching for ever'

The Times 20 March 2007 'A witness you can’t trust'

The Times 27 March 2007 'Poor-quality tapes will need to be enhanced'

The Times 4 April 2007 'Big Brother Talks’

The Times 5 April 2007 'Talking CCTV cameras will see crime and tick off louts’

The Times 9 May 2007 ‘Angry Portuguese ask why couple left the children alone’

The Times 31 May 2007 'Nearly all CCTV cameras 'are illegal'’

The Times 14 May 2007 'Detectives in search for Madeleine admit they have no suspect'

The Times 27 September 2007 'Boost in hunt for Rhys's killer as 12 identify youth on CCTV'

The Times 20 October 2007 'Eight out of ten CCTV images offer no help in solving crimes'

The Times 5 February 2008 'CCTV under the spotlight'

The Times 6 February 2008 'Every breath you take, every move you make, a camera will be watching you'

The Times 9 February 2008 'Living off the grid - how to escape the spies all around us'

The Times 29 March 2008 'Stop this devious revenue raiser’ 
The Times 29 March 2008 'Smile, your fine is in the post' 


\section{Appendix I}

Dear Resident,

I am undertaking research at the University College London on the impact of CCTV.

CCTV was installed on your estate in 2005, as part of the Digital Bridge project run by the Shoreditch Trust. I am undertaking research into how much people watch the Community Safety channel and the extent of resident participation in the project. I am very interested in finding out your views of CCTV and the Community Safety channel, regardless of whether or not you watch it. This project is independent of the Digital Bridge project and the Shoreditch Trust.

Your household is among a random sample of the Charles Square and Haberdasher Estates (where the CCTV project was piloted). It is important to find out residents' views on this project and I would therefore be very grateful if you could complete and return the short questionnaire attached in the stamped addressed envelope I have supplied. It will take no longer than 10-15 minutes to complete.

All questionnaires will be treated in complete confidence. The questionnaire has an identification number for mailing purposes only and therefore is anonymised.

You may receive a summary of the results if you wish. Please write your name and address on the back of the stamped addressed envelope if you are interested.

*Data Protection Act 1998*

By registering your name and address, you give consent to have your details stored in an electronic database for access only by the research team at UCL. The database will only be used to inform you of the results of the research and for no other purposes.

If you have any questions please contact me either by post or phone:

Inga Kroener

Department of Science and Technology Studies

University College London

Gower Street

London

WC1E 6BT

Tel no: 02076791328

Many thanks for your time and assistance. 


\section{Appendix II}

\section{CCTV Research Questionnaire}

This section asks about your television usage.

I. Is there a television set in your house? (Please circle)

Yes No

(If no, please proceed to question 4)

2. If yes, how often do you watch it? (Please tick one box)

Daily

4-5 times a week

2-3 times a week

Once a week

Once a month

Less often

3. Do you subscribe to the Digital Bridge television service? (Please circle)

Yes No

If no, why not?

If yes, why?

4. Are you aware of the Community Safety channel? (Please circle)

Yes No

(If no, please proceed to question 10)

5. Have you ever watched the Community Safety channel? (Please circle)

Yes No

If no, why not?

(If no, please explain and then proceed to question 10)

If yes, why? 
6. If yes, how often do you watch the Community Safety channel? (Please tick one box)

Daily

4-5 times a week

2-3 times a week

Once a week

Once a month

Less often

7. When was the last time you watched the Community Safety channel? (Please tick one box)

Today

Yesterday

Last week

2-3 weeks ago

Over a month ago

Over 6 months ago

Can't remember

8. What time of day did you watch it? (Please circle as many as appropriate)

Morning Afternoon Evening Night Don't know Can't remember

9. Have you ever witnessed a crime or similar incident on the Community Safety channel? (Please circle)

Yes No

(If no, please proceed to question I0)

If yes, please describe what happened:

If yes, did you report the incident to the police?

(Please circle)

Yes No 


\section{This section asks about your feelings on CCTV}

10. Prior to this questionnaire were you aware of the CCTV cameras on your estate? (Please circle)

Yes No

I I. Please choose the statement which is closest to your view: (Please tick)

I was given a lot of information about the installation of CCTV on the estate

I was given some information about the installation of CCTV on the estate

I was given little information about the installation of CCTV on the estate

I was given no information about the installation of CCTV on the estate

12. How satisfied or unsatisfied were you with the level of information you received about the installation of CCTV on your estate? (Please circle)

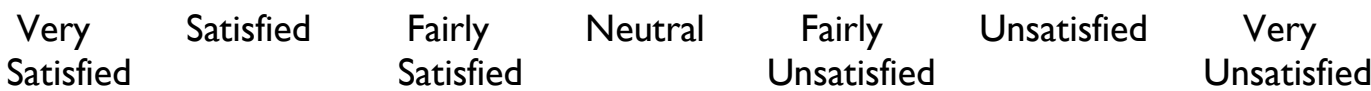

13. Before the installation of the CCTV cameras on the estate, were you asked to participate in a focus group (a small group discussion) by the Shoreditch Trust? (Please circle)

Yes No

If yes, please describe what happened?

If no, were you asked your opinion in any other way (by either the Shoreditch Trust or by anyone else)? (Please circle)

Yes No

If yes, please describe what happened?

If no, would you liked to have been asked your opinion? (Please circle)

Yes No 
This section asks you about safety and privacy

14. Please indicate how much you agree or disagree with the following statements:

(Please indicate your level of agreement or disagreement with each statement by circling the most appropriate response to each statement)

Since the introduction of CCTV on the estate I feel safer:

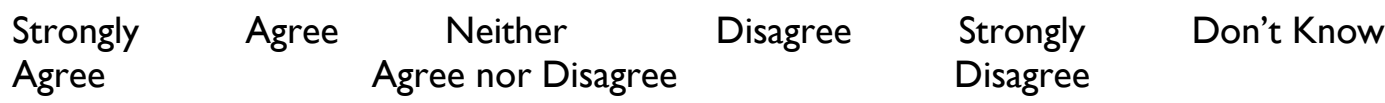

CCTV helps prevent crime on the estate:

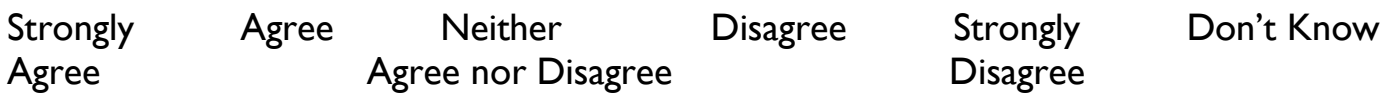

CCTV on the estate invades residents' privacy:

\begin{tabular}{|c|c|c|c|c|}
\hline $\begin{array}{l}\text { rongly } \\
\text { gree }\end{array}$ & Agree & $\begin{array}{l}\text { Neither } \\
\text { Agree nor Disagree }\end{array}$ & Disagree & $\begin{array}{l}\text { Strongly } \\
\text { Disagree }\end{array}$ \\
\hline
\end{tabular}

I5. Do you see any advantages to the Community Safety channel? (Please circle) Yes No

If yes, please state:

16. Do you have any concerns about the Community Safety channel? (Please circle)

Yes No

If yes, please state:

17. Have you ever been a victim of crime? (Please circle)

Yes No

If yes and you feel able to, it would be helpful if you could describe what happened: 
18. If you have any other comments, please write them in the space below:

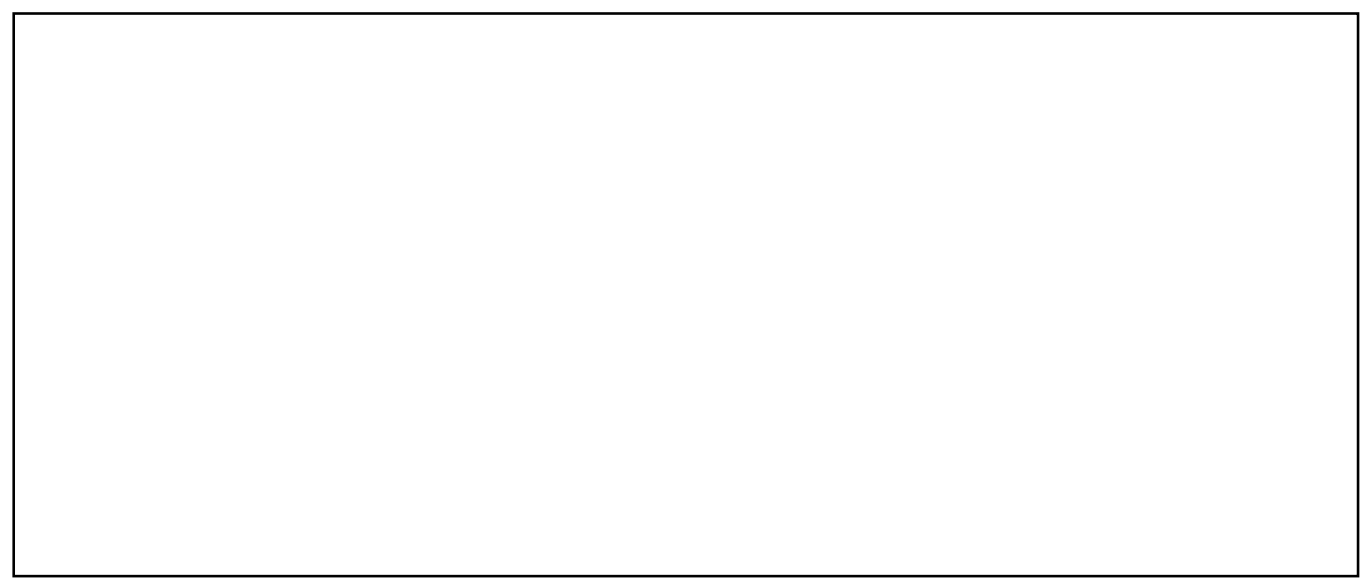

This section is about you

19. What is your sex? (Please circle)

Male Female

20. What is your marital status? (Please circle)

Single $\quad$ Married Divorced Other

2I. Please tick one box which best describes your ethnic origin:

Indian

Pakistani

Bangladeshi

Chinese

Asian - other

Black - Caribbean

Black - African

Black - other

Mixed Race

White - UK/Irish

White European

White - other

Other ethnic group

22. How many people currently live in your house (including yourself)?

23. How long have you lived at your current address? (Please tick the most appropriate)

I year

5 years

10 years

15 years

20 years

Over 20 years 
24. Which of these best describes your employment? (Please tick the most appropriate)

Employed full-time (30+ hours)

Employed part-time (8-29 hours)

Employed (less than 8 hours)

Self-employed

Not in paid employment

Student

Retired

25. What is your age group? (Please circle)

$18-35 \quad 36-50 \quad 51-65 \quad$ Over 65

26. Are you willing to participate in further research? (Please circle)

Yes No

If yes, please provide your contact details:

Name:

Address:

Telephone number:

Email address:

Many thanks for completing the questionnaire. Please now return it in the stamped addressed envelope. 
